\title{
Chemical genetic interactions of New Zealand bee products in Saccharomyces cerevisiae
}

\author{
Nazmi bin Harith Fadzilah
}

A thesis submitted to Victoria University of Wellington in fulfilment requirements for the degree of Masters of Science in Biotechnology

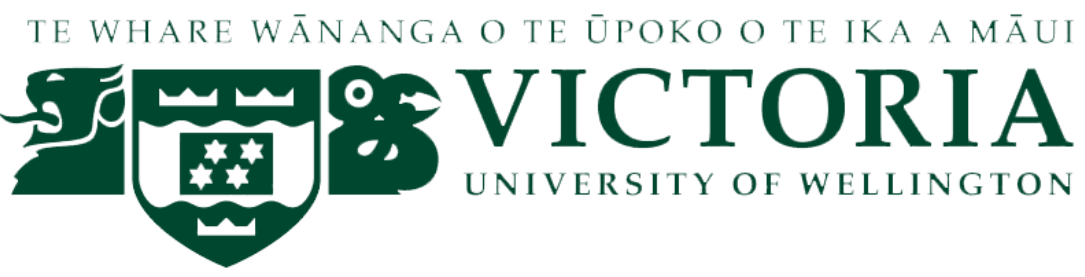




\section{Abstract}

Propolis, bee venom and bee pollen all have been used by humans traditionally for various medicinal purposes. Studies of these products have been limited primarily to antimicrobial, antifungal, anticancer and free radical scavenging properties. The mechanisms of action of these products remain largely unknown. This study investigates the biological effects of propolis, bee venom and bee pollen using chemical genomics and the yeast model organism. These products are screened against genome-wide yeast mutant libraries to determine the genes, proteins, and pathways that are targets of these products. I identified that propolis chelates iron and consequently creates an iron-deficient condition, which results in the upregulation of plasma membrane and vacuolar high-affinity iron transporters to maximise iron acquisition. Bee venom inhibited the biosynthesis of phosphatidylcholine via Opi3p that catalyses the final two steps of phosphatidylcholine biosynthesis within the CDPethanolamine pathway. Bee pollen showed a potential effect on GDP-mannose transport in which the GDP-mannose transport mutants confer hypersensitivity against bee pollen treatment. 


\section{Acknowledgement}

I would like to display my gratitude to all my friends and families who have helped me throughout the duration of my thesis work. Firstly, my supervisor Dr Andrew Munkacsi, thank you for taking me under your care until the completion of my Master's degree. Thank you for giving me the freedom and encouraging me to operate independently and try new things as I saw fit. Without your help and guidance I would not have developed the same level of practical skill nor critical thinking I now have. Also I would like to extend my thanks to other faculty members associated with our lab; Professor Paul Atkinsin, David Maass, Professor John Miller, Associate Professor and Paul Teesdale-Spittle for their helpful advice and feedback especially in our meetings.

To all of the Chemical Genetics lab group, you have always provided an enjoyable environment from which genuine friendships have developed. In particular I would like to thank Dinidu, Seesei, James, Christina and Namal for all their guide and advice in troubleshooting my experiments and in handling expensive equipment. Personal thanks to Bede for various invitations to his barbeque events. Honestly, it was my first kiwi barbeque experience and I really learned a lot about kiwi culture from you mostly. And also to Aidan, Liam, Eli, Mona, Brett, Amy, Tanisha, Natalie and Brett for their help and company.

Finally I would like to thank my family for all their support. Particularly my parents who have always encouraged me to follow my passions although we are thousands of miles apart, without your support I would simply not have been able to take my studies this far. To all my Malaysian friends who have always been like a family to me. Being with all of you makes me forget that I am still in New Zealand, struggling to finish my master's thesis. 


\section{Table of contents}

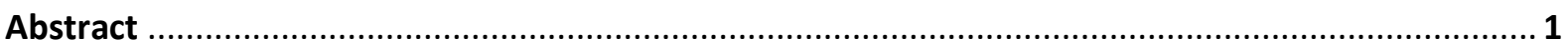

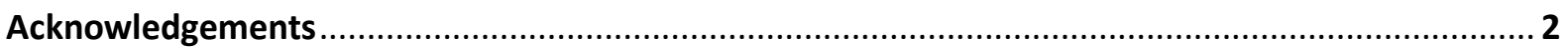

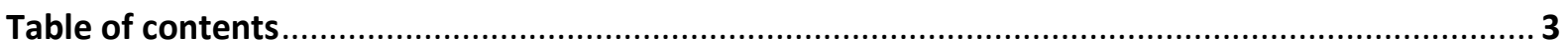

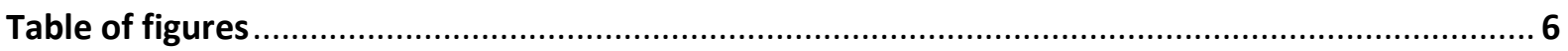

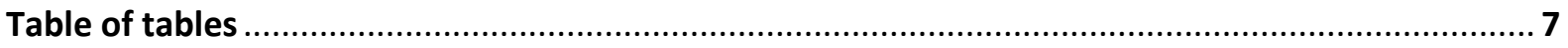

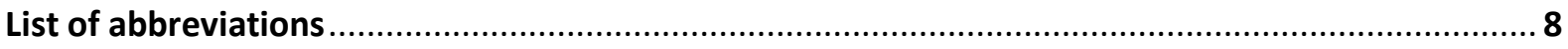

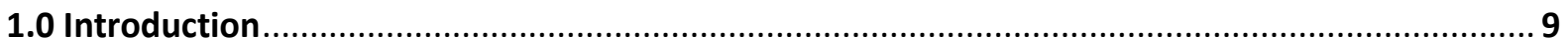

1.1 Natural products demand as health food a nutritional supplement ......................................... 9

1.2 Bee products' therapeutic use and pharmacological benefits ................................................... 9

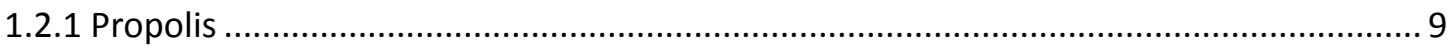

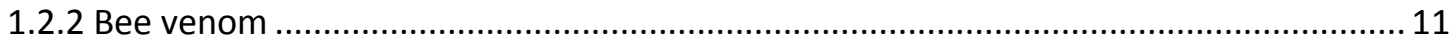

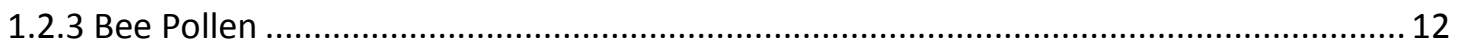

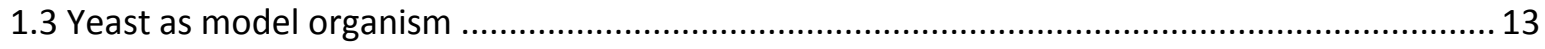

1.3.1 Advantage of using yeast as model organism ……................................................... 13

1.3.2 Ability to elucidate bioactivity on non-essential and essential genes ........................... 13

1.3.3 Feasibility of yeast to elucidate biological activity on protein expression and localisation

1.4 Chemical genetics to elucidate bee products' mode of action in yeast ................................... 15

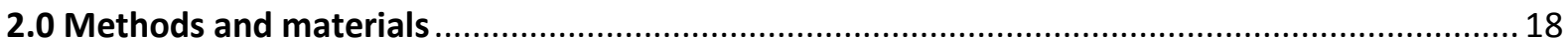

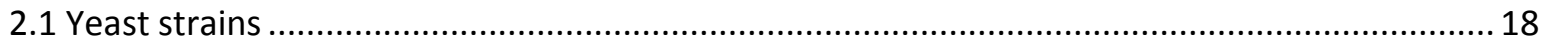

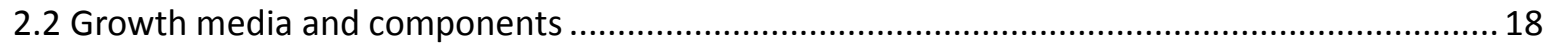

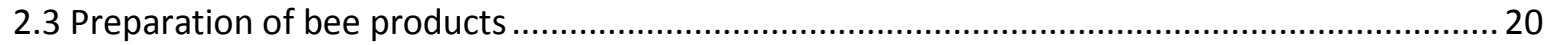

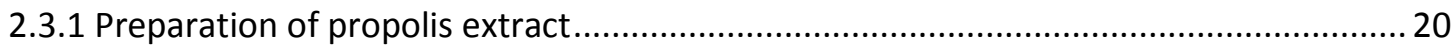

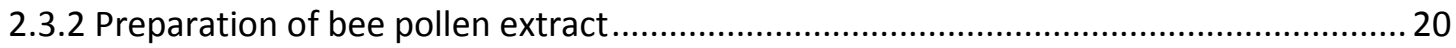

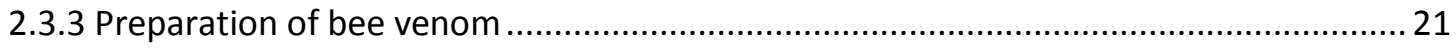

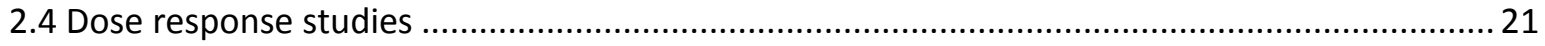

2.4.1 Propolis and bee pollen broth dose response .............................................................. 21

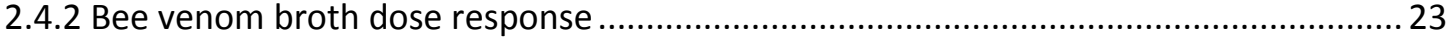

2.4.3 Propolis/ bee venom / bee pollen agar dose response ................................................ 24

2.5 Homozygous deletion library and DAmP library yeast colonies screening \& image acquisition analysis

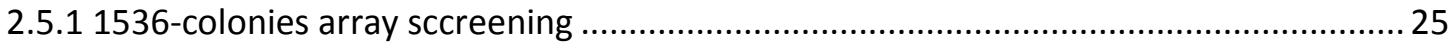

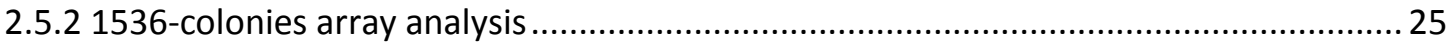


2.5.3 Propolis and bee pollen agar validation

2.5.4 Bee venom broth library screening and validation.................................................... 27

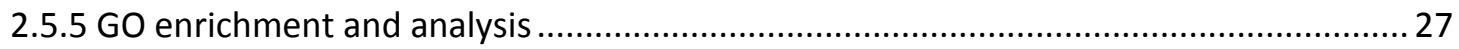

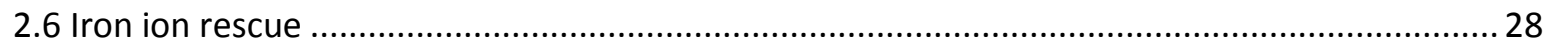

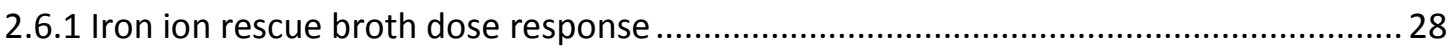

2.6.2 Other metal ion rescue broth dose response ............................................................ 30

2.6.3 OPERA imaging \& fluorescence quantification .............................................................. 30

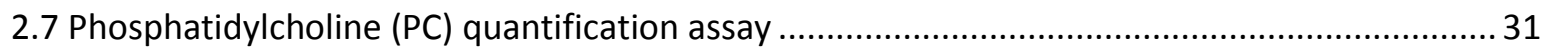

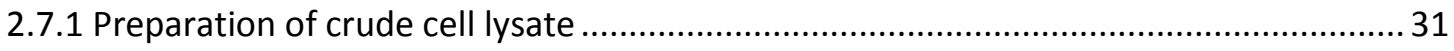

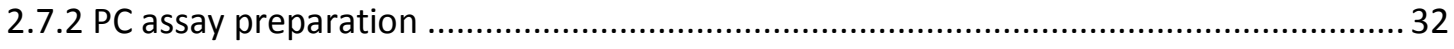

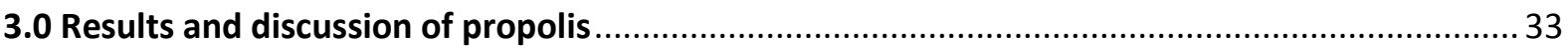

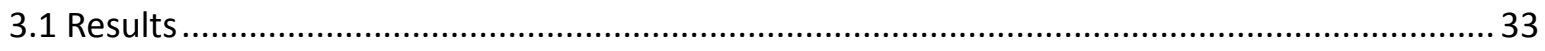

3.1.1 Methanolic fraction of propolis showed greater inhibition compared to crude fraction

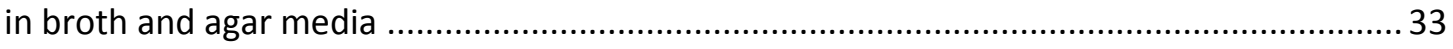

3.1.2 Chemical genetics screen indicates enrichment for iron ion transport...........................35

3.1.3 Iron supplementation rescues growth inhibition caused by propolis ............................37

3.1.4 Other metal ions supplementation indicates different growth rescue patterns ........... 50

3.1.5 GFP intensity and localization analysis indicates upregulation of high-affinity iron ion

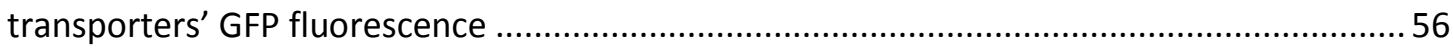

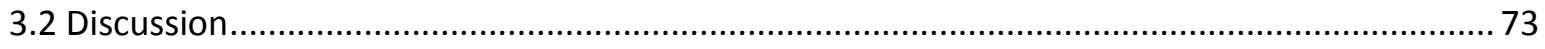

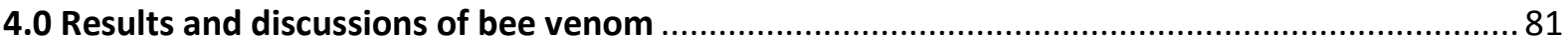

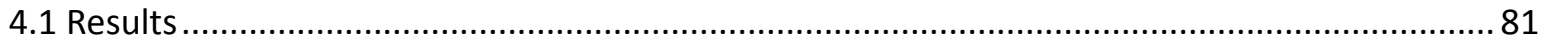

4.1.1 Bee venom did not show bioactivity in agar media....................................................... 81

4.1.2 Bee venom screen indicates sensitivity in PC metabolism process............................... 82

4.1.3 GFP intensity and localisation studies showed suppression of Opi3p-GFP fluorescence

4.1.4 PC quantification assay indicates PC decline with bee venom treatment .....................96

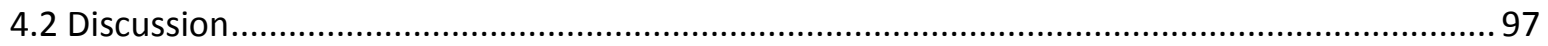

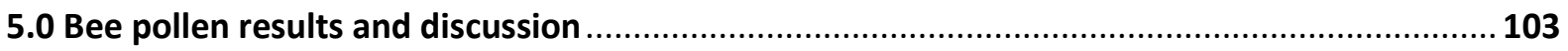

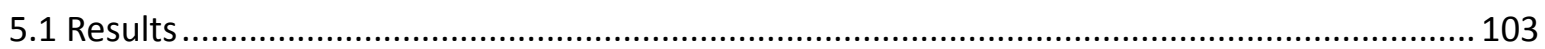

5.1.1 Methanolic fraction of bee pollen showed greater inhibition compared to crude

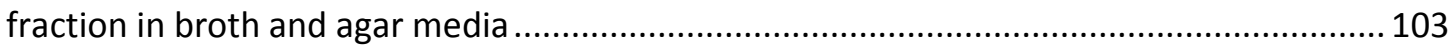

5.1.2 Bee pollen agar screen did not possess any biological process enrichment ................ 105

5.1.3 Broth dose response of GDP-mannose biosynthesis and transport deletion mutant strains indicate hypersensitivity in another GDP-mannose transport gene......................... 107

5.1.4 Opera image analysis of yeast GFP for GDP-mannose biosynthesis and transport strains indicates no changes in GFP fluorescence with bee pollen treatment 
5.2 Discussion 115

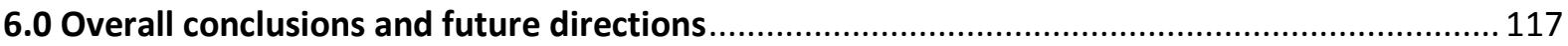

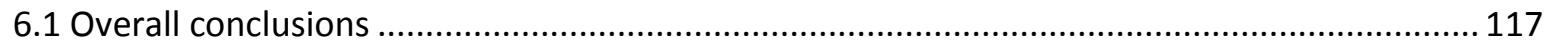

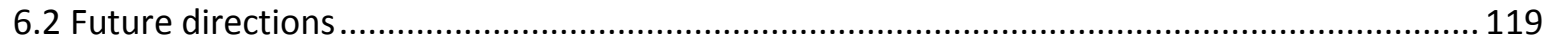

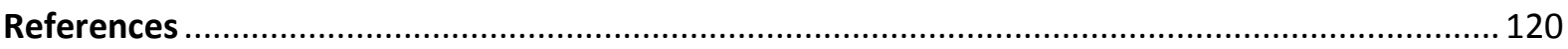

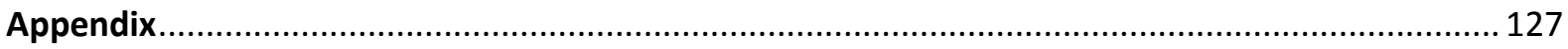

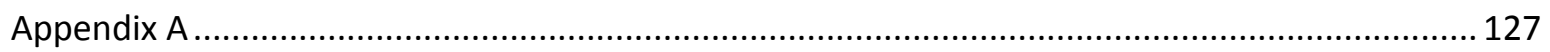

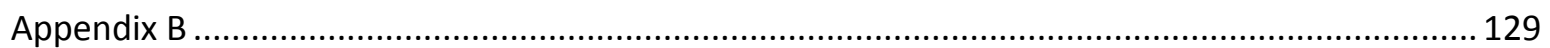




\section{Table of Figures}

Figure 1.1 Chemical genetic interactions can reproduce a synthetic lethal interactions

Figure 3.1 Propolis crude and methanolic fraction broth and agar dose response

Figure 3.2 his $3 \Delta$ border strains 1536 -array agar dose response

Figure 3.3 Broth dose response under Iron supplementation $(100 \mu \mathrm{M} \mathrm{FeCl})$

Figure 3.4 Broth dose response under different metal ion supplement

Figure 3.5 Opera GFP fluorescence intensity and localisation analysis.

Figure 3.6 Propolis chelates iron ion and induces iron depravation.

Figure 4.1 Bee venom broth and agar dose response.

Figure 4.2 Residual growth PC metabolism-related deletion mutant strains at mid-log phase and stationary phase.

Figure 4.3 Opera GFP fluorescence intensity and localisation analysis

Figure 4.4. PC quantification assay analysis

Figure 4.5. Bee venom inhibits PC biosynthesis via Opi3p

Figure 5.1 Bee pollen crude and methanolic fractions broth and agar dose response 104

Figure 5.2 Categorisation of all positive from bee pollen screening 106

Figure 5.3 Broth dose response of GDP-mannose biosynthesis and transport related deletion mutant strains

Figure 5.4 Opera GFP fluorescence intensity and localisation analysis

Figure 5.5 Bee pollen interferes GDP-mannose transport by blocking Vrg4p or Gda1p activity.... 116 


\section{Table of tables}

Table 1 Tabulated residual growth of select deletion strains with or without $100 \mu \mathrm{M} \mathrm{FeCl}_{2}$ after 24 hours inoculation

Table 2 Tabulated residual growth of select deletion strains under bee pollen treatment after 16 hours inoculation 109

Table A.1.1 Top ten most enriched GO term for biological processes from propolis homozygous deletion library screen

Table A.1.2 Top ten most enriched GO term for biological processes from propolis DAmP library screen

Table A.2.1 Top ten most enriched GO term for biological processes of bee venom yeast homozygous deletion library screen

Table B.1.1 Propolis validated hits from yeast homozygous deletion library screen

Table B.1.2 Propolis validated hits from yeast DAmP library screen

Table B.2.1 Bee venom validated hits from yeast homozygous deletion library

Table B.2.2 Bee venom validated hits from yeast DAmP library screen

Table B.3.1 Bee pollen validated hits from yeast homozygous deletion library screen

Table B.3.2 Bee pollen validated hits from yeast DAmP library screen 


\section{List of Abbreviations}

$\mathrm{CaCl}_{2}$

ClonNat

DAmP

DMSO

EDTA

$\mathrm{FeCl}_{2}$

G418

GDP

GFP

GO

$\mathrm{MgCl}_{2}$

$\mathrm{MnCl}_{2}$

OD

ORF

PA

PC

PE

RFP

ROS

SC

SD

SGD

snoRNA

$x x x \Delta$

$\mathrm{ZnCl}_{2}$
Calcium chloride

Nourseothricin

Decreased abundance by mRNA

perturbation

Dimethyl Sulfoxide

Ethylenediaminetetraacetic Acid

Iron chloride

Geneticin

Guanosine diphosphate

Green fluorescent protein

Gene Ontology

Magnesium chloride

Manganese chloride

Optical density

Open reading frame

Phosphatidic acid

Phosphatidylcholine

Phosphatidylethanolamine

Red fluorescent protein

Reactive oxygen species

Synthetic complete media

Synthetic dropout media

Saccharomyces Genome Database

Small nucleolar RNA

Deletion from deletion mutant array

Zinc chloride 


\subsection{Introduction}

\subsection{Natural products demand as health food and therapeutic treatment}

Since ancient times, humans have relied on the use of natural resources for treatment of diseases. A common misconception of historical medicinal practices is that our ancestors picked a random assortment of natural resources, be it plants, animal or even earth materials to make a concoction and administer it toward the sick. In fact, there is strong historical evidence of rational medicinal practices based on empirical methods (Alkhateeb, 2014; Borchardt, 2002). With the rich knowledge of natural products as source of medicine, the collective knowledge of the therapeutic benefit of the natural products is far from complete. Moreover, natural products still possess demand in developing countries and approximately half of modern medicines are derived from natural products (Cragg \& Newman, 2013).

\subsection{Bee products' therapeutic use and pharmacological benefits}

\subsubsection{Propolis}

Propolis is an accumulation of balsamic resins from plant leaf buds and barks (Ghisalberti, 1979). As it is a collection of resins, the constituents of its composition are found to vary according to season and geographical location (Brown, 1989; Khalil, 2006). It has two natural uses by the honey bees; as a cement to repair and protect the hive and as an antiseptic for the protection of their larvae, honey and combs (Seeley \& Morse, 1976). 
The historical uses of propolis can be traced back to the time of the greeks, Egyptians, persians and romans where it has been used to cure external and internal wounds and ulcers, painkillers, treating inflammations (Kuropatnicki et al., 2013).To this day, propolis is widely used by practictioners of alternative medicine and administered in different forms primarily as an antiseptic. Among common applications being as ointments for treating external injuries and inflammations and throat lozenge (Castaldo \& Capasso, 2002). A number studies that explores biological effects of propolis. Among them is the antimicrobial and antifungal properties of propolis (Elbaz \& Elsayad, 2012; Pavilonis et al., 2008; Ozen et al., 2010; Quiroga et al., 2006). There are studies that demonstrated efficacy of propolis as antioxidants and also as tumour suppressing properties (Valente et al., 2011; Li et al., 2007). There are studies that showed how propolis suppressed cancer cell lines and induced apoptosis in fungi (Valente et al., 2011; Castro et al., 2011). However, the mechanism of selective cancer cell suppression and apoptosis induction were unknown to whether the apoptosis was being induced directly or that apoptosis was a consequence of physiological changes caused by propolis. 


\subsubsection{Bee Venom}

Bee venom is traditionally used topically to treat skin diseases and orally to treat arthritis, rheumatism, and cancer (Hider, 1988). The main bioactive compounds of bee venom are melittin, apamin, adolapin and phospholipase A (Lariviere \& Melzack, 1996). Melittin, the main active component of bee venom is found to induce leak to phospholipid bilayer (Pratt et al., 2005) and found to exhibit cytotoxicity on a myriad of cancer cell lines by triggering both intrinsic and extrinsic apoptosis without inducing cytoxicity on normal cells via selectively targeting activated ras oncogenes (Orsolic, 2012; Moon et al., 2006; Jp et al., 2012). Also, it is found that melittin can suppress free radical production via calmodulin (Son et al., 2007). Adolapin is the component that contributes to antiinflammatory effect of bee venom.

Bee venom has been used in acupuncture, a new alternative therapy termed Bee venom acupuncture. Such therapy has found to reduce and prevent arthritic inflammation when performed in rats (Kwon et al., 2002; Lee et al., 2005). The anti-inflammatory effect of bee venom is mediated via inhibition of iNOS activity and iNOS mRNA expression, and TNF- $\alpha$ production which is contributed by the water soluble fraction comprised of melittin, adolapin, mast cell degranulating (MCD) peptide and phospholipase A (Kwon et al., 2002; Han et al., 2007). Another study demonstrated that bee venom can suppress inflammatory factors and reverse stimulation by inflammatory agent (Yin et al., 2005). Bee venom is also found to exhibit antimicrobial and antifungal effects in numerous studies (Yu et al., 2006; Fennel et al., 1968). Although growth inhibition of various bacterial and fungal species was demonstrated, it remains 
unclear whether bee venom directly induces pro-apoptotic signal or alters physiology that leads to apoptosis.

\subsubsection{Bee Pollen}

Bee pollen refers to the pollen dust which the bees accumulate on their body when collecting nectar (Bruno, 2005). For the honey bees, bee pollen serves as a source for proteins, fats and minerals (Villanueva et al., 2002). Similarly to propolis, the constituents of bee pollen is location- and season-dependent (Campos et al., 2008). For example, bee pollen products from different regions possess different therapeutic effects. The pollen was used by physicians as early as the $12^{\text {th }}$ century and was used increasingly after the development of pollen traps (Bogdanov, 2014).

Although the therapeutic mechanisms of bee pollen are largely unknown, bee pollen is sold to consumers as health food with therapeutic effects including hepatoprotective and anti-inflammatory properties (Pascoal et al., 2014) (Maruyama et al., 2010). In addition, bee pollen improved digestion (Wojckiki et al., 1986; Wojciki et al., 1985; Wang et al., 2007). Other benefits which bee pollen was found to possess are antioxidative properties and antimicrobial properties (Fatrcova-Sramkova et al., 2013). However, how bee pollen achieved these therapeutic benefits in cellular level had not been investigated. 


\subsection{Yeast as model organism}

\subsubsection{Advantage of using yeast as model organism}

Yeast (Saccharomyces cerevisiae) is well suited to study the mechanism of action of bioactive compounds. Yeast genes and proteins were conserved (Tugendreich et al., 1994). The data of the compound activity on yeast can be translated into other eukaryote subjects to a good degree. The yeast genome is well characterised and the compendium of information of genes known to yeast is available in Saccharomyces Genome Database (SGD; http://www.yeastgenome.org). Furthermore, yeast is the only organism with a genome-wide range of deletion strains available and this is attributed to the feasibility of genetic manipulation of the yeast genome (Nislow \& Giaever, 2007).

\subsubsection{Ability to elucidate bioactivity on non-essential and essential genes}

The development of the yeast deletion strain library allowed for precise genetic studies of molecular mechanisms of compounds (Winzeler et al., 1999). The use of deletion strain library for profiling a compound's mechanism of action has been demonstrated by identifying mutant strains which exhibit hypersensitivity, thus creating a chemical genetic profile for the bioactive compounds (Giaever et al., 1999; Glaever et al., 2002; Glaever et al., 2004; Parsons et al., 2004). Chemical genetic profiling adapts the principle of synthetic lethality. Synthetic lethality is a phenomenon in which two single null mutations produce viable organisms when it occurs separately but produce inviable organisms when both mutations occur together (Figure 1A) (Parsons et al., 2004; Hartman et al., 2001). It is found that the majority of the non-essential genes have synthetically 
lethal interaction with another one or two genes and with the most with 26 genes (Hartman et al., 2001). This would mean that these genes, which are coined "nonessential" genes have other redundant genes that carry out the same process but via distinct and compensatory pathways. Synthetic Genetic Array (SGA) analysis creates synthetic lethal screens by mating MAT $\alpha$ haploid yeast query mutants with the MATa haploid yeast deletion library which identifies the molecular function of the deleted genes and thus mapping the genetic interaction network (Tong et al., 2001). This allows identification of the functions of the non-essential genes.

In order to characterise the essential genes, which are genes that cause inviability upon deletion, a library called the decreased abundance by mRNA perturbation (DAmP) library was constructed (Schuldiner et al., 2005). This library of mutant essential genes is the alternative to using inducible gene inactivation via conditional protein disruption, transcriptional shut-off, or a heterozygous diploid mutant library that essentially reduces the gene dosage to $50 \%$ (Giaever et al., 1999). On the other hand, the DAmP library was constructed by inserting an antibiotic resistance cassette into $3^{\prime}$ untranslated region of an essential gene, thus disrupting the mRNA transcription process and leading to lower amount of mRNA production while ensuring these yeast strains remain viable (Breslow et al., 2008). The advantage of the DAmP library over the other methods of characterising essential genes is that the essential gene disruption does not cause severe steadystate growth defects making analysis difficult. 


\subsubsection{Feasibility of yeast to elucidate biological activity on protein expression and localisation}

Another significant advantage of yeast as compared to other model organisms is the availability of the green fluorescent-tagged protein (GFP) library. This library was generated by insertion of GFP sequence to the $3^{\prime}$ end of the desired open reading frame (ORF), creating a fusion protein with green fluorescence (Huh et al., 2003). This enabled observation of localisation of the proteins and quantification of the amount of fluorescence (protein expression). These measurements of localization and quantification correlated with the amount of protein measured using flow cytometry (Newman et al., 2006) and confocal microscopy (Carter et al., 2008).

\subsection{Chemical Genetics to elucidate bee products mode of action in yeast}

Chemical genetics is the most common method used to elucidate bioactive compounds' mechanism of action. The core principle of chemical genetics is that a compound acts upon the model organism to mimics a mutation (Parsons, et al., 2004). Employing the same principle of synthetic lethality to characterise a gene function, the compound can act as a secondary mutation to the existing deletion or suppressed strains. Thus, the strains sensitive to the compound treatment suggest the particular biological processes affected by the compound (Figure 1.1b, Parsons et al., 2004). Combination of $\sim 4800$ nonessential deletion mutants strains (Parsons et al., 2004) and 837 DAmP (Schuldiner et al., 2005) strains libraries provides extensive coverage of the yeast 
genome of 6200 genes hence allowing thorough characterisation of a compound's mode of action. Adding compound screening against yeast GFP library gives further idea of whether the impact of compound is affecting the expression of such proteins or hindering the activity of the affected proteins.

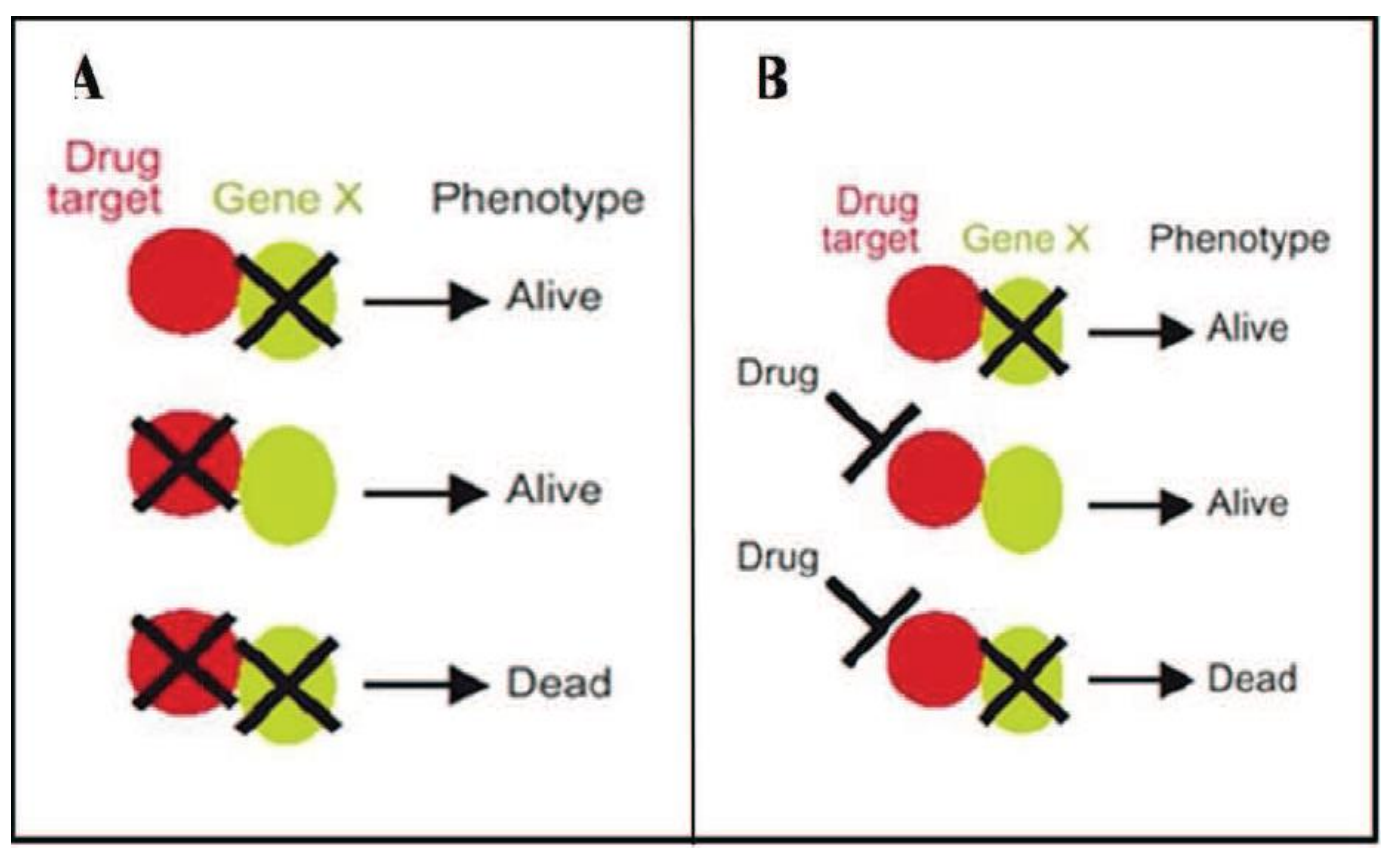

Figure 1.1. Chemical genetic can reproduce a synthetic lethal interactions. (A) A synthetic lethal interaction where deletion of two genes separately results in viable individuals whereas the combination of both genes being deleted results in inviable individual. (B) Chemical genetic interactions where certain particular gene deletion that is viable becomes inviable when treated with a bioactive compound at sub-lethal concentration which would not cause inviability to the wildtype. 
The chemical-genetic profiling is not restricted to screening one pure compound at a time but can accommodate a mixture of compounds for screening simultaneously. This is attractive when studying the nutritional effect of diet to the cell's physiology. The rationale for using the mixture is that the bee products has been used in its raw form. These raw forms, similar to any other raw natural products, consist of different bioactives and proteins which may work synergistically to give its desired effect. Our aim is to employ chemical genetic screens of the discussed extracts against the yeast haploid deletion strain library to assess the genetic target of these extracts thus, evaluating the claims of the use of these extracts and identify their other potential effects. 


\subsection{Methods and Materials}

\subsection{Yeast strains}

S. cerevisiae strains used in this thesis are as follows:

\begin{tabular}{|c|c|}
\hline Strain & Genotype \\
\hline BY4741 & $\begin{array}{l}\text { MATa his3 } \Delta 1 \text { leu2 } \Delta 0 \text { met } 15 \Delta 0 \\
\text { ura3 } \Delta 0\end{array}$ \\
\hline$\Delta x x x$ & $\begin{array}{l}\text { MATa } \mathrm{xx} \Delta:: k a n R ; \text { his } 3 \Delta 1 \text { leu2 } \Delta 0 \\
\text { met } 15 \Delta 0 \text { ura3 } \Delta 0\end{array}$ \\
\hline$X X X-G F P$ & $\begin{array}{l}\text { MATa } X X X-G F P:: \text { natR leu } 2 \Delta 0 \text { ura } 3 \Delta 0 \\
\text { met } 15 \Delta 0\end{array}$ \\
\hline$x x x-D A m P$ & $\begin{array}{l}\text { MATa } \quad x x x-D A m P:: k a n R ; \quad \text { his } 3 \Delta 1 \\
\text { leu } 2 \Delta 0 \text { met15 } \Delta 0 \text { ura } \Delta \Delta 0\end{array}$ \\
\hline
\end{tabular}

Our yeast homozygous deletion library and DAmP library were purchased from OpenBiosystems. Other than BY4741, other strains are representative of respective yeast libraries.

\subsection{Growth media and components}

S. cerevisiae strains were all cultured in one of the following growth media either in agar or in broth form. Appropriate antibiotics were also supplemented to the media; final concentration of $200 \mu \mathrm{g} / \mathrm{ml}$ geneticin (G418) for yeast deletion and DAmP library collection, $100 \mu \mathrm{g} / \mathrm{ml}$ ClonNAT (Werner bioAgents) and $20 \mu \mathrm{g} / \mathrm{ml}$ Hygromycin (Werner bioAgents) for yeast GFP collection. 
Yeast peptone dextrose (YPD) agar: 1\% (w/v) yeast extract (Becton, Dickinson and Company), 2\% (w/v) bacto-peptone (Becton, Dickinson and Company), 0.12\% $(\mathrm{w} / \mathrm{v})$ adenine (Sigma-Aldrich), 2\% (w/v) glucose (Sigma-Aldrich) and 2\% (w/v) g agar (Invitrogen). YPD broth was prepared without agar addition.

HEPES -buffered synthetic complete (SC+HEPES) agar: $0.17 \%(\mathrm{w} / \mathrm{v})$ yeast nitrogen base without amino acids or ammonium sulphate (Becton, Dickinson and Company), $0.1 \%(\mathrm{w} / \mathrm{v}$ ) monosodium glutamate (Sigma-Aldrich), $0.2 \%(\mathrm{w} / \mathrm{v}$ ) amino acid mixture to suit (Sigma-Aldrich), 20mM HEPES (Fisher Bioreagents), 2\% (w/v) agar (Becton, Dickinson and Company) and 2\% (w/v) glucose (Sigma-Aldrich). SC broth was prepared without agar addition.

Synthetic dropout (SD) agar: As with SC minus the addition of appropriate amino acid. SD broth was prepared without agar addition.

Amino acids mixture for SC media: $3 \mathrm{~g}$ adenine, $2 \mathrm{~g}$ uracil, $2 \mathrm{~g}$ inositol, $0.2 \mathrm{~g}$ paraaminobenzoic acid, $2 \mathrm{~g}$ alanine, $2 \mathrm{~g}$ asparagine, $2 \mathrm{~g}$ aspartic acid, $2 \mathrm{~g}$ cysteine, $2 \mathrm{~g}$ glutamic acid, 2 g glutamine, $2 \mathrm{~g}$ glycine, $2 \mathrm{~g}$ histidine, $2 \mathrm{~g}$ isoleucine, $10 \mathrm{~g}$ leucine, $2 \mathrm{~g}$ lysine, $2 \mathrm{~g}$ methionine, $2 \mathrm{~g}$ phenylalanine, $2 \mathrm{~g}$ proline, $2 \mathrm{~g}$ serine, $2 \mathrm{~g}$ threonine, $2 \mathrm{~g}$ tryptophan, $2 \mathrm{~g}$ tyrosine and $2 \mathrm{~g}$ valine.

SD amino acid mixture prepared in this thesis is a mixture of amino acids (Invitrogen) above minus $2 \mathrm{~g}$ histidine (SD-His). $2 \mathrm{~g}$ of this mixture is added in preparation of $1 \mathrm{~L}$ broth or agar media. 


\subsection{Preparation of bee products}

\subsubsection{Preparation of propolis extract}

Propolis was obtained from GoHealthy in the form of gelatin capsules containing a viscous liquid. Propolis (10 g) was dissolved in $30 \mathrm{ml}$ water and incubated overnight at $30^{\circ} \mathrm{C}$ in a shaking incubator. Propolis was then centrifuged at $16,000 \mathrm{~g}$ for 20 minutes and filtered through $0.22 \mathrm{~nm}$ pore size filter. The filtrate was labelled "crude propolis" and the residue was resuspended in $30 \mathrm{ml}$ methanol and incubated overnight at $30^{\circ} \mathrm{C}$ in shaking incubator. The methanolic propolis was centrifuged at 16, $000 \mathrm{~g}$ for 20 minutes and filtered through $0.22 \mathrm{~nm}$ pore size filter. The filtrate was collected and the methanol was evaporated from the methanolic extract of propolis using Labconco Centrivap 50 cold trap machine. The methanolic extract residue was resuspended in $100 \%$ DMSO. The treatment condition of crude and methanolic extracts of propolis was completed as the percentage of volume of propolis in total volume of media (\% $\mathrm{v} / \mathrm{v})$.

\subsubsection{Preparation of bee pollen extract}

Bee pollen was purchased from GoHealthy in the form of small granules within gelatin capsules. Pollen (1g) was dissolved in $40 \mathrm{ml} 100 \%$ DMSO and incubated overnight at $30^{\circ} \mathrm{C}$ in a shaking incubator. The extract was then centrifuged at $16,000 \mathrm{~g}$ for 20 minutes and filtered through $0.22 \mathrm{~nm}$ pore size filter. The filtrate was labelled "crude pollen" and the pellet was resuspended in 
$30 \mathrm{ml}$ methanol and incubated overnight at $30^{\circ} \mathrm{C}$ in a shaking incubator. The methanolic pollen was centrifuged at 16, $000 \mathrm{~g}$ for 20 minutes and filtered through $0.22 \mathrm{~nm}$ pore size filter. We collected the filtrate and evaporated off the methanol from the methanolic extract of pollen using cold trap machine. The methanolic extract residue was resuspended in 100\% DMSO. The treatment condition of the crude and methanolic extracts of bee pollen was completed as the percentage of volume of bee pollen in total volume of media $(\% \mathrm{v} / \mathrm{v})$.

\subsubsection{Preparation of bee venom}

Bee venom was obtained from HoneyLab Ltd. Bee venom (0.1438g) was dissolved in $12 \mathrm{ml}$ of water, vortexed at $1000 \mathrm{rpm}$ for 5 minutes, and filtered through $0.22 \mathrm{~nm}$ syringe filter. The filtrate was collected and stored at $-20^{\circ} \mathrm{C}$. The treatment condition of bee venom was completed as the volume of bee venom stock $(\mu \mathrm{l})$ in $1 \mathrm{ml}$ of media $(\mu \mathrm{l} / \mathrm{ml})$.

\subsection{Dose response studies}

\subsubsection{Propolis and bee pollen broth dose response.}

We prepared a fresh streak of BY4741 yeast strain from our frozen stock from the $-80^{\circ} \mathrm{C}$ freezer and incubate them overnight. We inoculated a fresh streak of BY4741 yeast strain in $2 \mathrm{ml} \mathrm{SC}$ broth and incubated the broth at $30^{\circ} \mathrm{C}$ overnight. We measured the absorbance of the overnight yeast culture and made a yeast stock at an $\mathrm{OD}_{600}$ of 0.1 for inoculation. 
We prepared a 96-well microtiter plate with each well containing $194 \mu \mathrm{l}$ of either media containing propolis or bee pollen at a range of concentrations. Each concentration was prepared in triplicate. We inoculated $6 \mu$ l of yeast on each well but some wells that will be used as blanks. We incubated the plate at $30^{\circ} \mathrm{C}$ and measured the absorbance at $\mathrm{OD}_{600}$ of the wells of the plate at 16 and 24 hours. The absorbance of each well was averaged across the corresponding triplicate and was normalised by subtracting the averaged value with the averaged value of the blanks. We analysed the absorbance by comparing the absorbance of the treated wells with the untreated control wells in the form of percentage termed "residual growth". The residual growth was calculated as follows:

Residual Growth (\%) $=\frac{\text { Absorbance of averaged treated wells }}{\text { Absorbance of untreated control wells }} \times 100 \%$

To study whether the concentrations of each bee product were simply growth inhibitory or toxic (killing the yeast), we performed another dose response using the same format as mentioned before but only at minimum inhibitory concentrations (MIC) which is the minimum concentration stop cell growth completely. After 2 hours and 6 hours of treatment with the respective bee products, we inoculated $30 \mu$ l of each well on YPD agar. We incubated the agar plate at $30^{\circ} \mathrm{C}$ overnight and photographed the agar plate. 


\subsubsection{Bee venom broth dose response}

Bee venom liquid dose response procedure was optimised for performing chemical genomic profiling of bee venom against both homozygous deletion library and DAmP library. With the streaked BY4741 prepared in 2.4.1, we inoculated the BY4741 strain into $5 \mathrm{ml}$ of YPD broth media, incubated overnight in $30^{\circ} \mathrm{C}$ incubator with rotation, added $15 \mathrm{ml}$ of sterile water, vortexed, and aliquoted $200 \mu \mathrm{l}$ of the mixture into each well of a 96 -well microtiter plate. We inoculated the yeast from the 96-well plate onto a fresh YPD agar plate and the agar plate was grown for 2 days in $30^{\circ} \mathrm{C}$ incubator. We then inoculated the YPD agar plate in 96 colony format into a 96 -well microtiter plate containing $200 \mu \mathrm{l}$ $\mathrm{SC}+\mathrm{HEPES}$. We placed the microtiter plate in $30^{\circ} \mathrm{C}$ incubator for 24 hours. The following day, we prepared a new microtiter plate containing $200 \mu \mathrm{l}$ of SC+HEPES broth media with different concentrations of bee venom. We ensured each treatment condition was made in triplicate. We inoculated the yeast from the cultured 96-well microtiter plate into 96-well microtiter plate with various bee venom treatment conditions. We measured the absorbance at $590 \mathrm{~nm}\left(\mathrm{OD}_{590}\right)$ using immediately after inoculation as our $0^{\text {th }}$ hour. We let the yeast grow overnight inside $30^{\circ} \mathrm{C}$ incubator and measured absorbance at 16 and 24 hours. We normalised the $\mathrm{OD}_{590}$ reading by deducting the absorbance of each well of the $16^{\text {th }}$ and $24^{\text {th }}$ hours' $O D_{590}$ with the $0^{\text {th }}$ hour $\mathrm{OD}_{590 .}$ 


\subsubsection{Propolis / bee venom / bee pollen agar dose response.}

The yeast stock was prepared the same way as yeast stock from broth dose response but with two additional stocks that were one-tenth and onehundreth of the first prepared stock. We prepared a 24-well plate with each well containing $500 \mu \mathrm{l}$ SC+HEPES agar with or without treatment of propolis, bee venom or bee pollen at specified concentrations. We inoculated $1 \mu$ l of each yeast stock onto each well, incubated the plate at $30^{\circ} \mathrm{C}$ for 48 hours, and photographed the 24-well plate at 24 and 48 hours.

We further optimised the concentration of propolis and bee pollen for 1536 yeast colony array format by preparing different treatment conditions of bee pollen and propolis in $40 \mathrm{ml} \mathrm{SC+HEPES}$ agar contained in Singer plates. We used Singer Rotor HDA to inoculate yeast from a plate from the homozygous deletion library onto each $40 \mathrm{ml}$ SC+HEPES agar conditions. We grew the inoculated plates in $30^{\circ} \mathrm{C}$ incubator and photographed each plate at 24 hours. The colony size is then measured and analysed as described in 2.5 .2 


\subsection{Homozygous deletion library and DAmP library yeast colonies screening \&}

image acquisition analysis

\subsubsection{Homozygous deletion library and DAmP library yeast colonies screening}

We prepared $40 \mathrm{ml} \mathrm{SC}+$ HEPES agar media with containing $1 \% \mathrm{v} / \mathrm{v}$ propolis or $2 \%$ $\mathrm{v} / \mathrm{v}$ bee pollen. We also prepared similar set of SC + HEPES agar media with equivalent amount of DMSO as solvent control. Each treated plates are in triplicate. We used Singer Rotor HDA to pin from our 1536 array homozygous deletion library and DAmP library onto the experimental plates. The inoculated plates are grown at $30^{\circ} \mathrm{C}$ and the plates were photographed after 24 hours.

\subsubsection{6-colonies array analysis}

Yeast in 1536-colonies array format were used in the screening step. This array allows for four replicates of each mutant strains in each Singer plate. We used $R$ "Gitter" software package to measure the mutant yeast colony size in 1536-array format in Singer plate (Wagih \& Parts, cran-r-project.org, 2014). Gitter generate a .DAT format data accessible using Excel 2013 from our photographed yeast plates. We modified the format of the files to make log files of the containing colony sizes of all Boone library plates and their triplicates under solvent treatment and the other triplicates under extract treatment. We uploaded the log file onto Rothstein Lab's Data Review Engine to analyse colonies and provides statistical assessment of the colony size differences under solvent treatment in 
comparison to extract treatment (Dittmar et al., 2010). The Data Review Engine provides us with the growth ratio of each mutant and their corresponding $p$-values which we used to pick as sensitive or resistant strains. The growth ratio was measured as follows:

Growth ratio $=\frac{\text { Colony size of yeast control strain }}{\text { Colony size of yeast treated strain }}$

\subsubsection{Propolis and bee pollen agar validation}

The validation step is performed to verify hits that were obtained from our library screens. This step is crucial to eliminate false hits and thus ensuring the reproducibility of hits obtained. We prepared a set of SC+HEPES agar in petri dishes at concentration range of $0.03-1 \% \mathrm{v} / \mathrm{v}$. We grew deletion strains which were hits from the homozygous deletion and DAmP library screening each in $2 \mathrm{ml}$ $\mathrm{SC}+\mathrm{HEPES}$ broth in $30^{\circ} \mathrm{C}$ incubator with rotation. We used a 96-well microtiter plate to prepare wells containing $1 \times 10^{6}$ cells $/ \mathrm{ml}$ and diluted down at 1:10 dilution in subsequent wells up until the sixth wells. Using multi-channel pipette, we blotted $1 \mu \mathrm{l}$ of each strain and its subsequent dilution from the microtiter plate onto the petri dishes containing propolis or bee venom at specified concentrations and petri dishes containing SC+HEPES and equivalent amount of DMSO. We incubated the petri dishes for 48 hours and photographed the yeast colonies. We chose a concentration for assessment based on the highest possible concentration that did not inhibit the growth of our BY4741 wildtype strain. 


\subsubsection{Bee venom broth library screening and validation}

We inoculated cells from our frozen stock of homozygous deletion library and DAmP library onto YPD + Geneticin agar media. We grew the agar plates in $30^{\circ} \mathrm{C}$ overnight and inoculated yeast colonies from the grown agar media onto 96-well microtiter plate containing SC+HEPES $200 \mu \mathrm{l}$ media broth and incubated overnight. We inoculated yeast from the overnight broth into the prepared 96well microtiter plates containing $200 \mu \mathrm{I}$ SC+HEPES media either with or without $0.1 \mu \mathrm{l} / \mathrm{ml}$ bee venom. Each strain treatment was done in triplicate. We incubated the plates at $30^{\circ} \mathrm{C}$ and measured the absorbance at $\mathrm{OD}_{590}$ after 16 and 24 hours post-inoculation. The absorbance reading was averaged across its replicates, and the treated and untreated strains were compared to calculate residual growth. Positive strains were identified with residual growth of less than $80 \%$ and $p$-value of less than 0.05 . For validation studies, we grew selected strains from the screening experiment and completed the rest of the procedure identical to the library screening; the only exception was the cut-off for validated positives was residual growth of less than $70 \%$ and $p$-value of less than 0.05 .

\subsubsection{GO enrichment and analysis}

GO enrichment analysis is a categorisation step of our validated positives. It annotates each positives, called GO term and divided the validated positives into groups of common GO term based on biological proess, molecular function and cellular component (Ashburner et al., 2000). It asses statistical significance of each GO term groups by comparing the positives gained in a particular Go 
term from study against the total number of genes included in the study (background) that belonged to the GO term. Therefore, the more number of positives belonging to a particular GO term acquired, the more statistically enriched that GO term which are reflected upon their corresponding p-values. Such analysis tool is available on Yeastmine (Balakrishnan et al., 2012). I uploaded our positives on Yeastmine but the analysis of the homozygous deletion library and DAmP library of each bee product treatment is done separately because of different yeast backgrounds.

\section{6 Iron ion rescue}

\subsubsection{Iron ion rescue broth dose response}

We prepared a custom agar plate by inoculating selected strains from the yeast deletion library into 96-well microtiter plate containing $200 \mu \mathrm{l}$ SC or SC+HEPES in a format in which each strain has triplicate wells. We used Singer Rotor HDA to inoculate the yeast from the previous microtiter plate onto the YPD agar plate and grew the yeast for 24 hours at $30^{\circ} \mathrm{C}$. We then used Singer Rotor HDA to inoculate the yeast from our custom agar plate into 96-well microtiter plate containing $200 \mu \mathrm{l}$. The inoculated 96 -well plate was grown for 24 hours at $30^{\circ} \mathrm{C}$. Each treatment was prepared in triplicate.

To study the effect of iron rescue under different propolis treatment concentrations, we grew select strains in a particular propolis concentration ranging from $0 \%$ (untreated) to $1 \%$ (agar screening concentration) with or 
without $100 \mu \mathrm{M} \mathrm{FeCl}_{2}$ supplementation. We incubated the plates for 24 hours at $30^{\circ} \mathrm{C}$ and measured absorbance at $\mathrm{OD}_{590}$ using Perkin Elmer Envision Plate Reader. We normalised the absorbance reading by deducting the average absorbance reading of each triplicate wells with the average absorbance of the media without yeast triplicate of each plate and compared the normalised absorbance reading of the a strain without $\mathrm{FeCl}_{2}$ supplementation to that of the same strain with $100 \mu \mathrm{M} \mathrm{FeCl}_{2}$ supplementation.

To study the effect of different iron concentrations rescuing the growth of yeast under propolis treatment, we repeated the same procedure as above, but with using a fixed concentration of $0.25 \%$ propolis treatment; this was the minimal concentration of propolis to completely inhibit growth of yeast even after 48 hours and a concentration of $\mathrm{FeCl}_{2}$ ranging from $0 \mu \mathrm{M}$ to $100 \mu \mathrm{M}$. We also included another plate containing only SC+HEPES media as untreated control. For analysis, we measured the residual growth using the following equation:

Residual Growth $(\%)=\frac{\text { Average } \text { strain } O D \text { reading with } 100 \mu \mathrm{M} \text { iron } s}{\text { Average } \text { strain OD reading solvent control }} \times 100 \%$ We compared the residual growth of each strain and at each $\mathrm{FeCl}_{2}$ concentration to that of BY4741 strains. 


\subsubsection{Other metal ion rescue broth dose response}

We prepared 96-well microtiter containing $200 \mu \mathrm{l}$ media containing SC+HEPES media with $100 \mu \mathrm{M}$ copper chloride $\left(\mathrm{CuCl}_{2}\right), 100 \mu \mathrm{M}$ manganese chloride $\left(\mathrm{MnCl}_{2}\right), 100 \mu \mathrm{M}$ magnesium chloride $\left(\mathrm{MgCl}_{2}\right)$, or $100 \mu \mathrm{M}$ zinc chloride $\left(\mathrm{ZnCl}_{2}\right)$ and including another triplicate without metal ion supplementation. We tested the metal ion supplementation effect against propolis treatment at $0 \%$ (untreated), $0.06 \%, 0.25 \%$ and $1 \%$. Each strains are tested against each $100 \mu \mathrm{M}$ metal ion supplementation and range or propolis treatment in triplicate.

\subsubsection{OPERA imaging \& fluorescence quantification}

We replicated a GFP library copy from frozen GFP library copy from the $80^{\circ} \mathrm{C}$ freezer onto SC-HIS with ClonNAT and Hgh. Our GFP strains possess mCherry RFP fluorescence for nucleus identification. Overlapped GFP and RFP marker signal is indicated by yellow fluorescence signal, indicating colocalisation. The construction of the strain is described in Bircham et al. (2011). We inoculated select GFP strains chosen from propolis and bee venom validation each into $5 \mathrm{ml}$ tube containing $2 \mathrm{ml} \mathrm{SC}$ broth and grow the strains overnight. We inoculated $10 \mathrm{ul}$ of each strain into a separate cuvette and measured the absorbance of each grown strain. For each strain we prepared a stock yeast which has the absorbance of OD0.1 in $1 \mathrm{ml} 1.5 \mathrm{ml}$ microcentrifuge tube. We prepared a PelkinElmer 384 fluorescence plate to contain $45 \mu$ l media with particular treatment conditions along with untreated media as comparison. We inoculated $15 \mu \mathrm{l}$ of each yeast stock into respective wells of the fluorescence plate. We incubated the plate for 7.5 hours for the cells to grow and reached sufficient number for 
imaging and fluorescence quantification. Both GFP and RFP images were acquired using OPERA confocal microscope and GFP fluorescence quantification was performed using OPERA-bundled Acapella software, following the procedure outlined by Bircham et al. (2010) but 1000 millisecond exposure time was applied instead. The microscopic images of the GFP and RFP were overlaid.

\subsection{Phosphatidylcholine (PC) quantification assay}

\subsubsection{Preparation of crude cell lysate}

The phosphatidylcholine (PC) assay was done using the Abcam phosphatidylcholine assay kit (ab83377). We performed broth dose response as described in 2.4 .3 with bee venom concentrations tested at 0.1 and $0.2 \mu \mathrm{l} / \mathrm{ml}$ respectively and six replicates. Following 18 hours after yeast inoculation, all six replicates of solvent control and two bee venom concentrations were pooled into $1.5 \mathrm{ml} 1.5 \mathrm{ml}$ microcentrifuge tube. $10 \mu \mathrm{l}$ of each pool was then diluted with $990 \mu \mathrm{l}$ sterile water in cuvettes. The absorbance was measured at $660 \mathrm{~nm}$ and the reading of each diluted pool was correlated with the cell concentration to assess the cell concentration of each pool. The cell concentration was then normalised in a way that each pool had an amount of cells equal to the pool with the least amount of cells. All normalised pools were then centrifuged at $16000 \mathrm{~g}$ for 5 minutes. The supernatant was removed from each pool. To each pool, 100 $\mu \mathrm{l}$ of sterile glass beads along with $200 \mu$ l extraction buffer were added $(0.2 \% \mathrm{v} / \mathrm{v}$ Triton, $1 \%$ SDS, $100 \mathrm{mM} \mathrm{NaCl}, 10 \mathrm{mM}$ Tris-Cl (pH9.0), $1 \mathrm{mM}$ EDTA). Each pool was 
then vortexed for 12 minutes at maximum speed. The mixture of each pool was removed and added to fresh $1.5 \mathrm{ml}$ microcentrifuge tube.

\subsubsection{PC assay preparation}

The assay was conducted following the protocol supplied by Abcam. Briefly, a standard of $0,2,4,6,8$ and $10 \mu$ l of diluted PC standard was prepared and PC assay buffer was added to bring the total volume of $50 \mu \mathrm{l}$ in 96 -well microtiter plate. PC reaction mix was prepared with PC assay buffer, PC Hydrolysis Enzyme, PC probe and PC development mix at ratio of 44:2:2:2. 50 $\mu$ l of each pooled sample was added to the 96-well microtiter plate in triplicate. $50 \mu \mathrm{l}$ of the PC reaction mix was added to each standard and sample well, bringing the final volume of $100 \mu \mathrm{l}$ in each well. For the background controls, $50 \mu \mathrm{l}$ of background mix that consists of PC assay buffer, PC probe and PC development mix added at the ratio of $46: 2: 2$ was added instead. The plate was shaken at $1000 \mathrm{rpm}$ for 30 seconds, wrapped with aluminium foil and incubated at room temperature for 1 hour instead of the outlined protocol of 30 minutes. The incubated plate was then fed into Bio System Multiwell plate scanner and absorbance at $570 \mathrm{~nm}$ was measured for each well. The absorbance reading of each strain and treatment was normalised against their respective strain background absorbance readings. The normalised absorbance readings were then correlated with their corresponding PC concentration following the protocol supplied by Abcam. The data was then graphed and p-value was calculated for statistical significance by using Student t-test. 


\subsection{Results and Discussion of Propolis}

\subsection{Results}

\subsubsection{Methanolic fraction of propolis showed greater inhibition compared to}

crude propolis in both agar and broth media.

The methanolic extract of propolis showed greater potency than the crude water-dissolved extract in both liquid media and agar media (Figure 3.1). In crude propolis, we observed strong inhibition at $2 \% \mathrm{v} / \mathrm{v}$, whereas the methanolic extract showed complete inhibition at a concentration as low as $0.25 \% \mathrm{v} / \mathrm{v}$. We found similar pattern when we performed the dose response assay in agar media in which inhibition was observed in $2 \%$ crude fraction propolis but we found strong inhibition even at concentration as low as $0.5 \% \mathrm{v} / \mathrm{v}$ methanolic extract. Although we observed that the agar media required greater concentration of propolis to exert potency, the methanolic fraction of bee propolis was still more inhibitory compared to the crude fraction. 
A.
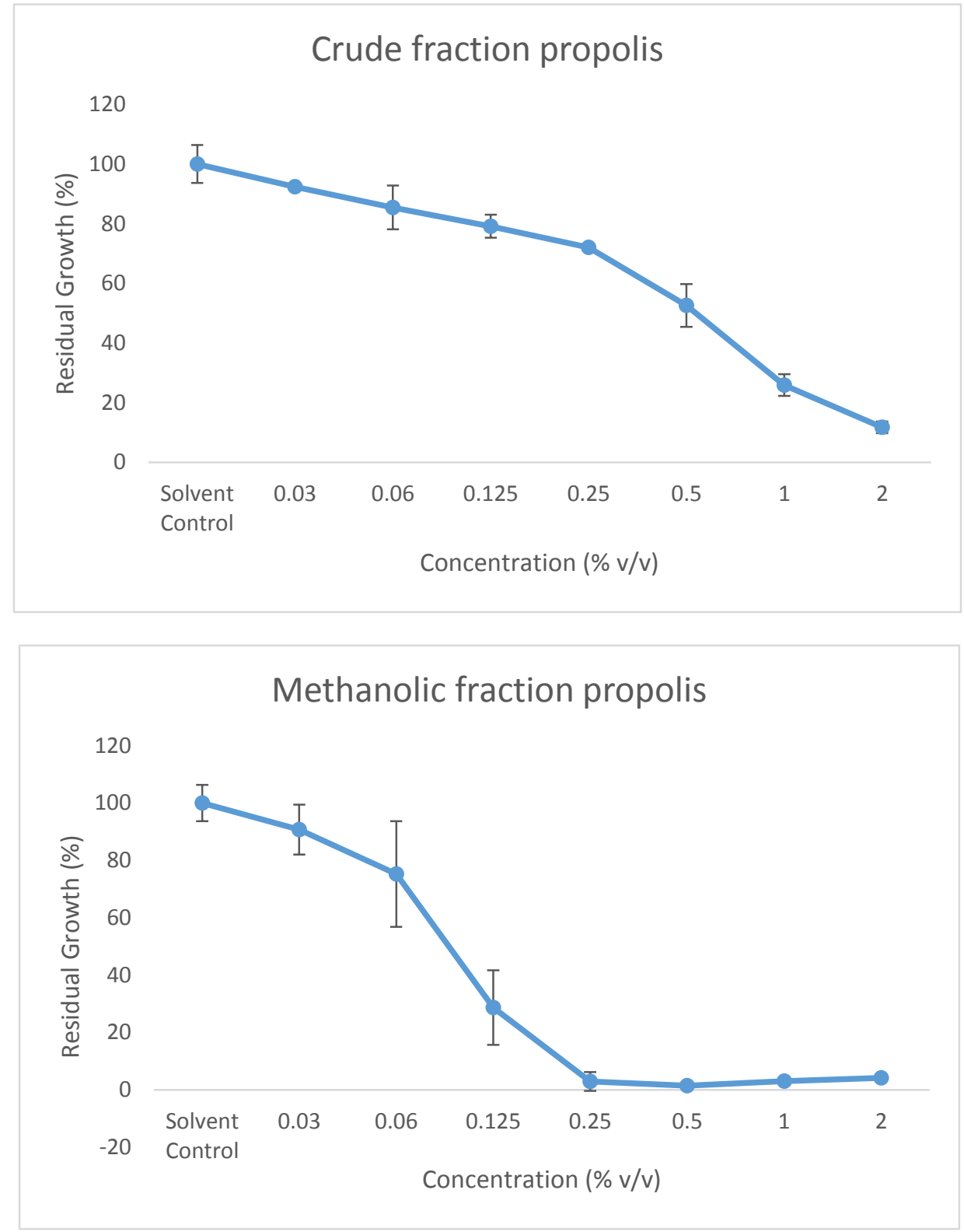

B.

Crude fraction propolis

Methanolic fraction propolis

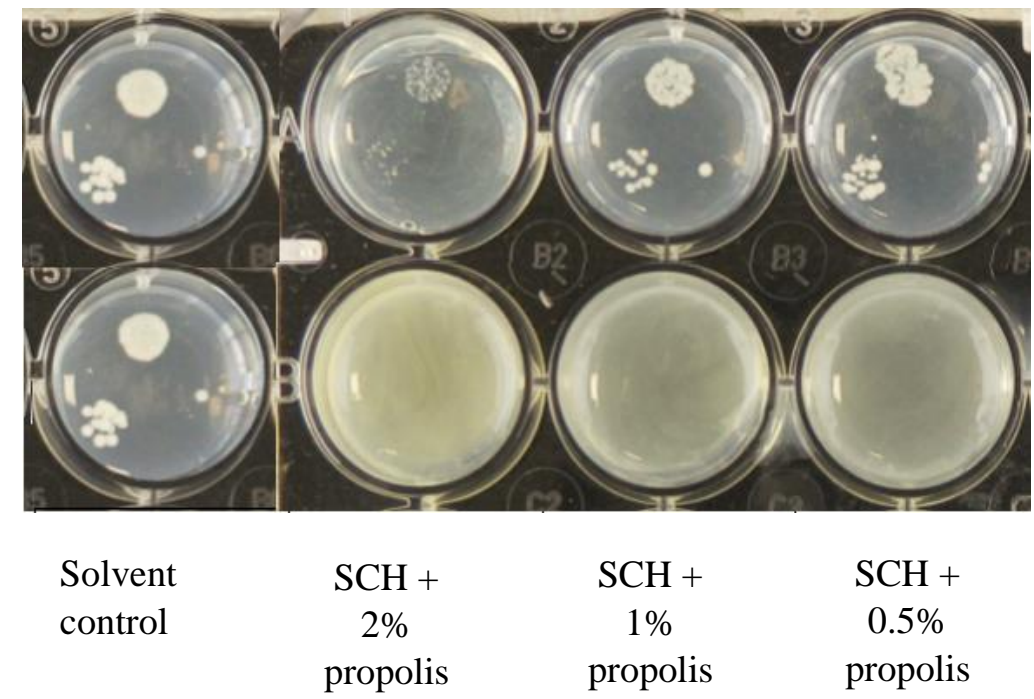


Figure 3.1. (A)Residual growth of crude fraction and methanolic fraction propolis at 24th hour after inoculation. (B) BY4741 wildtype yeast colonies grown on 500 $\mu$ SC+HEPES (SCH) agar media with presence of bee propolis between $0.5 \%-2 \% \mathrm{v} / \mathrm{v}$ in $10^{6}$ cells on top $10^{4}$ cells on bottom left and $10^{2}$ cells on bottom right. The colony size was taken 48 hours after inoculation.

\subsubsection{Chemical genetics screen indicates enrichment for iron ion transport}

To move on to screening our homozygous deletion and DAmP libraries, we chose to proceed with using methanolic extracts of propolis because it was more potent than crude extract. To optimise the concentration for chemical genetic screening, we performed agar dose response of a plate from our deletion library collection in 1536-colonies array format. We performed the dose response assay at concentration between $0.5-2 \% \mathrm{v} / \mathrm{v}$. Using ScreenMill, we picked the concentration of screening based on the median growth ratio of our his $3 \Delta$ border control strains (Figure 3.2). The his $3 \Delta$ strain were used to assess growth inhibition as our homozygous deletion library strains all has HIS3 gene deleted (refer section 2.1). We chose $1 \% \mathrm{v} / \mathrm{v}$ because the growth ratio was in the range of 1.10 to 1.20 , which indicates $10-20 \%$ reduction in growth of yeast under propolis treatment, and also the fact that the growth ratio is similar to that at $1.5 \%$ and $2 \%$. This 10 - 
$20 \%$ growth defect leaves an $80-90 \%$ window open to detect additional growth defect due to genetic mutations in the deletion and DAmP libraries.

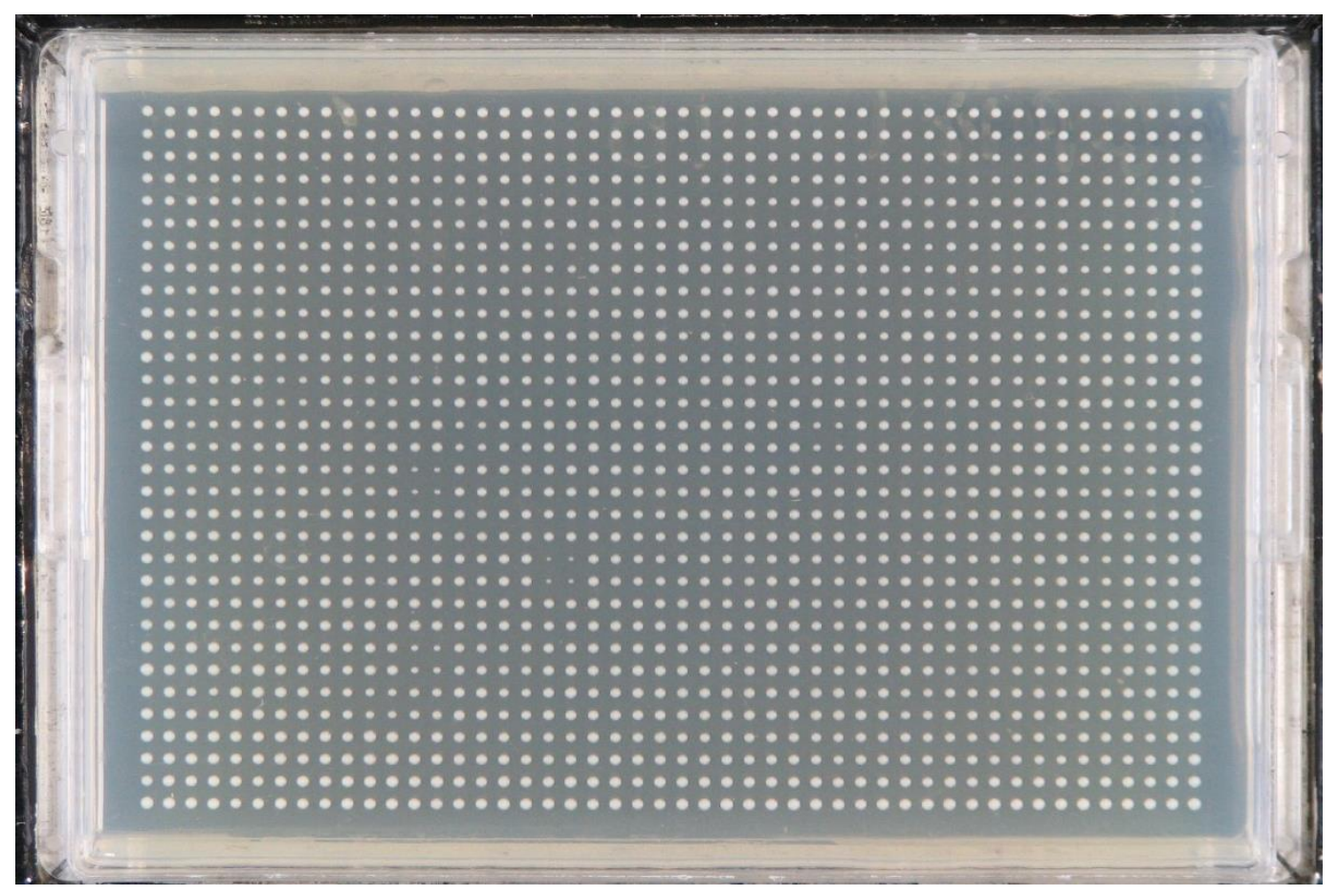

Figure 3.2. his3 $\Delta$ border strains were used for selecting propolis concentration

for screening. Above is the experimental plate at $1 \% \mathrm{v} / \mathrm{v}$ propolis treatment. The colony size was measured using Screenmill Data Review Engine (Dittmar, Reid, \& Rothstein, 2010)

From the screening of propolis against yeast haploid deletion library and the DAmP library, 22 out of $\sim 4300$ deletion mutant strains exhibited a significant growth defect, i.e., mutant strains showing growth ratio of greater than 1.2 (Appendix Table B.1.1). We used SGD YeastMine web software to assess for biological process enrichment from our validated positives. From YeastMine, the top validated hits belong to response to chemical, followed by ion transport and 
DNA damage response (Appendix Table A 1.1). On the other hand, 24 out of 839 strains from the DAmP library exhibited hypersensitivity against propolis treatment (Appendix Table B.1.2). We utilised YeastMine to find the most enriched biological process affected by propolis treatment. During this process, we separated hits from deletion library and DAmP library and identified that metal ion transport was the most enriched biological process, particularly iron ion transport (Appendix Table A.1.1). Other than metal ion transport, propolis also showed enrichment for response to stress and intracellular mRNA localisation. The DAmP library showed enrichment for small nucleolar RNA (snoRNA) which snoRNA is to aid specific ribosomal RNA (rRNA) modification (Dieci, Preti, \& Montanini, 2009). It is interesting that the top ten most enriched processes were all consists of RRP43, SEN1, CSL4 and PRP4 (Table A.1.2).

\subsubsection{Iron supplementation rescued growth inhibition caused by propolis.}

To further investigate the target of iron metabolism, we performed a liquid dose response of propolis from $0.03 \% \mathrm{v} / \mathrm{v}$ to $1 \% \mathrm{v} / \mathrm{v}$ concentration under $100 \mu \mathrm{M}$ $\mathrm{FeCl}_{2}$ supplementation on our wildtype and deletion mutant strains of the genes involved in iron-ion transport (Philpott \& Protechenko, 2008). We found that iron supplementation rescued the growth inhibition induced by propolis across all our deletion strains as well as the BY4741 wildtype (Figure 3.3, Table 1). The deletion strains involved in plasma membrane high-affinity iron ion transport all showed hypersensitivity toward propolis treatment at concentration as low as $0.03 \% \mathrm{v} / \mathrm{v}$ propolis where the complete inhibition (less than $10 \%$ residual growth) was 
observed. However, aft1 $\Delta$ and aft2 $\Delta$ mutants showed hypersensitivity but not complete inhibition. Aft1p and Aft $2 p$ are both transcriptional factors that play a central role in iron ion homeostasis sharing some substrate targets (Courel, Lallet, Camadro, \& Blaiseau, 2005; Yamaguchi-Iwai, Dancis, \& Klausner, 1995; Blaiseau, Lesuisse, \& Camadro, 2001).

Also, strains such as fet $3 \Delta$ and atx $1 \Delta$ showed greater sensitivity against propolis even with presence of $100 \mu \mathrm{M} \mathrm{FeCl}{ }_{2}$ compared to wildtype and other deletion strains (Figure 3.3A). The ferrireductase deletion mutants, fre $1 \Delta$, fre2 $\Delta$, fre $3 \Delta$, fre6 $\Delta$ showed different response at $0.03 \% \mathrm{v} / \mathrm{v}$ propolis where complete inhibition was achieved in fre $1 \Delta$, hypersensitivity was achieved in fre6 $\Delta$ and fre3 $\Delta$, whilst fre $2 \Delta$ showed inhibition similar to BY4741 wildtype. fre $4 \Delta$ and fre $5 \Delta$ mutant strains were not investigated in this study since these strains do not exist in our deletion library. The siderophore iron transport deletion mutant strains ( $\operatorname{arn} 1 \Delta$, $\operatorname{arn} 2 \Delta, \operatorname{arn} 3 \Delta, \operatorname{arn} 4 \Delta)$ showed hypersensitivity against propolis at $0.03 \% \mathrm{v} / \mathrm{v}$ with

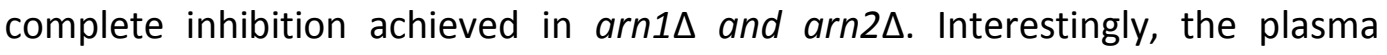

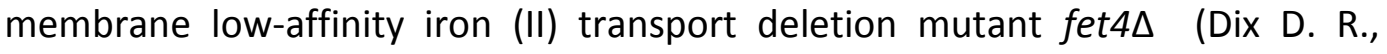
Bridgham, Broderius, Byersdorfer, \& Eide, 1994) was not inhibited at $0.03 \% \mathrm{v} / \mathrm{v}$ propolis indicating that the low affinity iron transporter were unaffected by propolis treatment. The vacuolar iron transporters deletion mutant fet5 $\Delta$ and fth $1 \Delta$ showed hypersensitivity against $0.03 \%$ v/v propolis treatment both at $\sim 40 \%$ residual growth but $s m f 3 \Delta$ showed sensitivity comparable to wildtype. The FIT proteins deletion mutants, fit1-3A all showed propolis sensitivity comparable to wildtype. Taken together, these results indicate that iron content is essential in 
resisting propolis-induced growth inhibition and that some but not all mechanisms of iron uptake is essential as yeast response against propolis treatment.

(A)
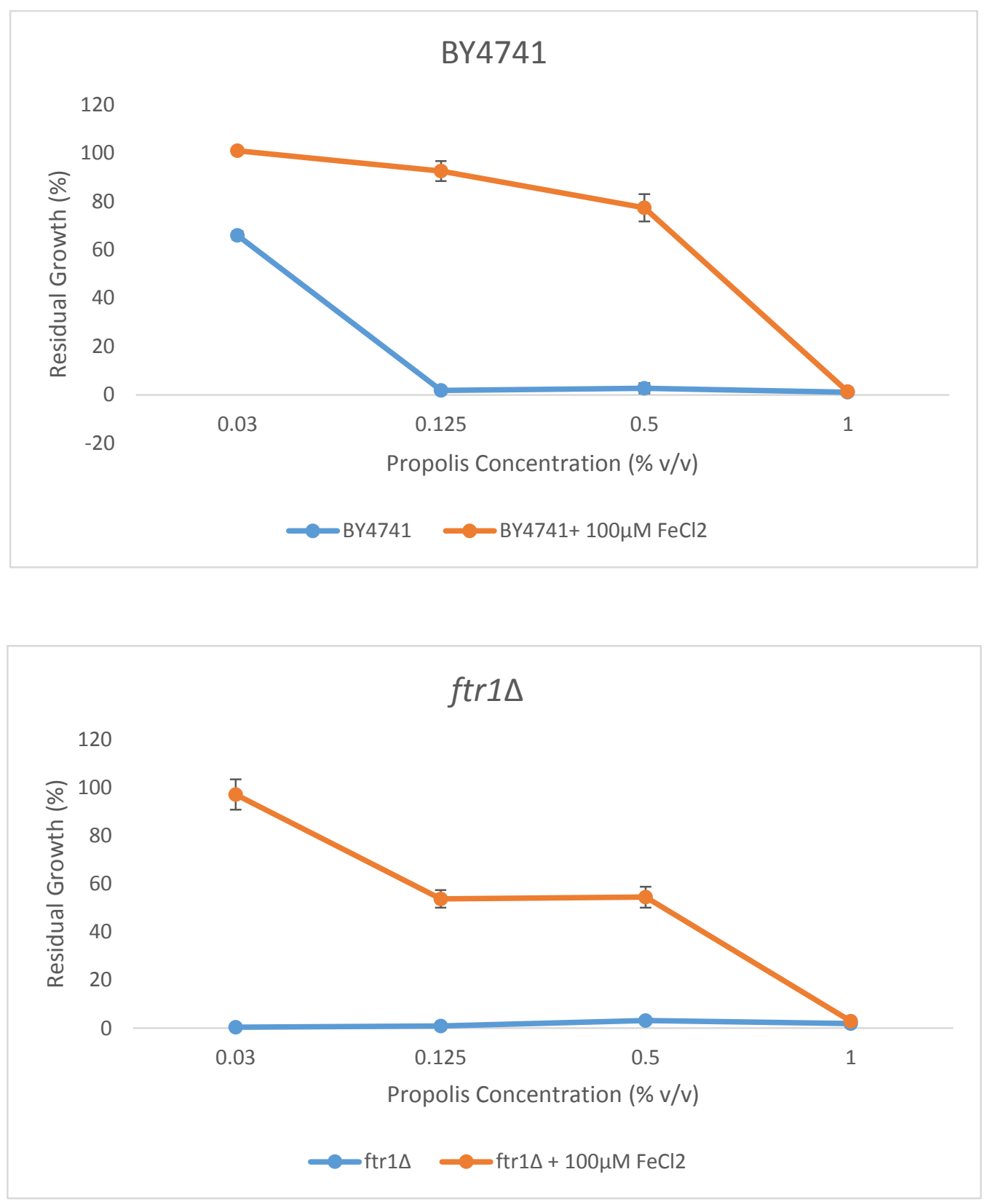

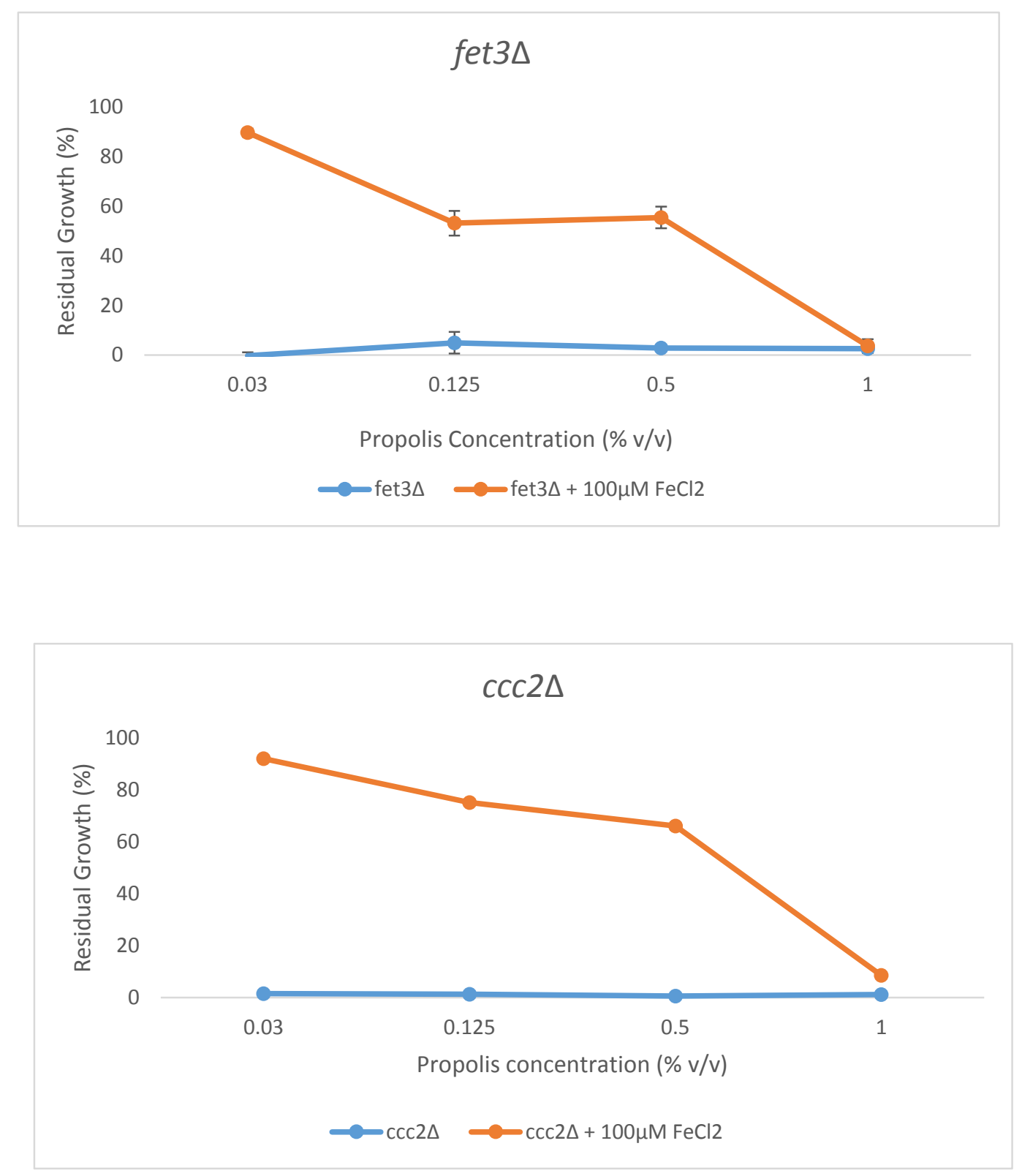


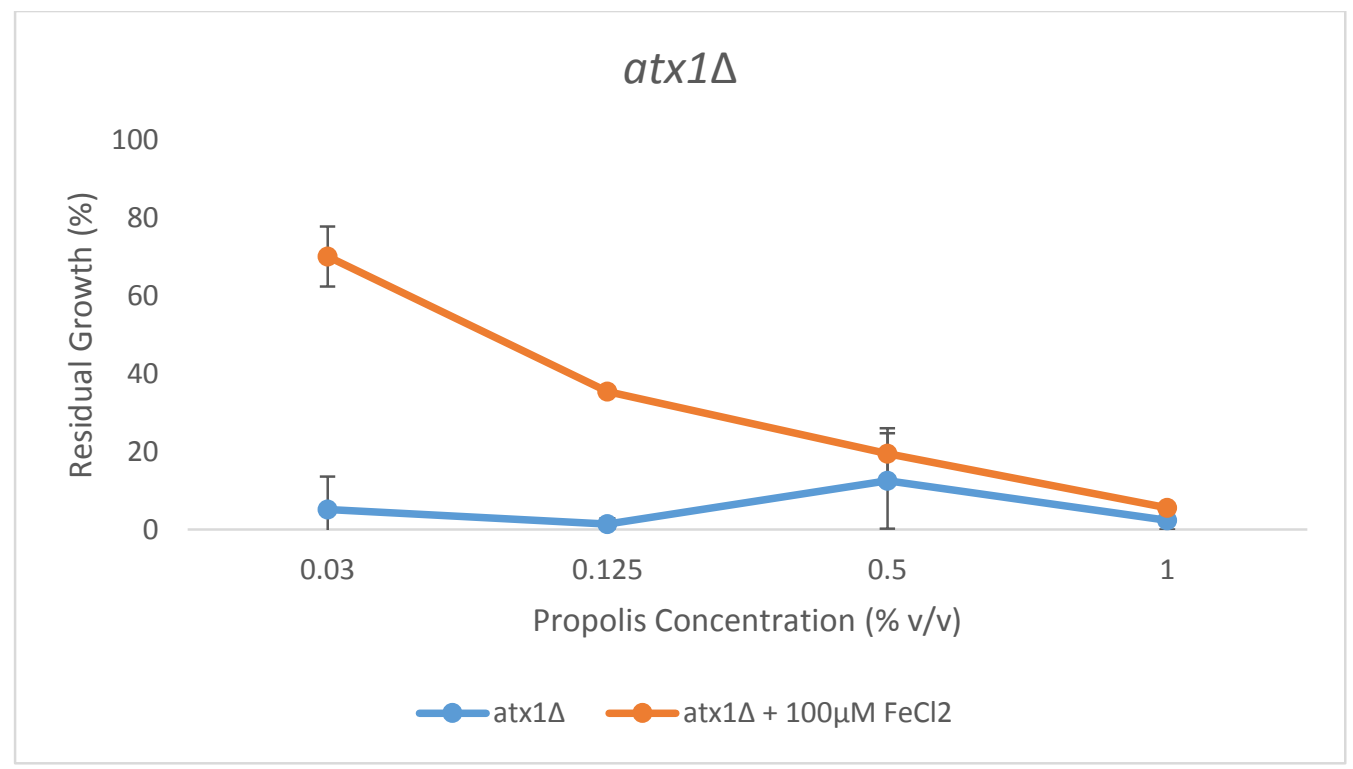

(B)

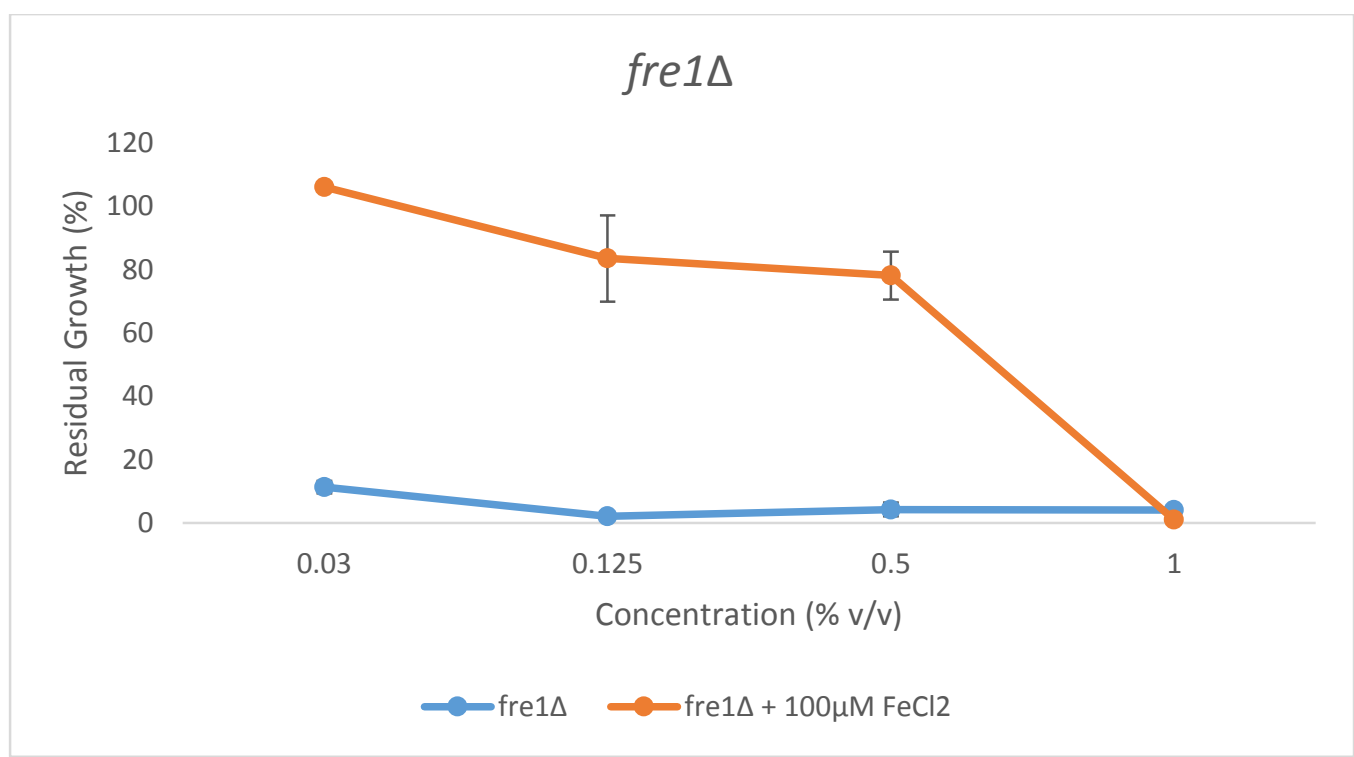


fre2 $\Delta$

120

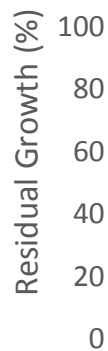

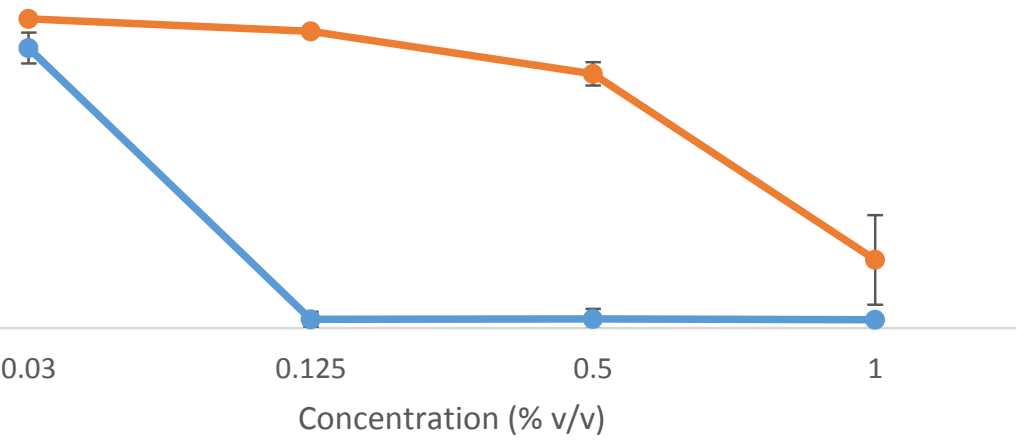

$\longrightarrow$ fre2 $\longrightarrow$ fre $2 \Delta+100 \mu \mathrm{M} \mathrm{FeCl} 2$

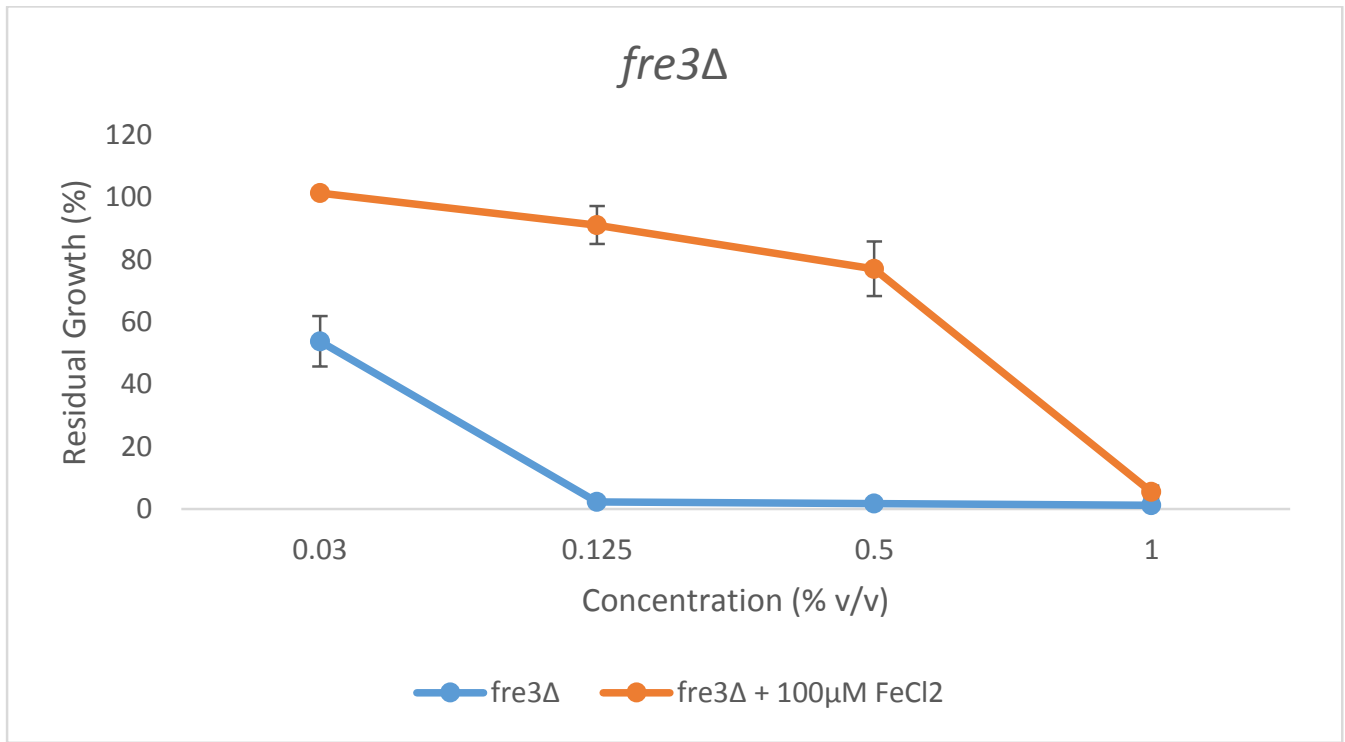


(C)
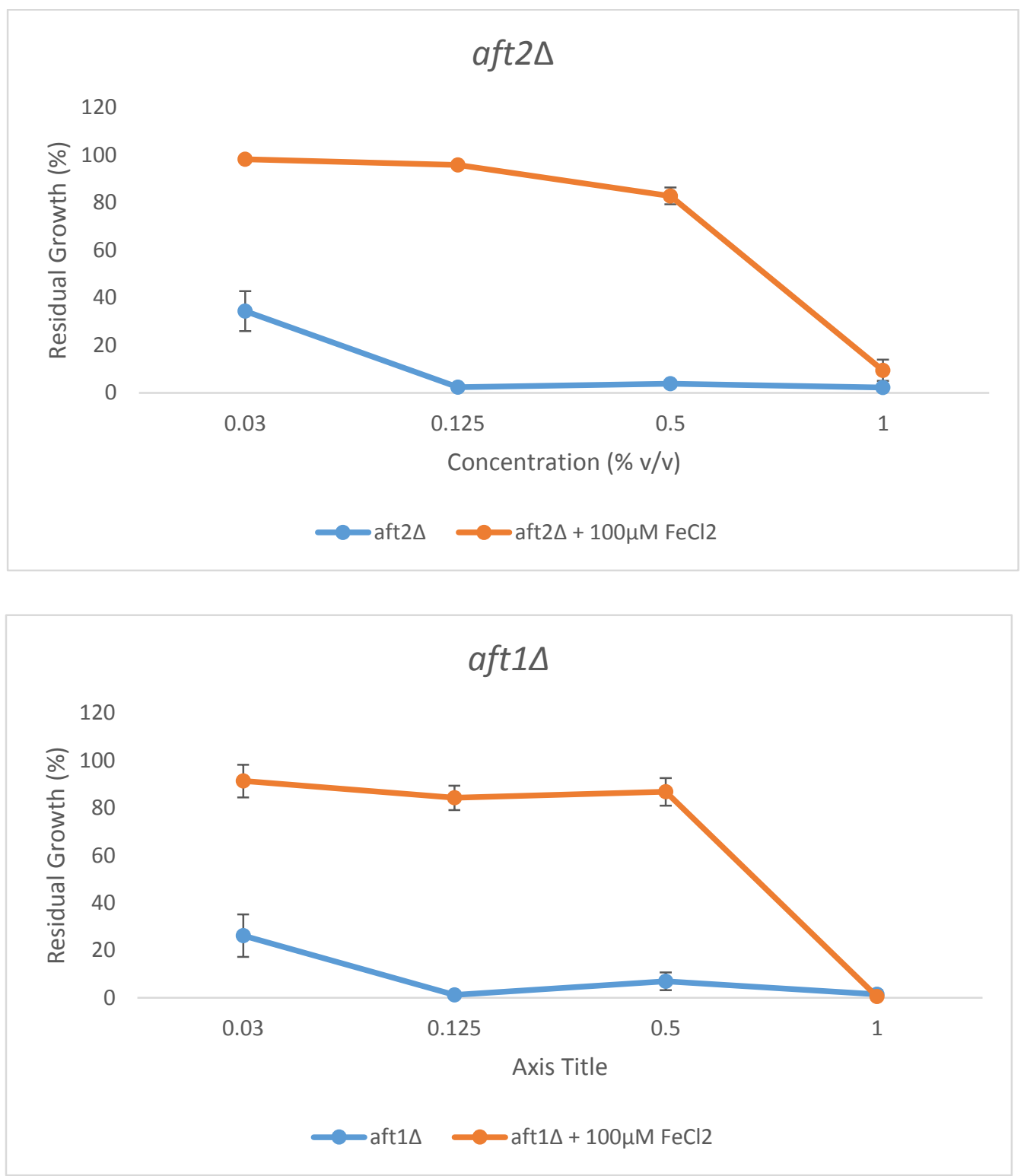
(D)
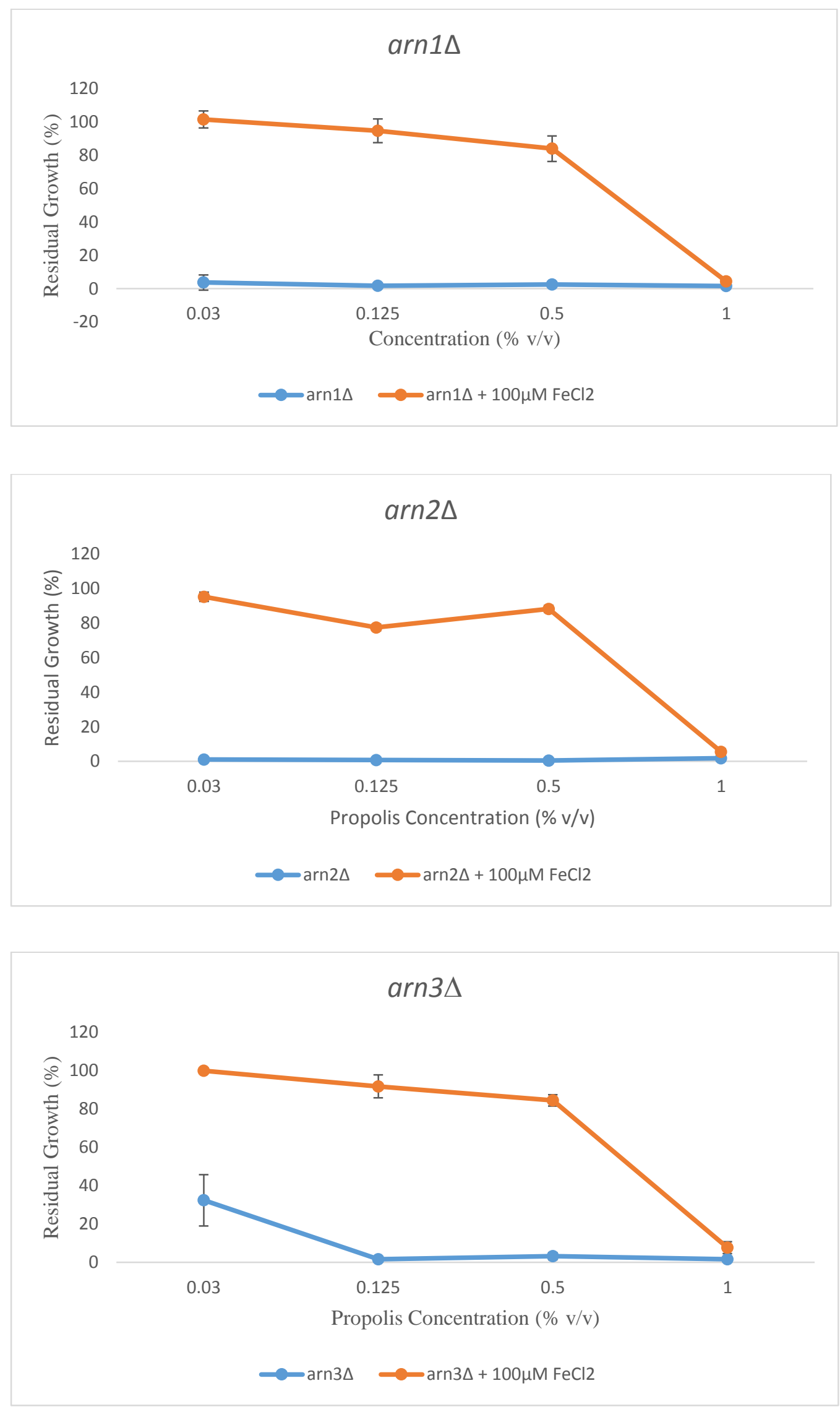


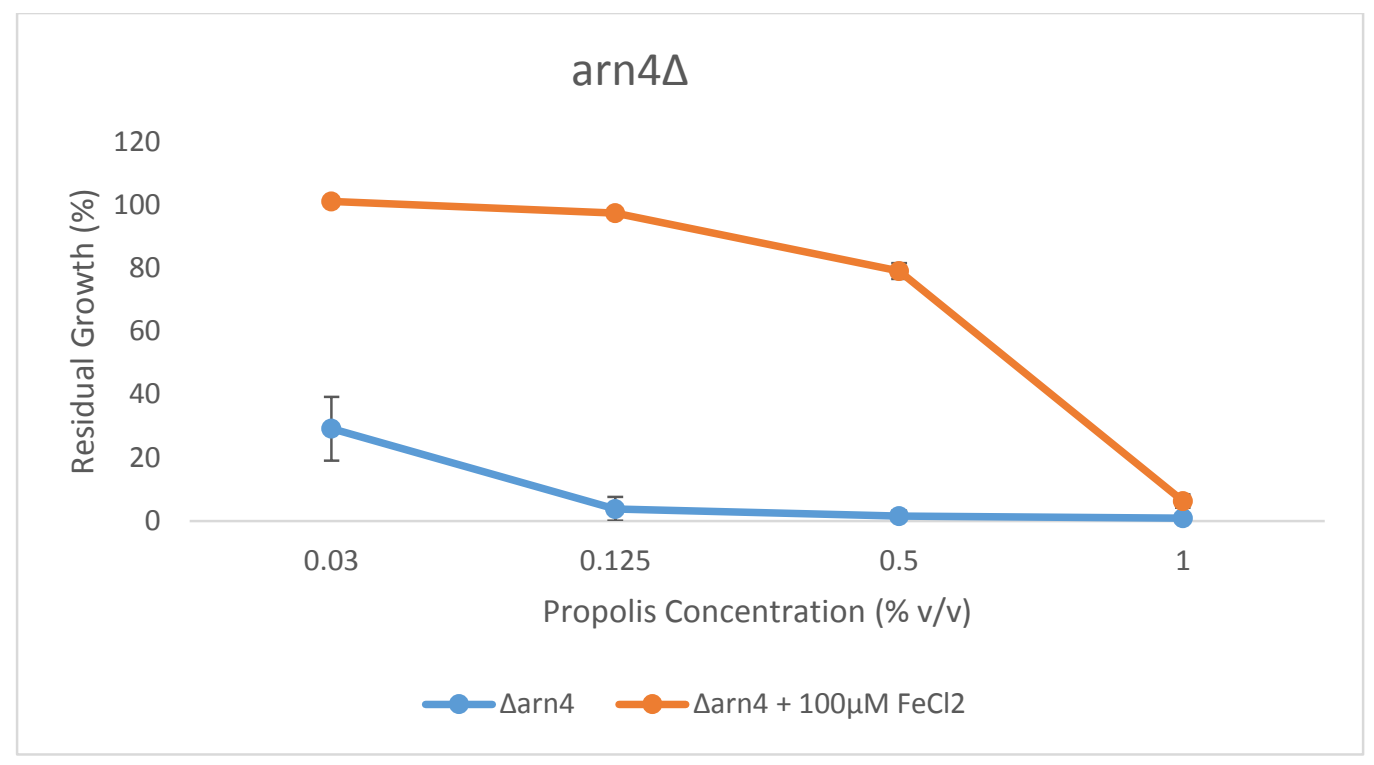

(E)

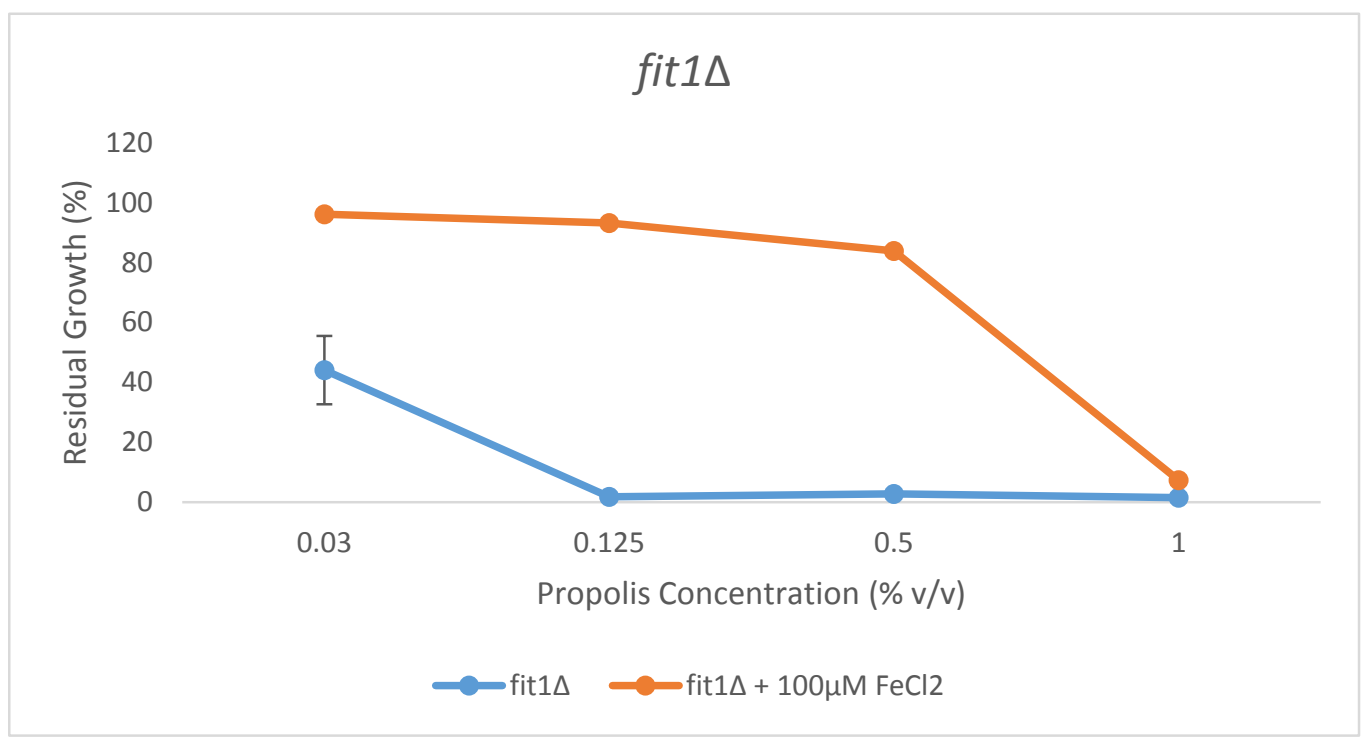




\section{fit2 $\Delta$}

120

बอ 100

占 80

느 60

$\frac{\sqrt{0}}{\frac{\pi}{2}} 40$

을 20

0

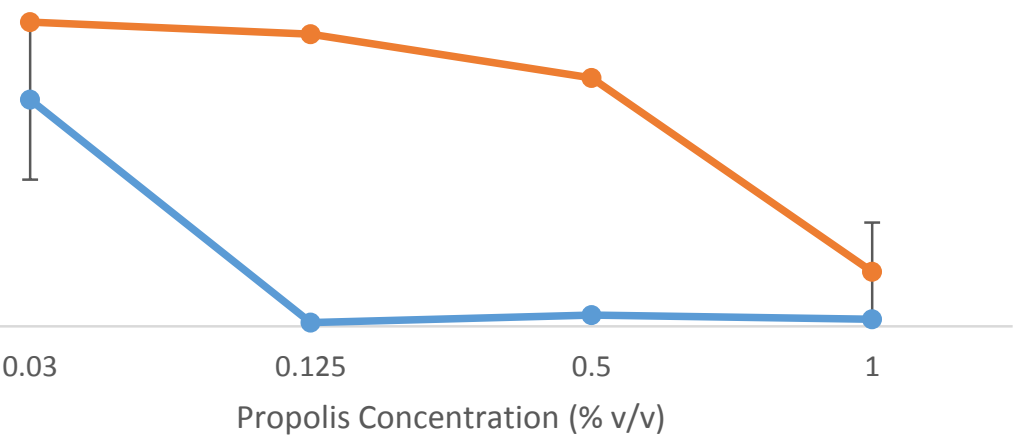

$\longrightarrow$ fit2 $\longrightarrow$ fit $2 \Delta+100 \mu \mathrm{M} \mathrm{FeCl} 2$

fit $3 \Delta$

120

ㅇำ 100

苦 80

ㄴํ 60

$\frac{\overline{0}}{\frac{0}{3}} 40$

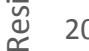

0
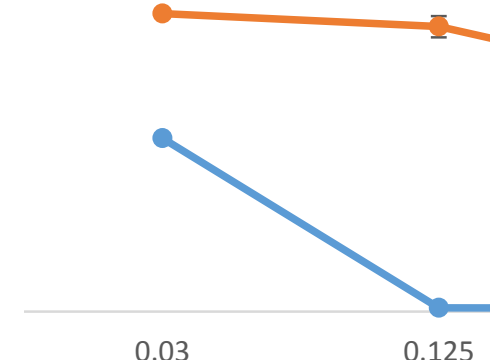

0.125

Propolis Concentration (\% v/v)

fit3 $\longrightarrow$ fit $3 \Delta+100 \mu \mathrm{M} \mathrm{FeCl} 2$ 
(F)

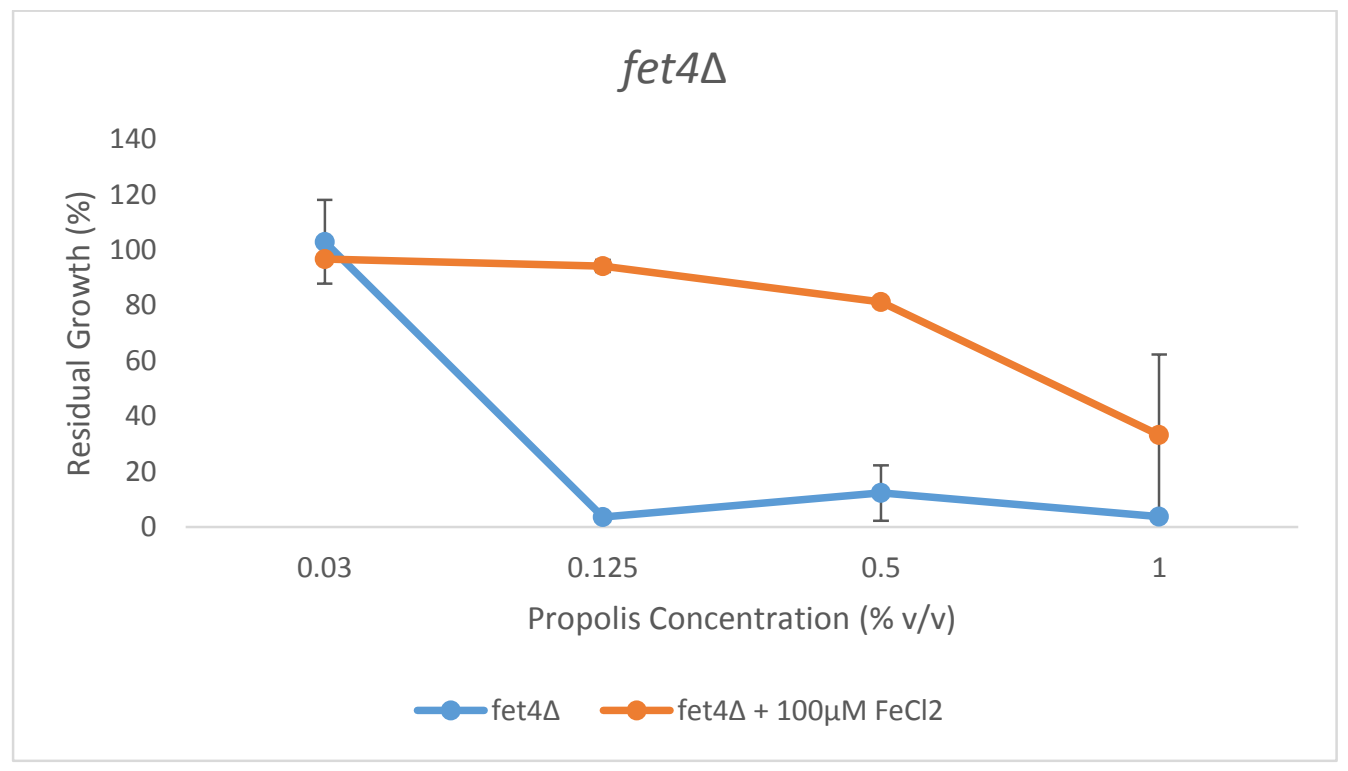

(G)

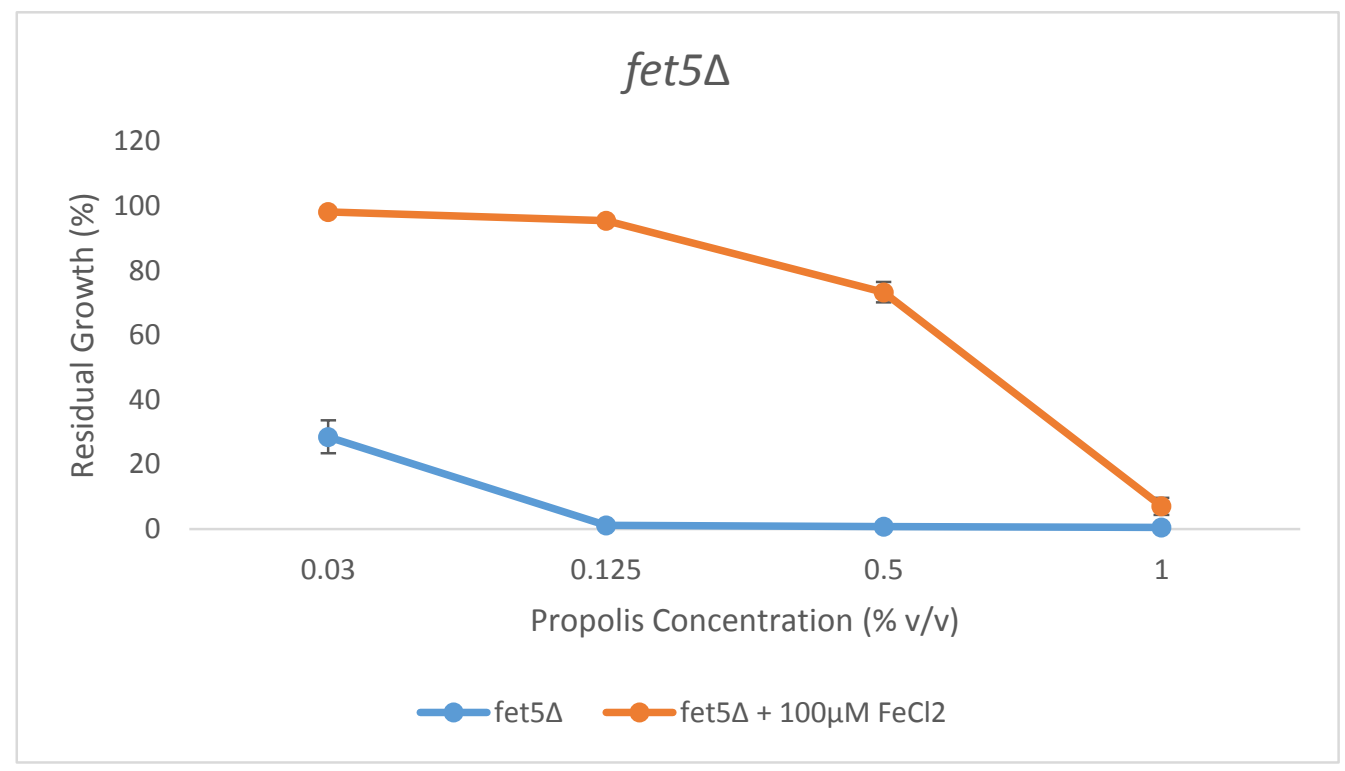



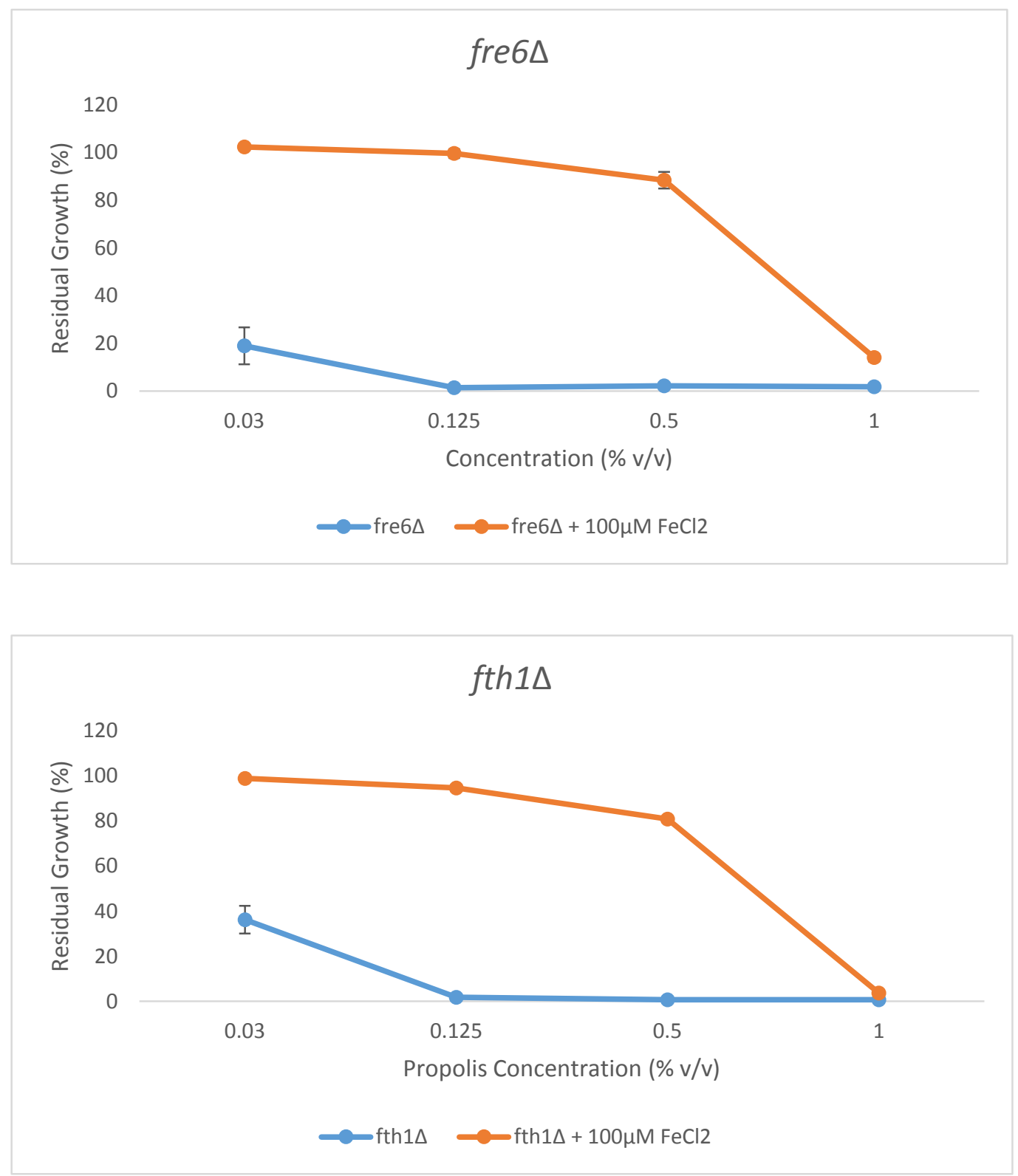
(H)

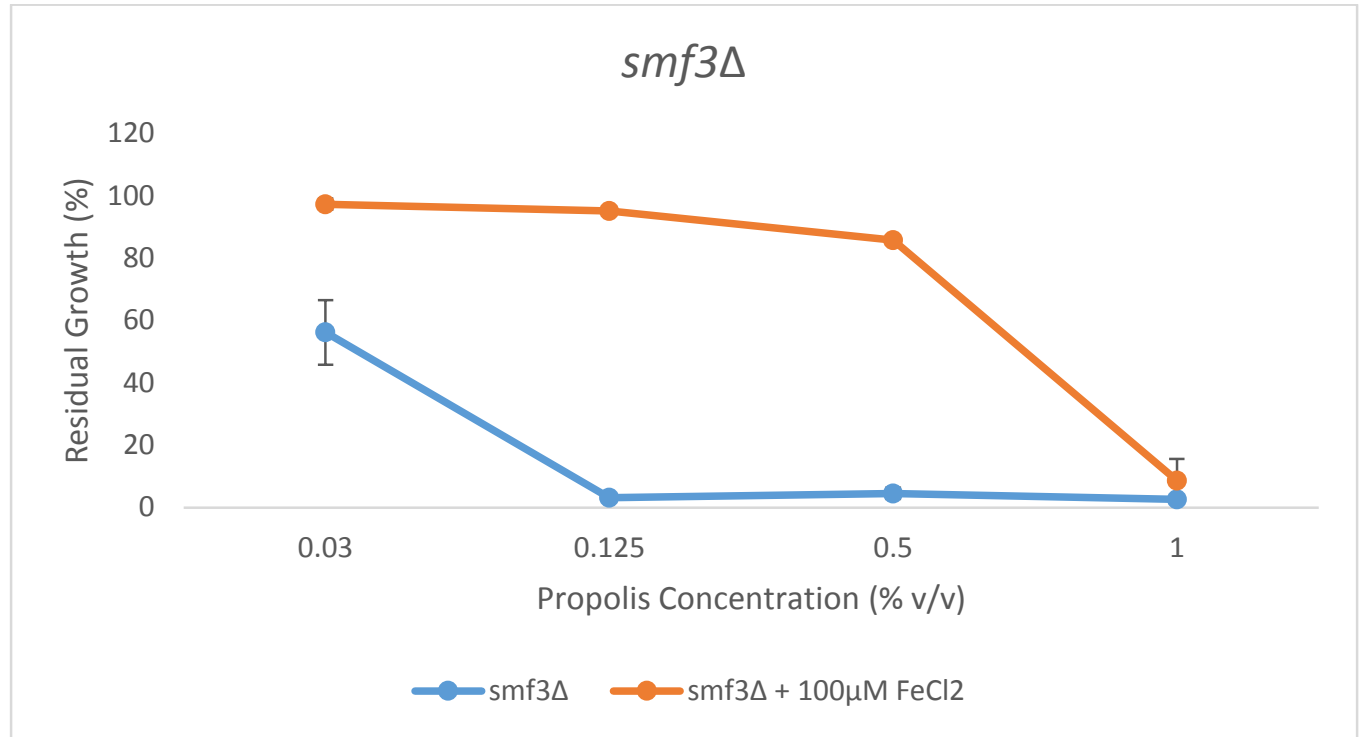

Figure 3.3 Residual growth of select deletion strains under propolis treatment with or without $100 \mathrm{uM} \mathrm{FeCl} 2$ after 24 hours inoculation. (A) BY4741 wildtype (B) High affinity plasma membrane iron ion transport. (C) Regulators of iron ion transport. (D) Siderophore-bound plasma membrane iron transporters. (E) Siderophore-bound iron retention proteins (F) Low-affinity plasma membrane iron ion transport. (G) High-affinity vacuolar iron transport. (H) Low-affinity vacuolar iron ion transport. Error bars represents standard deviation of residual growth. 


\begin{tabular}{|c|c|c|c|c|}
\hline & \multicolumn{4}{|c|}{ Residual Growth (\%) } \\
\hline & $0.03 \%$ & $0.13 \%$ & $0.50 \%$ & $1 \%$ \\
\hline BY4741 & 65.90 & 1.83 & 2.74 & 1.10 \\
\hline $\mathrm{BY} 4741+100 \mu \mathrm{M} \mathrm{FeCl}_{2}$ & 100.90 & 92.52 & 77.36 & 1.31 \\
\hline$\Delta f t r 1$ & 0.41 & 0.96 & 3.22 & 1.88 \\
\hline$\Delta f \operatorname{tr} 1+100 \mu \mathrm{M} \mathrm{FeCl}_{2}$ & 97.22 & 53.81 & 54.49 & 2.94 \\
\hline$\Delta$ fet3 & 0.18 & 4.98 & 2.83 & 2.61 \\
\hline$\Delta$ fet3 $+100 \mu \mathrm{M} \mathrm{FeCl}_{2}$ & 89.53 & 53.10 & 55.40 & 3.67 \\
\hline$\Delta c c c 2$ & 1.51 & 1.26 & 0.63 & 1.22 \\
\hline$\Delta c c c 2+100 \mu \mathrm{M} \mathrm{FeCl} 2$ & 92.06 & 75.12 & 66.06 & 8.59 \\
\hline$\Delta a t \times 1$ & 5.14 & 1.42 & 12.52 & 2.40 \\
\hline$\Delta a t x 1+100 \mu \mathrm{M} \mathrm{FeCl}_{2}$ & 70.11 & 35.40 & 19.49 & 5.56 \\
\hline$\Delta$ fre1 & 11.39 & 2.14 & 4.28 & 4.16 \\
\hline$\Delta$ fre $1+100 \mu \mathrm{M} \mathrm{FeCl}_{2}$ & 106.00 & 83.49 & 78.10 & 1.16 \\
\hline fre2 $\Delta$ & 89.83 & 2.77 & 2.87 & 2.63 \\
\hline$\Delta$ fre $2+100 \mu \mathrm{M} \mathrm{FeCl}_{2}$ & 99.18 & 95.19 & 81.52 & 21.86 \\
\hline$\Delta$ fre3 & 53.82 & 2.30 & 1.75 & 1.25 \\
\hline$\Delta$ fre3 + $100 \mu \mathrm{M} \mathrm{FeCl}_{2}$ & 101.37 & 91.14 & 77.08 & 5.53 \\
\hline$\Delta a f t 2$ & 34.37 & 2.41 & 3.87 & 2.17 \\
\hline$\Delta a f t 2+100 \mu \mathrm{M} \mathrm{FeCl}_{2}$ & 98.28 & 95.86 & 82.81 & 9.46 \\
\hline$\Delta a f t 1$ & 26.13 & 1.16 & 6.88 & 1.46 \\
\hline$\Delta a f t 1+100 \mu \mathrm{M} \mathrm{FeCl}_{2}$ & 91.34 & 84.26 & 86.82 & 0.54 \\
\hline$\Delta \operatorname{arn} 1$ & 3.76 & 1.81 & 2.58 & 1.67 \\
\hline$\Delta a r n 1+100 \mu \mathrm{M} \mathrm{FeCl}_{2}$ & 101.56 & 94.72 & 84.01 & 4.43 \\
\hline$\Delta a r n 2$ & 1.08 & 0.84 & 0.42 & 1.79 \\
\hline$\Delta a r n 2+100 \mu \mathrm{M} \mathrm{FeCl}_{2}$ & 95.13 & 77.45 & 88.17 & 5.52 \\
\hline$\Delta a r n 3$ & 32.33 & 1.58 & 3.26 & 1.63 \\
\hline$\Delta a r n 3+100 \mu \mathrm{M} \mathrm{FeCl}_{2}$ & 99.75 & 91.58 & 84.29 & 7.63 \\
\hline$\Delta a r n 4$ & 29.20 & 3.79 & 1.56 & 0.80 \\
\hline$\Delta a r n 4+100 \mu \mathrm{M} \mathrm{FeCl}_{2}$ & 101.16 & 97.43 & 79.11 & 6.29 \\
\hline fit1 $\Delta$ & 44.04 & 1.82 & 2.71 & 1.50 \\
\hline$\Delta$ fit1 $+100 \mu \mathrm{M} \mathrm{FeCl}_{2}$ & 96.16 & 93.14 & 83.84 & 7.30 \\
\hline$\Delta f i t 2$ & 74.51 & 1.26 & 3.81 & 2.41 \\
\hline$\Delta$ fit2 $+100 \mu \mathrm{M} \mathrm{FeCl}_{2}$ & 99.95 & 95.90 & 81.64 & 18.01 \\
\hline$\Delta f i t 3$ & 57.56 & 1.25 & 1.15 & 1.82 \\
\hline$\Delta f i t 3+100 \mu \mathrm{M} \mathrm{FeCl}_{2}$ & 98.86 & 94.58 & 73.98 & 5.67 \\
\hline$\Delta f e t 4$ & 103.02 & 3.60 & 12.31 & 3.83 \\
\hline$\Delta$ fet $4+100 \mu \mathrm{M} \mathrm{FeCl}_{2}$ & 96.86 & 94.30 & 81.32 & 33.22 \\
\hline$\Delta$ fet5 & 28.50 & 1.09 & 0.76 & 0.52 \\
\hline$\Delta$ fet5 $+100 \mu \mathrm{M} \mathrm{FeCl}_{2}$ & 98.13 & 95.43 & 73.28 & 7.02 \\
\hline$\Delta$ fre6 & 18.99 & 1.51 & 2.19 & 1.90 \\
\hline$\Delta$ fre6 $+100 \mu \mathrm{M} \mathrm{FeCl}_{2}$ & 102.33 & 99.58 & 88.39 & 14.04 \\
\hline$\Delta f t h 1$ & 36.23 & 1.83 & 0.77 & 0.72 \\
\hline$\Delta f t h 1+100 \mu \mathrm{M} \mathrm{FeCl}_{2}$ & 98.96 & 94.66 & 80.81 & 3.76 \\
\hline$\Delta s m f 3$ & 56.18 & 3.14 & 4.52 & 2.57 \\
\hline$\Delta s m f 3+100 \mu \mathrm{M} \mathrm{FeCl}_{2}$ & 97.31 & 95.17 & 85.77 & 8.61 \\
\hline
\end{tabular}


Table 1. Tabulated residual growth of select deletion strains with or without 100 $\mathrm{uM} \mathrm{FeCl} 2$ after 24 hours inoculation.

\subsubsection{Other metal ions supplementation indicates different growth rescue patterns}

It is noteworthy that the high-affinity iron transporter also utilises copper ions to carry out the iron uptake (Askwith \& Kaplan, 1998). Thus, it might be possible that copper ions supplementation also rescues propolis-induced growth defects similar to ion. We were also curious as to whether other metal ions would have any effect as well. The reason being propolis is rich in flavonoids and flavonoids were demonstrated to have metal ion chelation activity (Kandaswami \& E. Middleton, 1997). To test this, we conducted a growth assay on BY4741, $\Delta$ fre 1 , $\Delta a t x 1, \Delta f t r 1, \Delta f e t 3, \Delta c c c 2, \Delta a f t 1, \Delta a r n 1, \Delta a r n 2, \Delta a r n 3$ and $\Delta a r n 4$ mutant strains with $0.03 \% \mathrm{v} / \mathrm{v}$ methanolic fraction propolis and $100 \mu \mathrm{M}$ of $\mathrm{CuCl}_{2}, \mathrm{MnCl}_{2}, \mathrm{MgCl}_{2}$, $\mathrm{CaCl}_{2}$, or $\mathrm{ZnCl}_{2}$ (Figure 3.4). The BY4741 wildtype indicated that iron restored growth, whereas zinc was significantly lower compared to that of no metal ion supplementation media. Zinc ion supplementation media did not show a significant difference compared to no metal ion supplementation media for fet $3 \Delta$, but we observed complete inhibition by propolis under zinc ion supplementation media.

The other metal ions showed no significant differences compared to no metal ion media in terms of residual growth in BY4741 wildtype. However, the highaffinity iron ion transport strains exhibited less than $10 \%$ residual growth under no metal ion supplementation media with the exception of $\Delta a f t 1$. Also, these high- 
affinity iron ion transport strains showed specific growth rescue patterns on each metal ions supplementation. $\Delta a f t 1$ exhibited some growth rescue effect under propolis treatment in media containing zinc, magnesium and manganese ions. $\Delta f e t 3$ showed significant growth rescue effect for all metal ion supplementations except for zinc ion. $\Delta a t x 1$ exhibited growth rescue with only copper and iron ion supplementation. $\Delta c c c 2$ also showed similar growth rescue with copper ion supplementation but it is also observed that there is a slight but significant growth rescue with magnesium ion supplementation as well. $\Delta$ fre 1 showed significant growth rescue effect with all but calcium ion and zinc ion supplementation. $\Delta a t x 1$, $\Delta c c c 2$, and $\Delta f r e 1$ shared a similar noteworthy pattern in which copper ion supplementation rescued growth inhibition better than iron ion supplementation. In contrast, some other strains such as $\Delta f e t 3$ and $\Delta f \operatorname{tr} 1$ had $\mathrm{MgCl}_{2}$ supplementation rescue growth better than $\mathrm{CuCl}_{2}$ although the rescue is less than $\mathrm{FeCl}_{2}$ supplementation. No metal ions were found to rescue $\Delta a r n 1$ and $\Delta a r n 2$ inhibition by propolis except for iron. Overall, all strains shared similar pattern to that of BY4741 wildtype in which $\mathrm{FeCl}_{2}$ supplementation restored the growth phenotype while $\mathrm{ZnCl}_{2}$ exacerbated the growth inhibition. 
(A)
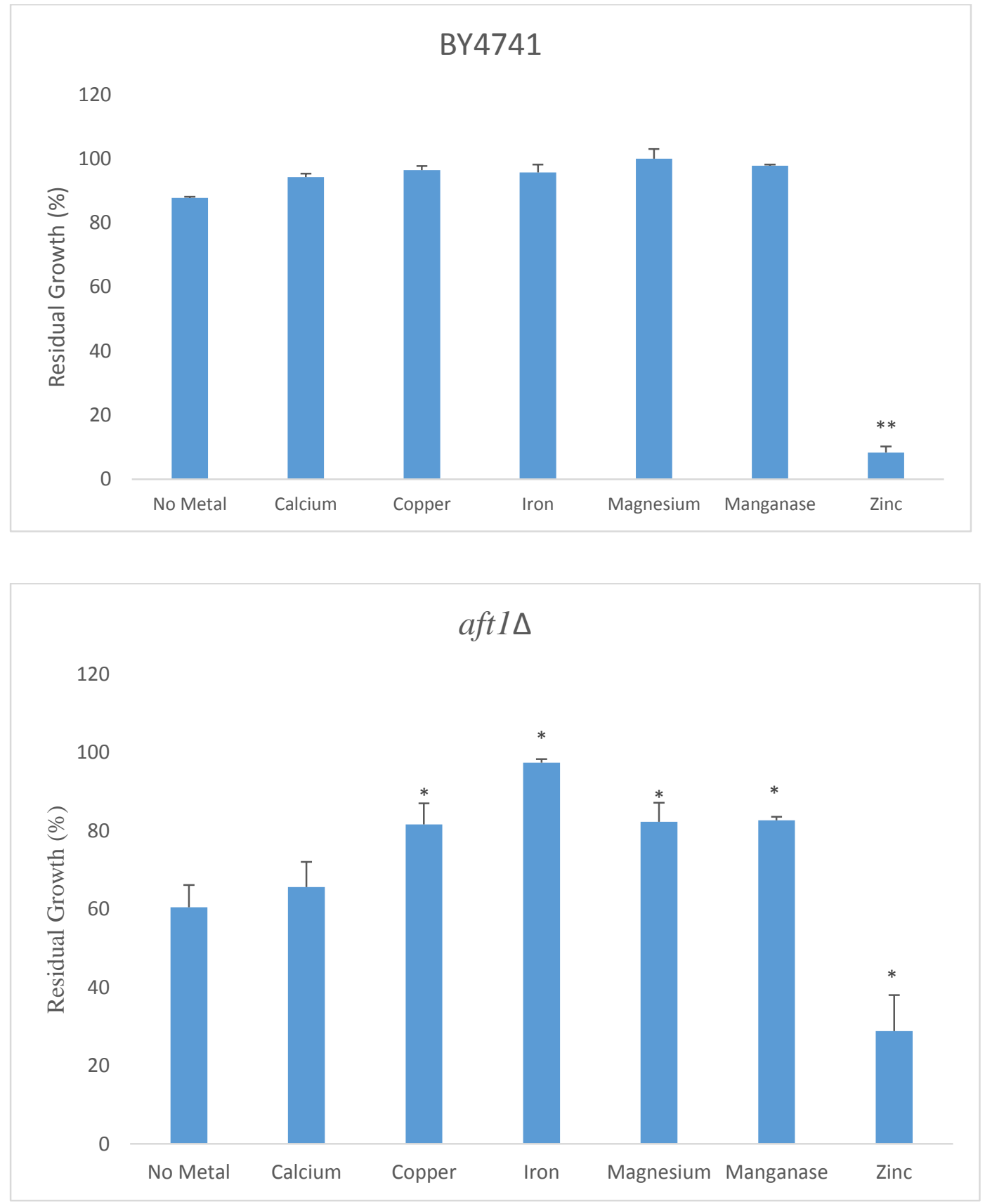

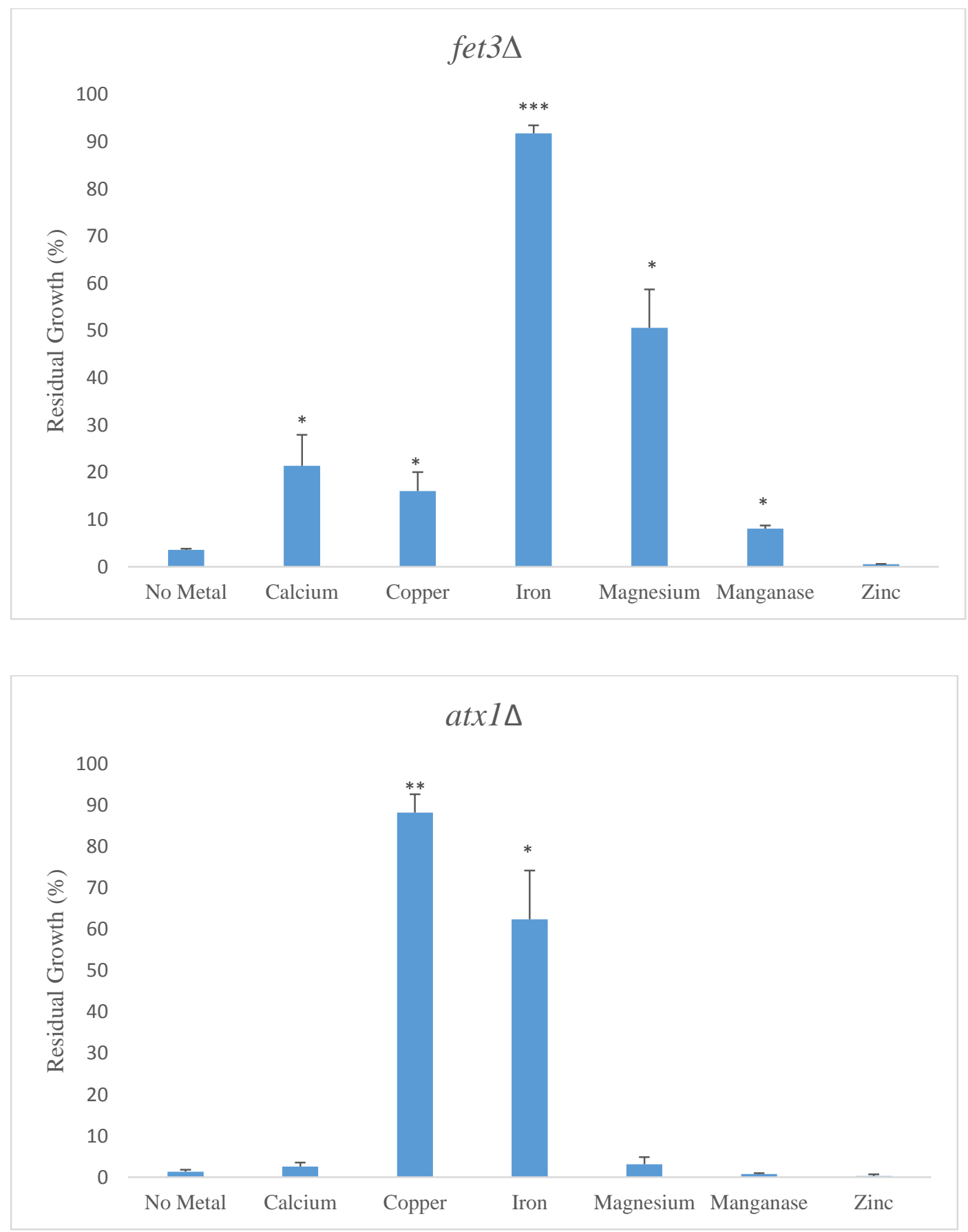

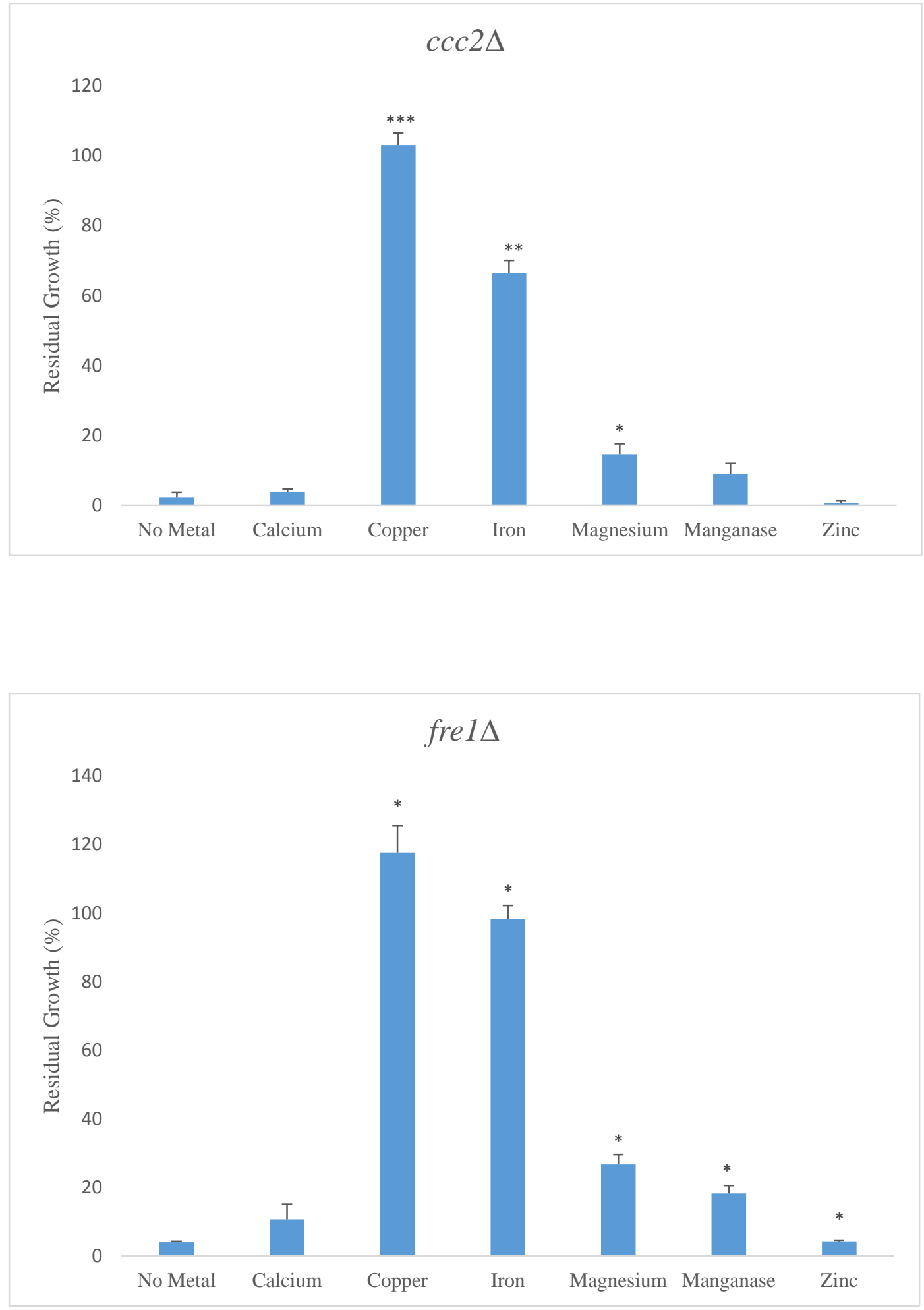
(B)
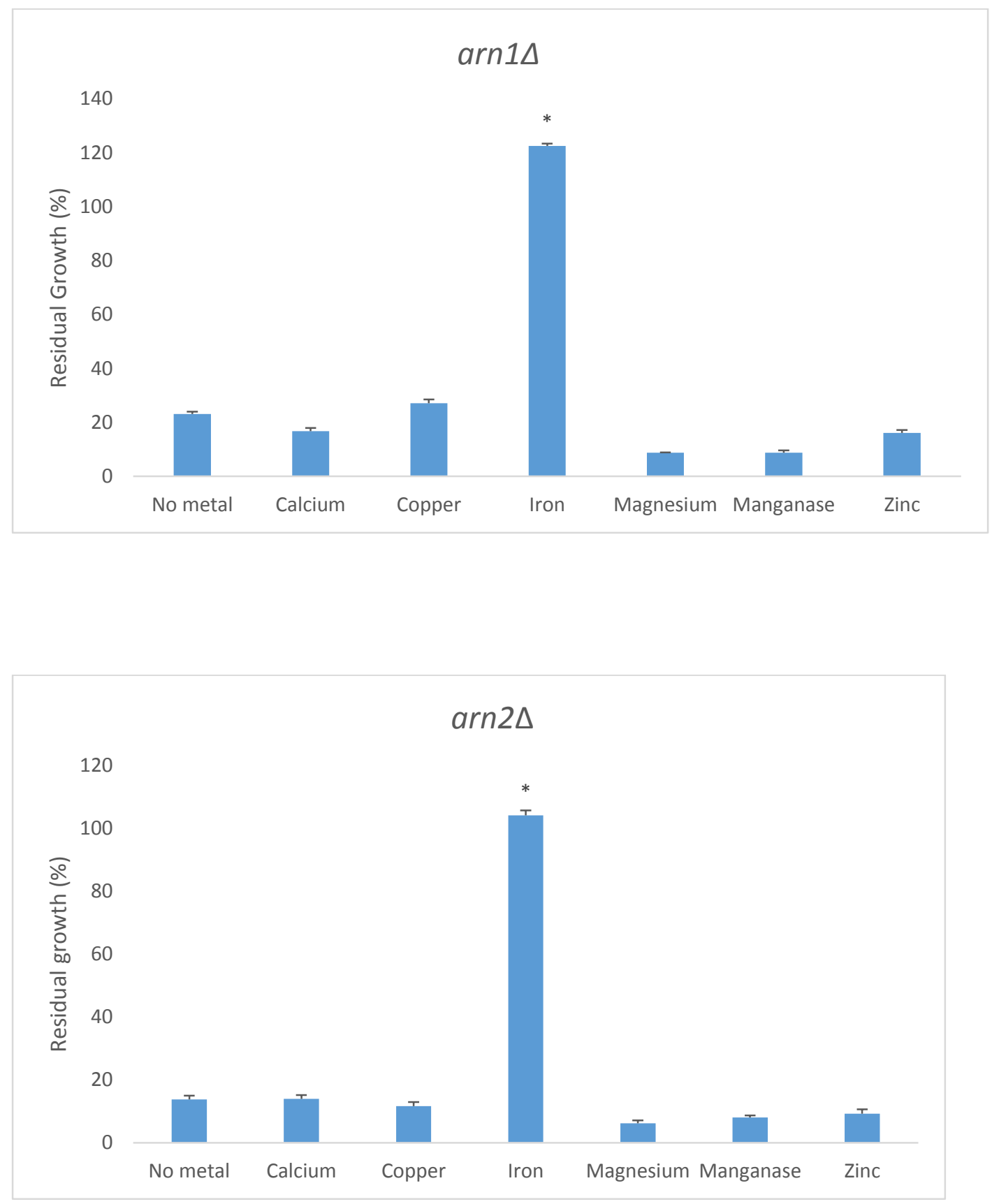

Figure 3.4 Residual growth of BY4741 wildtype, under $0.03 \% \mathrm{v} / \mathrm{v}$ methanolic fraction propolis and various metal ion supplementation (Student's $t$-test ${ }^{*} P<0.05 ;{ }^{*} P<0.01 ;{ }^{* *} P<0.001$ ). Metal ions are supplemented as follows: calcium $\left(100 \mu \mathrm{M} \mathrm{CaCl}_{2}\right)$, copper $\left(100 \mu \mathrm{M} \mathrm{CuCl}_{2}\right)$, iron $\left(100 \mu \mathrm{M} \mathrm{FeCl}_{2}\right)$, magnesium $(100 \mu \mathrm{M} \mathrm{MgCl})$, manganese $(100 \mu \mathrm{M} \mathrm{MnCl} 2)$, zinc $\left(100 \mu \mathrm{M} \mathrm{ZnCl}_{2}\right)$. Error bars represent standard deviation of averaged residual growth. 


\subsubsection{GFP Intensity and localisation analysis indicates upregulation of high- affinity iron ion transporters' GFP fluorescence}

Given my observation that iron supplementation rescued propolis-induced inhibition whereas zinc supplementation exacerbated the condition, I would like to know how propolis with or without iron or zinc could affect the expression and localisation of high-affinity and low-affinity iron transport proteins. To investigate this question, we evaluated GFP localization and intensity in the following strains under propolis treatment with iron or zinc supplementation: Fet3p-GFP, Aft1pGFP, Atx1p-GFP, Ccc2p-GFP and Ftr1p-GFP which are the high affinity iron ion transport proteins; Arn1p-GFP, Arn2p-GFP, and Arn3p-GFP which are the siderophore-bound iron ion transport proteins; Fet4p-GFP which is the lowaffinity plasma membrane iron ion transport; Fet5p-GFP, Fth1p-GFP and Fre6pGFP which are the high affinity vacuolar iron transport; and Smf3p-GFP which is involved in vacuolar low-affinity iron ion transport. Plasma membrane ferrireductases Fre1-3p-GFP, plasma membrane siderophore transporter Arn4pGFP and iron capturing complex Fit1-3p-GFP were not included in this study because these strains were not included in our yeast GFP library.

Using Acapella software, I found that GFP strains of high-affinity plasma membrane and vacuolar iron transporters exhibited significant differences compared to its solvent control with exception of Aft1p-GFP. These strains showed an increase in GFP fluorescence intensity upon propolis treatment and propolis treatment with zinc supplementation although the propolis and propolis with zinc supplementation had comparable levels of intensity indicating 
upregulation of these proteins (Figure 3.5). In these strains, iron supplementation in propolis-treated media showed GFP intensity comparable to the solvent control.

(A)
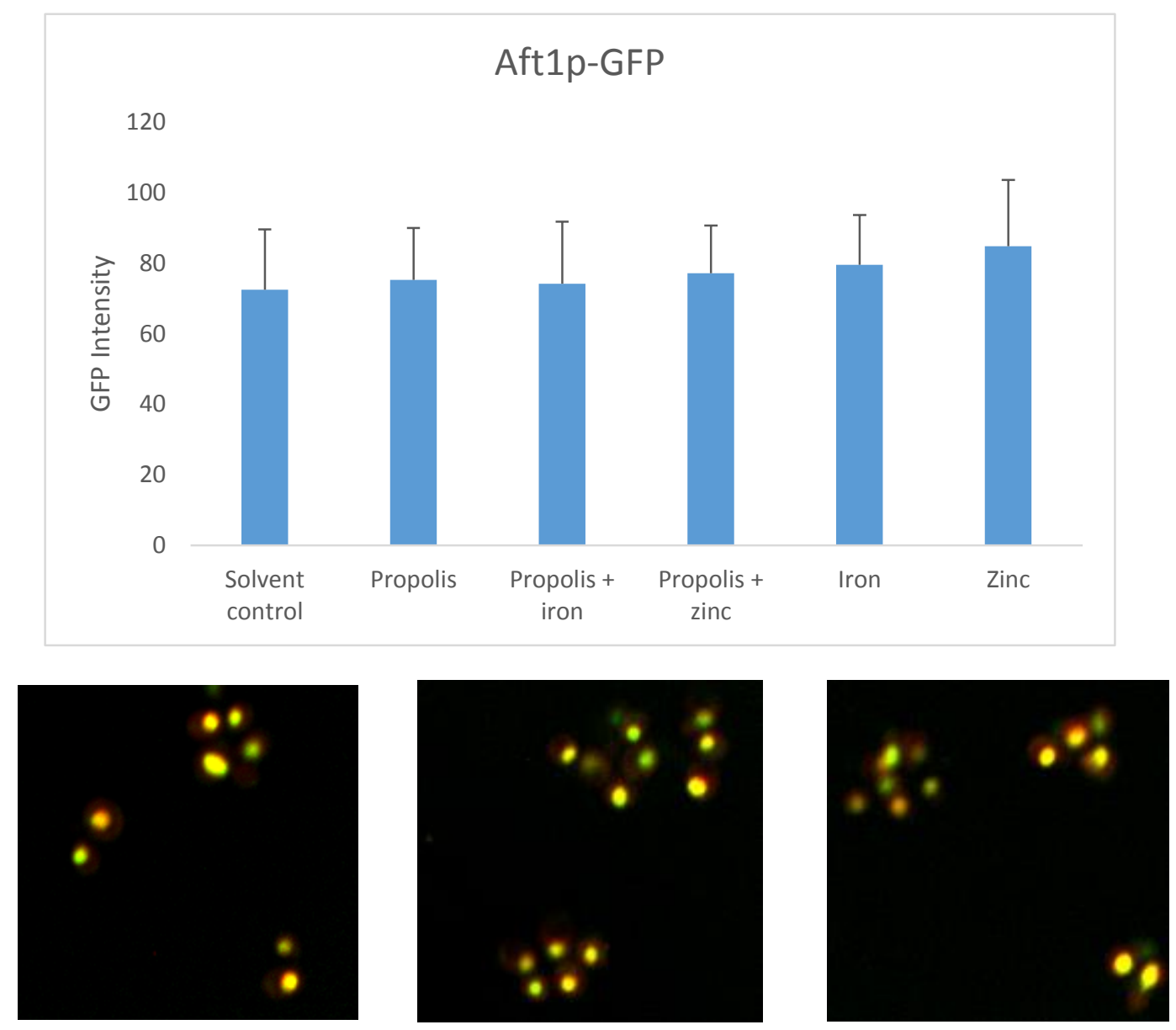

Solvent control

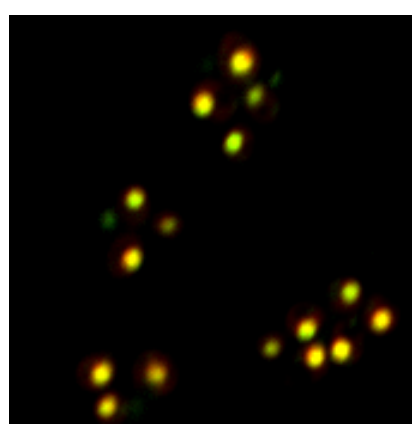

Propolis + zinc
Propolis

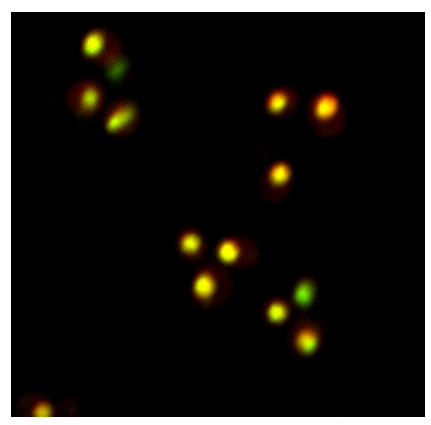

Control + iron
Propolis + iron

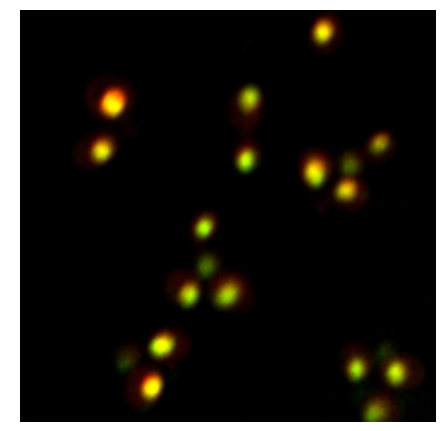

Control + zinc 
(B)

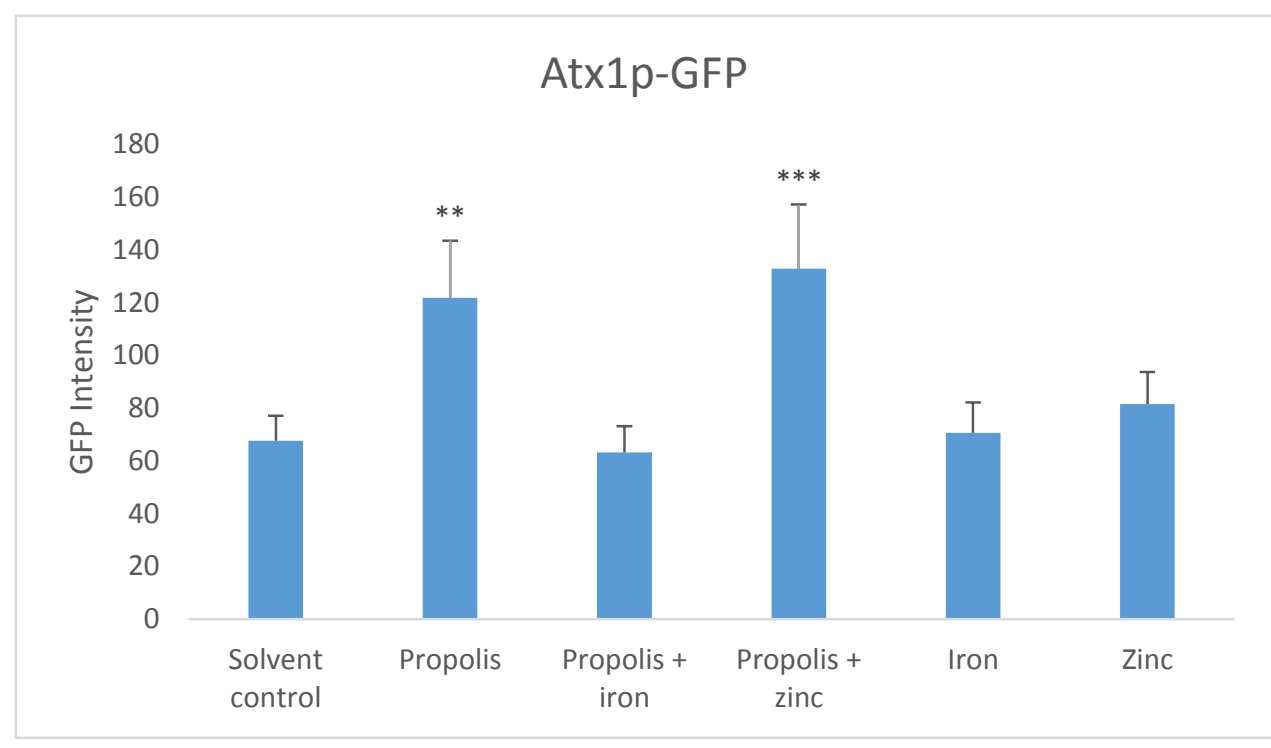

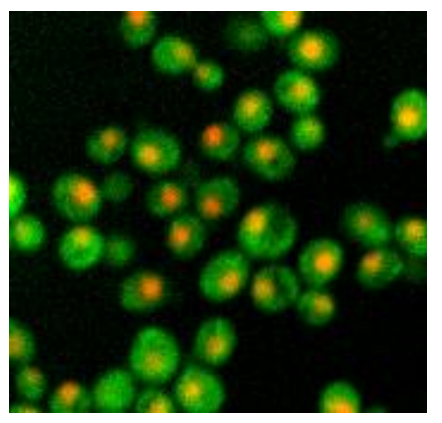

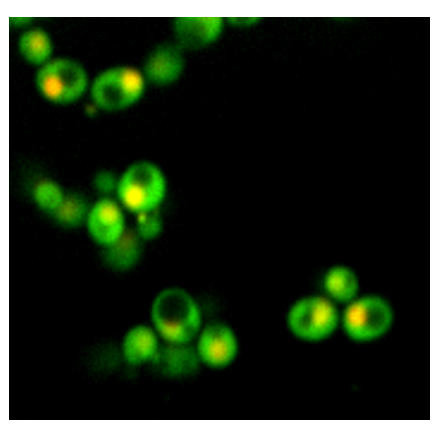

Solvent control
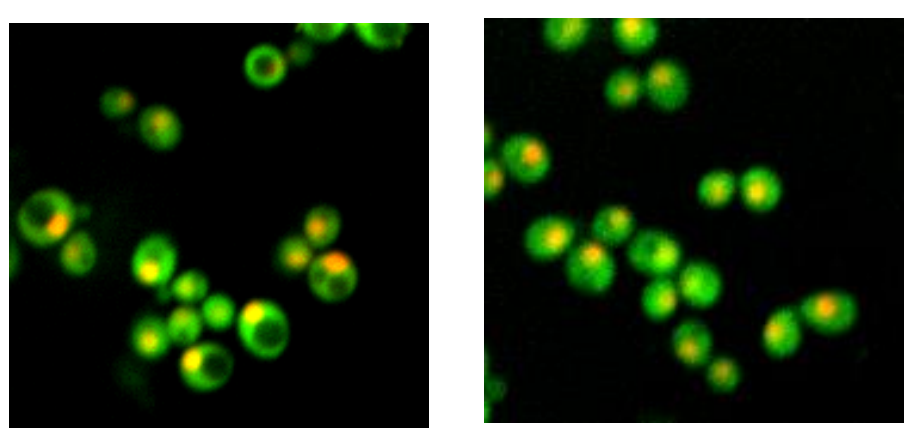

Propolis + zinc

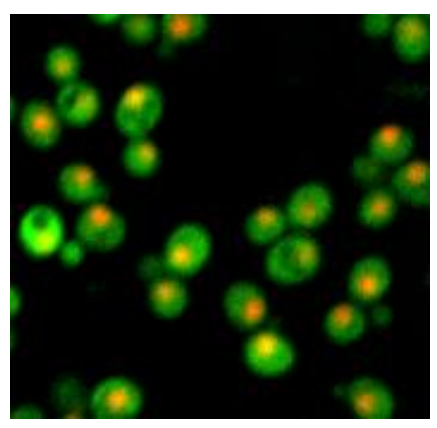

Propolis

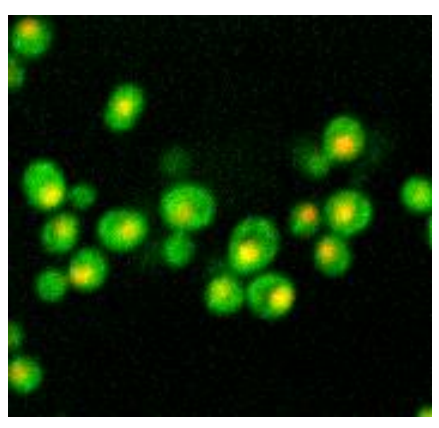

Propolis + iron

Control + iron
Control + zinc 

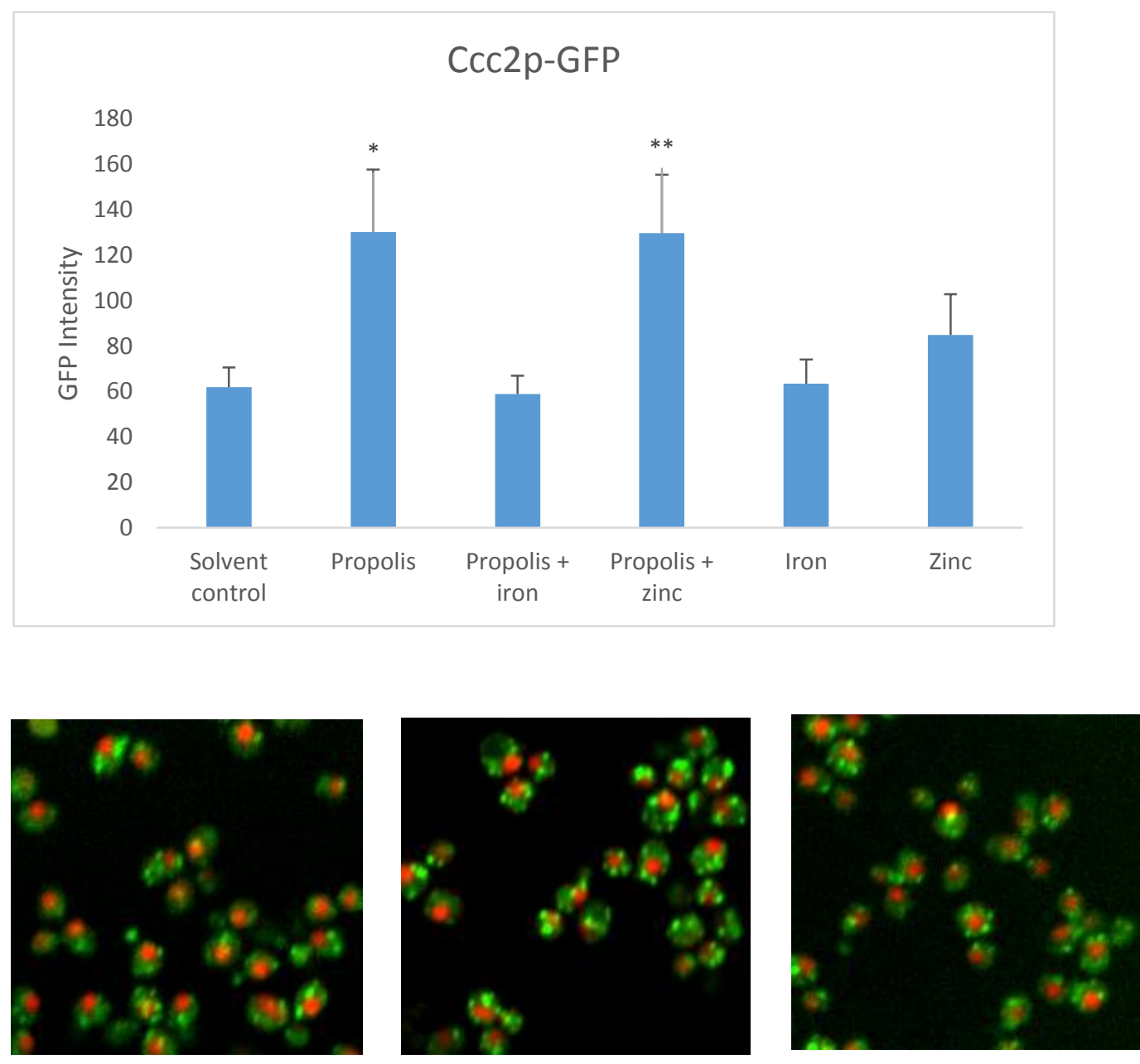

Solvent control

Propolis

Propolis + iron
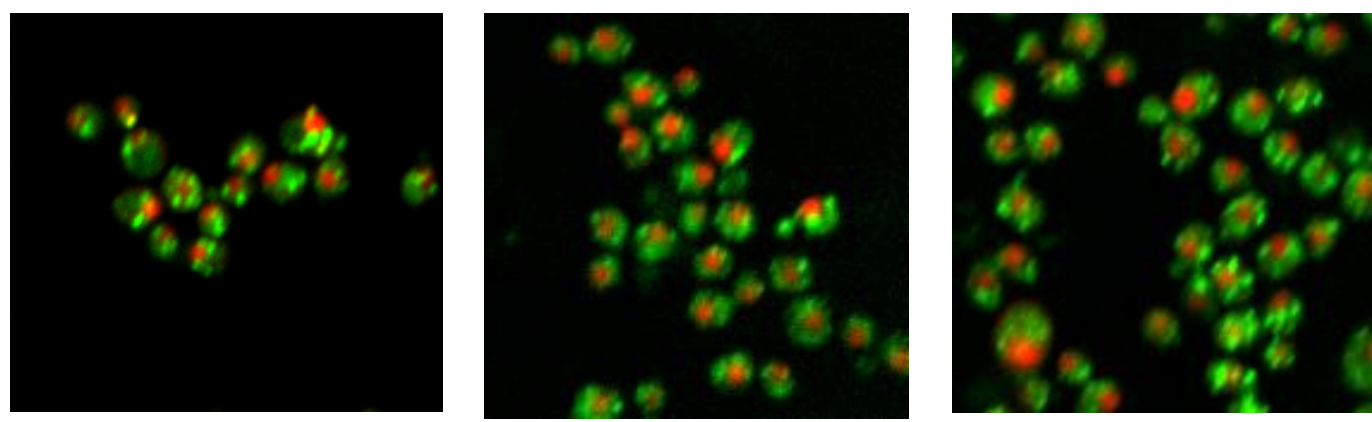

Propolis + zinc

Control + iron

Control + zinc 

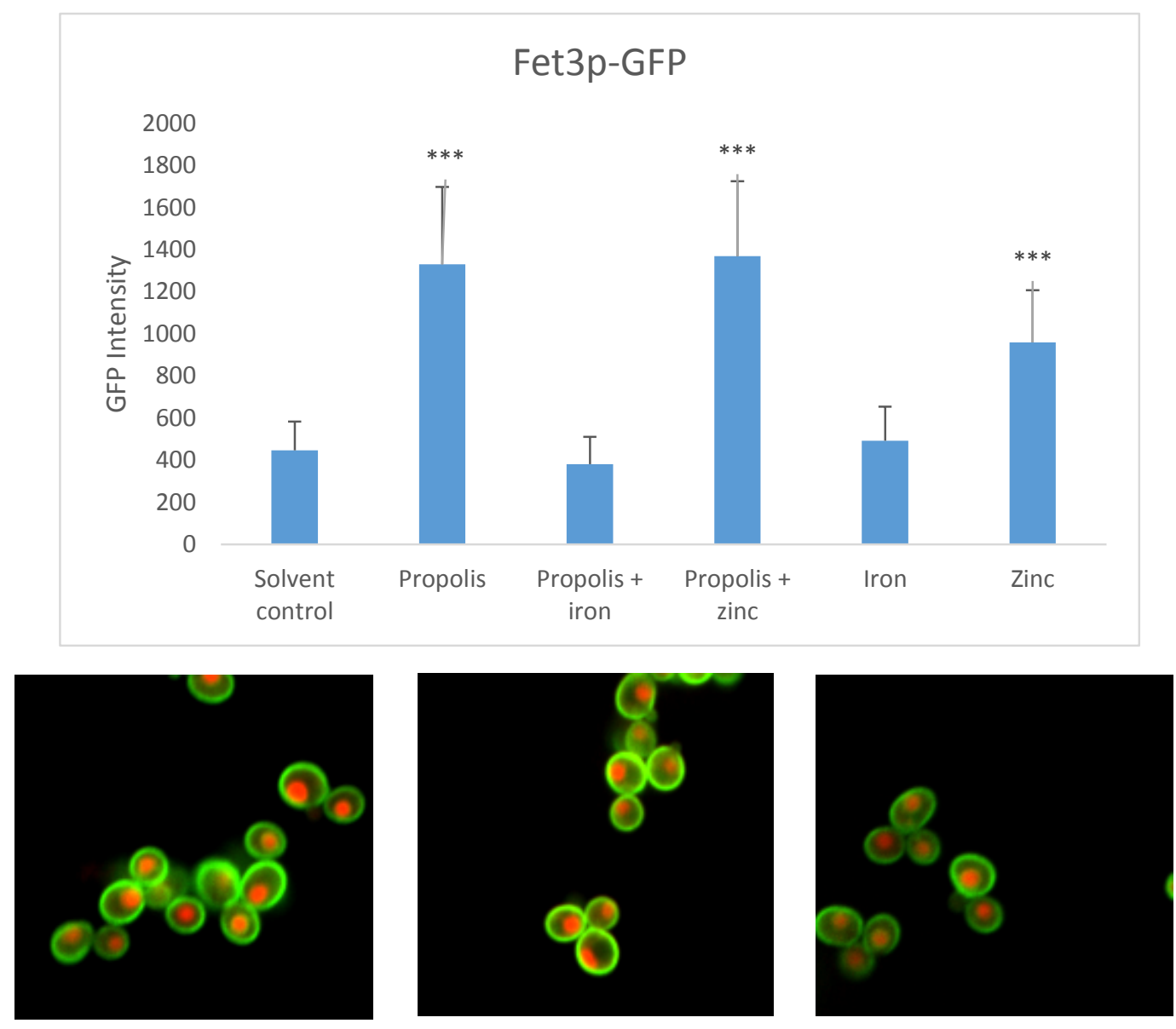

Solvent control

Propolis

Propolis + iron
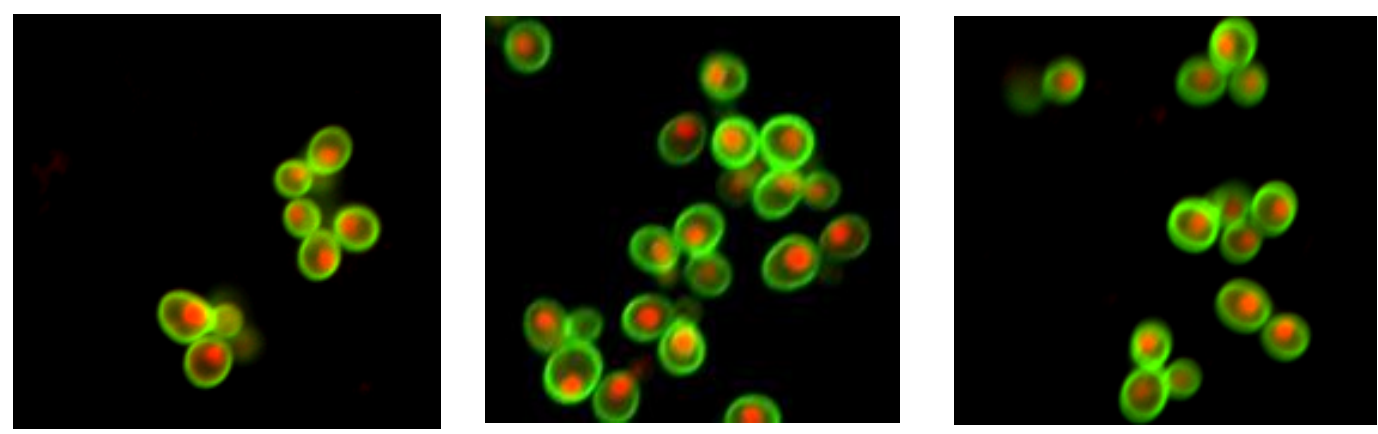

Propolis + zinc

Control + iron

Control + zinc 

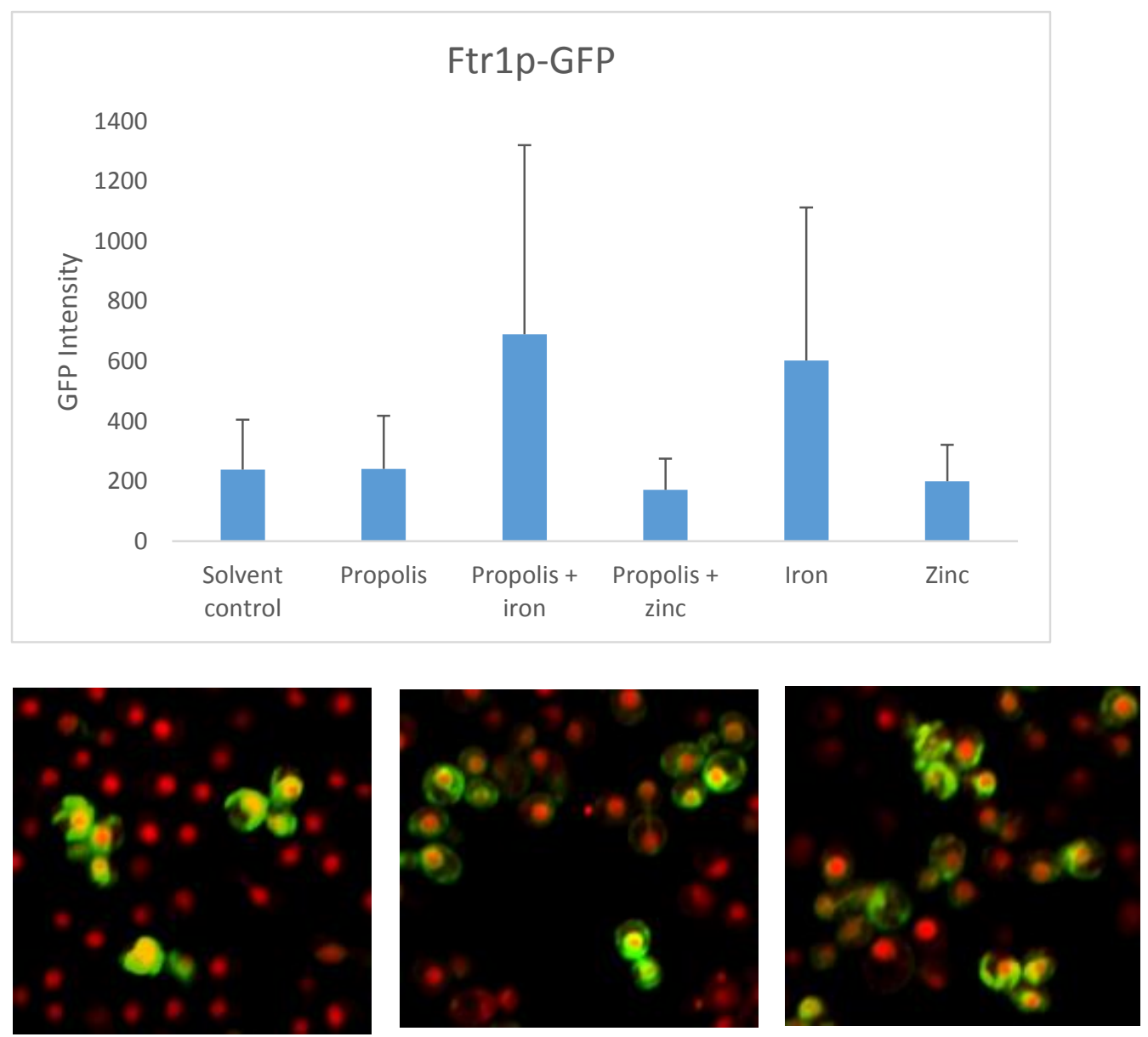

Solvent control
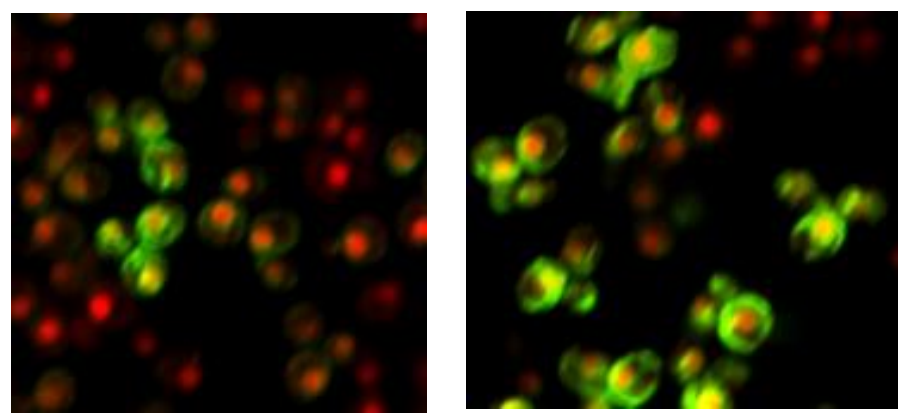

Control + iron
Propolis + iron

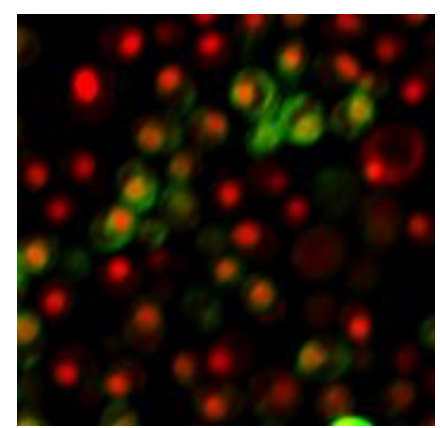

Control + zinc 
(C)

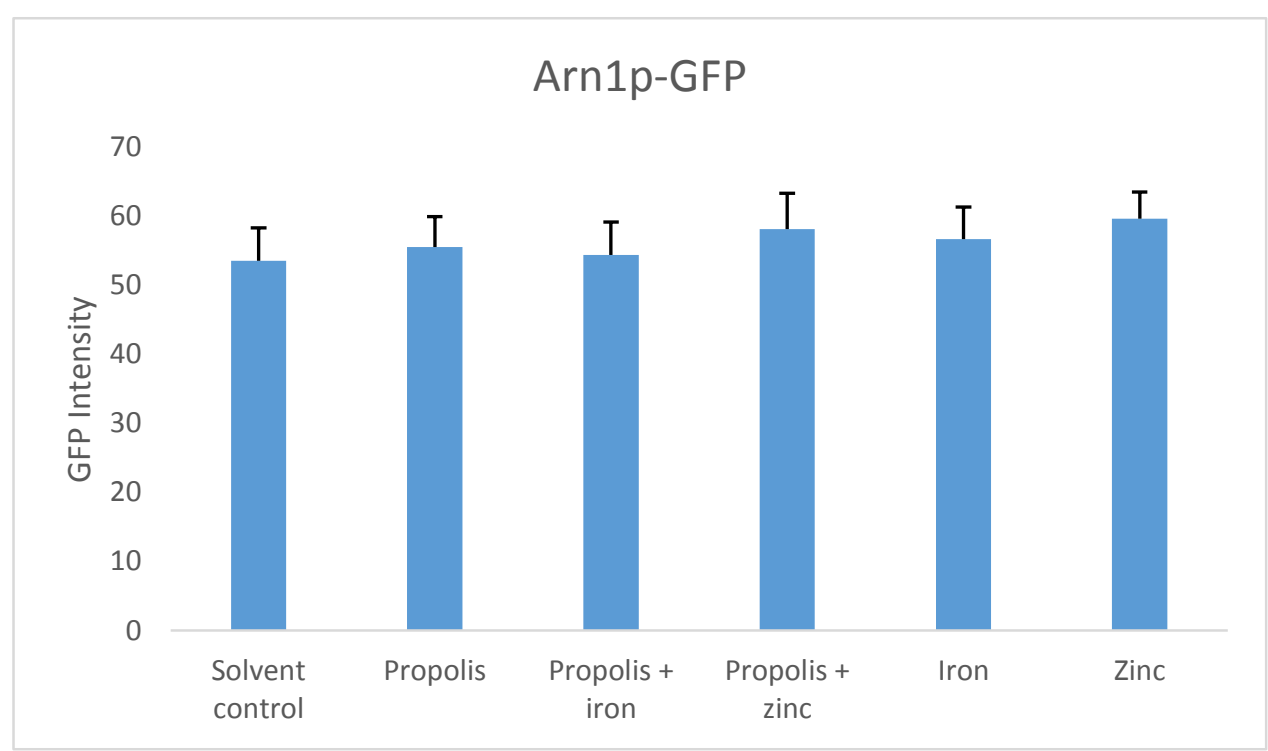

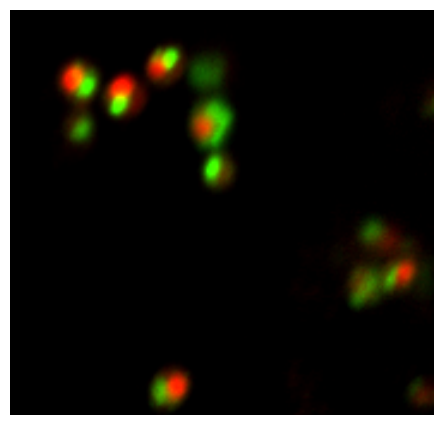

Solvent control

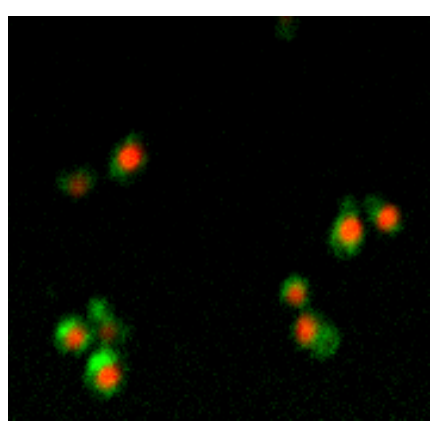

Propolis + zinc

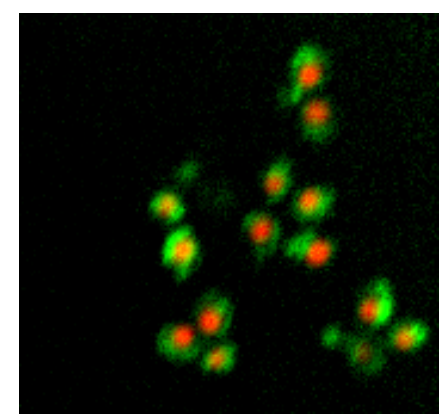

Propolis
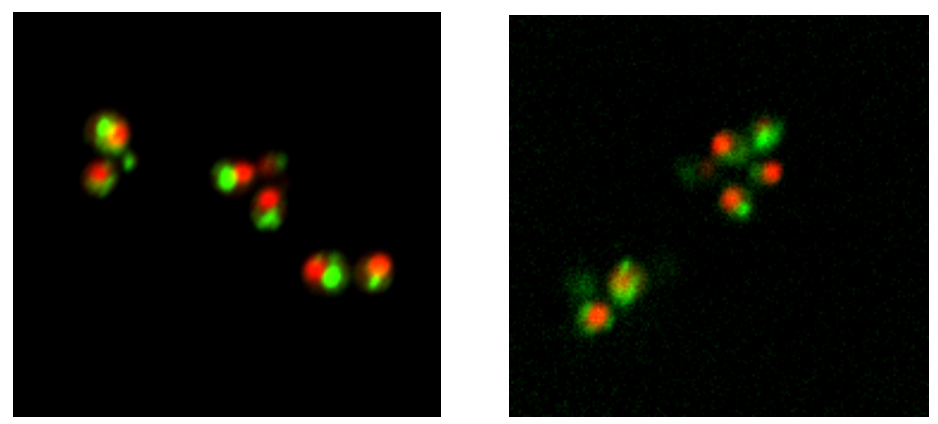

Control + iron

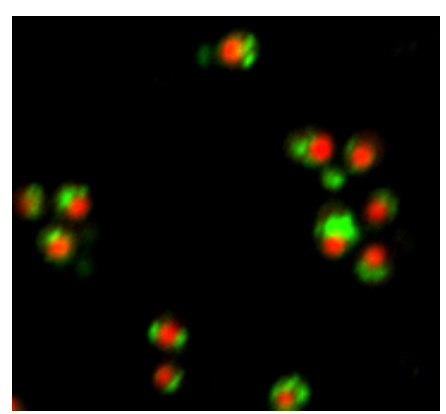

Propolis + iron 

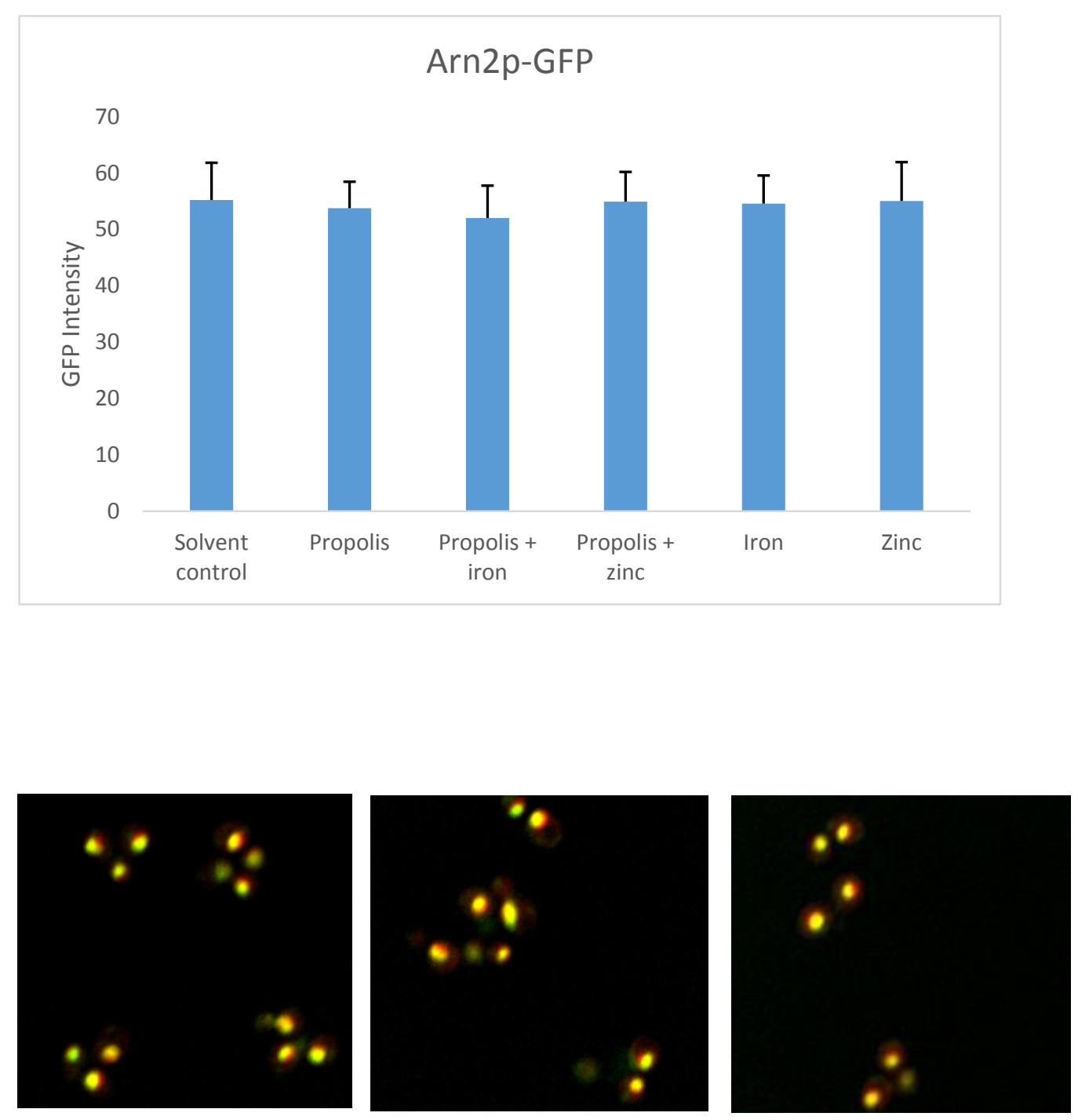

Solvent control

Propolis

Propolis + iron
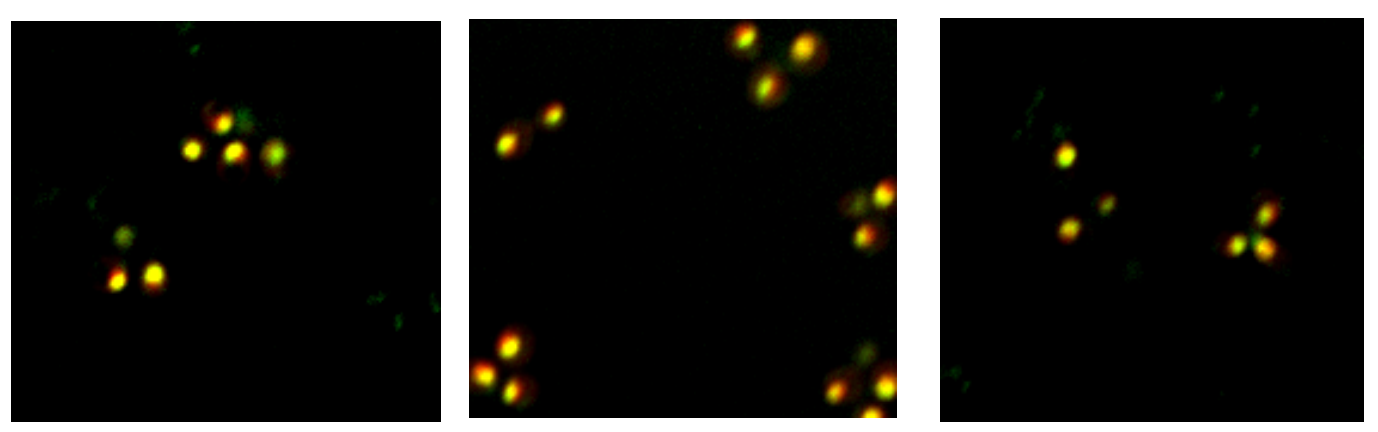

Propolis + zinc

Control + iron

Control + zinc 

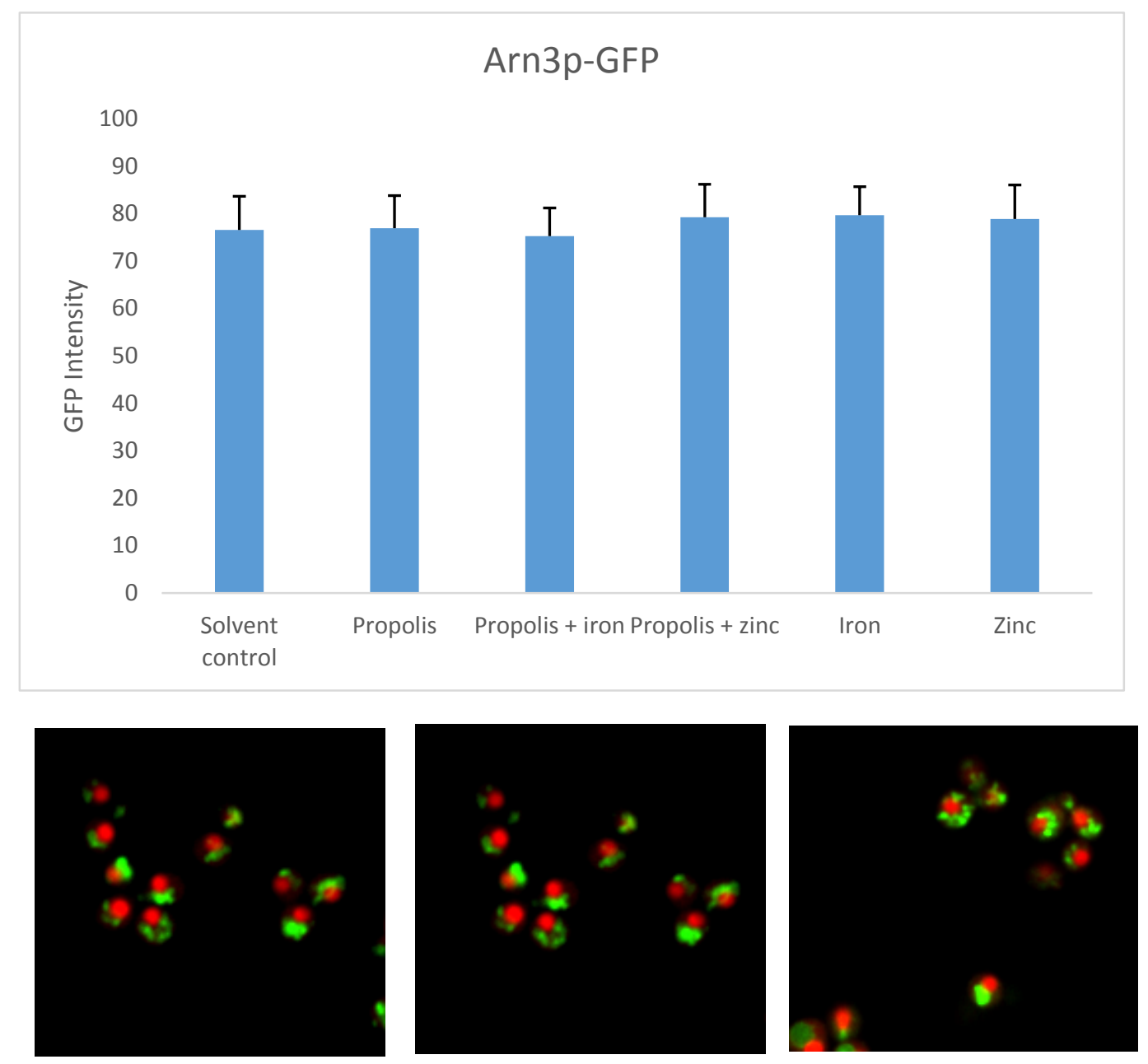

Solvent control

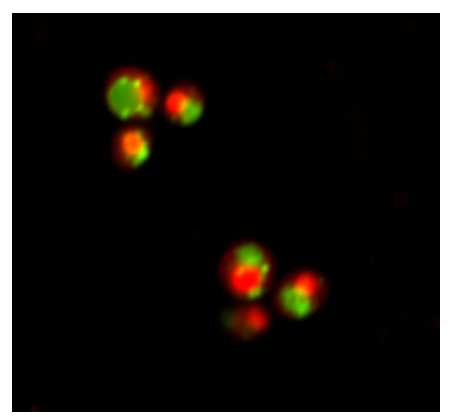

Propolis + zinc
Propolis

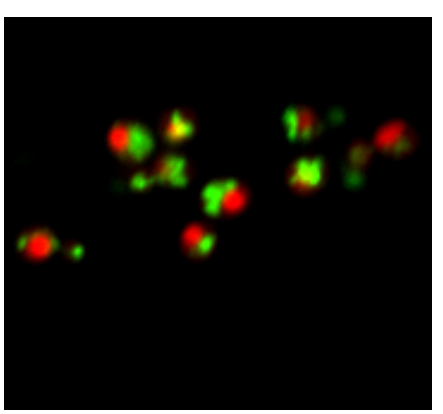

Control + iron

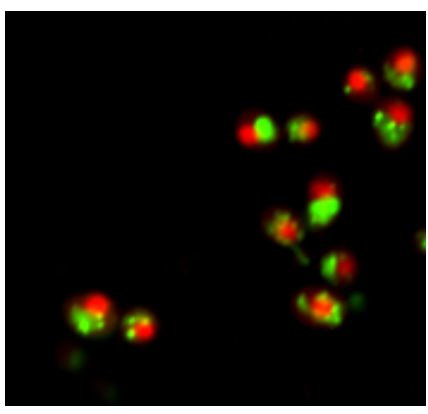

Control + zinc 
(D)
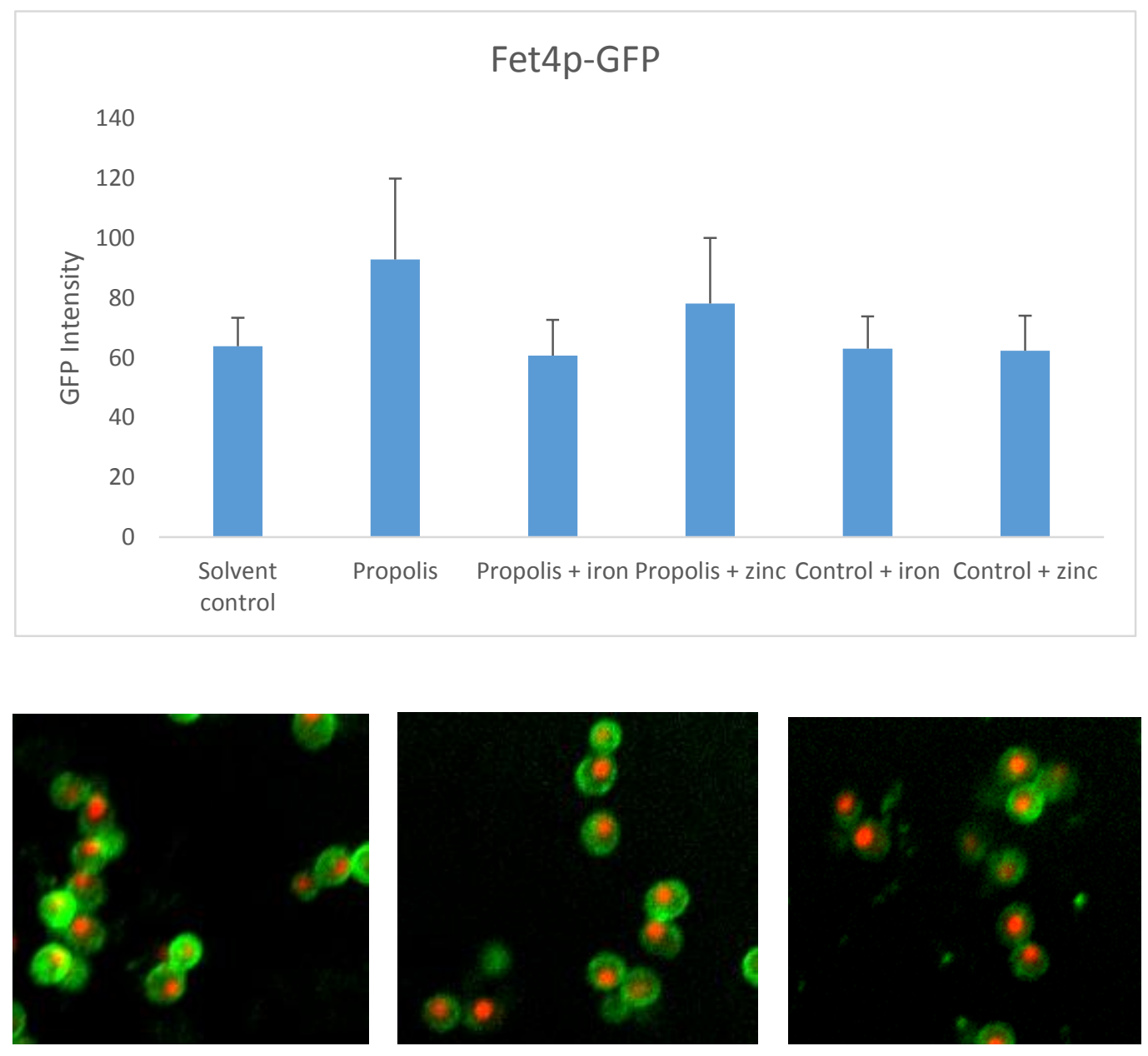

Solvent control

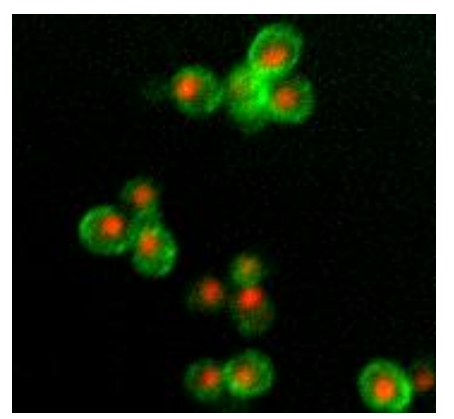

Propolis + zinc
Propolis

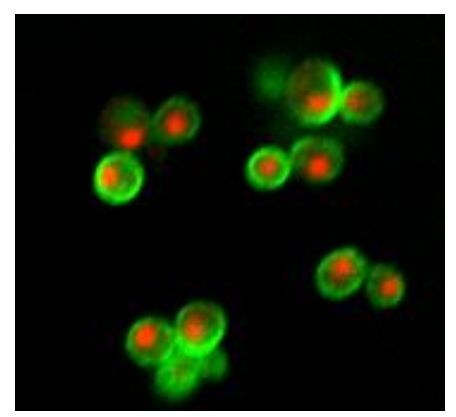

Control + iron

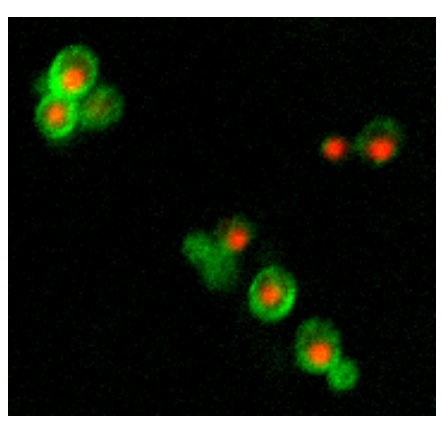

Control + zinc 
(E)

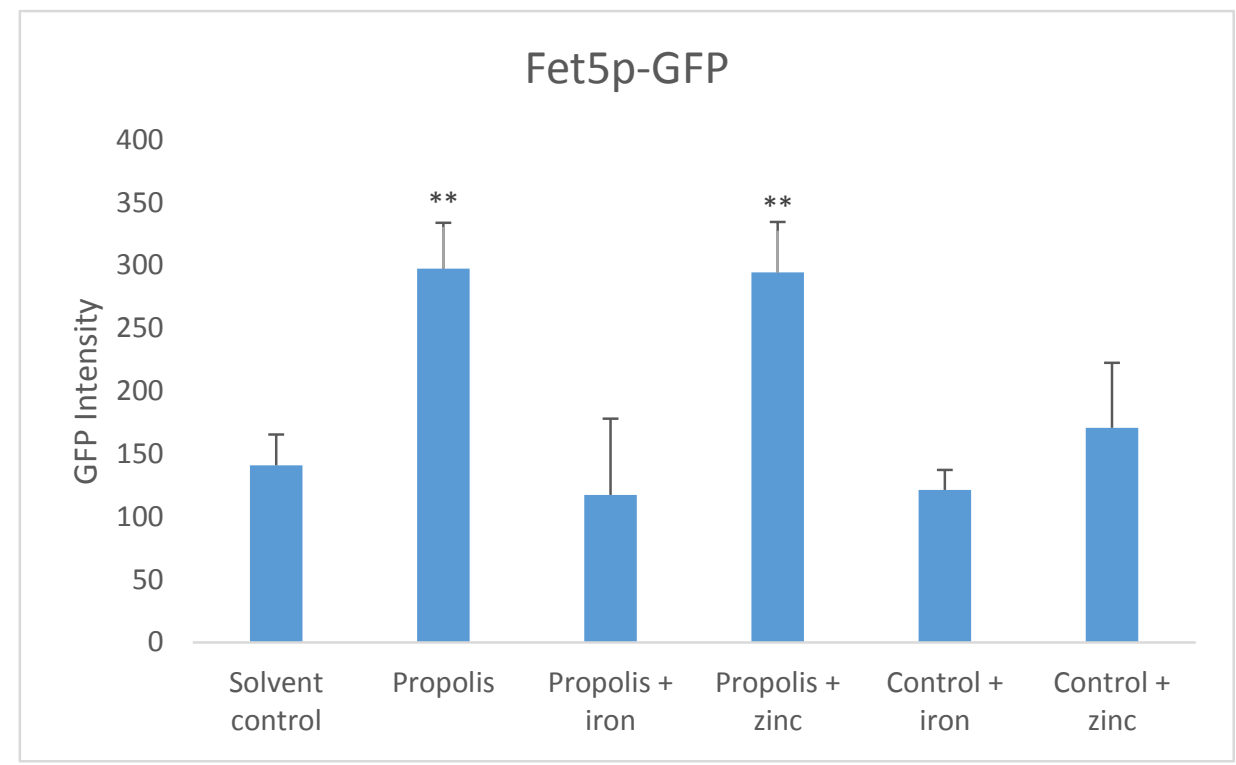

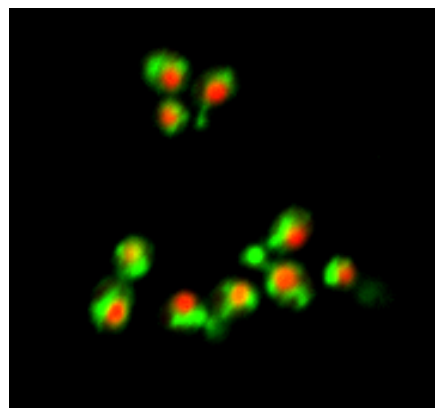

Solvent control

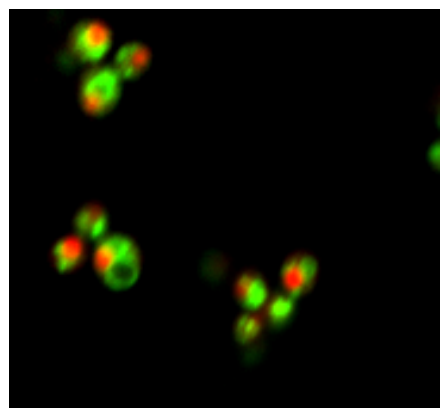

Propolis + zinc

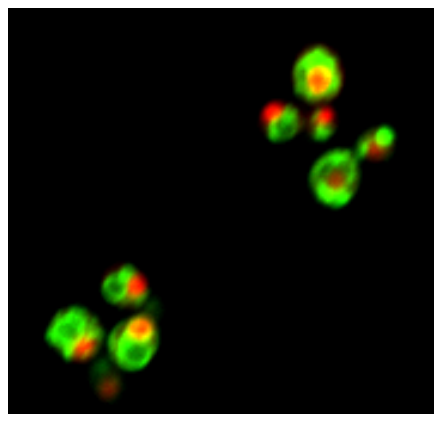

Propolis

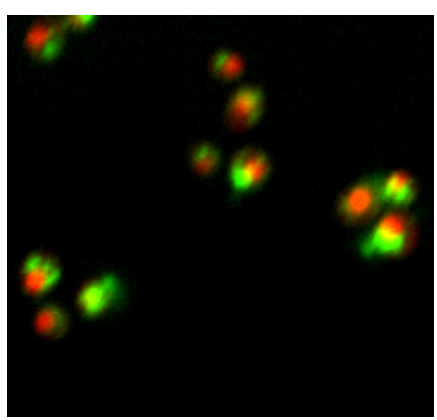

Control + iron

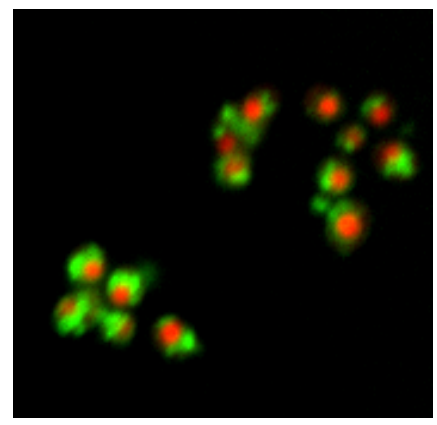

Propolis + iron

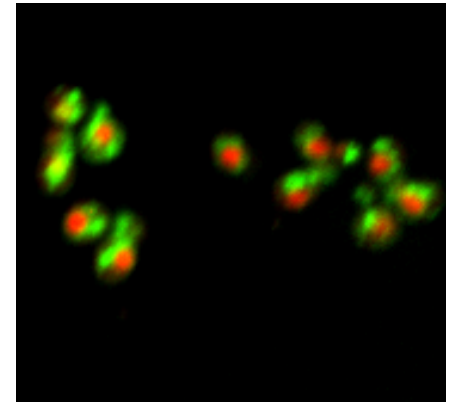

Control + zinc 


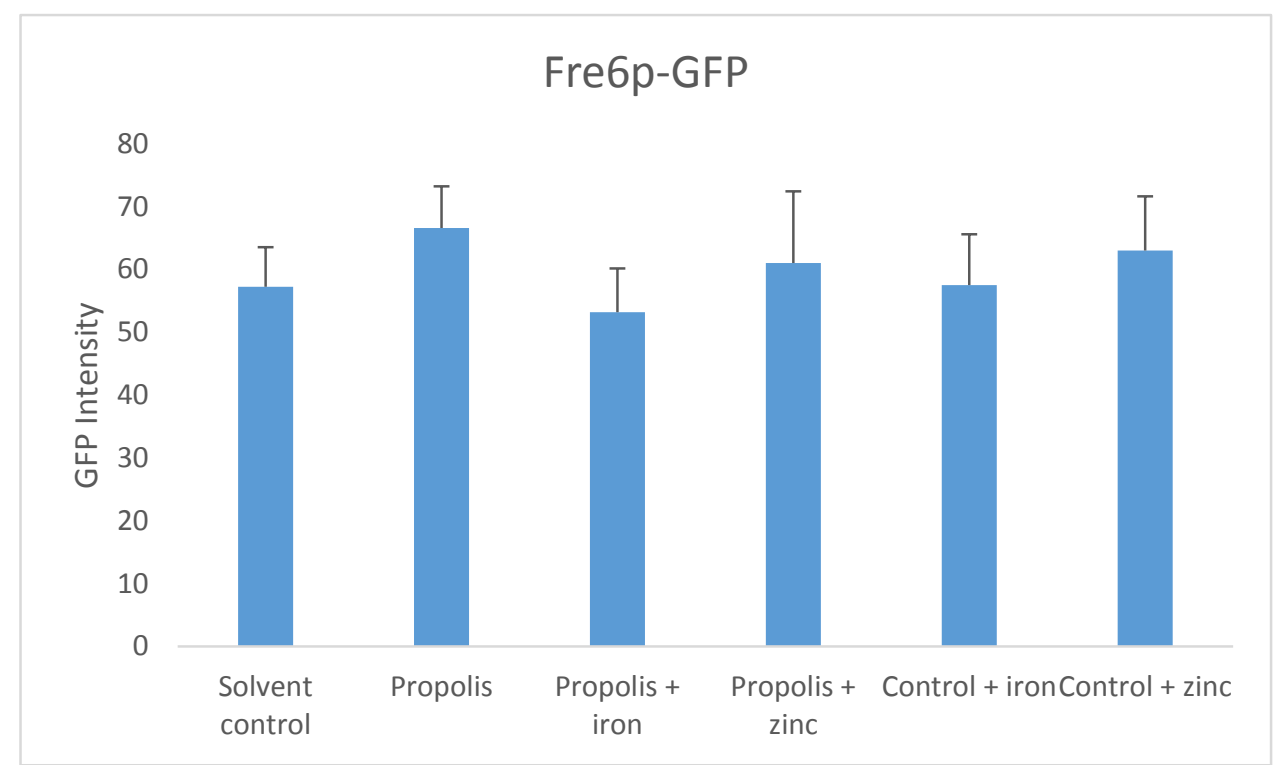

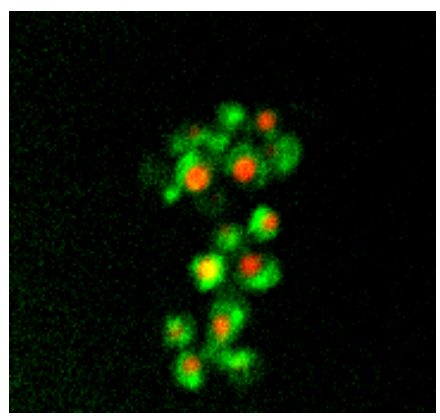

Solvent control
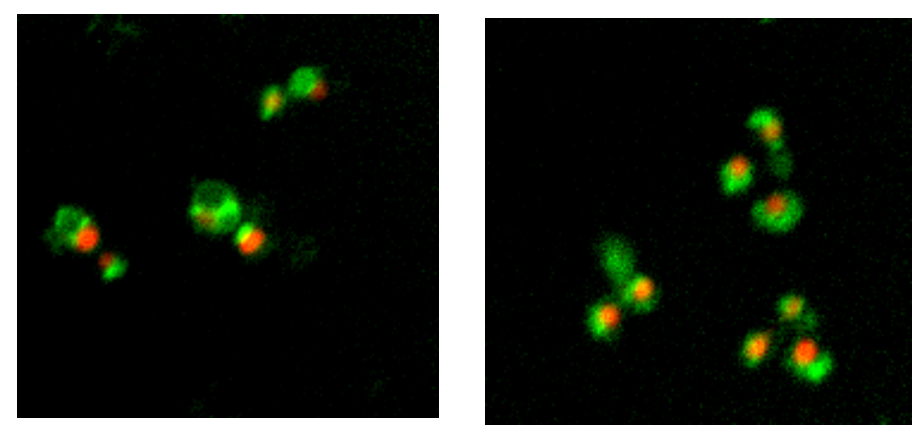

Propolis + zinc

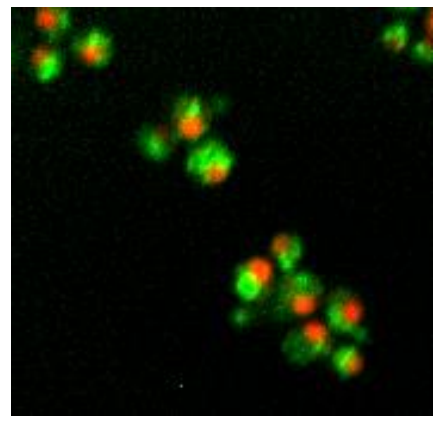

Propolis

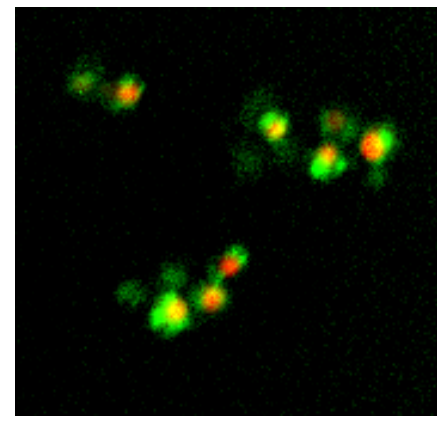

Propolis + iron

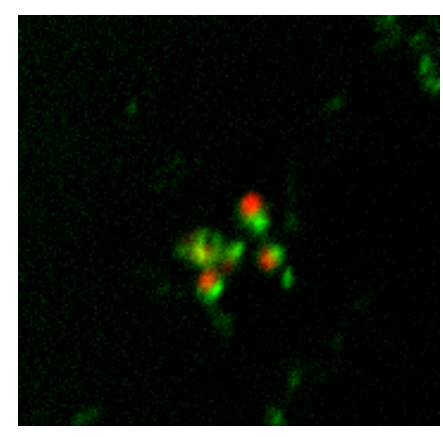

Control + zinc 

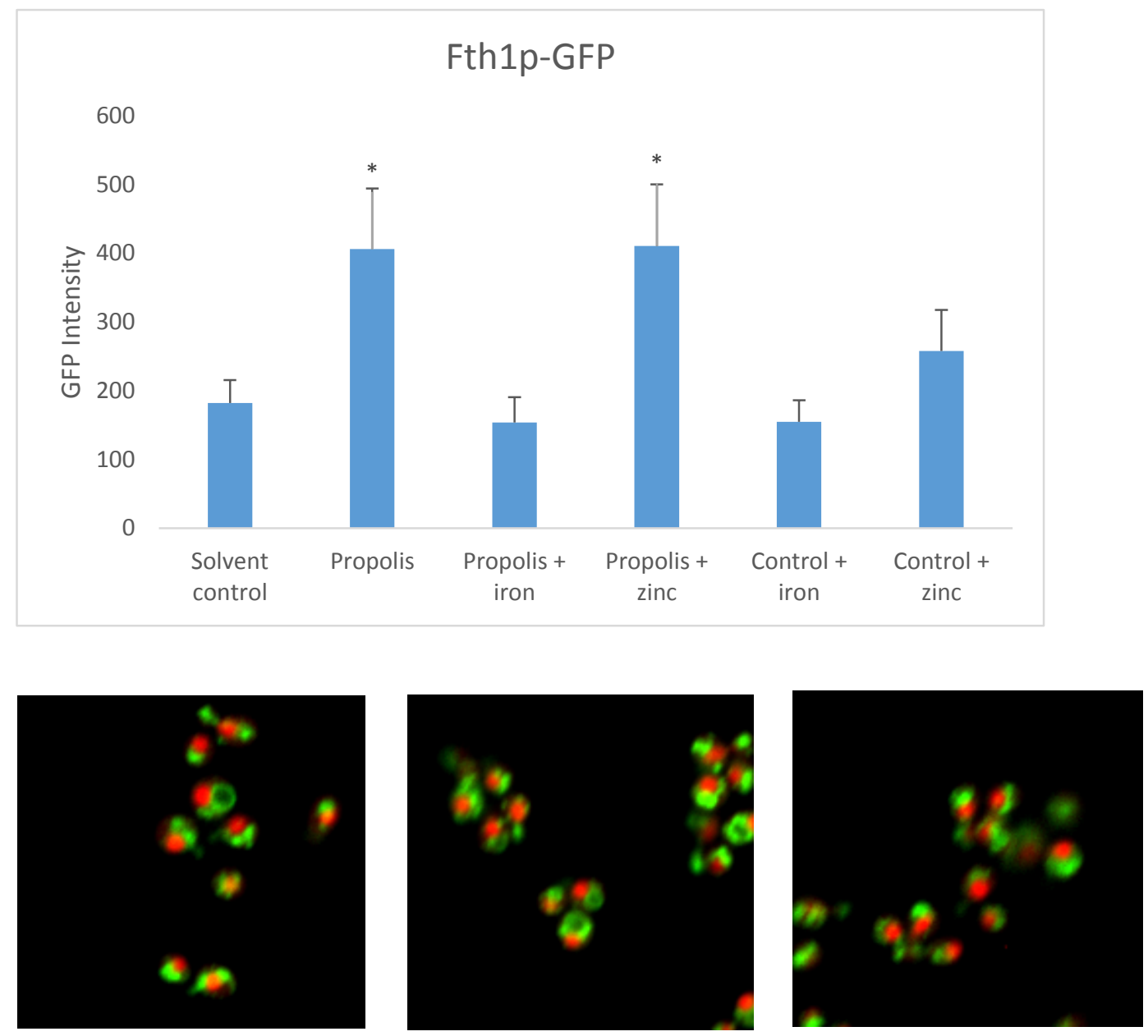

Solvent control

Propolis

Propolis + iron
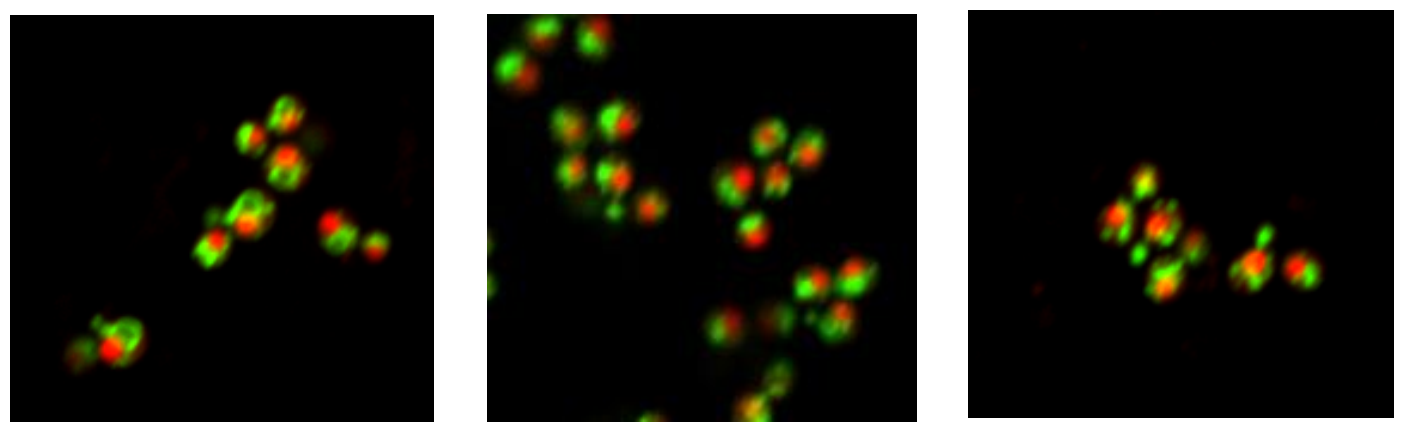

Propolis + zinc

Control + iron

Control + zinc 


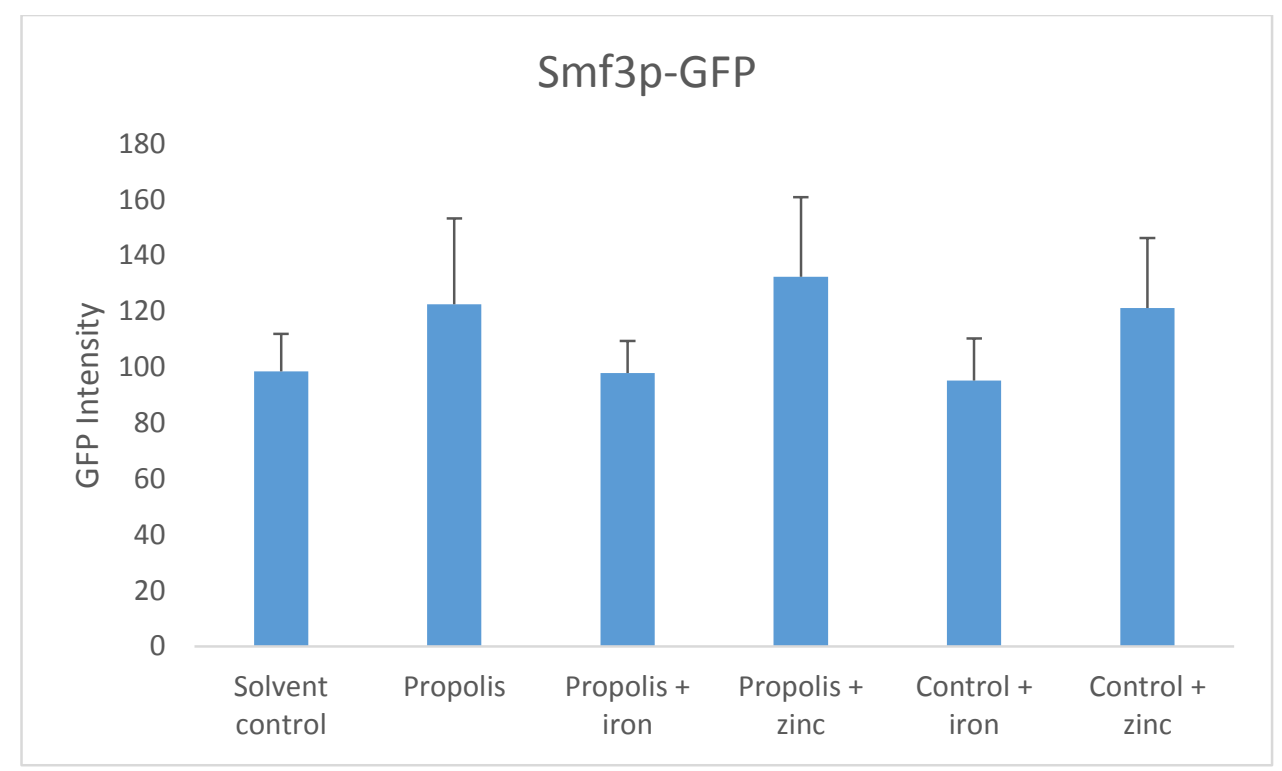

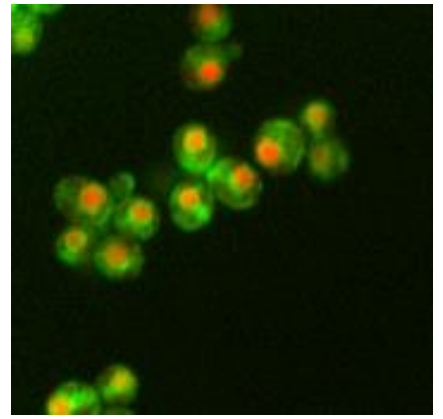

Solvent control

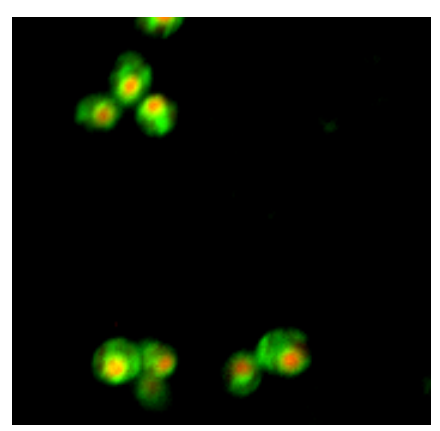

Propolis + zinc

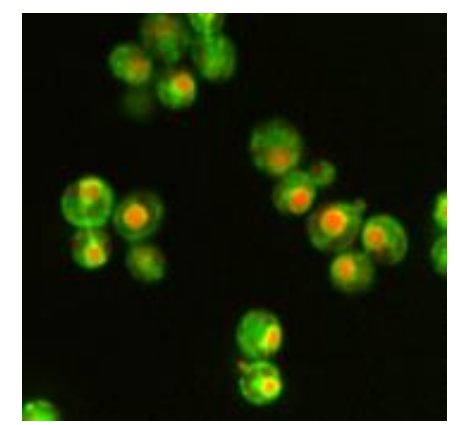

Propolis

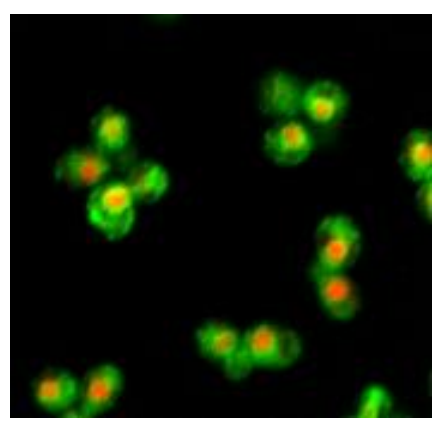

Control + iron

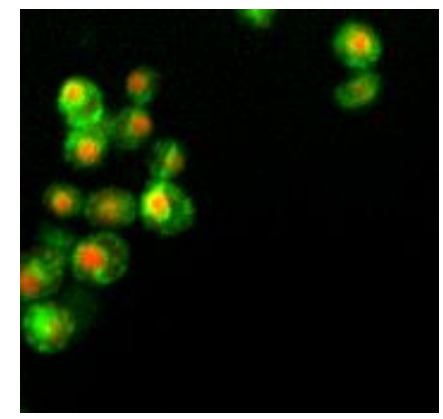

Propolis + iron

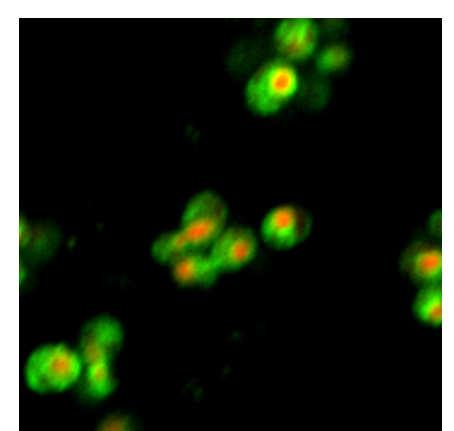

Control + zinc 
Figure 3.5 GFP intensity values of yeast-GFP strains (Student's $t$-test ${ }^{*} P<0.05$; ${ }^{*} P<0.01$;

$* * * P<0.001)$. (A) Regulator of iron ion transport (B) High affinity extracellular iron ion transport. (C) Siderophore-bound iron ion transporters. (D) Low affinity extracellular iron ion transport. (E) Vacuolar iron ion transport.

The high-affinity plasma membrane iron transporter GFP strains, Fet3p-GFP, Atx1p-GFP and Ccc2p-GFP showed higher intensity upon propolis treatment and propolis treatment with zinc supplementation compared to without propolis treatment (Figure 3.5A). Also, iron supplementation was found to reduce the level of GFP intensity back to untreated levels. In contrast, zinc supplementation to the media along with propolis treatment showed GFP intensity similar to the propolis only treatment for Fet3p-GFP, Atx1p-GFP and Ccc2p-GFP. Interestingly, Fet3p-GFP showed significant increase in GFP intensity under media with $100 \mu \mathrm{M} \mathrm{ZnCl}$. This was not observed in other high-affinity iron transport GFP strains. Atx1p-GFP showed a change in localisation where the fluorescence was lost from the vacuole in the propolis-treated media and propolis-treated media with zinc supplementation compared to cytoplasmic localization in control media (Figure 3.5A). Morever, we found some localisation of Atx1p in nucleus as well under propolis, propolis with iron supplementation and propolis with zinc supplementation treatment as observed by yellow fluorescence indicating RFP and GFP marker signal overlap. Ccc2p-GFP showed the same punctate fluorescence across all treatment conditions with greater GFP fluorescence in propolis-treated and propolis with zinc supplementation media (Figure 3.5A). On the other hand, Aft1p-GFP and Ftr1p-GFP showed no significant GFP-intensity 
changes nor localization changes across all treatment conditions compared to their respective solvent control (Figure 3.5A). We observed abnormalities of Ftr1p-GFP fluorescence but we have confirmed that the Ftr1p-GFP of our collection exhibited such behaviour after repeated tests.

For the siderophore iron transporters, Arn1p-GFP, Arn2p-GFP and Arn3p-GFP did not show any significant difference in GFP-intensity or localization across all treatment conditions (Figure 3.5B). These results indicate that the propolis treatment did not affect the expression or activity of the Arn proteins. Similarly for the low-affinity iron transporter Fet4p-GFP strain, we did not observe any change in GFP intensity or localisation of GFP fluorescence across all treatment conditions (Figure 3.5C).

The vacuolar high-affinity iron transporters GFP strains Fet5p-GFP and Fth1pGFP showed a significant increase in GFP fluorescence in propolis-treated and propolis with zinc supplementation media (Figure 3.5D). However, we did not observe localisation changes across all treated media for Fet5p-GFP and Fth1pGFP. The vacuolar ferrireductase Fre6p-GFP and low-affinity vacuolar iron transporter did not exhibit any change in GFP intensity or localisation across all treatments (Figure 3.5E).

Based on the results from the yeast-GFP intensity and localisation analysis, propolis caused an increase in extracellular and vacuolar high-affinity iron transport GFP intensity, indicating an increase in these proteins' expression levels under propolis treatment. In contrast, none of the low-affinity iron transport proteins showed any changes in GFP expression. Moreover, certain transporter 
GFP strains also showed changes in localisation though not all high-affinity iron transport strains share that characteristic. Though we saw a significant increase in GFP intensity in Fet3p-GFP strain under the media with zinc supplementation but without propolis treatment, this pattern was not observed in all other strains. Moreover, for strains that showed significant increase of its GFP intensity under propolis treatment or propolis treatment with zinc supplementation, the intensity levels were not significantly different. Thus, the effect of zinc in respect to exacerbating the propolis-induced growth inhibition may not occur by zinc ions augmenting the bioactivity of propolis.

\subsection{Discussion}

We have performed liquid dose response and agar dose response in the water soluble fraction and methanolic fraction of propolis and found that the methanolic fraction is more potent in inhibiting yeast growth. We performed screening of propolis against our deletion library collection and DAmP library collection at $1 \% \mathrm{v} / \mathrm{v}$ and validated the results by performing dilution assay in agar media. Our validated positives showed enrichment for iron ion transport. To further investigate which iron ion transport is being affected by propolis treatment and determine whether the amount of iron in media could affect the propolis biological activity, we challenged deletion strains involved in iron ion transport with $0.06 \% \mathrm{v} / \mathrm{v}$ propolis with or without presence of high level of iron $100 \mu \mathrm{M}$. We found that hypersensitivity is observed within the high-affinity iron ion transport with the exception of $\Delta a f t 1$ that showed strong inhibition at 
$0.03 \% \mathrm{v} / \mathrm{v}$ propolis. Also, it was observed that iron supplementation rescued growth inhibition by propolis even beyond the MIC. We also determined if other metals could provide similar phenotypic rescue. This is to confirm whether the propolis activity reduce free iron ion levels specifically or it reduces all metal ions availability as well. Each deletion strain showed specific phenotypic rescue patterns in which some strains had particular metal ions that rescued growth inhibition at varying degrees. Intriguingly, zinc ions were found to increase the inhibition by propolis.

Next, we investigated whether propolis might affect the expression and localisation of the iron transport proteins. We found a significant increase in GFP intensity for Fet3p-GFP, Atx1p-GFP and Ccc2p-GFP under propolis treatment and the iron supplementation brings the GFP intensity back to the solvent control's level. Furthermore, propolis-treated with zinc supplementation condition also displayed higher GFP intensity at similar level to propolis-treated condition. There was also a change in localisation observed in Atx1p-GFP where the strains under propolis-treated and propolis-treated with zinc conditions showed no GFP fluorescence in vacuole. We speculated that Atx1p are released from vacuole to accommodate iron transport efficiency in response to propolis treatment. Taken together, these results suggest that propolis selectively stimulates the high-affinity iron transport proteins. Alternatively, propolis may remove iron from yeast cells and upregulate the high-affinity iron transporter proteins in response of iron deprivation inside yeast. No upregulation of Arn1p and Arn2p expression (Figure 3.5B) suggests that the siderophore iron transporters were not vital in low iron deprivation 
response and that the high-affinity iron transporter being the primary means of iron uptake in yeast.

In yeast, there are three mechanisms for the uptake and vacuolar transport of iron (Figure 3.6). The first is the high affinity iron transport that is primarily

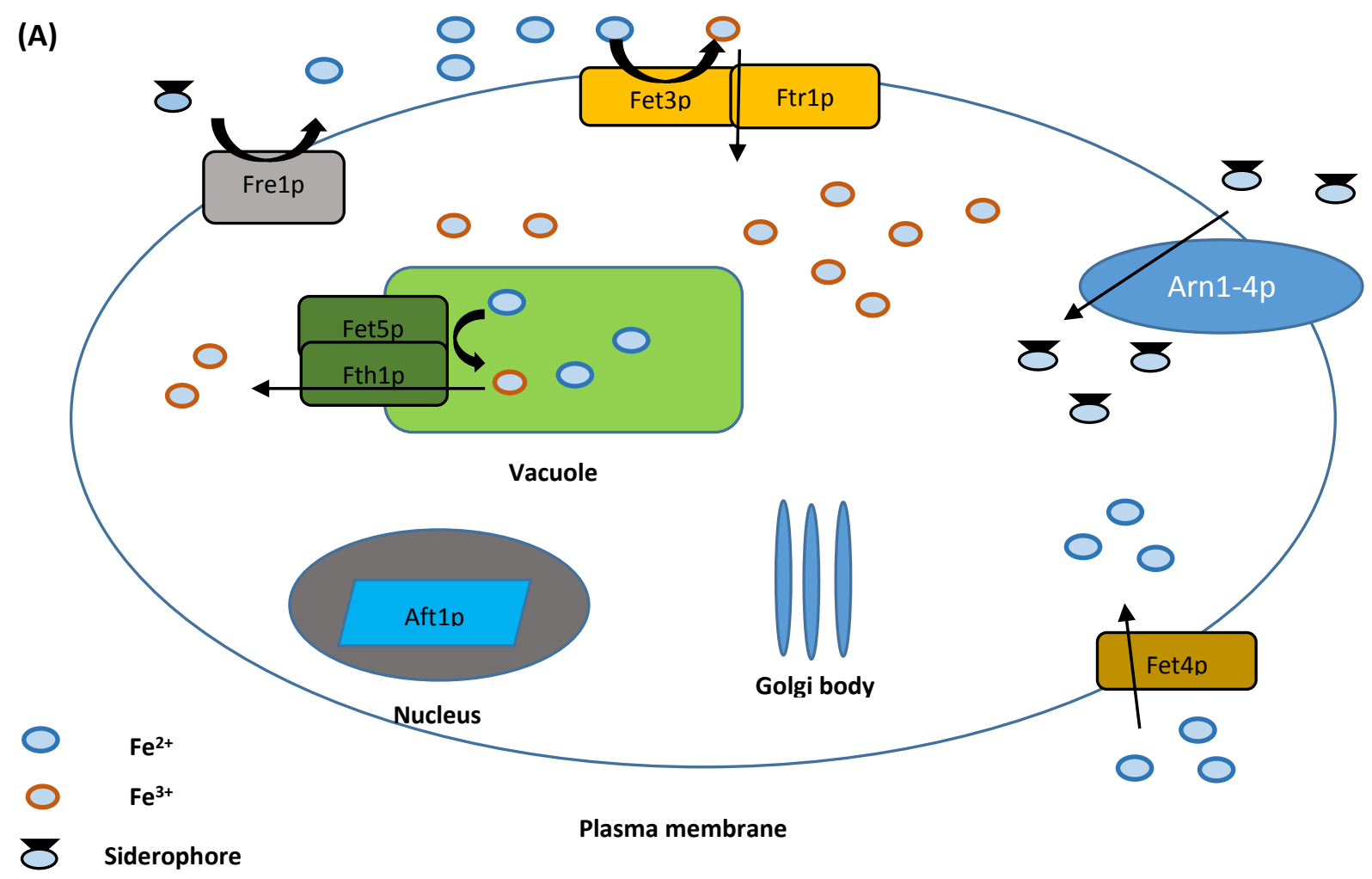


(B)

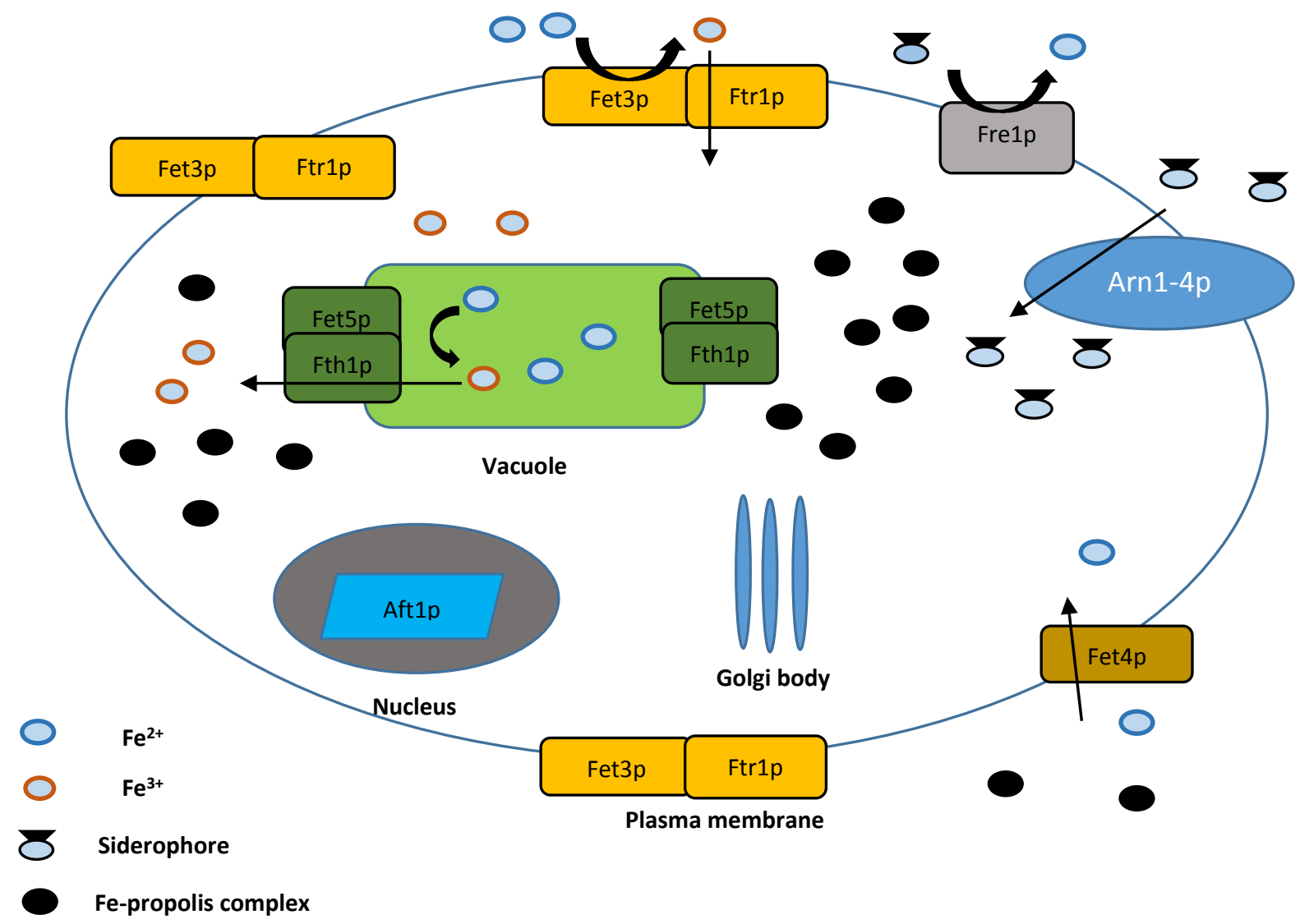

Figure 3.6 Propolis chelates iron and induces iron deprivation. (A) Iron transport process under normal iron conditions. (B) Upregulation of both extracellular and vacuolar high-affinity iron transporters following propolis treatment

carried out by Ftr1p through the activity of Fet3p, Atx1p and Ccc2p. This iron uptake process begins with the activity of ferrireductase Fre1p that reduces siderophore-bound iron and also cupric copper. The activity of Fre1-3p removes siderophore, releasing free ferrous ions (Figure 3.6A). The Fet3p-Ftr1p complex oxidises the low-affinity ferrous ions to high-affinity ferric ions that are then transported into the cells via the Ftr1p subunit (Askwith \& Kaplan, 1998; Stearman et al., 1996; Yun et al., 2001). The second pathway is involved in low- 
affinity ferrous iron uptake which is mediated by Fet4p and SMF family proteins and their expression was found to be inversely related with high-affinity iron transport (Dix D. et al., 1997; Hassett et al., 2000). The third pathway of iron uptake is via Arn1-4p siderophore transporters in which these transporters specifically recognise siderophore for uptake into cells (Heymann et al., 2000; Yun et al., 2001).

Our results suggest that propolis acts as a metal ion chelator, particularly iron, and it removes iron ion availability from yeast (Figure 3.6B). Hypersensitivity of high-affinity iron ion transport deletion strains against propolis treatment indicates that these proteins are essential in providing response against iron deficient conditions. This is further evident from the fluorescence analysis of our GFP-tagged high-affinity iron ion transport proteins in which all transport proteins were increased in abundance upon propolis treatment. Therefore, under propolis treatment, I propose that propolis quenches the iron available from the yeast environment and in response there is an increase in high-affinity iron ion transport to maximise the uptake of iron. This model is further supported by my observation that a high iron environment is created when iron is added to growth media. The iron sequestration ability of propolis present within the media could not completely remove iron from the yeast media. This is further supported with the liquid dose response of yeast against propolis treatment under optimal iron supplementation when the propolis concentration is increased up until to $1 \% \mathrm{v} / \mathrm{v}$ (agar screening 
concentration) causing complete inhibition of growth. In this case, $1 \% \mathrm{v} / \mathrm{v}$ propolis was sufficient to completely remove $100 \mu \mathrm{M}$ iron ions from the media, creating iron-deficinent environment. It is noteworthy however, that Aft1p, which plays a role in positive regulation of iron ion transport, did not show any significant change in expression.

However, as observed in our metal ion rescue experiment, certain deletion strains as well as wildtype exhibit partial growth rescue phenotype under supplementation of ions other than iron or copper (Figure 3.4). A possible reason for this could be attributed to two factors; the non-high affinity iron ion transporter are non-specific in its metal ion transport capabilities (Li \& Kaplan, 1998) and also that natural products such as flavonoids express metal ion chelating activities specific to each metal ion (Mladenka et al., 2011; Flora \& Pachauri, 2010) . In both vacuolar and extracellular environment, the noniron metal ion supplementation outcompetes iron from being chelated by flavonoids, minimising the iron deprivation effect that potentially causes growth inhibition in yeast. Moreover, in the vacuolar environment, the highaffinity iron transporters are upregulated in response to propolis treatment, which maximises iron uptake as well as the uptake of other metal ions. This increase of non-iron ions would competitively minimise iron chelation. In contrast, for the non-high affinity iron ion transporters deletion mutants (Figure 3.4), only iron successfully rescued growth which suggests that the highaffinity iron transporters are highly specific in its activities. The high-affinity iron ion transport mutants thus result in a failure of circumventing iron deprivation by propolis. It is plausible that the variable growth rescue effects in these 
mutants possibly correlates with the efficiency of that particular metal ion as electron donor to take over iron function upon propolis treatment.

Based on SGD (http://yeastgenome.org), I found only Aft1 belong under GO term for positive regulation iron ion transport. This suggests that there are other regulators of iron ion transport, such as Aft2 that might be involved in upregulating the transporter proteins that belong to another $\mathrm{GO}$ term, cellular iron ion homeostasis. However, the role of proteins within the context of cellular iron ion homeostasis was not explored in this study.

Metal ion chelating activity is a common factor for flavonoids although flavonoids display different degrees of effectiveness (Mladenka, et al., 2011; Kandaswami \& E. Middleton, 1997). Heavy metal ions are able to prolong the production of reactive oxygen species and free radicals (Prousek, 2007), thus it is plausible that the chelating activity of flavonoids within propolis protects cells from mitochondrial damage. In the case of propolis, focusing only on iron, the propolis chelates iron, reducing the iron availability inside or outside yeast, creating a low iron condition. Yeast in turn, upregulates both extracellular and vacuolar high-affinity iron transport specifically to maximise iron content within yeast. As we did not observe any change of expression of ARN1-3p siderophore transporter and Fet4p low-affinity iron transporter, I predict that both low affinity iron transporters and siderophore iron transpoters are not involved in yeast response to iron deprivation by propolis.

Different studies were carried out in analysing biological components of propolis isolated from different geographic locations. It was found that propolis 
of different countries has different flavonoid compositions even within the geographical region of a country (Santos et al., 2002; Shiva et al., 2007; Uzel et al., 2005; Ahn et al., 2004). One study explored the activity of Brazilian propolis by employing a similar genome-wide screening approach similar to that used here in my thesis (Castro et al., 2011). This group demonstrated that propolis induced yeast apoptosis via the release of cytochrome c into cytoplasm and also has demonstrated an increase in reactive oxygen species (ROS). This group finding would seem to be in conflict with our findings in regard to propolis because our findings would imply propolis would cause reduction of ROS due to its iron chelation which in turn would reduce ROS production. However, another group had demonstrated that under iron deprivation, apoptosis was induced by the release of cytochrome $\mathrm{c}$ in cytoplasm and also increased ROS levels (Koc et al., 2005). Therefore, we propose that the iron chelating activity of propolis could potentially protect yeast cells from damage by inducing apoptosis. Our findings added a new but congruent explanation on how the biological process of yeast cells were affected by propolis. However, we did not explore the correlation between propolis with ROS levels and also markers for apoptosis in this study to confirm whether there was apoptosis in our propolis studies as previously described by (Castro et al., 2011). 


\subsection{Results and discussion of bee venom}

\subsection{Results}

\subsubsection{Bee venom did not show bioactivity in agar media.}

We performed liquid dose response of BY4741 in SC+HEPES broth and agar dose response in SC+HEPES agar. We determined the ideal inhibition for our library screening at concentration of $0.2 \mu \mathrm{l} / \mathrm{ml}$ (Figure $4.1 \mathrm{~A}$ ), where the residual growth was between $80 \%-90 \%$ (=10-20\% growth inhibition) in broth. On the other hand, we found that bee venom did not exhibit bioactivity in agar (Figure 4.1B). However, when we scaled the experiment against our deletion library, we found that our bee venom concentration was too strong during our first screening against the first 304 deletion strains in which we obtained more than $50 \%$ hits with significant growth defects. Therefore, we performed a liquid dose response of bee venom against our first 76 deletion strains (equivalent to 196 -well plate excluding our his $3 \Delta$ border strains) and picked the best concentration that resulted in approximately 10 hits. From the study, we selected $0.1 \mu \mathrm{l} / \mathrm{ml}$ bee venom that resulted in 10 hypersensitive strains per 96-well plate, an amount feasible for our genome-wide analysis (figure 4.1). 
(A)

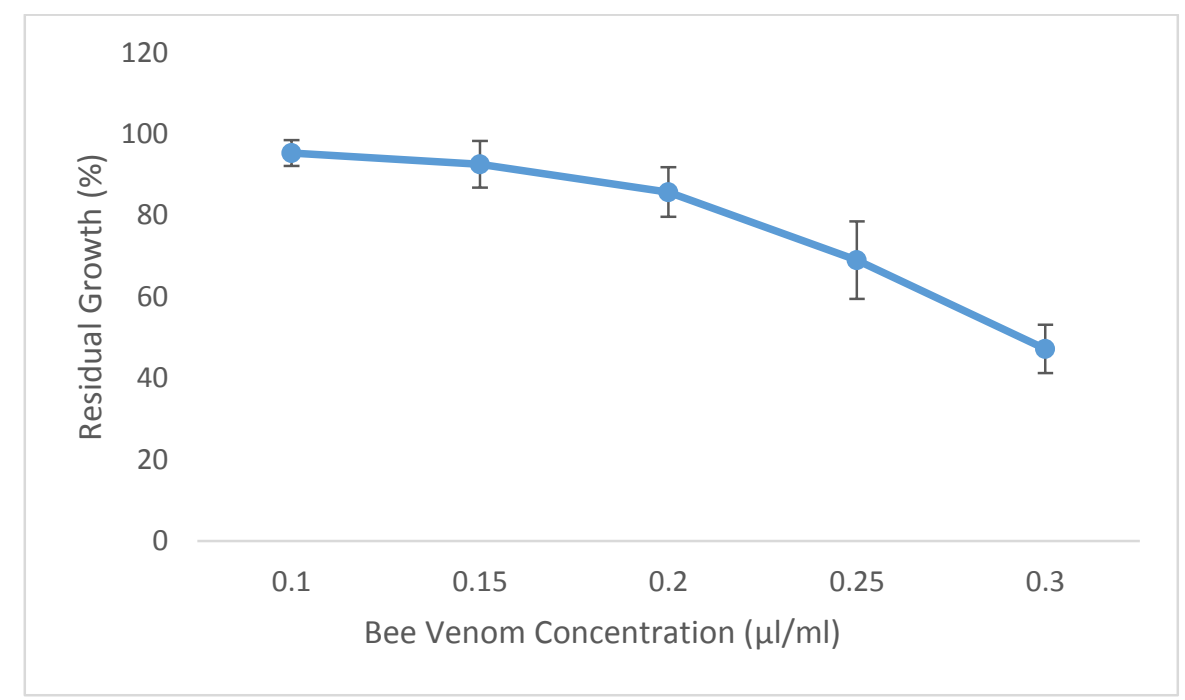

(B)

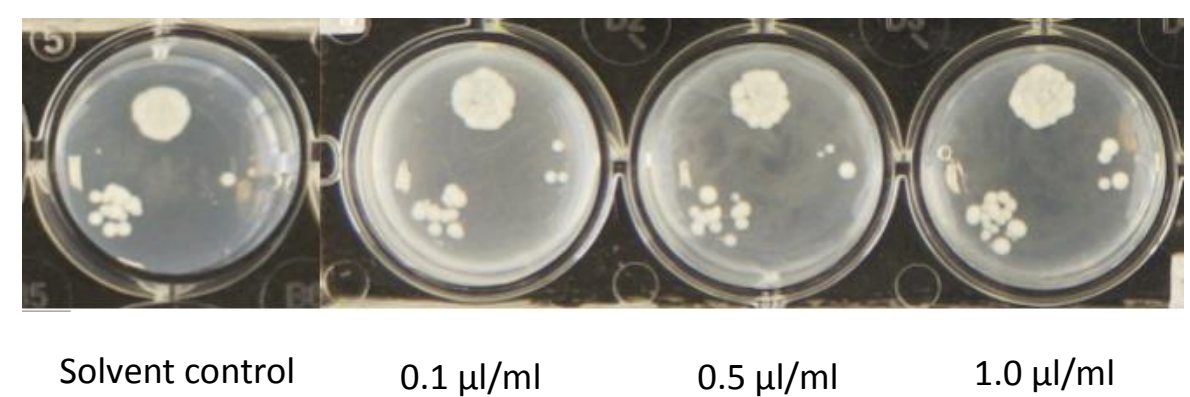

Figure 4.1(A). Residual growth response of BY4741 against bee venom treatment under broth SCH media at mid-log (16 ${ }^{\text {th }}$ hour).(B) Bee venom dose response under agar SCH media.

\subsubsection{Bee venom screen indicates sensitivity in PC metabolism process}

From our primary screen of $\sim 4300$ gene deletion strains and 837 DAmP strains, we found 108 gene deletion strains and 47 Damp strains that had statistically significant growth defects based on a Student's t-test $(P<0.05)$ and residual growth $<70 \%$. Of these, the growth defect was reproduced in 54 deletion 
strains (Table B.2.1) and 8 DAmP strains (Table B.2.2) in an independent analysis. To acquire information of the possible biological process enrichment, I submitted these 54 genes to YeastMine and identified that histone H3-K79 methylation, global genome nucleotide-excision repair and nucleotide-excision repair were the top three most enriched biological processes (Table A.2.1). Due to the time constraints of this thesis, I chose to explore the biological process belonging to the most sensitive gene deletion mutant, which is $\Delta s r f 1$ (Table B.2.1). $\Delta s r f 1, \Delta p s d 2$, $\Delta p c t 1, \Delta e p t 1, \Delta o p i 3, \Delta c k i 1, \Delta c p t 1, \Delta p s d 1, \Delta s p o 14, \Delta i s c 1$ and $\Delta / r o 1$ which involves either in PC anabolism or catabolism (Ejsing et al., 2009). $\Delta c d s 1, \Delta c h o 1$ and $\Delta e c t 1$ were also involved in PC biosynthesis but they were not included because they were absent from our deletion library collection. We performed a broth growth assay of these mutant strains with $0.1 \mu \mathrm{l} / \mathrm{ml}$ and $0.2 \mu \mathrm{l} / \mathrm{ml}$ bee venom. The 0.1 $\mu \mathrm{l} / \mathrm{ml}$ was performed as it has the same concentration as performed during screening as explained in 4.1 .1 whereas $0.2 \mu \mathrm{l} / \mathrm{ml}$ was the ideal concentration which we observed $\sim 85 \%$ residu4.al growth (i.e. $~ 15 \%$ growth inhibiton) in the broth dose response studies (Figure 4.1A). As explained in $3.1,0.2 \mu \mathrm{l} / \mathrm{ml}$ bee venom gives the ideal concentration for screening but we had too many hits at that particular concentration that we reduce the screening concentration to 0.1 $\mu \mathrm{l} / \mathrm{ml}$. Thus, by increasing the bee venom concentration to $0.2 \mu \mathrm{l} / \mathrm{ml}$, we could discover more mutant strains that hypersensitive to bee venom treatment that would not be discovered when the dosage of bee venom was $0.1 \mu \mathrm{l} / \mathrm{ml}$. We indeed found fewer hits on $0.1 \mu \mathrm{l} / \mathrm{ml}$ where only $\Delta p c t 1$ and $\Delta s r f 1$ was hypersensitive at BY4741 wildtype mid-log phase (16 ${ }^{\text {th }}$ hour) and only $\Delta c p t 1$ was hypersensitive at BY4741 wildtype stationary phase $\left(24^{\text {th }}\right.$ hour) (Figure 4.2$)$. On the other hand, we 
found $\Delta p c t 1 \Delta c k i 1$, and $\Delta c p t 1$ to be hypersensitive at mid-log phase and $\Delta e k i 1$, $\Delta p c t 1, \Delta e p t 1, \Delta c k i 1$, and $\Delta c p t 1$ were hypersensitive at stationary phase. BY4741 was found to show significant difference of $87 \%$ residual growth (13\% growth inhibition) at mid-log phase which is coherent with our previous broth dose response assay (Figure 4.1A). $\Delta p s d 1$ appeared to be growth stimulating under bee venom treatment but the difference was not statistically significant. We had to omit $\Delta o p i 3, \Delta i s c 1$, and $\Delta / r o 1$ because they exhibit slow growth that infeasible for broth dose response experiment. The incongruent hypersensitive hits at BY4741 wildtype mid-log phase and BY4741 wildtype stationary phase is likely due to difference of growth rate across all mutant strains that either their mid-log phase comes later than the BY4741 wildtype that their hypersensitivity is observed at $24^{\text {th }}$ hour but not at $16^{\text {th }}$ hour or that their mid-log phase comes earlier than BY4741 wildtype that their hypersensitivity is observed at $16^{\text {th }}$ hour but not at $24^{\text {th }}$ hour. All these mutant strains hits could be categorised in three particularly pathways relating to PC metabolism. One group consists of Eki1 and Ept1 which utilises ethanolamine to make PE, another group consists of Cki1, Pct1, Cpt1 and Ept1 that utilises choline to make PE and the final group consists of Spo14 and Srf1 that breaks down PC to PA and choline (Birner et al., 2001; Ejsing et al., 2009; Kennedy et al., 2011) .These results suggests that the bee venom may inhibit specific proteins within the PC metabolic processes (Figure 4.5). 
A.

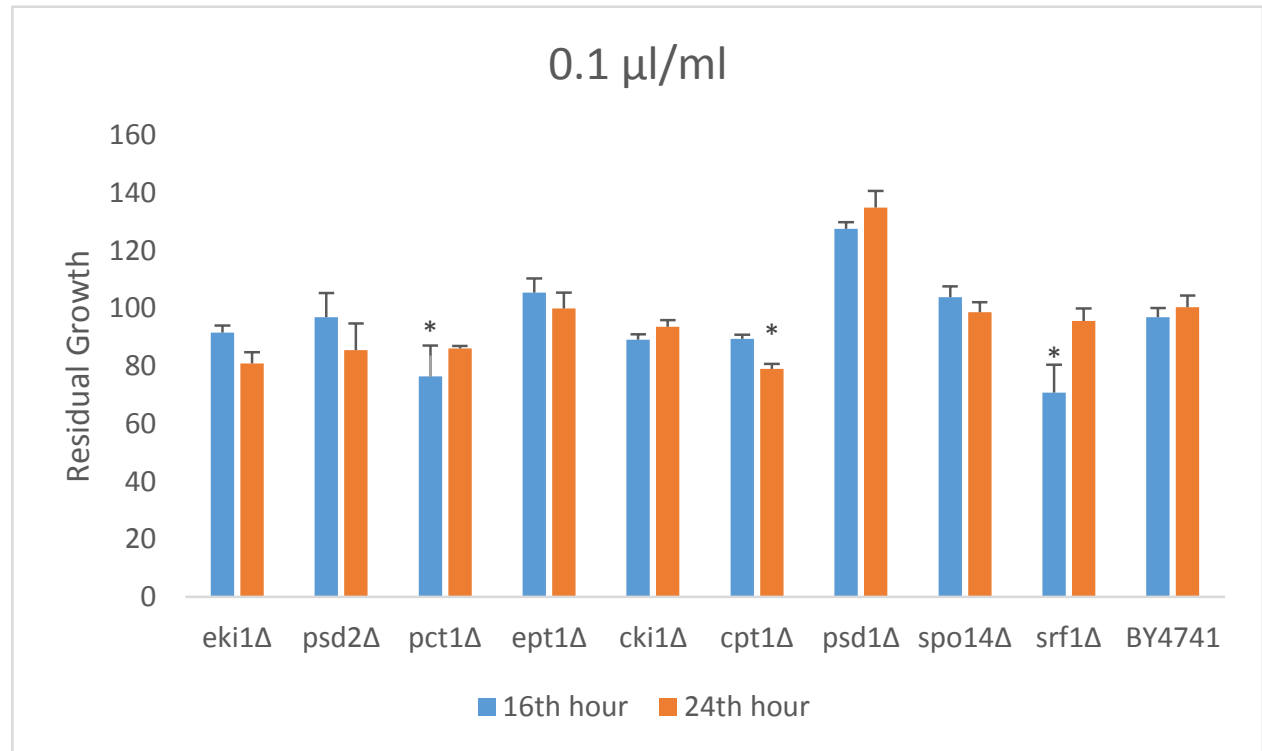

B.

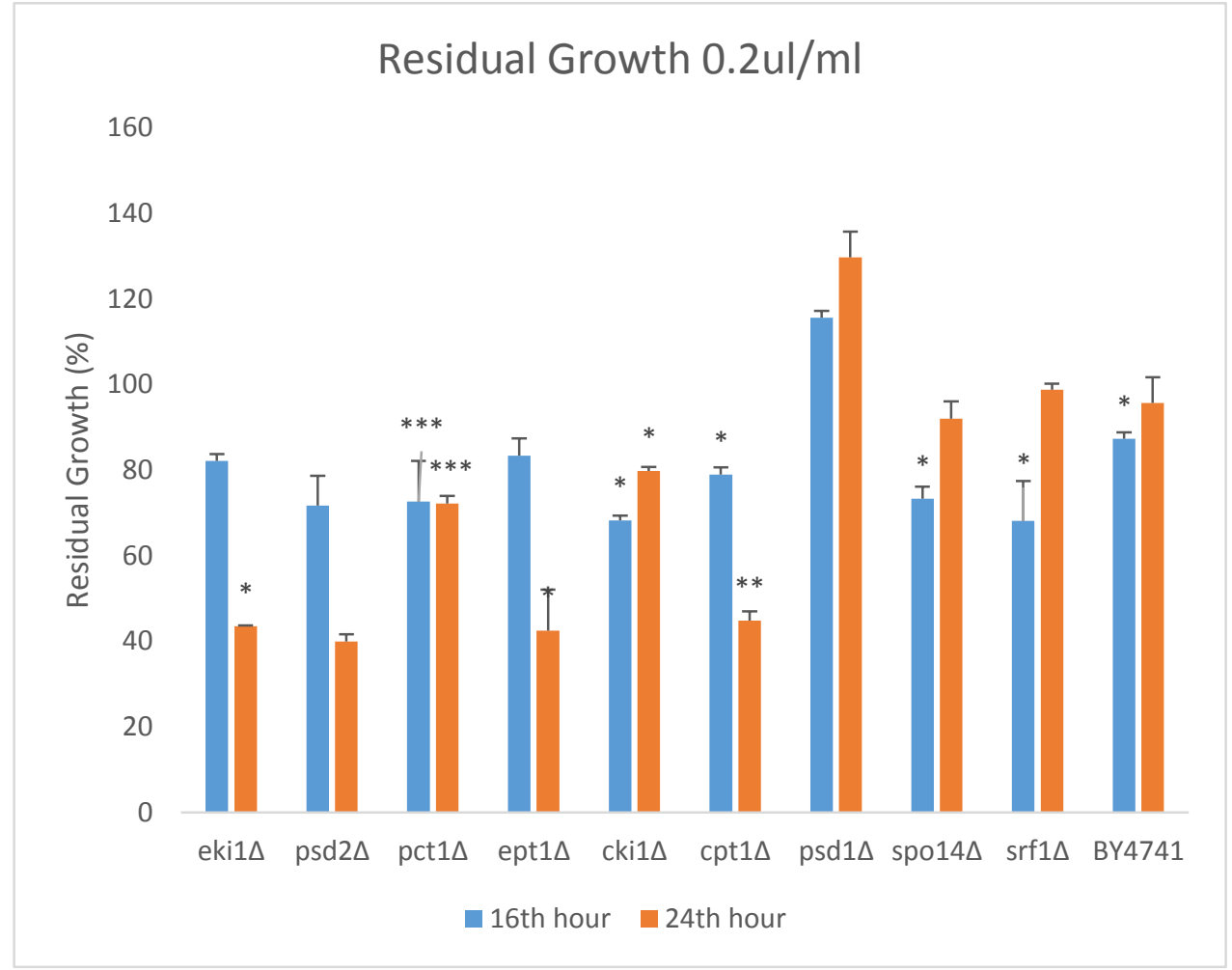

Figure 4.2.(A) Residual growth of deletion strains involved in phosphatidylcholine metabolism under $0.1 \mu \mathrm{l} / \mathrm{ml}$ bee venom treatment at BY4741 wildtype mid-log phase (16 ${ }^{\text {th }}$ hour) and stationary phase $\left(24^{\text {th }}\right.$ hour $)$. (B) Residual growth under $0.2 \mu \mathrm{l} / \mathrm{ml}$ bee venom treatment at 
BY4741 wildtype mid-log phase ( $16^{\text {th }}$ hour) and stationary phase $\left(24^{\text {th }}\right.$ hour). (Student's $t$-test $\left.{ }^{*} P<0.05 ;{ }^{* *} P<0.01 ;{ }^{* * *} P<0.001\right)$

\subsubsection{GFP intensity and localisation studies showed suppression of Opi3p-GFP fluorescence}

To study the effect of bee venom on the proteins in PC metabolism, I measured the expression levels of proteins involved in glycerol biosynthesis metabolism and PC metabolism as from Ejsing et al. (2009), in response to 0.1 $\mu \mathrm{l} / \mathrm{ml}$ or $0.2 \mu \mathrm{l} / \mathrm{ml}$ bee venom. Specifically I examined Spo14p-GFP, Cki1p-GFP, Eki1p-GFP, PCt1p-GFP, Cho2p-GFP, Psd1p-GFP, Cpt1p-GFP, Ept1p-GFP and Opi3p GFP, strains similar to 4.1.2. Srf1p-GFP, Isc1p-GFP, Psd2p-GFP and Iro1p-GFP were not included in this study for these strains were not available in the yeast GFP library.

We did not observe any significant changes in GFP intensity or localisation

of Cho2p-GFP, Psd1p-GFP, Spo14p-GFP, Cki1p-GFP, Eki1p-GFP, PCt1p-GFP, Cpt1pGFP, or Ept1p-GFP. Only Opi3p-GFP showed a significant decrease in GFP intensity under bee venom treatment and this was not associated with a change in localisation (Figure 4.3). 


\section{Opi3p-GFP}

600
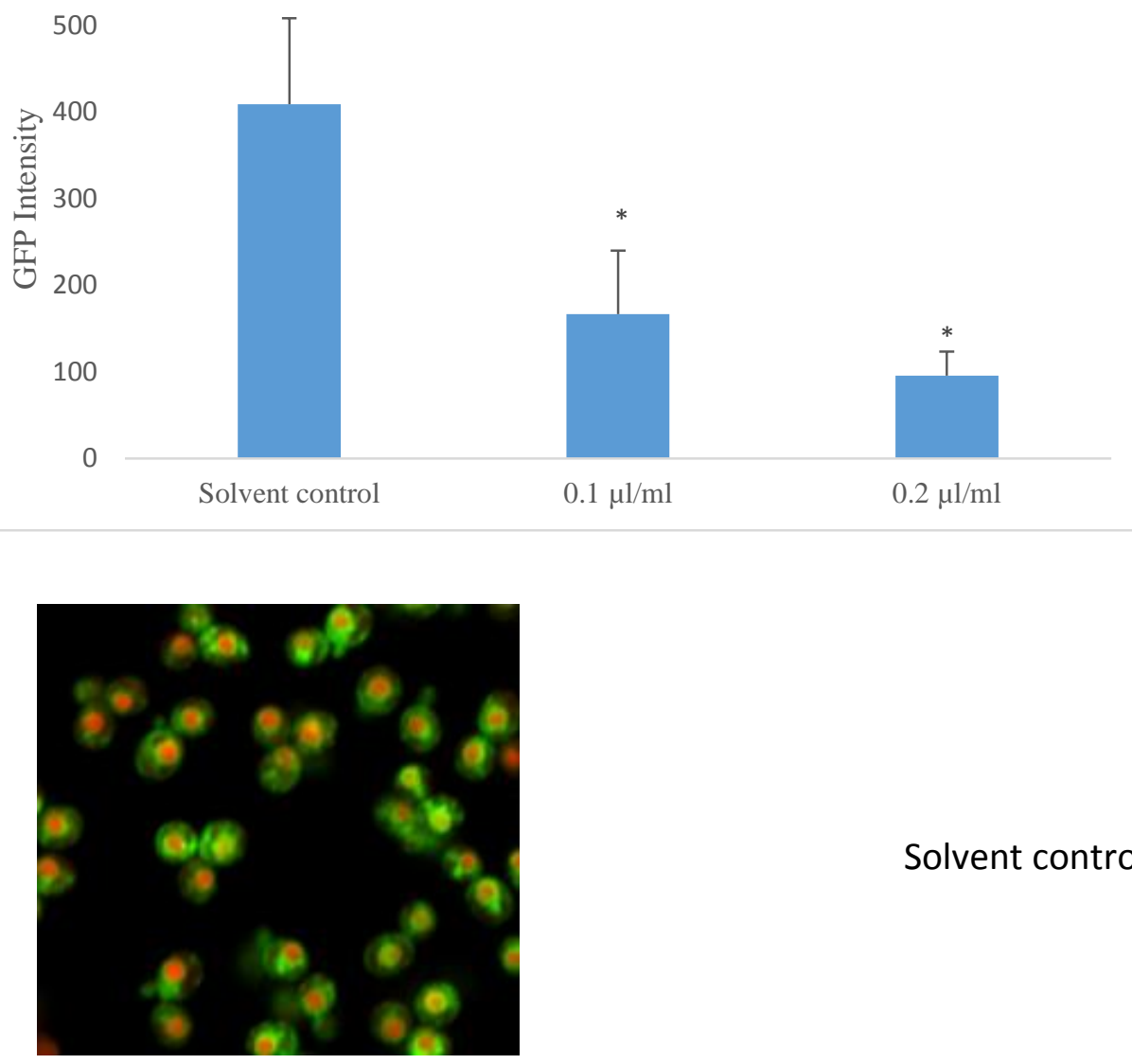

Solvent control

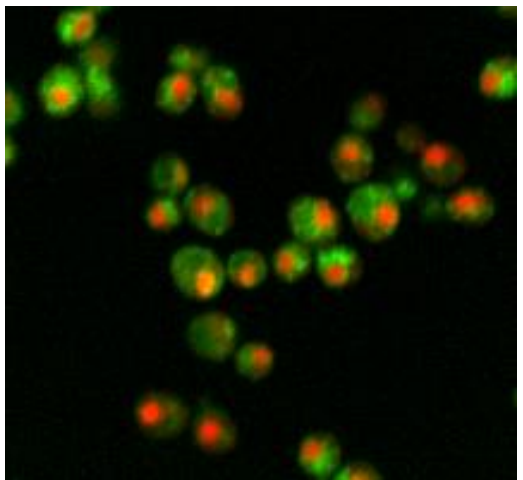

$0.1 \mu \mathrm{l} / \mathrm{ml}$ bee venom

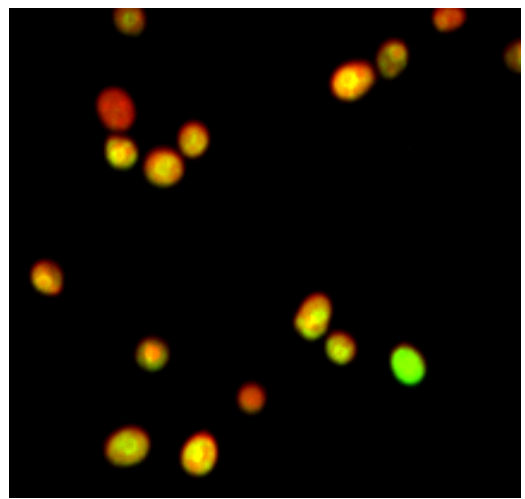

$0.2 \mu \mathrm{l} / \mathrm{ml}$ bee venom 

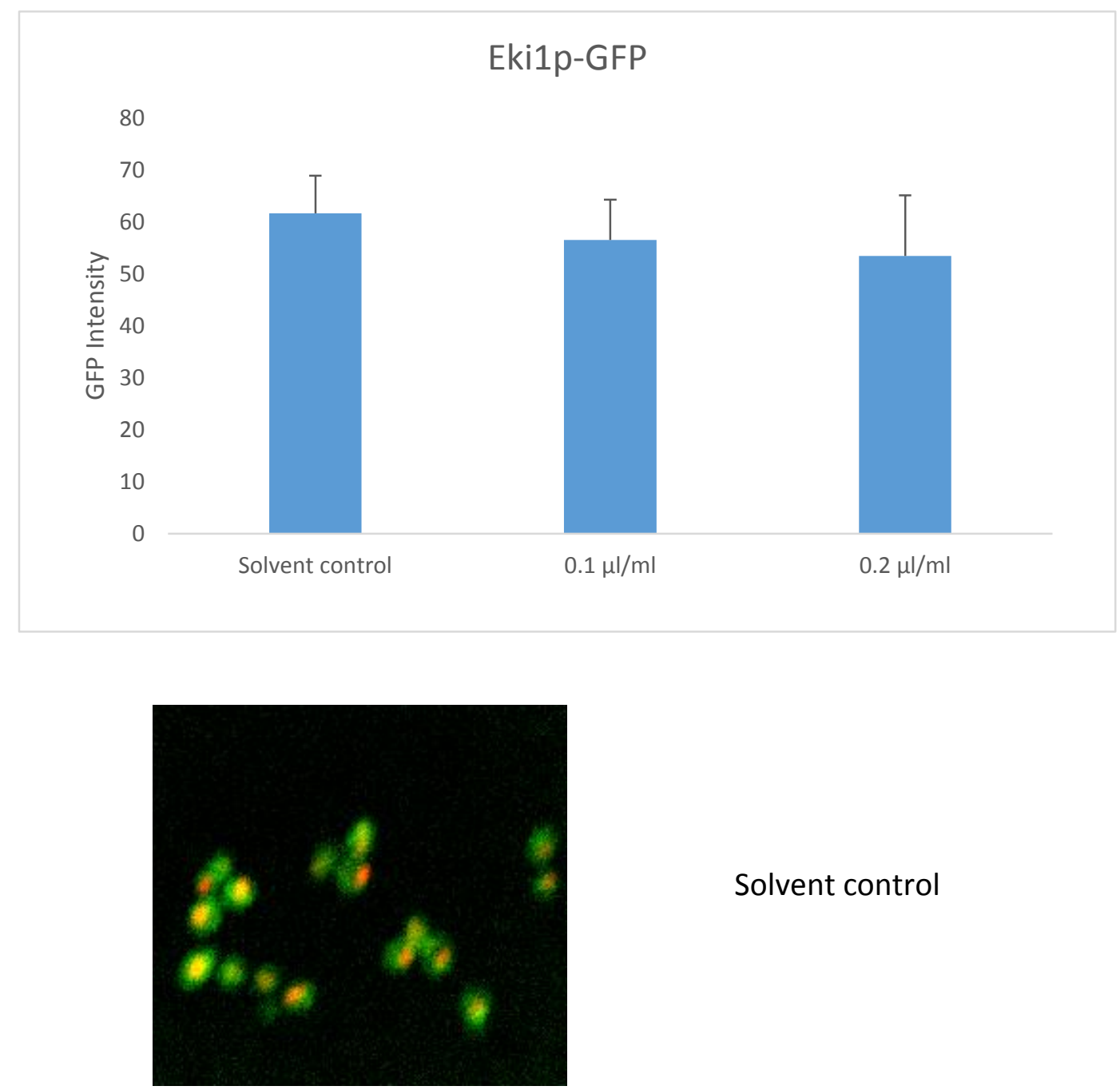

Solvent control

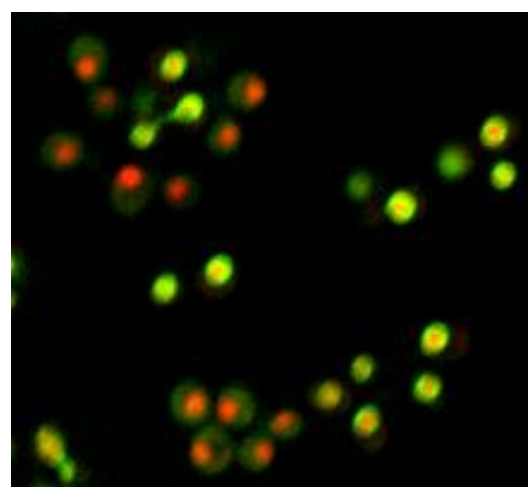

$0.1 \mu \mathrm{l} / \mathrm{ml}$ bee venom

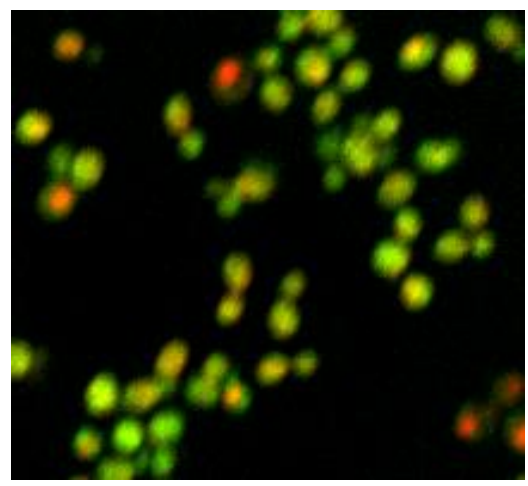

$0.2 \mu \mathrm{l} / \mathrm{ml}$ bee venom 

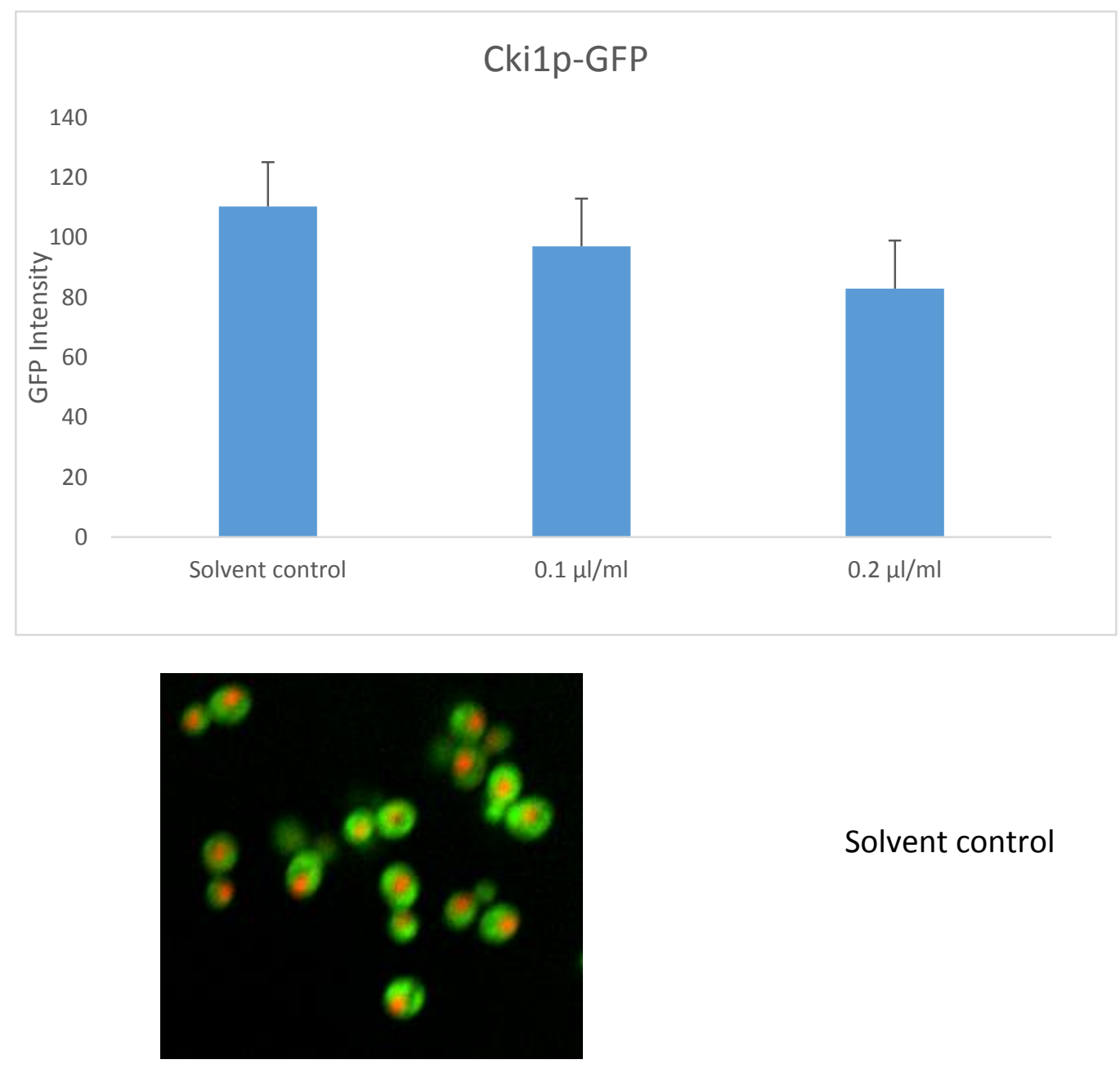

Solvent control

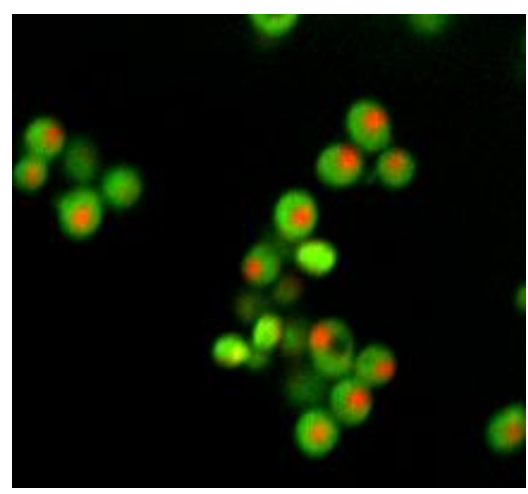

$0.1 \mu \mathrm{l} / \mathrm{ml}$ bee venom

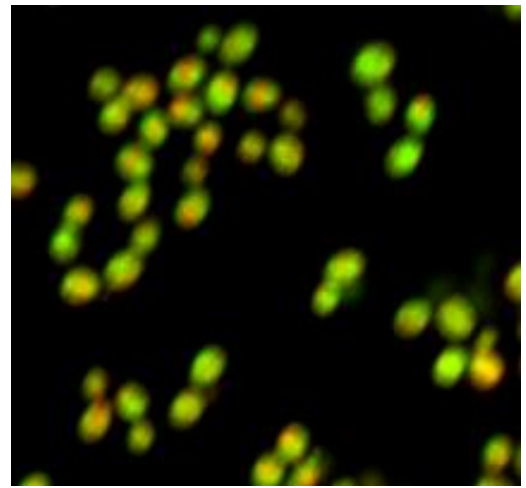

$0.2 \mu \mathrm{l} / \mathrm{ml}$ bee venom 

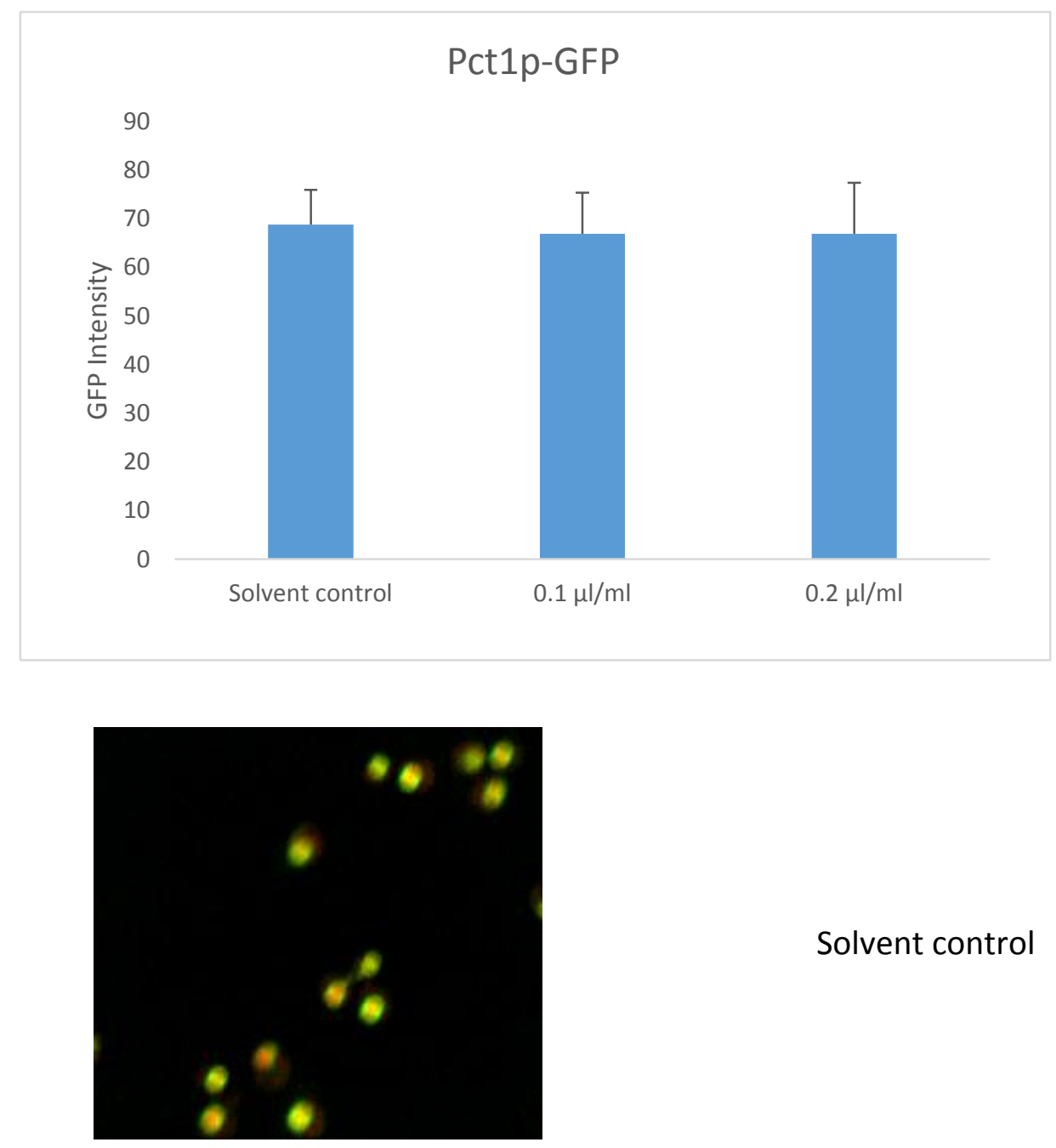

Solvent control

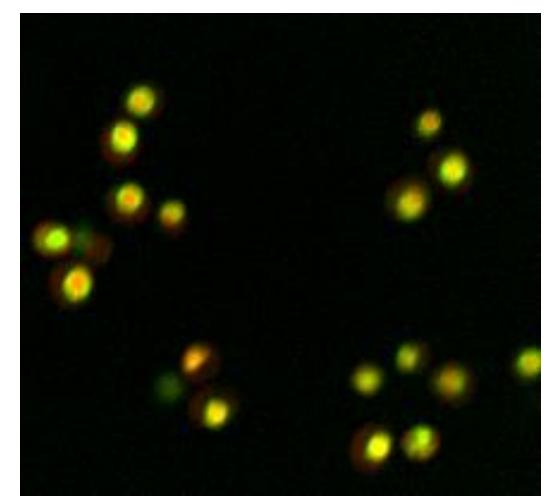

$0.1 \mu \mathrm{l} / \mathrm{ml}$ bee venom

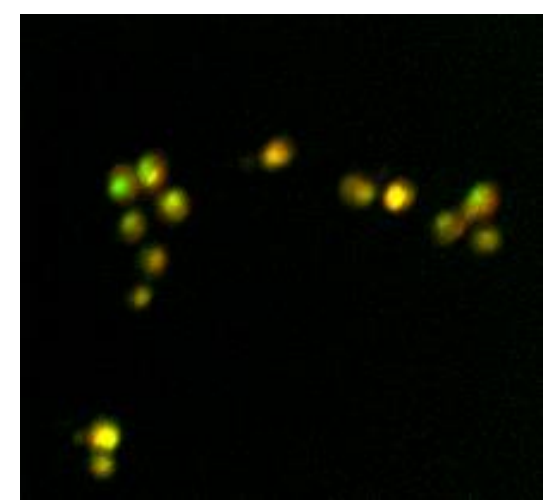

$0.2 \mu \mathrm{l} / \mathrm{ml}$ bee venom 

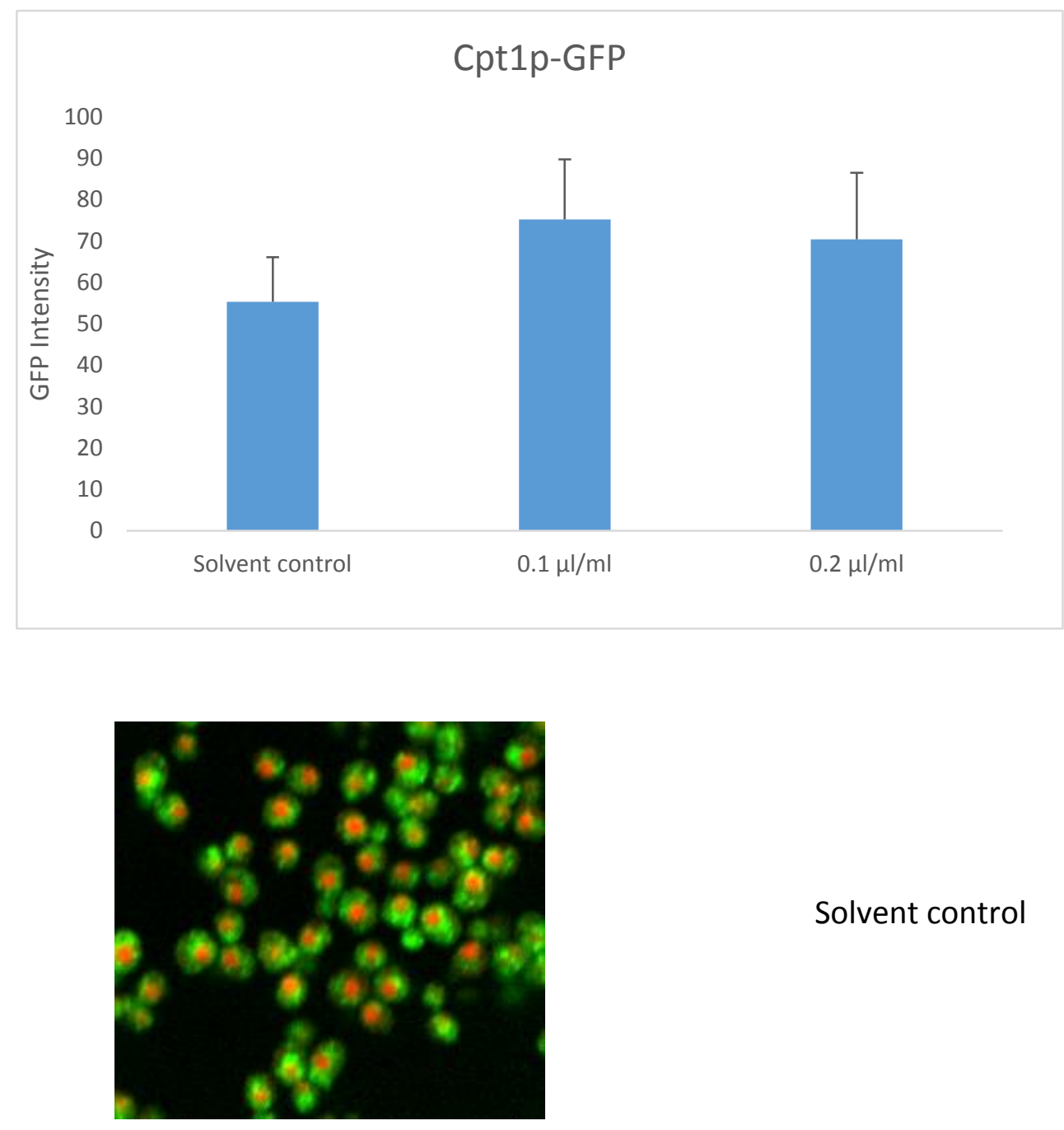

Solvent control

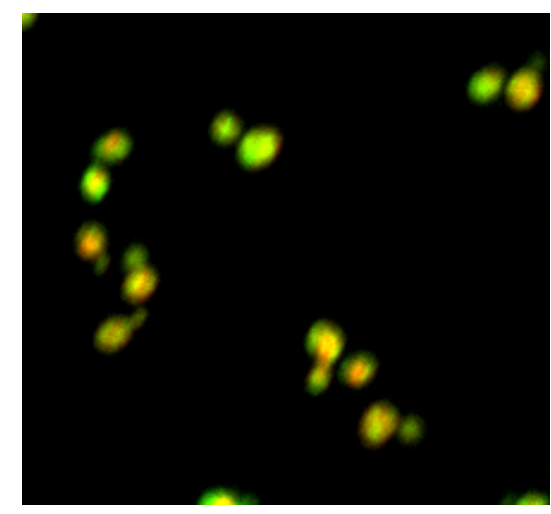

$0.1 \mu \mathrm{l} / \mathrm{ml}$ bee venom

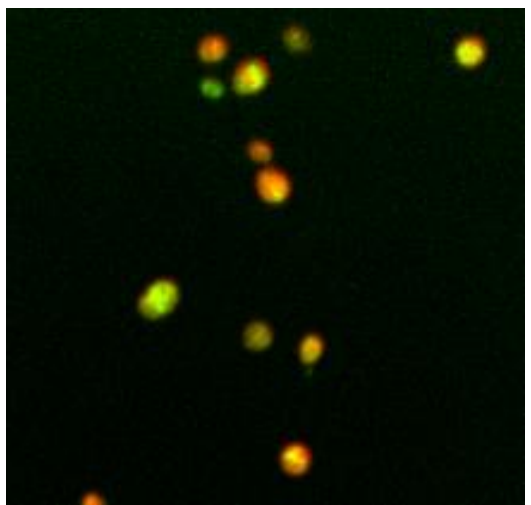

$0.2 \mu \mathrm{l} / \mathrm{ml}$ bee venom 

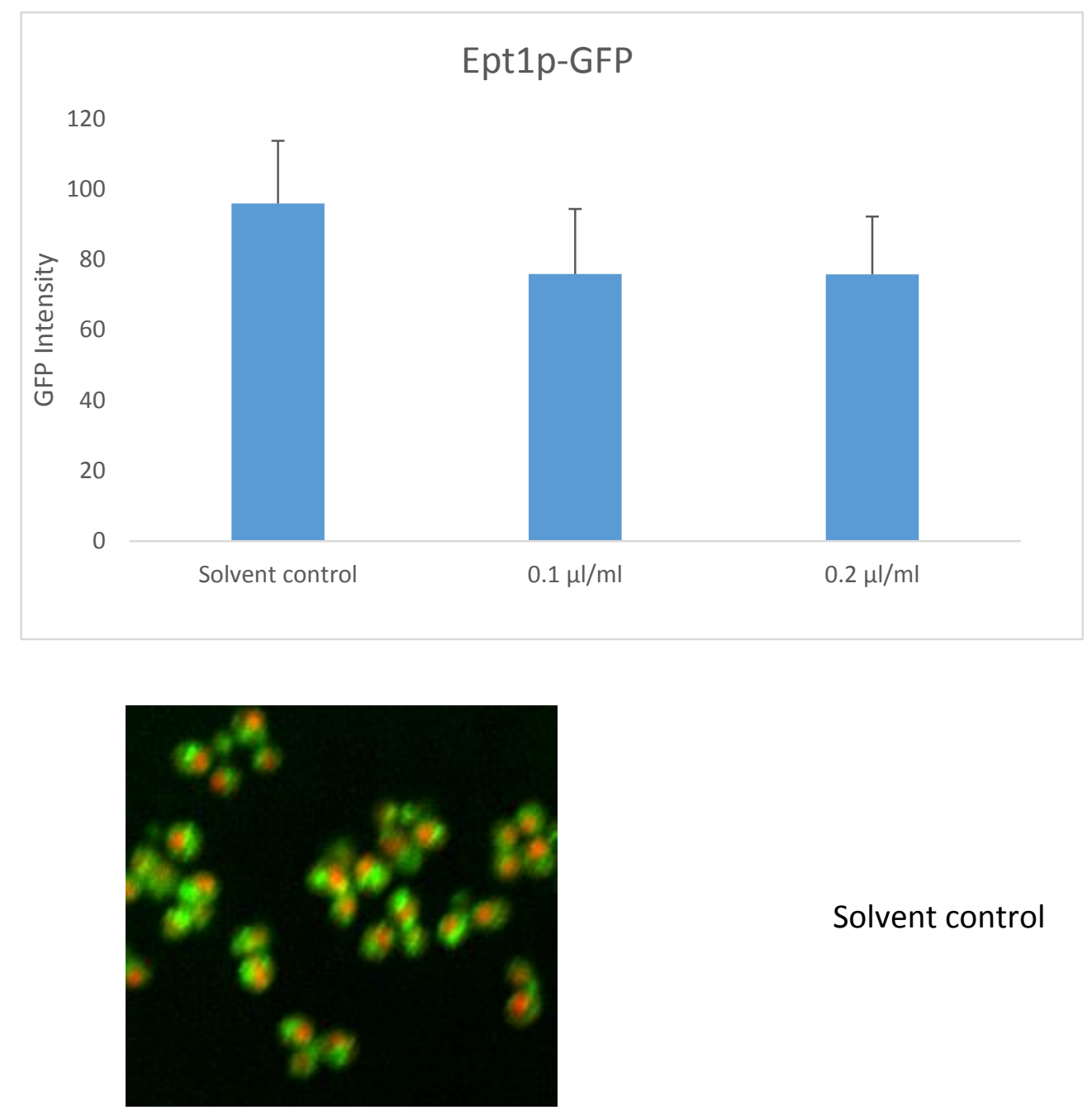

Solvent control

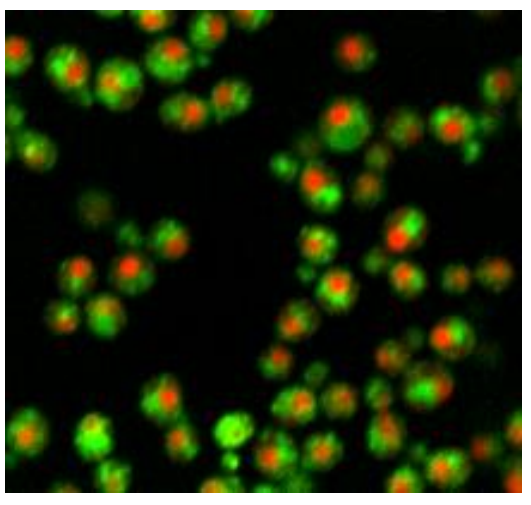

$0.1 \mu \mathrm{l} / \mathrm{ml}$ bee venom

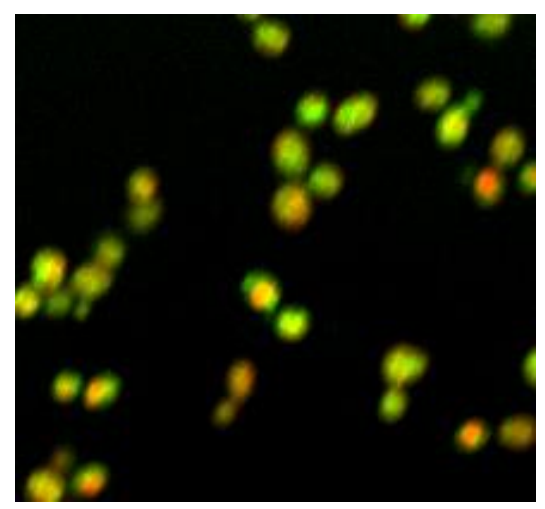

$0.2 \mu \mathrm{l} / \mathrm{ml}$ bee venom 

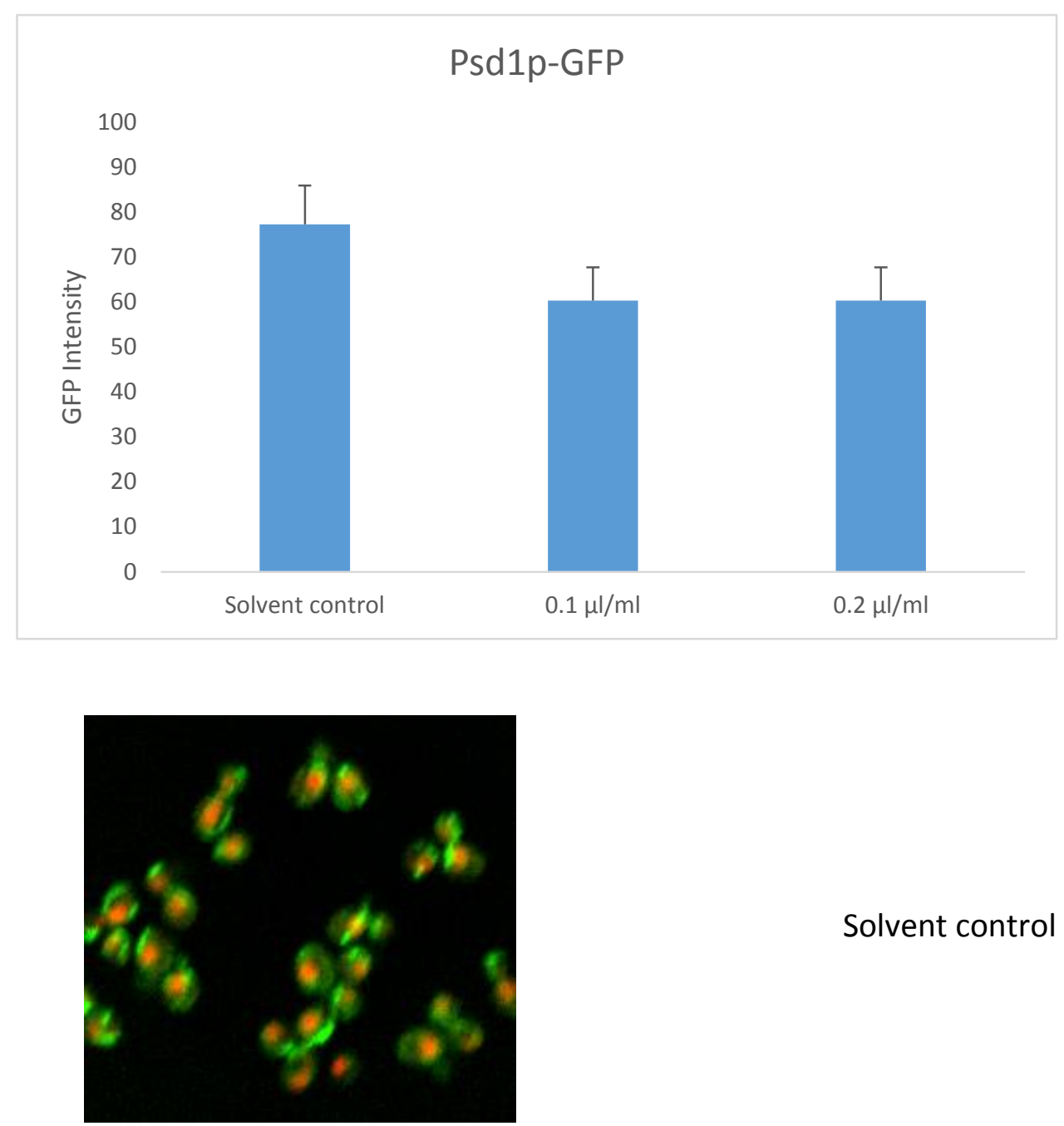

Solvent control

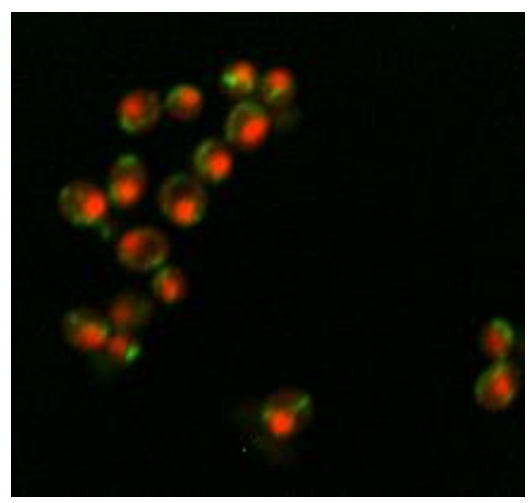

$0.1 \mu \mathrm{l} / \mathrm{ml}$ bee venom

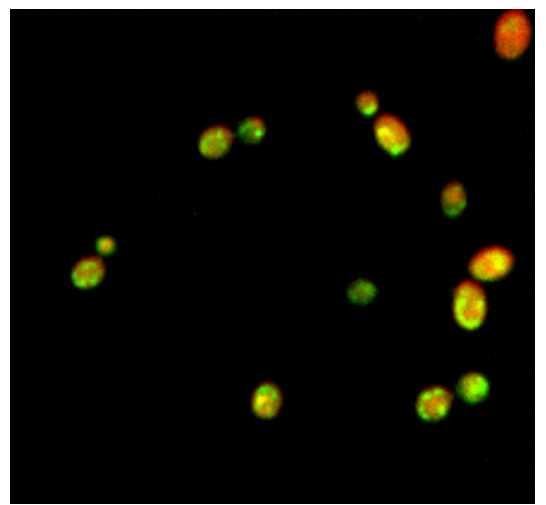

$0.2 \mu \mathrm{l} / \mathrm{ml}$ bee venom 

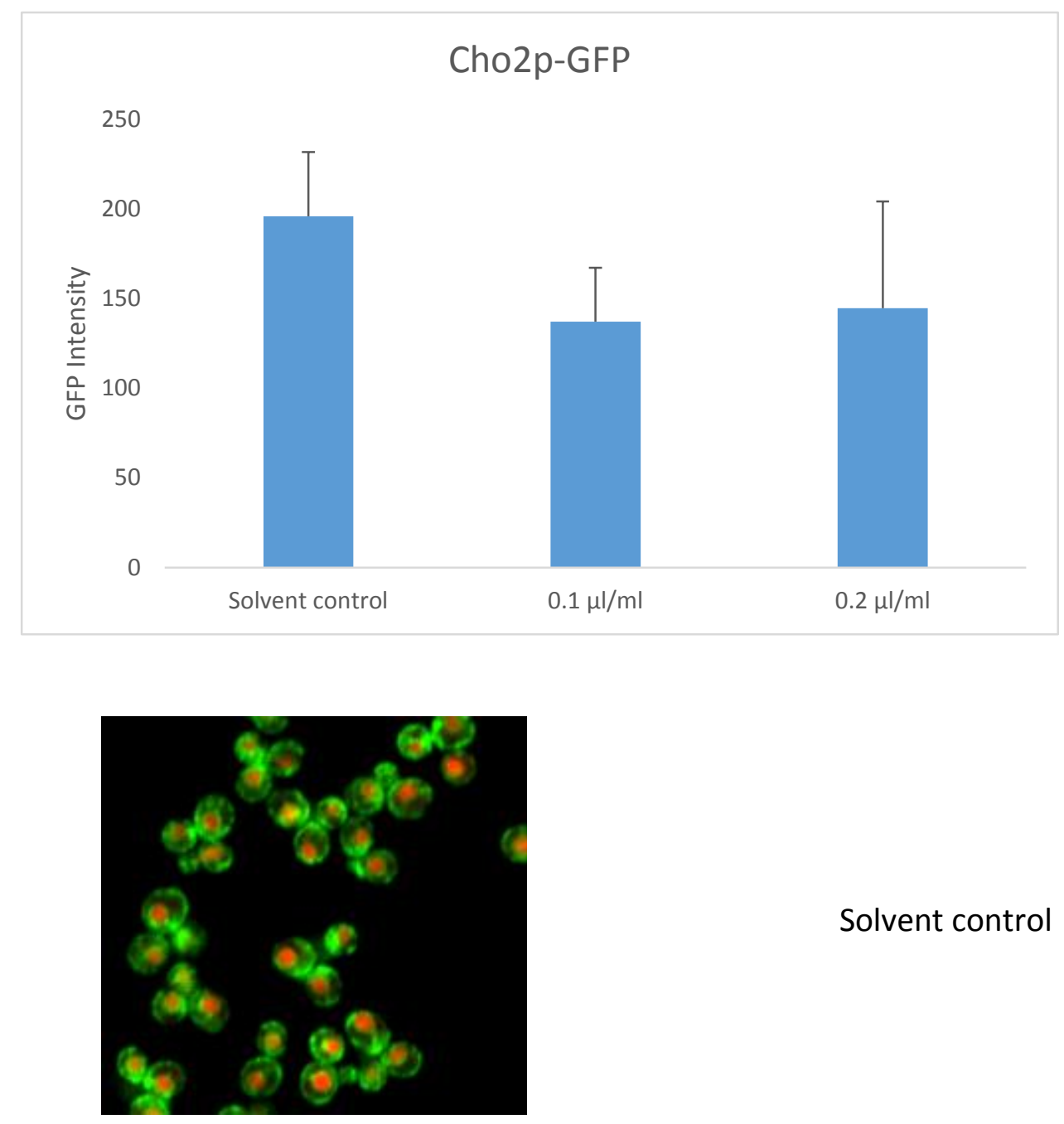

Solvent control

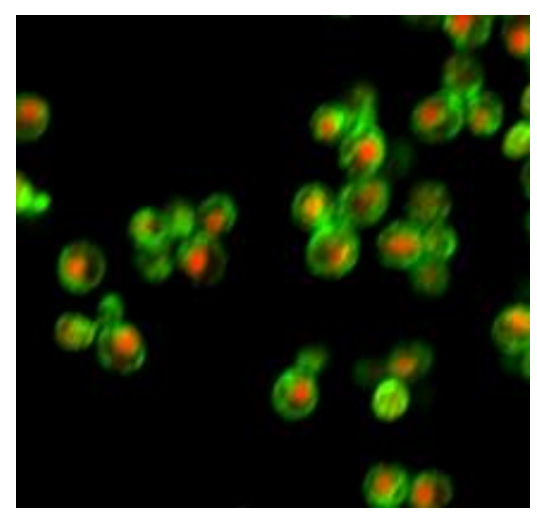

$0.1 \mu \mathrm{l} / \mathrm{ml}$ bee venom

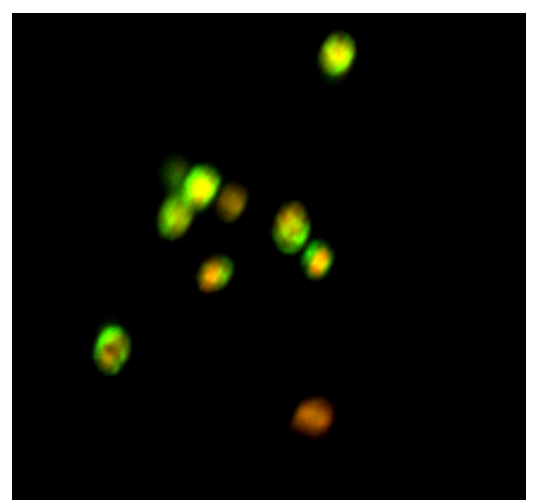

$0.2 \mu \mathrm{l} / \mathrm{ml}$ bee venom 

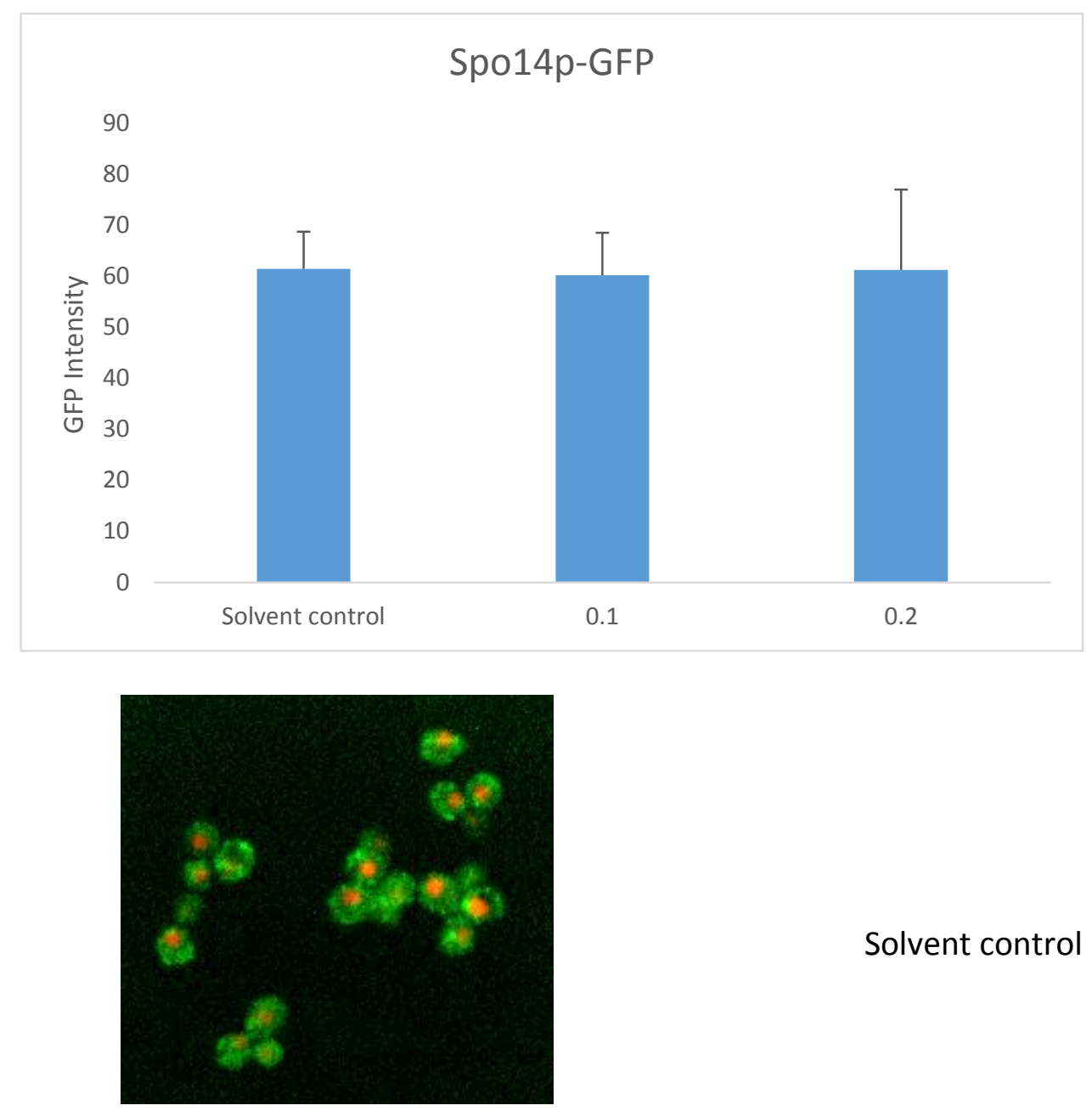

Solvent control

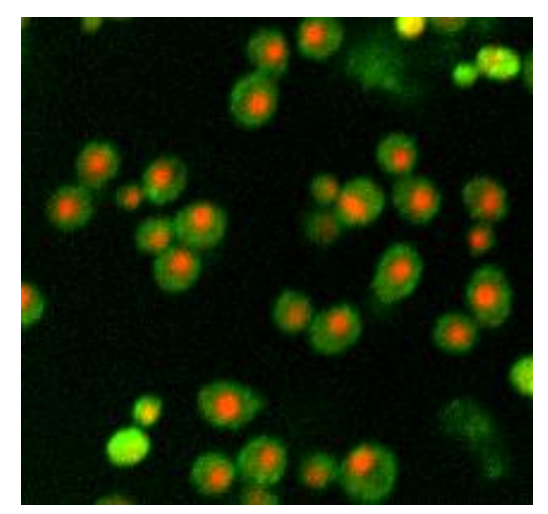

$0.1 \mu \mathrm{l} / \mathrm{ml}$ bee venom

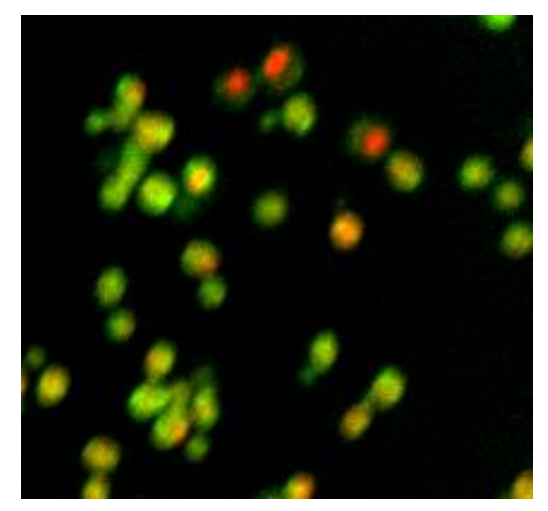

$0.2 \mu \mathrm{l} / \mathrm{ml}$ bee venom 
Figure 4.3 GFP intensity measurement of GFP-tagged proteins involved and their respective fluorescence localisation (Student's $t$-test ${ }^{*} P<0.05$ ). Red fluorescence indicates nucleus location.

It is noteworthy that at $0.2 \mu \mathrm{l} / \mathrm{ml}$ bee venom treatment, the cells appear to be smaller and for the non-nuclear localised yeast GFP strains, the RFP fluorescence overlaps with the GFP fluorescence which the RFP signal is found in cytoplasm(e.g. Opi3p-GFP in Figure 4.3). This suggests that nucleolar proteins are now found outside nucleus implicating that the membrane integrity of yeast is compromised. These results suggest that bee venom may affect yeast's physiology by selectively inhibiting Opi3p expression and this Opi3p downregulation effect might explain the leak of RFP signal observed at $0.2 \mu \mathrm{l} / \mathrm{ml}$.

\subsubsection{PC quantification assay indicates PC decline with bee venom treatment}

To directly measure the effect of bee venom on PC metabolism, I quantified PC in BY4741 wildtype, $\Delta s r f 1$ and $\Delta s p o 14$ with two concentrations of bee venom, $0.1 \mu \mathrm{l} / \mathrm{ml}$ and $0.2 \mu \mathrm{l} / \mathrm{ml}$. $\Delta$ spo14 was also included for we would like to observe the effect bee venom on PC metabolism under absence of PC breakdown mechanism. BY4741 and $\Delta$ srf1 showed a significant decrease of PC under $0.1 \mu \mathrm{l} / \mathrm{ml}$ and $0.2 \mu \mathrm{l} / \mathrm{ml}$ bee venom treatment (Figure 4.4). However, spo14 $\Delta$ showed no significant difference under $0.1 \mu \mathrm{l} / \mathrm{ml}$ bee venom treatment but a significant decrease of PC concentration was observed under $0.2 \mu \mathrm{l} / \mathrm{ml}$ bee venom. Interestingly, the PC phenotype of spo14 $\Delta$ in $0.2 \mu \mathrm{l} / \mathrm{ml}$ bee venom was 
not as dramatic as compared to $\operatorname{srf1\Delta }$ and BY4741 wildtype. These results indicate that bee venom either suppresses PC synthesis or upregulates PC catabolism.
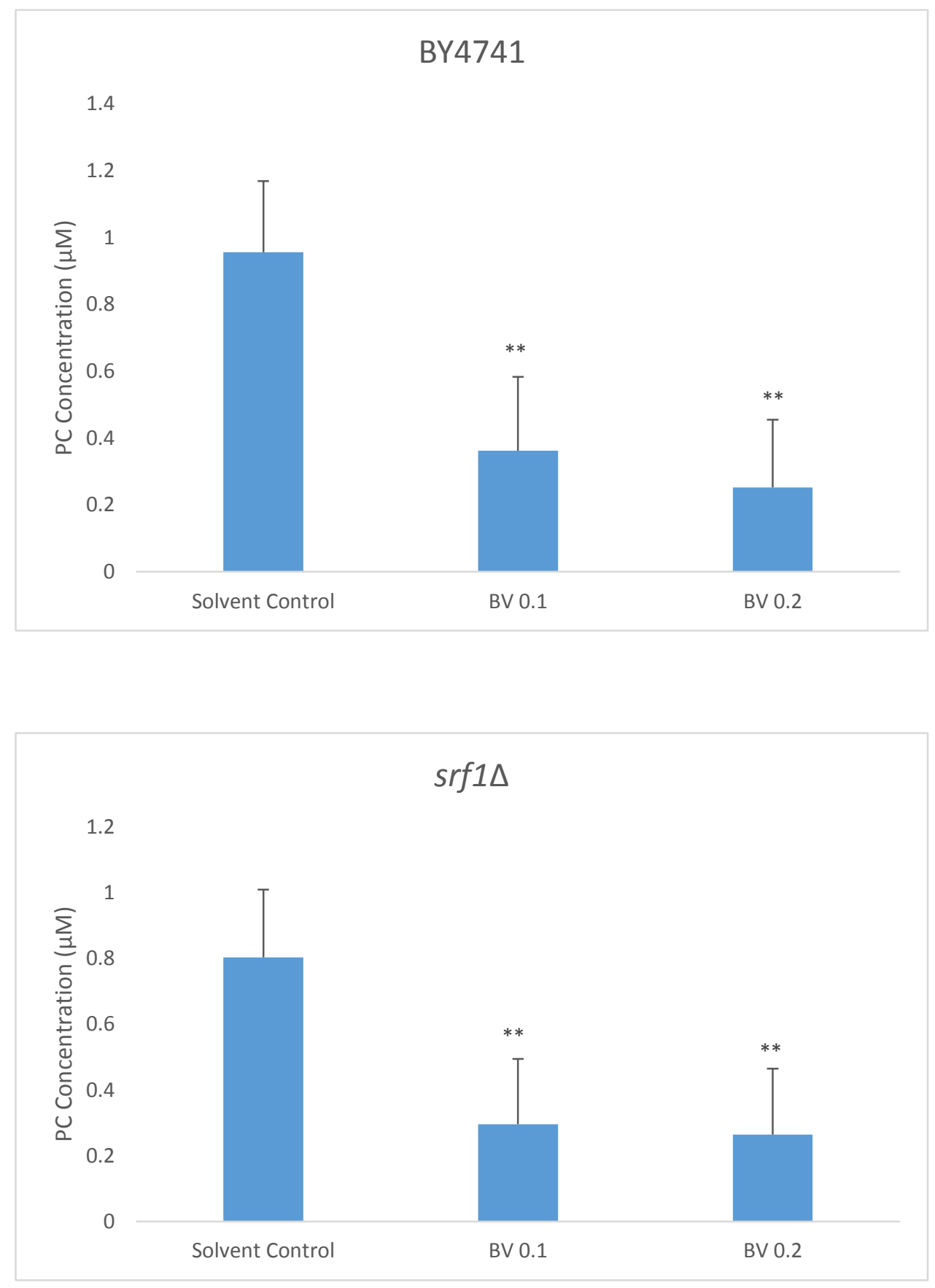


\section{spo14}

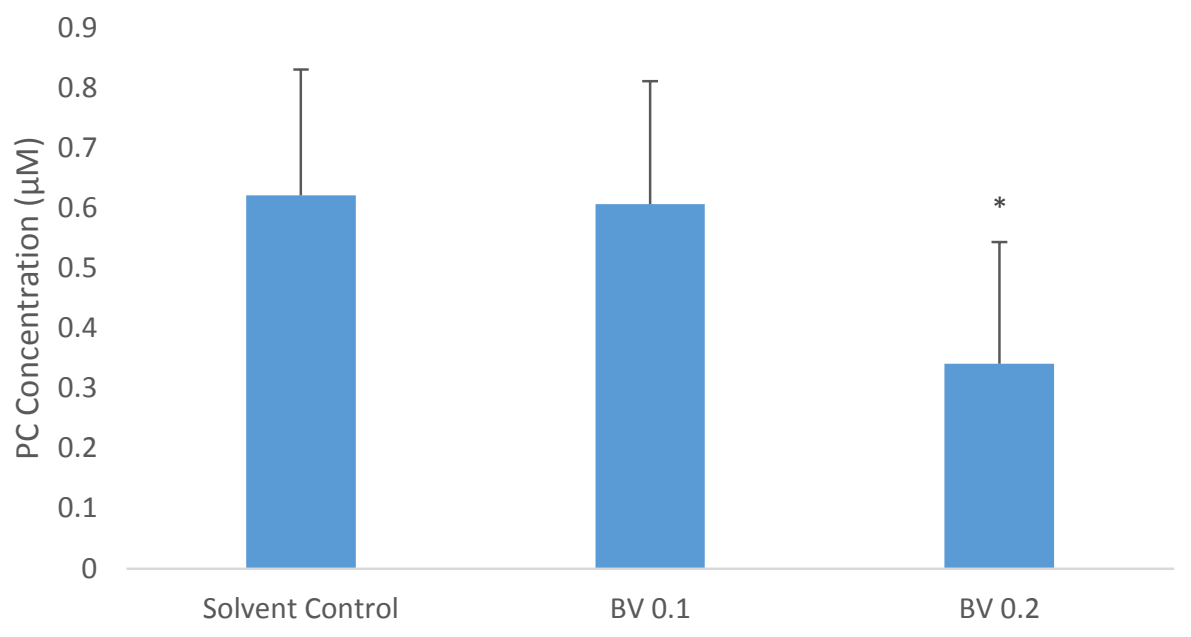

Figure 4.4. $\mathrm{PC}$ amount of BY4741, $\Delta$ spo14 and $\Delta s r f 1$ under 2 different bee venom concentration. BV 0.1 and 0.2 represents $0.1 \mu \mathrm{l} / \mathrm{ml}$ and $0.2 \mu \mathrm{l} / \mathrm{ml}$ bee venom respectively. (Student's $t$-test $* P<0.05 ; * *<0.01$ )

\subsection{Discussion}

As I identified that bee venom was not bioactive in agar, possibly due to heat-sensitive bioactive components of bee venom (e.g. melittin) not being stable in molten agar when the bee venom was added to agar. Genome-wide analyses of bee venom were then conducted in liquid media and we determined that 108 deletion strains were hypersensitive to bee venom and we used one of the most sensitive strains $(\operatorname{srf} 1 \Delta)$ to elucidate molecular mechanisms of bee venom in regulating PC metabolism.

There are two pathways in which PA could be converted to PC. The first one being the conversion to PC via PS and PE intermediates whereas the other one involves DAG intermediate. The DAG intermediate has two primary pathways; one 
that produces PC directly from DAG and the other one indirectly via PE intermediate (Ejsing et al., 2009). Eki1p and Ept1 synthesise PE via CDPethanolamine pathway (Birner, Burgermeister, Schneiter, \& Daum, 2001; Ejsing, et al., 2009) via exogenous ethanolamine as its starting materials (Birner et al., 2001). Cki1p, Cpt1p, Pct1p and Ept1p on the other hand, manufacture PC directly from exogenous choline. Ept1p is essential for both PE and PC biosynthesis to occur (Birner et al., 2001). In contrast, mutant strains $p s d 1 \Delta$ and $p s d 2 \Delta$, which synthesise PE from PS under the CDP-ethanolamine pathway, were not hypersensitive to bee venom. The Kennedy pathway for manufacturing PC via Cki1p becomes essential in the $p s d 1 \Delta p s d 2 \Delta$ double mutant but not eki1 $\Delta$, which implies that the PE-mediated Kennedy pathway for PC synthesis is insufficient to meet the minimum PC amount required for yeast viability. Therefore, the hypersensitivity observed in eki1 $1, p c t 1 \Delta, e p t 1 \Delta$ cki1 1 , , and $\operatorname{cpt} 1 \Delta$ (figure 4.2B) may be due to bee venom inhibiting proteins within the CDP-ethanolamine pathway, causing reduction of PE or PC. On the other hand, the hypersensitivity of eki1 $\Delta$ may be due to the significant reduction of PE due to the defective machinery of PE biosynthesis from exogenous ethanolamine source coupled with inhibition of PE synthesis via CDP-ethanolamine pathway by bee venom. 
Furthermore, srf1 $\Delta$ but not spo14 $\Delta$ was found to be hypersensitive against bee venom. Spo14p is phospholipase D that directly breaks down PC to PA and choline and Srf1p is regulator to Spo14p activity (Ejsing et al., 2009; Kennedy et al., 2011). This suggests that unregulated Spo14p phospholipase D activity but not its absence is required for hypersensitivity. This is coherent with my hypothesis that bee venom regulates the levels of PC in yeast via inhibition of PC biosynthesis.

Protein expression level analysis by GFP intensity indicated that only Opi3p levels were downregulated by bee venom treatment. Even the proteins that function upstream of Opi3 in CDP-ethanolamine pathway, Psd1p and Cho2p did not show downregulation of expression as observed in Opi3p. This suggests that bee venom inhibits PC anabolism by suppressing Opi3p activity that catalyses the last two steps of PC biosynthesis. These results abrogate the possibility of my earlier inference that bee venom specifically inhibits PE biosynthesis from the ethanolamine pathway and PC biosynthesis from the choline pathway. Furthermore, we did not observe any increase of Spo14p upon bee venom treatment which suggests that bee venom did not increase breakdown of PC. However, it is possible that PC is being removed by activity of Lro1p; unfortunately Lro1p expression under bee venom treatment was not assessed in our study. In summary, my GFP analyses suggest that bee venom inhibits PC biosynthesis by selectively suppressing Opi3p from synthesising PC.

The results from our PC levels assay indicate that there are significant reduction of PC amount under bee venom treatment for BY4741 wildtype, srf1 $\triangle$ and spo14 . spo14 $\Delta$ showed less reduction of PC under bee venom treatment 
compared to solvent control which is consistent with the function of Spo14p, a phospholipase D that breaks down PC. However, the fact that PC reduction is still observed in spo14 $\Delta$ implicates other proteins that recycle constituents of PC (e.g., Lro1p).

$\mathrm{PC}$ is involved in membrane signalling in which it is a precursor to various secondary messenger molecules and thus implicating the significance of PC in cells to generate PC-derived messenger that results in cell growth (Wright et al., 2004). Previous studies demonstrated that inactivation of PC increased apoptosis and the cause of apoptosis linked with accumulation of the PC precursor, CDP-choline (Cui et al., 1996; Gasull et al., 2002; Williams et al., 1998). This is in line with our observation of pct1 $\Delta$ being less hypersensitive to bee venom treatment compared to $\operatorname{cpt1} 1 \mathrm{a}$ and ept1D (Figure 4.2B) as Pct1p catalyses the reaction of choline phosphate and CDP to form CDP-choline (Ejsing et al., 2009). However, we did not found downregulation of Cpt1p and Ept1p in our yeast GFP assay, suggesting that the bee venom-induced cell death (via apoptosis or necrosis) is not via CDPaccumulation. 


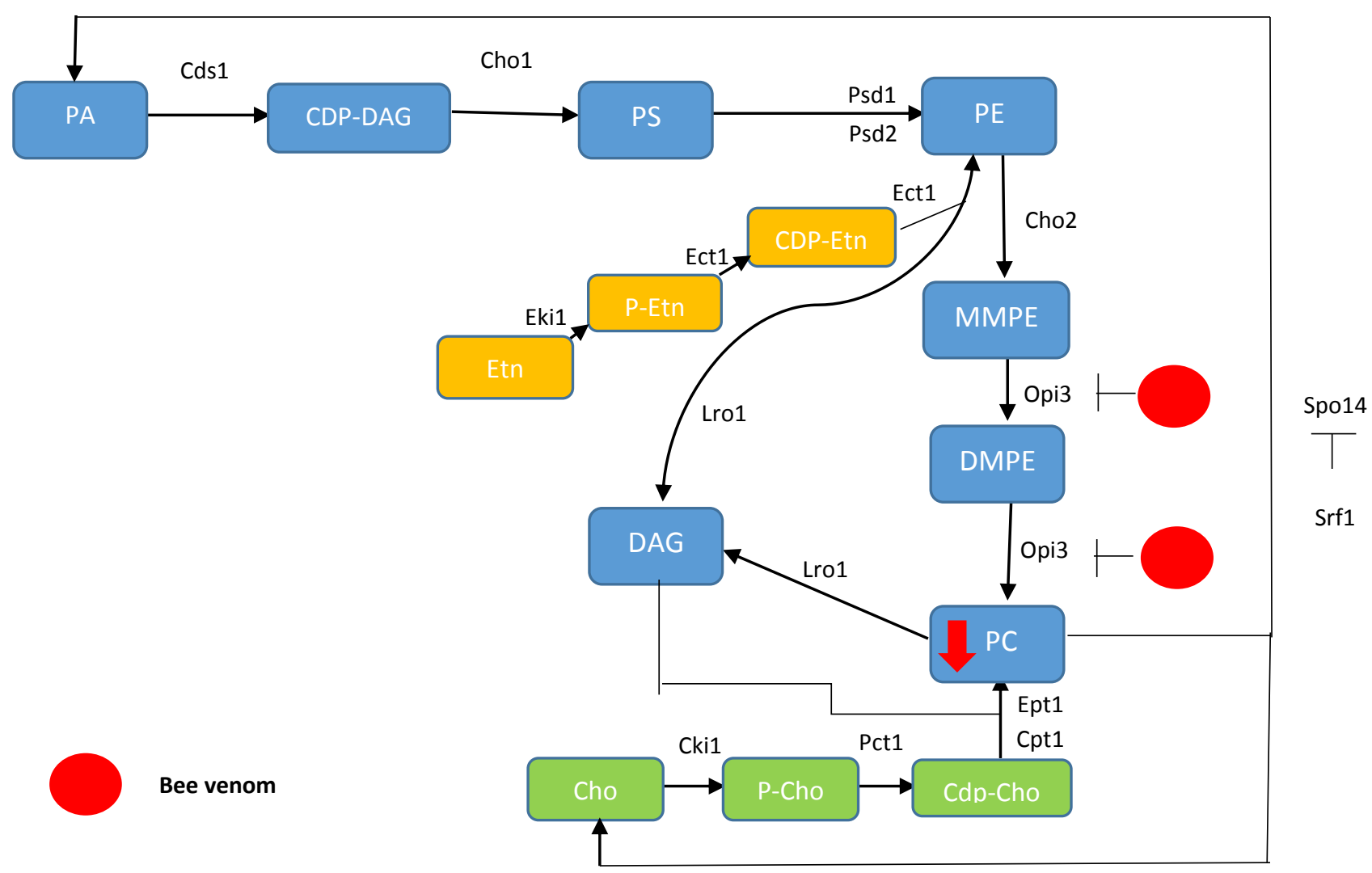

Figure 4.5 Bee venom inhibits PC biosynthesis via Opi3p. PC biosynthesis and salvage network pathways. CDP: Choline diphosphate; DAG: Diacylglycerol; Etn: Ethanolamine; P-Etn: Phosphorylated ethanolamine; Cho: Choline; MMPE: monomethyl-phosphatidylethanolamine; DMPE: Dimethyl-phosphatidylethanolamine

Together, our results indicate that bee venom induces growth inhibition by suppressing PC (Figure 4.6). However, Cki1p, PCt1p, Cpt1p and Ept1p that manufacture CDP-choline and convert it to PC were found not to be suppressed by bee venom (Figure 4.3). This suggests that bee venom does not induce growth inhibition by CDP-choline accumulation. Therefore, the bee venom might simply suppressing yeast growth by means of suppressing the PC-derived secondary messenger molecules or additional pro-survival signals other implicated in cell growth. Alternatively, growth inhibition may be a consequence of deficient PC 
levels affecting the integrity of the cell membrane. This chapter provides possible mechanisms to explain the previous use of bee venom as an antifungal treatment (Yu et al., 2012; Samy et al., 2006; Fennel et al., 1968).

\subsection{Bee pollen results and discussion}

\subsection{Results}

\subsubsection{Methanolic fraction of bee pollen showed greater inhibition compared to} crude fraction in broth and agar media

The methanolic fraction of bee pollen showed greater potency than the crude fraction in both liquid and agar media (Figure 5.1). The highest concentration of crude pollen ( $2 \% \mathrm{v} / \mathrm{v}$ ) yielded $80 \%$ growth inhibition, while $0.25 \%$ $v / v$ of the methanolic extract yielded $100 \%$ growth inhibition. In contrast, the crude extract of the bee pollen was not bioactive at any concentration in agar (Figure 5.2.). We thus determined to use $2 \% \mathrm{v} / \mathrm{v}$ of the methanolic extract of bee pollen, a concentration that inhibited growth in 1536-yeast array agar by $10 \%$ of his $3 \Delta$ to screen the genome-wide libraries of mutant strains in agar. 
(A)
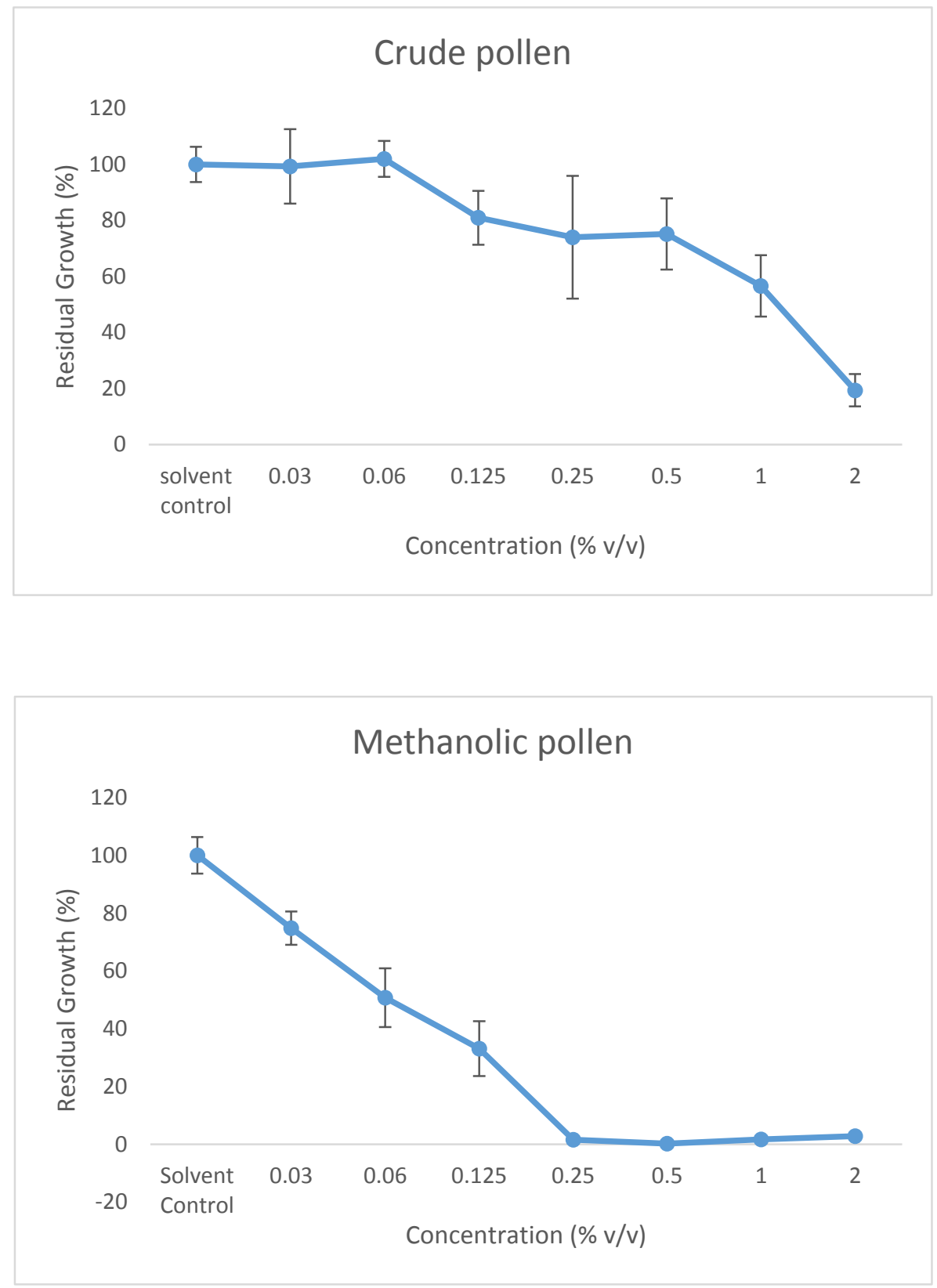
(B)

\section{Crude pollen}

Methanolic pollen

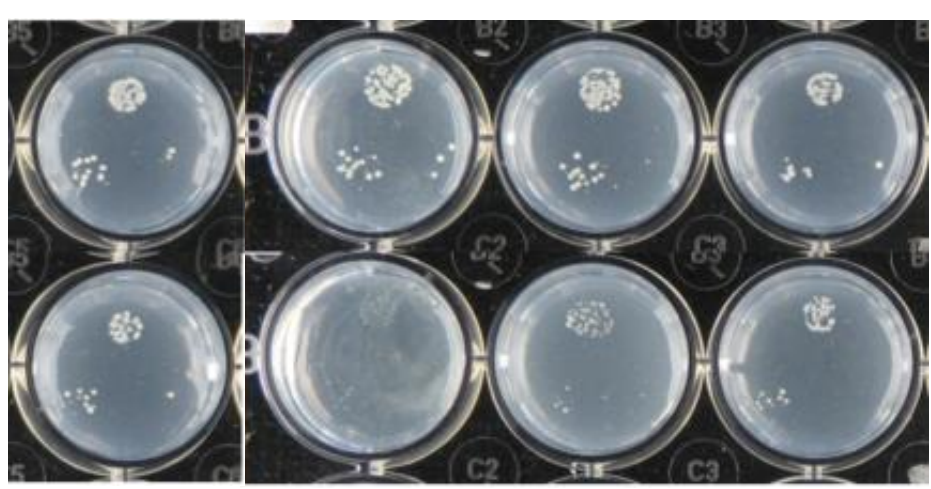

$\begin{array}{lccc}\text { Solvent } & 2 \% & 1 \% & 0.5 \% \\ \text { Control } & \text { pollen } & \text { pollen } & \text { pollen }\end{array}$

Figure 5.1.(A) Residual growth of crude and methanolic fraction of pollen under different concentrations. Residual growth was measured 16 hours after yeast inoculation. (B) Agar dose response of pollen in $500 \mu \mathrm{l} \mathrm{SCH}+$ pollen. Image was taken 48 hours after yeast inoculation.

\subsubsection{Bee pollen agar screen did not show any biological process enrichment}

Of the $\sim 4300$ deletions mutant strains, only 3 deletion strains were validated as being significantly inhibited by bee pollen; bem $1 \Delta$, swi $4 \Delta$ and tef $4 \Delta$ (Appendix Table B.3.1). From the DAmP library of 838 knockdown mutant strains, bee pollen treatment significantly inhibited growth of 10 strains; Yrb2-DAmP, Sec11-DAmP, Prp40-DamP, Sec4-DAmP, Cdc7-DAmP, Cft1-DAmP, Vrf4-DAmP, Rpc17-DAmP, Ctf13-DAmP, Rnt1-DAmP (Appendix Table B.3.2). Based on Gene Ontology (GO) enrichment analyses of these 13 genes using YeastMine, there was not enrichment for any process or pathway of the three deletion genes; however, the top three DAmP genes were enriched for the regulation of chromatin silencing 
at telomere, regulation of chromatin silencing and regulation of gene silencing. To explore further categorisation, we utilised yeast GO-SLIM Mapper (www.yeastgenome.org) to categorise each of our positives and group them in broad categories. We found that 7 out of 13 genes were involved in unique processes, while three genes were involved in mitotic cell cycle and three additional genes were involved in mRNA processing (Figure 5.2). Similar to the case of bee venom, we decided to explore the biological process of the mutant gene that was most hypersensitive to bee pollen, VRG4-DAmP. This gene is involved in GDP-mannose transport (Dean, Zhang, \& Poster, 1997) along with Gda1, Psa1 and Sec53 (Caspi, 2007).

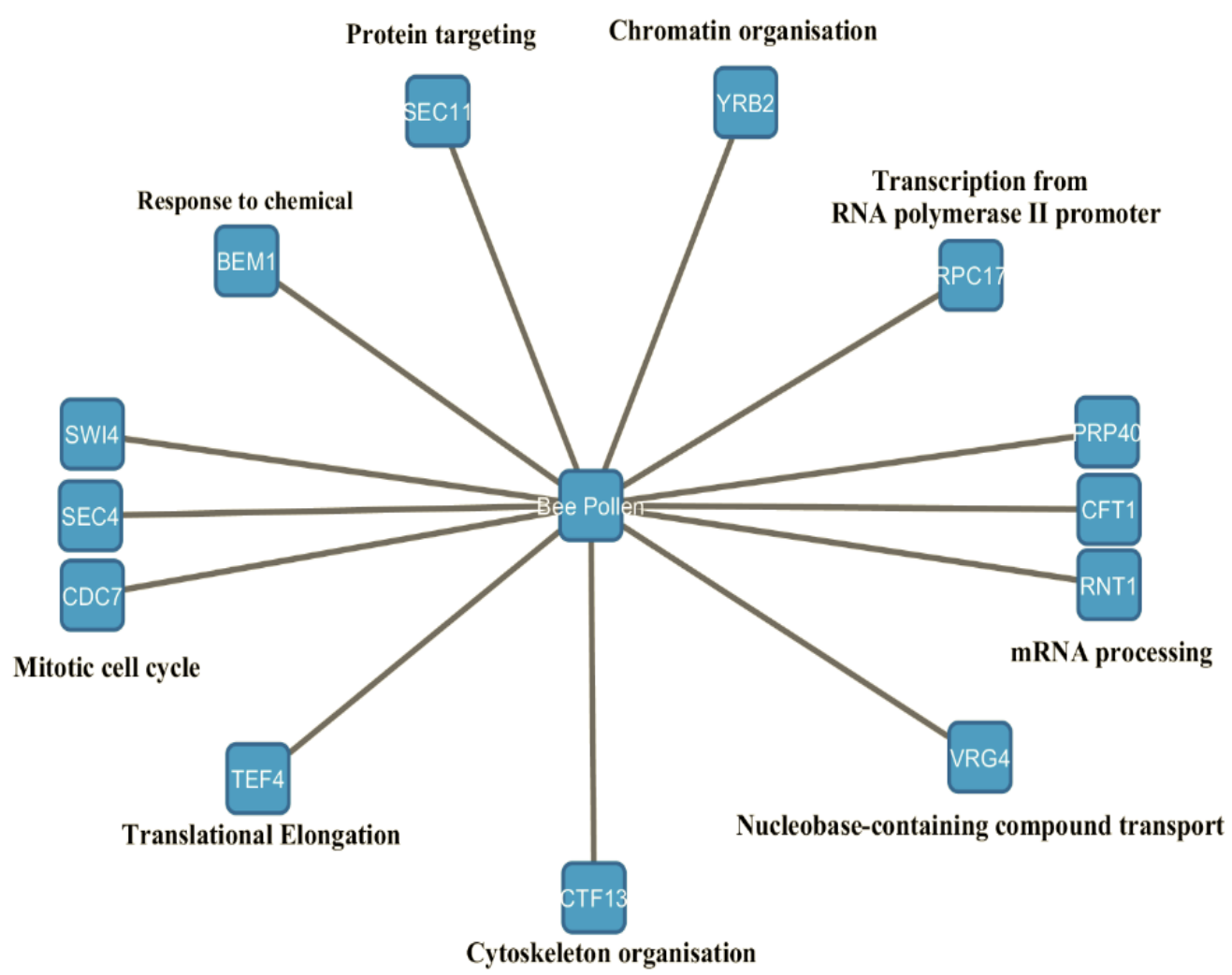


Figure 5.2 categorisation of all positive from bee pollen screening. The network was made using Cytoscape (Cline, et al., 2007)

\subsubsection{Broth dose response analysis of GDP-mannose biosynthesis and transport} deletion mutant strains indicates hypersensitivity in another GDP-mannose transport gene

To investigate the activity of bee pollen on GDP-mannose transport, we evaluated the growth of mutants impaired in GDP-mannose biosynthesis ( $p s a 1 \Delta$, gda1 $\Delta$ and Vrg4-DAmP). Sec53 gene was not included as it was unavailable from our homozygous deletion and DAmP library. At $0.125 \% \mathrm{v} / \mathrm{v}$ of bee pollen, we found that Vrg4-DAmP and gda1 $\Delta$ exhibited hypersensitivity compared to BY4741 whereas psa1 $\Delta$ showed no sensitivity at all (Figure 5.3,Table 2); these results are in agreement with our identification of $\mathrm{Vrg}$ 4-DAmP being hypersensitive in our genome-wide screen .

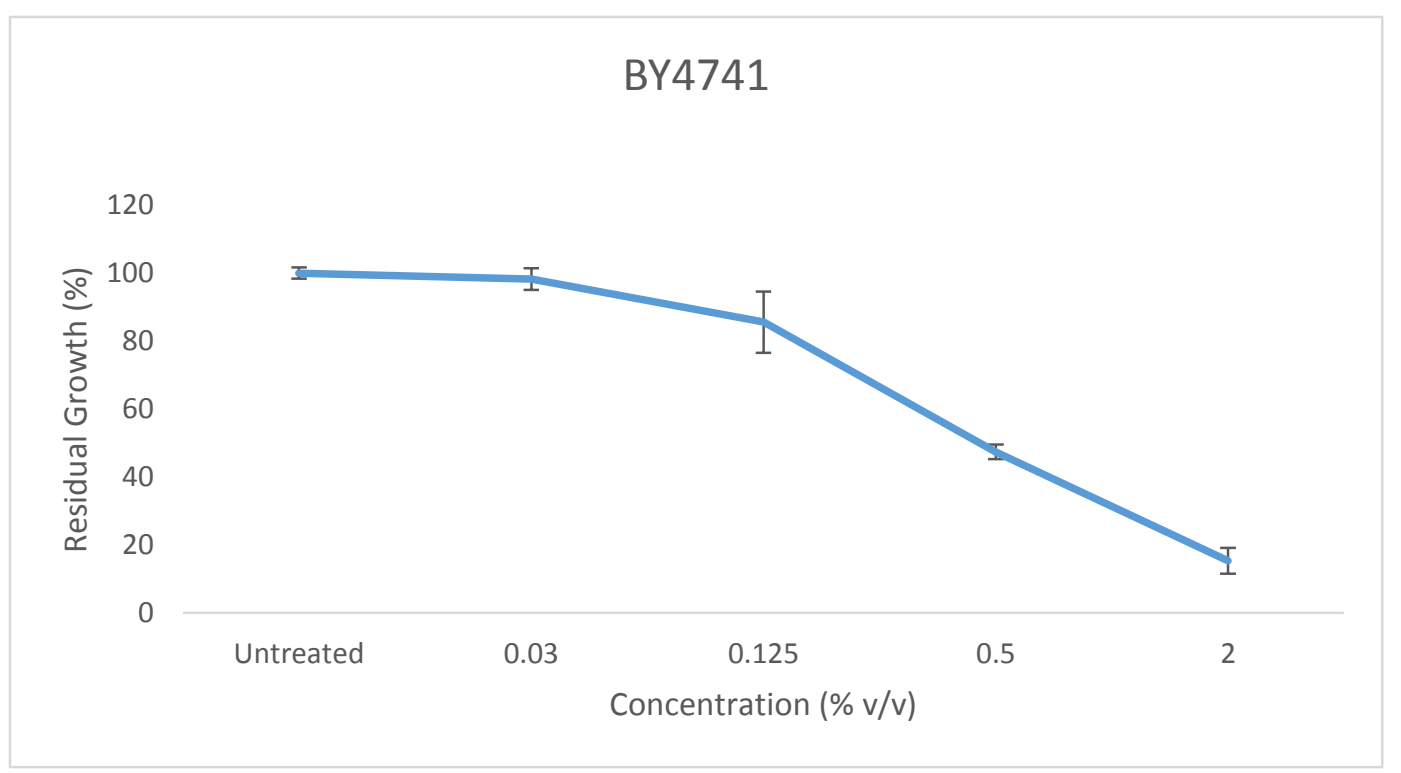



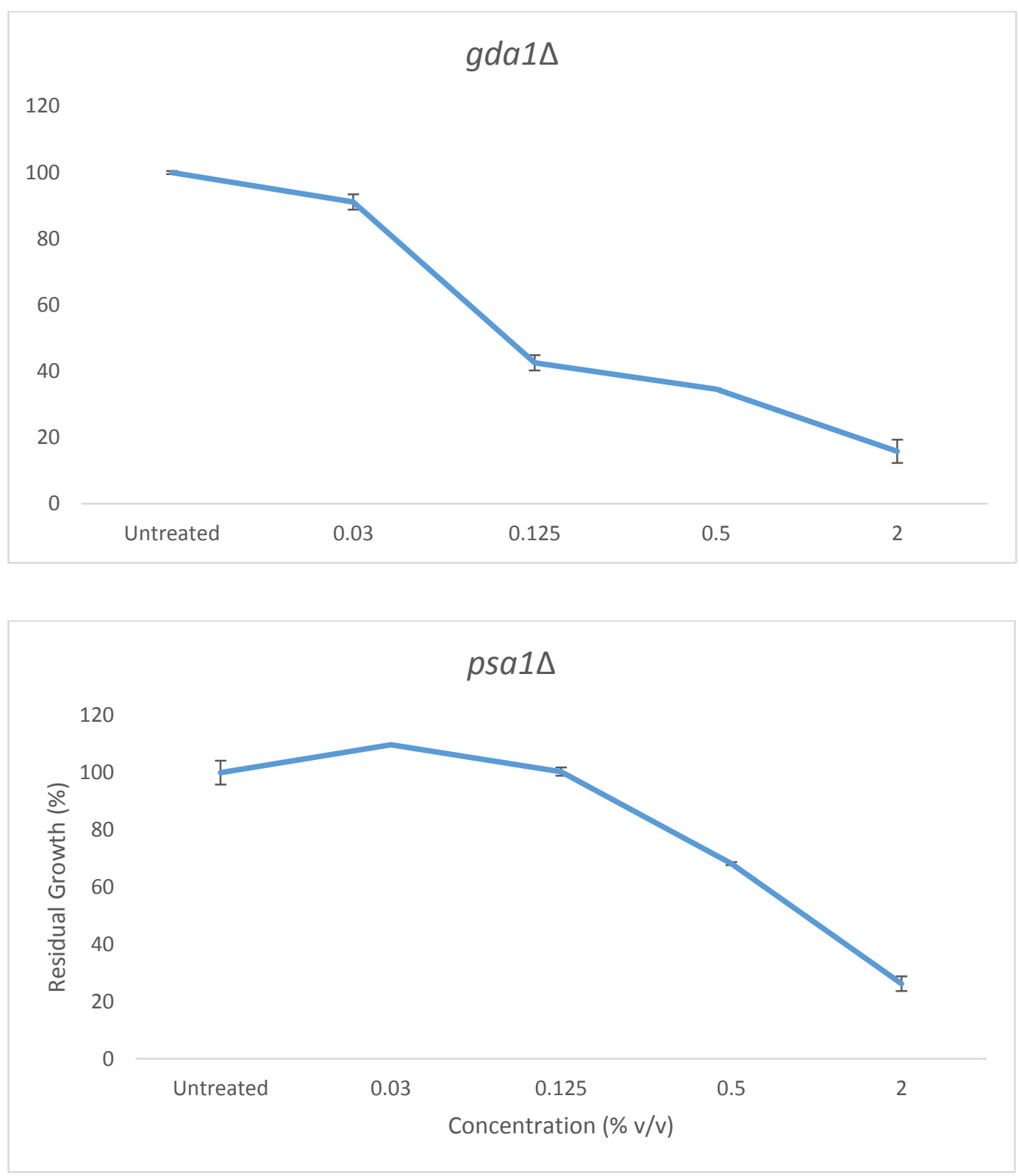


\section{Vrg4-DAmP}

120

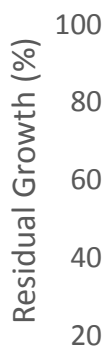

0

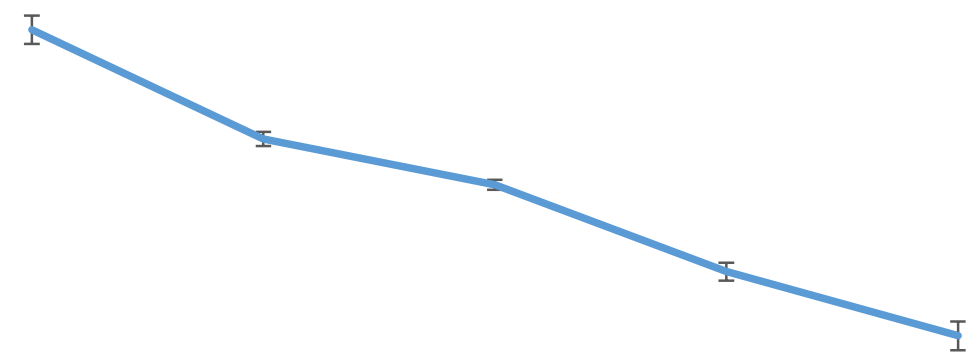

Untreated

0.03

0.125

0.5

2

Concentration (\% v/v)

Figure 5.3. Broth dose response assay of GDP-Mannose transport deletion mutants. The residual growth was calculated based on absorbance $\left(\mathrm{OD}_{590}\right)$ reading at $16^{\text {th }}$ hour

\begin{tabular}{|c|c|c|c|c|}
\hline \multirow{2}{*}{} & \multicolumn{4}{|c|}{ Residual Growth (\%) } \\
\cline { 2 - 5 } & $\Delta g d a 1$ & $\Delta p s a 1$ & Vrg4-DAmP & BY4741 \\
\hline $0.03 \%$ Pollen & 91.06 & 103.76 & 71.92 & 98.23 \\
\hline $0.125 \%$ Pollen & 42.55 & 100.36 & 60.19 & 85.58 \\
\hline $0.5 \%$ Pollen & 34.61 & 68.17 & 37.85 & 47.38 \\
\hline $2 \%$ Pollen & 15.81 & 26.22 & 21.37 & 15.36 \\
\hline
\end{tabular}

Table 2. Tabulated residual growth values of select strains under bee pollen treatment bee venom after 16 hour inoculation. 


\subsubsection{Opera image analysis of yeast GFP for GDP-mannose biosynthesis and transport strains indicates no changes in GFP fluorescence with bee pollen treatment}

To investigate the effect of pollen on the expression levels of proteins in the synthesis and transport of GDP-mannose, we treated Vrg4p-GFP, Gda1p-GFP, Sec53-GFP and Psa1p-GFP strains with two concentrations of bee pollen $(0.5 \%$ $\mathrm{v} / \mathrm{v}, 2 \% \mathrm{v} / \mathrm{v})$. We increased the dosage of bee pollen from $0.125 \% \mathrm{v} / \mathrm{v}$ in the previous 24 hour growth analysis since the GFP assay requires a more brief incubation with the bee venom (5 hours). We observed no significant changes in GFP intensity and no observable changes in localisation in all four GFP strains (Figure 5.4). Vrg4p-GFP, Gda1p-GFP and Sec53p-GFP all showed punctate fluorescence indicative of Golgi body localisation in both solvent control and also the two different bee pollen concentrations (Figure 5.4A-C). Psa1p-GFP showed fluorescence throughout the cells in control and pollen-treated media (Figure 5.4D). These results suggest that the bioactivity of bee pollen was achieved by either targeting buffering pathways that are essential under absence of Gda1p or downregulation of $\mathrm{Vrg} 4 \mathrm{p}$ or inhibiting activity of the $\operatorname{Vrg} 4 \mathrm{p}$ without altering the expression level and localisation of the protein. 
(A)

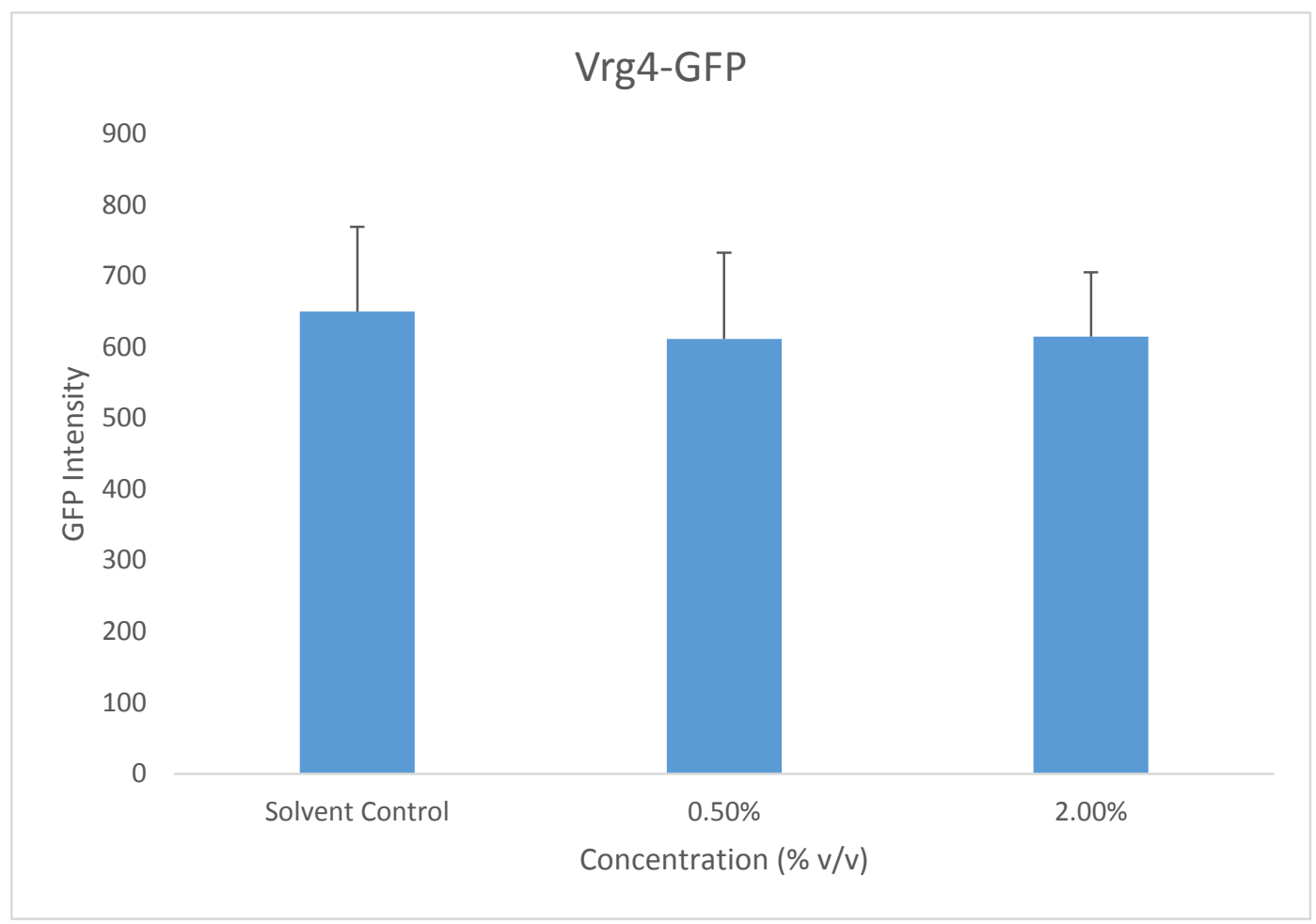

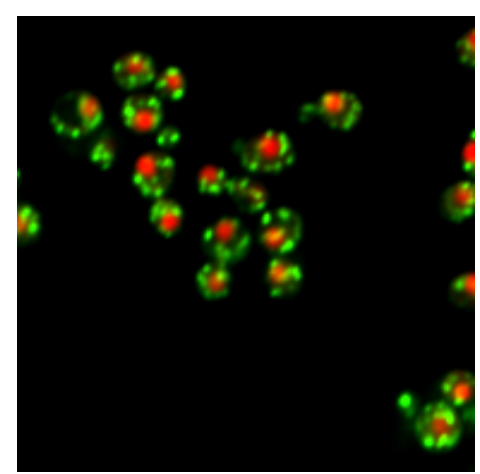

Solvent control

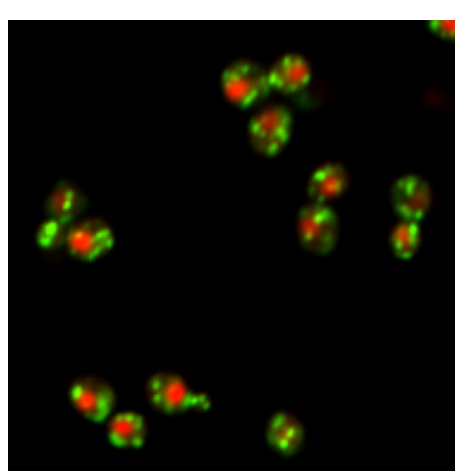

$0.5 \% \mathrm{v} / \mathrm{v}$

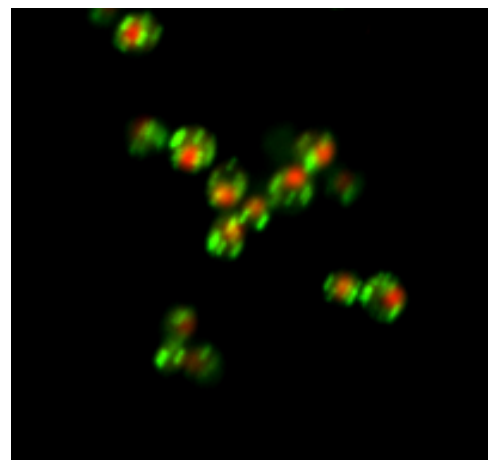

$2 \% \mathrm{v} / \mathrm{v}$ 
(B)
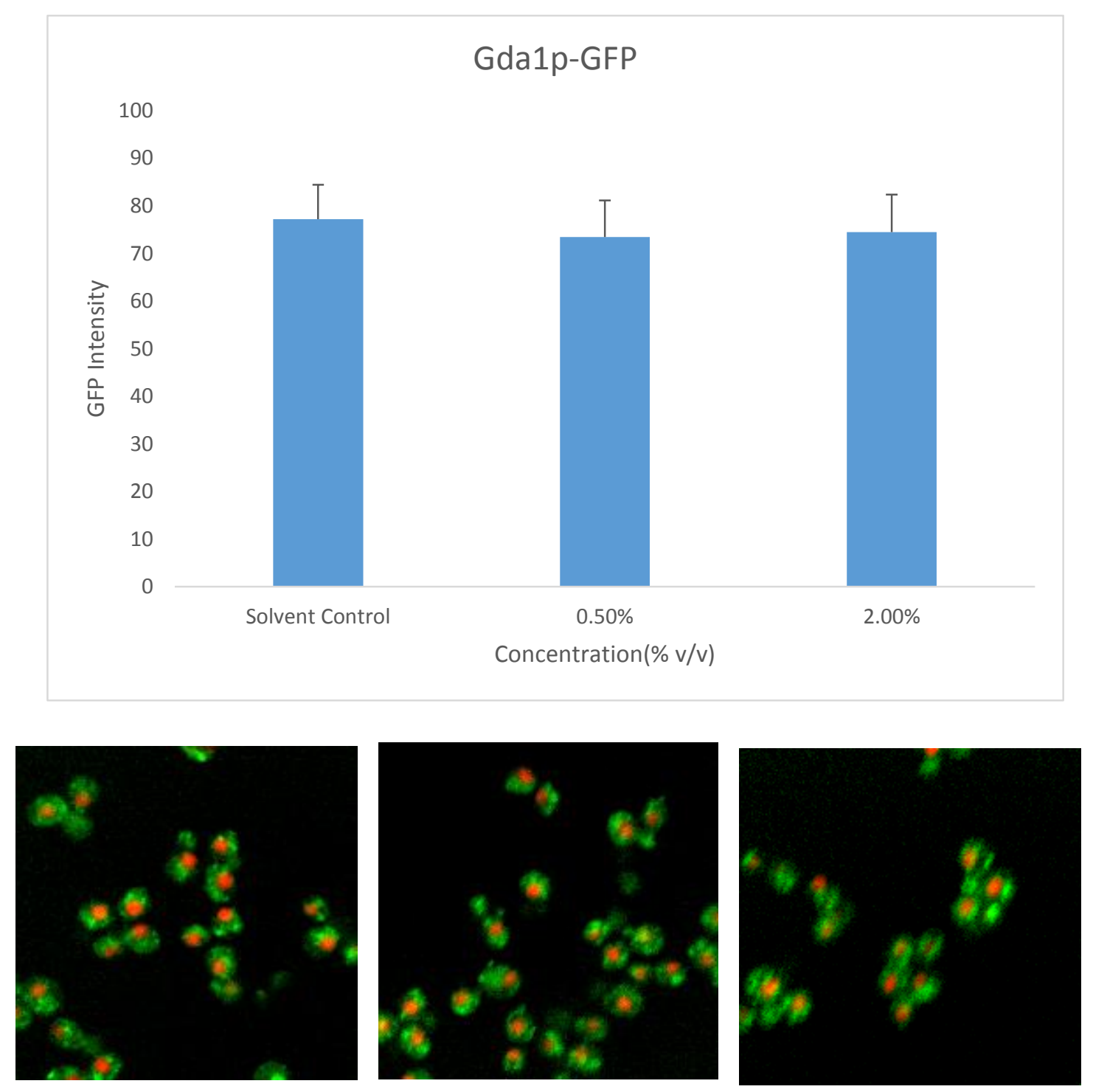

Solvent control

$0.5 \% \mathrm{v} / \mathrm{v}$

$2 \% \mathrm{v} / \mathrm{v}$ 
(C)

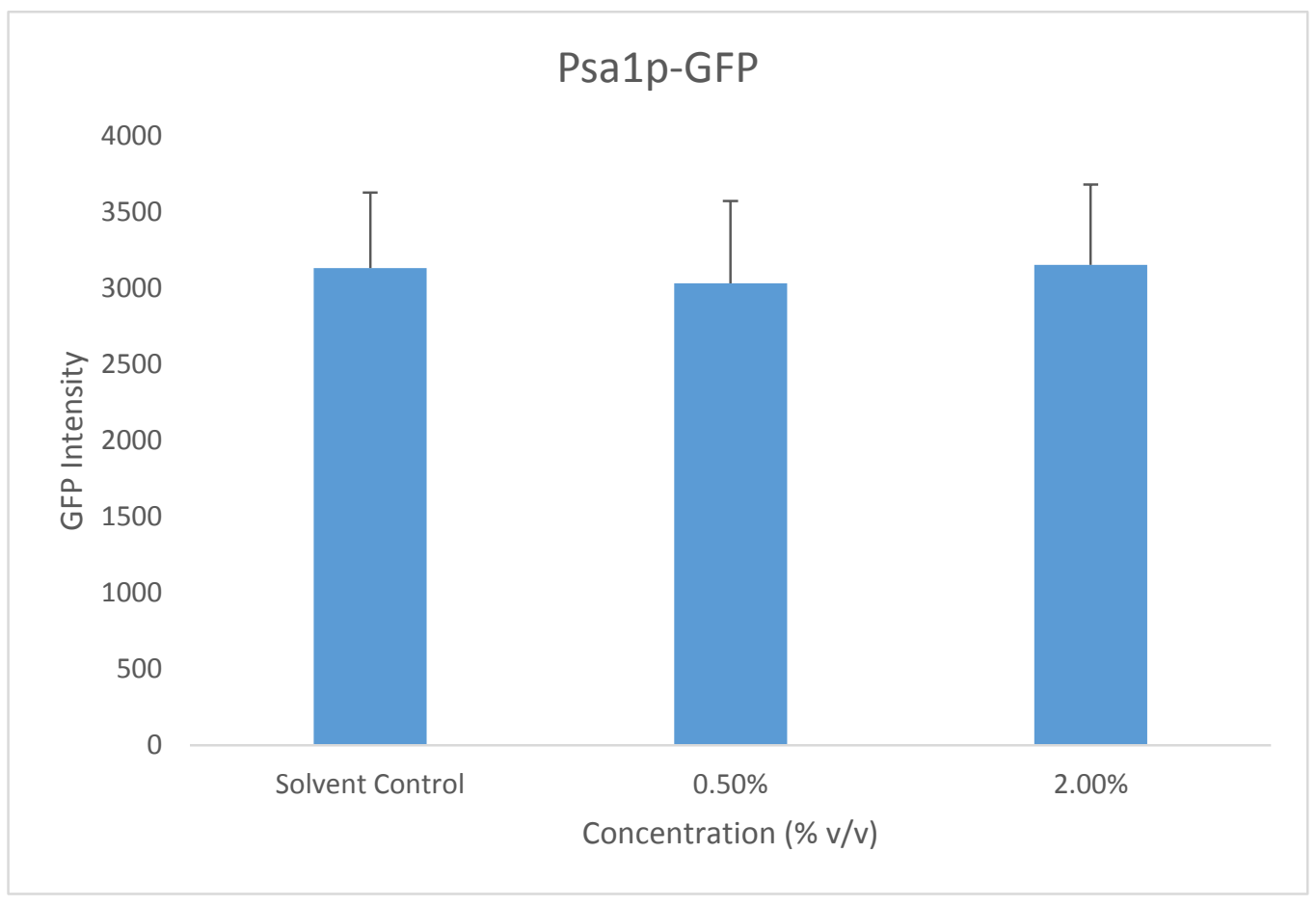

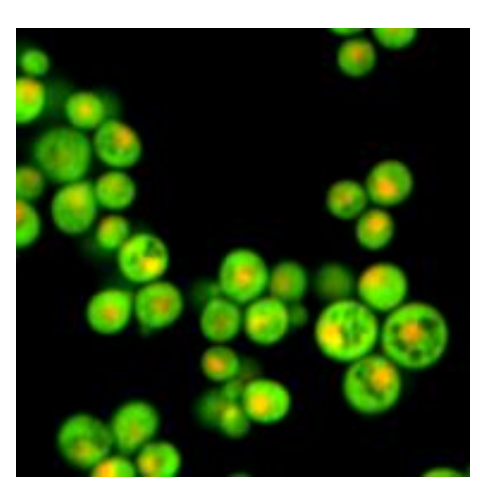

Solvent control

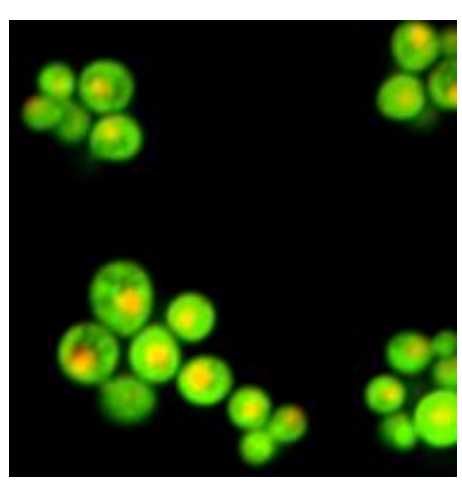

$0.5 \% \mathrm{v} / \mathrm{v}$

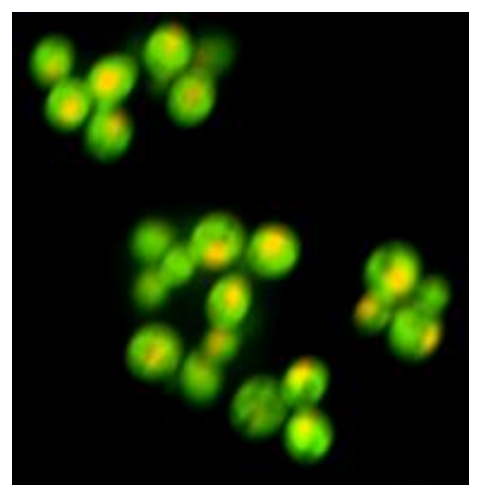

$2 \% \mathrm{v} / \mathrm{v}$ 
(D)

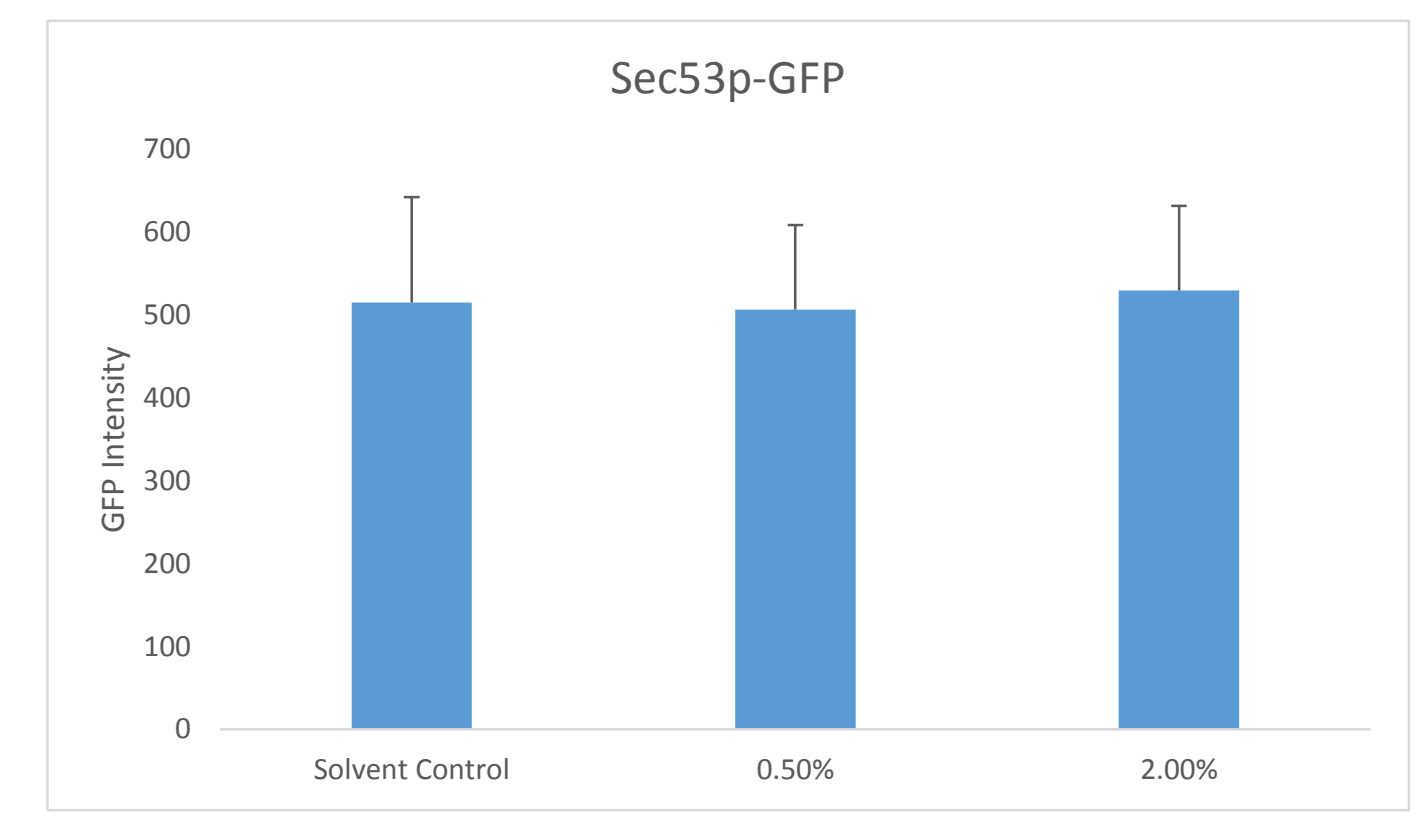

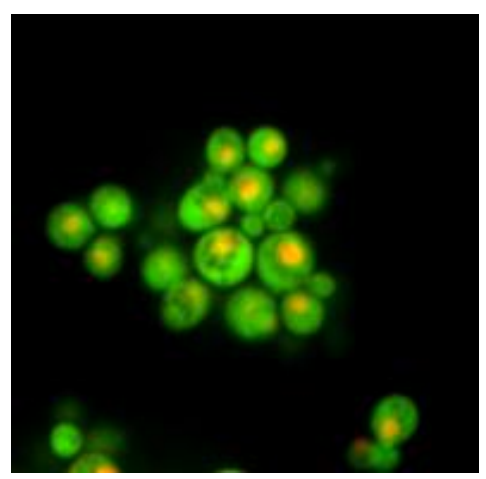

Solvent control

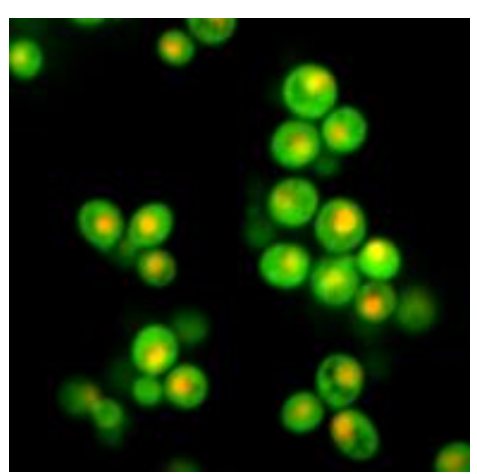

$0.5 \% \mathrm{v} / \mathrm{v}$

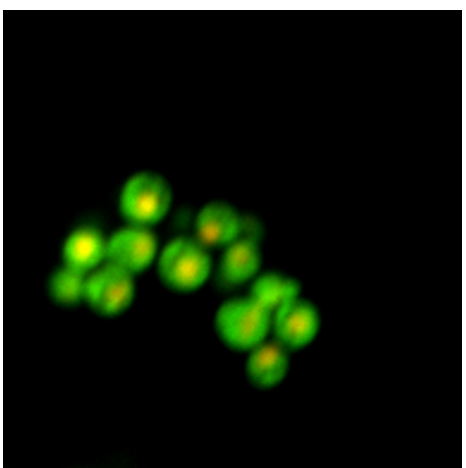

$2 \% \mathrm{v} / \mathrm{v}$

Figure 5.4 GFP intensity measurement and localisation analysis of GDP-mannose transport and biosynthesis proteins indicate that there is no changes of GFP intensity and localisation.
(A) Vrg4p-GFP
(B) Gda1p-GFP
(C) Psa1p-GFP
(D) Sec53p-GFP 


\subsection{Discussion}

Bee pollen showed greater bioactivity in the methanolic fraction compared to the crude fraction. Screening of bee pollen against both our deletion library collection and DAmP library collection elucidated that the bioactivity of bee pollen occurs via nine processes, most notably via GDP-mannose biosynthesis based on the $\mathrm{Vrg} 4-\mathrm{DAmP}$ and gda1 $\Delta$ strains being sensitive to $0.125 \% \mathrm{v} / \mathrm{v}$ bee pollen, a concentration that is less than the $2 \% \mathrm{v} / \mathrm{v}$ concentration used in the genome-wide analyses.

GDP-mannose is an essential component for cells to modify proteins and lipids through $\mathrm{N}$-linked and O-linked glycosylation. $\mathrm{Vrg} 4 \mathrm{p}$ essential in regard to GDP-mannose because Vrg4p acts as GDP-mannose transporter that brings in GDP-mannose from the site of synthesis at the cytoplasm into the Golgi lumen (Dean et al., 1997). These glycosylation steps modify proteins resulting in specificity in activity and stability in structure (Herscovic \& Orlean, 1993), which are necessary to give proteins and lipids GDP-mannose is made by the precursor form $\alpha$-D-mannose 6 -phosphate that is then acted upon by Sec53p phosphomannomutase and Psa1p GDP-mannose pyrophosphorylase to synthesise GDP- $\alpha$-D-mannose (Herscovic \& Orlean, 1993). Golgi body acquire GDPmannose through the exchange of GMP as anti-porter which the latter is made available through the activity of Gda1p GDPase that breaks down GDP into GMP in Golgi lumen (Abeijon et al., 1993; Berninsone et al., 1994). Absence of Vrg4p or GDA1p expression were both implicated in reduction in glycosylated proteins and lipids (Abeijon et al., 1993; Dean et al.1997). 
(A)

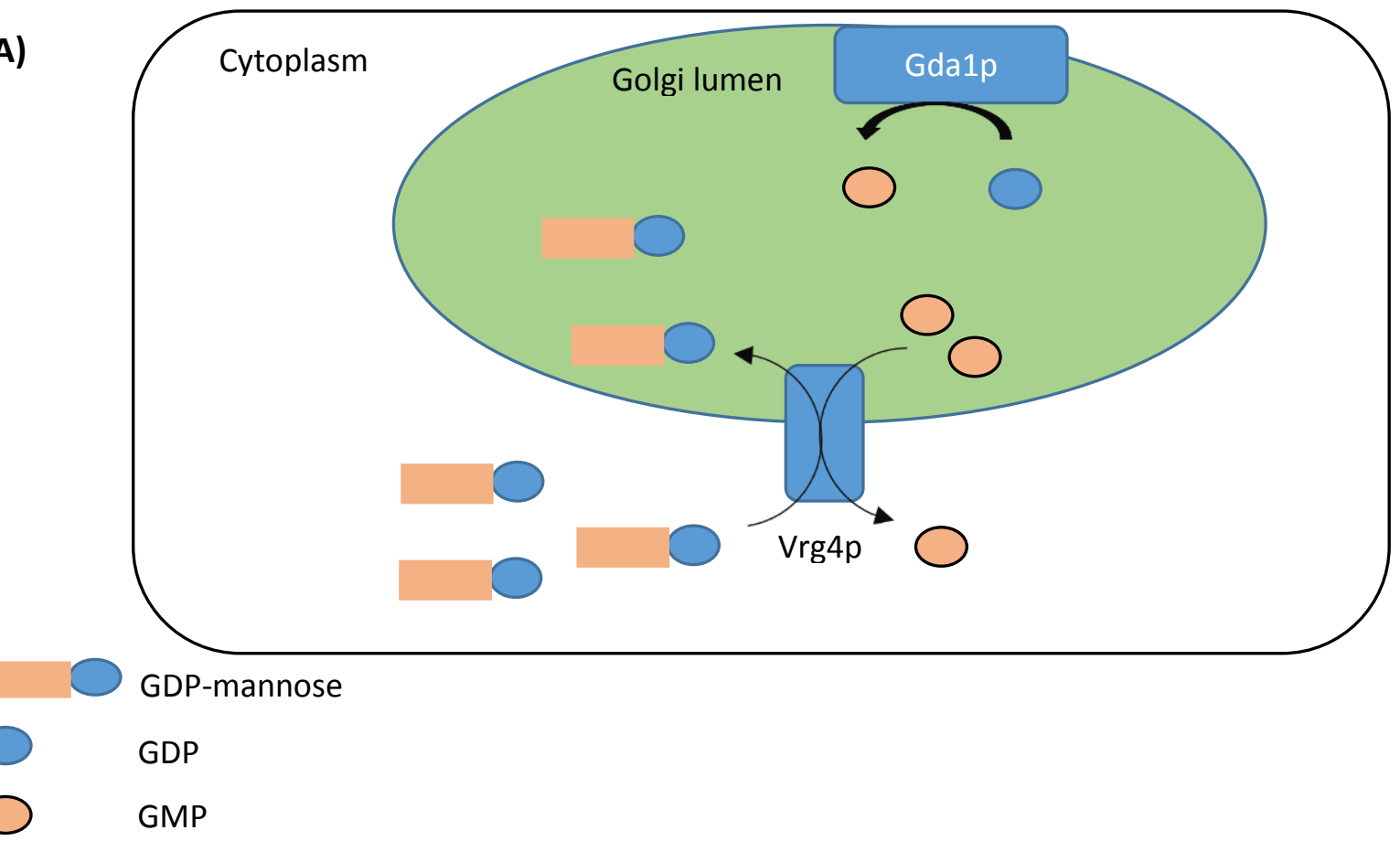

(B)

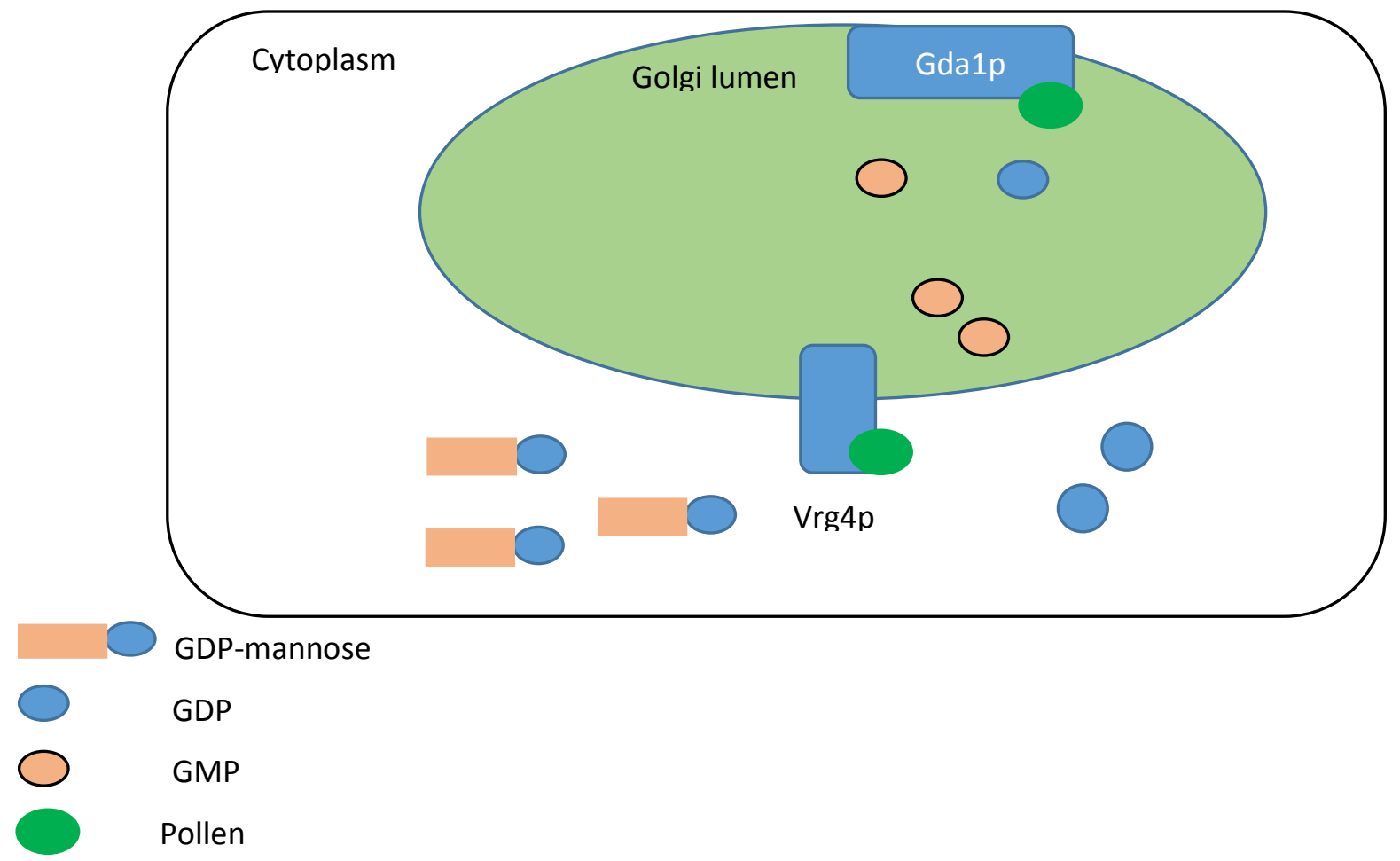

Figure 5.5 Bee pollen interferes GDP-mannose transport by blocking Vrg4p or Gda1p activity (A) GDP-mannose transport under normal conditions. (B) Bee pollen inhibits GDP- 
mannose transport either via blocking the $\operatorname{Vrg} 4 \mathrm{p}$ transporter or inhibiting the Gda1p enzyme from breaking down GDP to GMP.

Our results indicate the sensitivity of the mutant strains that are necessary for GDP-mannose transport but not for biosynthesis. Since we identified that growth of Vrg4p and Gda1p mutants were sensitive to bee pollen and that this growth inhibition did not include changes in the localization or expression levels of these proteins, I propose that the bee pollen interferes with the activity of Vrg4p, possibly by preventing the binding of GDP-mannose or GMP to Vrg4p (GDPmannose transporter) or by inhibiting the binding of GDP to Gda1p (GDPase) (Figure 5.5). In both cases, GDP-mannose cannot be delivered effectively into Golgi lumen which impairs the glycosylation process. Deficiency of glycosylation would then lead to inviability of yeast. However, the effects of bee pollen on protein and lipid glycosylation were not directly examined in this study.

\section{Overall conclusions and future directions}

\subsection{Overall conclusions}

The aim of this thesis was to elucidate the biological pathways affected by the activity of propolis, bee venom and bee pollen. This thesis utilised the deletion library of 4,100 nonessential genes, the DAmP knockdown library of 838 essential genes, and select GFP strains to identify specific genes and proteins that are targets of these bee products. 
In chapter 3, propolis had shown an enrichment for iron ion transport from the initial primary screen of the deletion and DAmP libraries. From there on, we conducted follow up dose responses with various metal ion supplementation and also conducted GFP fluorescence analysis to elucidate genes and proteins that are targets of propolis in inducing iron deprivation. The iron chelating bioactivity of propolis was not previously reported.

In contrast, the results of the genome-wide analyses of bee venom bioactivity in chapter 4 did not show an enrichment for any biological process or pathway. I thus chose to further investigate the most hypersensitive strain, $\operatorname{srf1\Delta }$. I determined that bee venom selectively targets Opi3p, a protein that catalyses the final two steps of PC biosynthesis. As PC homeostasis has not been previously reported as a target of bee venom, my results demonstrate that, despite lack of GO enrichment in the genome-wide analyses, it remains feasible to discover and characterise novel biological targets of a natural compound.

Similarly, the genome-wide analysis of bee pollen did not result in enrichment for any particular biological process. We instead chose one particular process required for normal growth in bee pollen-treated cells, GDP-mannose transport, for further investigation. Since we determined that normal GDP-mannose transport was required for normal growth in bee pollen-treated cells without any changes in expression levels of GDP-mannose transport proteins, we propose that GDP-mannose transport is a buffering mechanism targeted by bee pollen. 


\subsection{Future directions}

There are a number of possibilities from our work on propolis, bee venom and bee pollen that would be useful for further investigation. In the case of propolis, the role of zinc in causing greater hypersensitivity to deletion mutant strains has not been investigated. In the case of bee venom, it would be interesting to investigate the possible effect of bee venom on Lro1p and other lipid intermediates salvaged from PC such as DAG and PA (Ejsing, et al., 2009). In the case of bee pollen, it is critical to further investigate the possible buffering network involving GDP-mannose homeostasis. In addition, there are other biological processes and pathways that were implicated to be affected by the bee products in my genome-wide analyses. Furthermore, as explained in chapter 1, different regions have different compositions and thus may possess different biological activities. We indeed observed this when our propolis showed different biological process enrichment compared to Castro group (2011). Also, this thesis explored the bee products as a mixture instead of its respective constituents. Although this is justified as these products are consumed as raw as it is, we could gain insights on which of its components attributed to its biological activities and hence characterise them. However, given the time constraint of my thesis, I was not able to further investigate these processes. 


\section{References}

Abeijon, C., Yanagisawa, K., Mandon, E. C., Hausler, A., Moremen, K., Hirschberg, C., \& Robbins, P. (1993). Guanosine Diphosphatase Is Required for Protein and Sphingolipid Glycosylation in the Golgi Lumen of Saccharomyces cerevisiae. Journal of Cell Biology, 122(2), 307-323.

Ahn, M.-R., S. K., Hamasaka, T., Bang, K.-S., \& Nakayama, T. (2004). Antioxidant Activity and Constituents of Propolis Collected in Various Areas of Korea. Journal of Agricultural and Food Chemistry, 101(4), 7286-7292. doi:10.1021/jf048726s

Alkhateeb, F. (2014). Lost Islamic History; Reclaiming Muslim Civilisation from the Past. London: Hurst Publishers.

Ashburner, M., Ball, C. A., Blake, J. A., Botsetein, D., Butler, H., Cherry, J. M., . . Sherlock, G. (2000). Gene Ontology: tool for the unification of biology. Nature Genetics, 25(1), 25-29. doi:10.1038/75556

Askwith, C., \& Kaplan, J. (1998). Iron and copper transport in yeast and its relevance to human disease. Trends in biochemical sciences, 23(4), 135-138. doi:10.1016/S0968-0004(98)01192-X

Balakrishnan, R., Park, J., Karra, K., Hitz, B. C., Binkley, G., Hong, E. L., . . Cherry, J. M. (2012). YeastMine-an integrated data warehouse for Saccharomyces cerevisiae data as a multipurpose tool-kit. Database (Oxford), bar062, bar062. doi:10.1093/database/bar062

Berninsone, P., Miret, J. J., \& Hirschberg, C. B. (1994). The Golgi Guanosine Diphosphatase Is Required for Transport of GDP-Mannose into the Lumen of Saccharomyces cerevisiae Golgi Vesicles. The Journal of Biological Chemistry, 269(1), 207-2011.

Bircham, P. W., Maass, D. R., Roberts, C. A., Kiew, P. Y., Low, Y. S., Yegambaram, M., . . Atkinson, C. A. (2011). Secretory pathway genes assessed by high-throughput microscopy and synthetic genetic array analysis. Molecular Biosystems, 7(9), 2589-2598. doi:10.1039/c1mb05175

Birner, R., Burgermeister, M., Schneiter, R., \& Daum, G. (2001). Roles of Phosphatidylethanolamine and of Its Several Biosynthetic Pathways in Sacchamromyces cerevisiae. Molecular Biology of the Cell, 12(4), 997-1007. doi:10.1091/mbc.12.4.997

Blaiseau, P.-L., Lesuisse, E., \& Camadro, J.-M. (2001). Aft2p, a Novel Iron-regulated Transcription Activator That Modulates with Aft1p, Intracellular Iron Use and Resistance to Oxidative Stress in Yeast. The Journal of Biological Chemistry, 276(36), 34221-34226. doi:10.1074/jbc.M104987200

Bogdanov, S. (2014, February). Pollen: Production, Nutrition and Health: A Review. Retrieved from Bee-Hexagon: www.bee-hexagon.net/files/file/fileE/Health/PollenBook2Review.pdf

Borchardt, J. (2002). The Beginnings of Drug Therapy. Drug ews Perspectives, 15(3), 187-192.

Breslow, D. K., Cameron, D. M., Collins, S. R., Schuldiner, M., Stewart-Ornstein, J., Newman, H. W., ... Weissman, J. S. (2008). A comprehensive strategy enabling high-resolution functional analysis of the yeast genome. Natural Methods, 5(8), 711-718.

Breslow, D. K., Cameron, D. M., Collins, S. R., Schuldiner, M., Stewart-Ornstein, J., Newman, H. W., ... Weissman, J. S. (2008). A comprehensive strategy enabling high-resolution functional analysis of the yeast genome. Nature Methods, 5(8), 711-718. doi:10.1038/nmeth.1234

Brown, R. (1989). Hive Products: pollen, propolis and royal jelly. Bee World , 70(3), 109-117. 
Bruno, G. (2005). Bee Pollen, Propolis and Royal Jelly. Retrieved from Huntington College of Health Sciences: www.hchs.edu/literature/Bee_\%20Pollen-Propolis-and-Royal_Jelly.pdf

Campos, M. G., Bogdanov, S., Almeida-Muradian, L. B., Szczesna, T., Mancebo, Y., Frigerio, C., \& Ferreira, F. (2008). Pollen composition and standardisation of analytical methods. Journal of Apicultural Research and Bee World, 47(2), 156-163. doi:10.3896/IBRA.1.47.2.12

Carter, A., Middleton, R., Adams, L., Hill, S., Kellam, B., Mumtsidu, E., .. Burgeon, E. (2008). Cell Aura Resource Details. Retrieved from Cell Aura: http://www.cellaura.com/resourcedetails/69/index.html

Caspi, R. (2007). BIOCYC Database collection. Retrieved 12 27, 2014, from http://biocyc.org/YEAST/NEW-IMAGE?type=PATHWAY\&object=PWY-5659

Castaldo, S., \& Capasso, F. (2002). Propolis, an old remedy used in modern medicine. Fitoterapia, 73(Supplement 1), S1-S6. doi:10.1016/S0367-326X(02)00185-5

Castro, P. A., Marcela, Savoldi, Bonatto, D., Barros, M. H., Goldman, M. h., ... Goldman, G. H. (2011). Molecular Characterization of Propolis-Induced Cell Death in Saccharomyces cerevisiae. Eukaryotic Cell, 10(3), 398-411. doi:10.1128/EC.00256-10

Cline, M. S., Smoot, M., Cerami, E., Kuchinsky, A., Landys, N., Workman, C., . . Lotia, S. (2007). Integration of biological networks and gene expression data using Cytoscape. Methods in Molecular Biology, 1021, 2366-2382. doi:10.1038/nprot.2007.324

Courel, M., Lallet, S., Camadro, J.-M., \& Blaiseau, P.-L. (2005). Direct Activation of Genes Involved in Intracellular Iron Use by the Yeast Iron-Responsive Transcription Factor Aft2 without Its Paralog Aft1. Molecular and Cellular Biology, 25(15), 6760-6771. doi:10.1128/MCB.25.15.6760-6771.2005

Cragg, G. M., \& Newman, D. J. (2013). Natural Products: A continuing source of novel drug leads. Biochimica et Biophysica Acta, 1830(6), 3670-3695. doi:10.1016/j.bbagen.2013.02.008

Cui, Z., Houweling, M., Chen, M. H., Record, M., Chap, H., Vance, D. E., \& Terce, F. (1996). A Genetic Defect in Phosphatidylcholine Biosynthesis Triggers Apoptosis in Chinese Hamster Ovary Cells. Journal of Biological Chemistry, 271(25), 14668-14671. doi:10.1074/jbc.271.25.14668

Dean, N., Zhang, Y. B., \& Poster, J. B. (1997). The VRG4 Gene Is Required for GDP-mannose Transport into the Lumen of the Golgi in the Yeast, Saccharomyces cerevisiae. The Journal of Biological Chemistry, 272(50), 31908-31914. doi:10.1074/jbc.272.50.31908

Dieci, G., Preti, M., \& Montanini, B. (2009). Eukaryotic snoRNAs: A paradigm for gene expression flexibility. Genomics, 94(2), 83-88. doi:Eukaryotic snoRNAs: A paradigm for gene expression flexibility

Dittmar, J. C., Reid, R. J., \& Rothstein, R. (2010). ScreenMill: A freely available software suite for growth measurement, analysis and visualisation of high-throughput screen data. $B M C$ Bioinformatics, 1-11.

Dittmar, J., Reid, R., \& Rothstein, R. (2010). ScreenMill: a freely available software suite for growth measurement, analysis and visualization of high-throughput screen data. $B M C$ Bioinformatics, 11:353, 1-11. doi:10.1186/1471-2105-11-353 
Dix, D. R., Bridgham, J. T., Broderius, M. A., Byersdorfer, C. A., \& Eide, D. J. (1994). The FET4 Gene Encodes the Low Affinity Fe(II) Transport Protein of Saccharomyces cerevisiae. The Journal of Biological Chemistry, 269(42), 26092-26099.

Dix, D., Bridgham, J., Broderius, M., \& Eide, D. (1997). Characterisation of the FET4 Protein of Yeast. Evidence for a direct role in the transport of iron. The Journal of Biological Chemitry, 272(18), 11770-11777. doi:10.1074/jbc.272.18.11770

Ejsing, C. S., Sampaio, J. L., Surendranath, V., Duchoslav, E., Ekroos, K., Klemm, R. W., ... Shevchenko, A. (2009). Global analysis of the yeast lipidome by quantitative shotgun mass spectrometry. Proceedings of the National Academy of Sciences of the United States of America, 2136-2141. doi:10.1073/pnas.0811700106

Elbaz, G. A., \& Elsayad, I. I. (2012). Comparison of the Antimicrobial Effect of Egyptian Propolis vs New Zealand Propolis on Streptococcus mutans and Lactobacili in Saliva. Oral Health \& Preventive Dentistry, 10(2), 155-160. doi:10.3290/j.ohpd.a28003

Fatrcova-Sramkova, K., Nozkova, J., Kacaniova, M., Mariassyova, M., Rova, K., \& Stricik, M. (2013). Antioxidant and antimicrobial properties of monofloral bee pollen. Journal of Environmental Science \& Health, 48(2), 133-138. doi:10.1080/03601234.2013.727664.

Fennel, J., Shipman, W., \& Cole, L. (1968). Antibacterial Action of Melittin A polypeptide From Bee Venom. Proceedings of The Society For Experimental Biology and Medicine, 127(3), 707-708. doi:10.3181/00379727-127-32779

Flora, S. J., \& Pachauri, V. (2010). Chelation in Metal Intoxication. International Journal of Environmental Research and Public Health, 7(7), 2747-2788. doi:10.3390/ijerph7072745

Gasull, T., DeGregorio-Rocasolano, N., Enguita, M., Hurtan, J., \& Trullas, R. (2002). Inhibition of phosphatidylchoine synthesis is associated with excitotoxic cell death in cerebellar granule cell cultures. Amino Acids, 23(1), 19-25. doi:10.1007/s00726-001-0104-8

Giaever, G., Shoemaker, D. D., Jones, T. W., Lian, H., Winzeler, E. A., Astromoff, A., \& Davis, R. W. (1999). Genomic profiling of drug sensitivities via induced haploinsufficiency. Nature, 21(3), 278-283. doi:10.1038/6791

Glaever, Guri; Chu, Angel M.; Ni, Li; Connelly, Carla; Riles, Linda; Veronneau, Steeve; Dow, Sally; Lucau-Danilla, Ankuta; Anderson, Keith; Andre, Bruno; Arkin, Adam P.; Astromoff, Anna; Bakkoury, Mohamed El; Bangham, Rhonda; Benito, Rociz; Johnston, M. (2002). Functional profiling Saccharomyces cerevisiae genome. Nature, 418, 387-391. doi:10.1038/nature00935

Glaever, Guri; Flaherty, Patrick; Kumm, Jochen; Proctor, Michael; Nislow, Corey; Jaramillo, Daniel F.; Chu, Angel M.; Jordan, Michael I.; Arkin, Adam P.; Davis, Ronal W.. (2004). Chemogenomic profiling: Identifying the functional interactions of small molecules. Proceedings of the National Academy of Sciences of the United States of America, 101(3), 793-798. doi:10.1073/pnas.0307490100

Han, Sang Mi; Lee, Kwang Gill; Yeo, Joo Hong; Kweon, Hae Yong; Woo, Soon Ok; Lee, Myeong Lyeol; Baek, Ha Ju; Kim, Sun Yeou; Park, Kwan Kyu. (2007). Effect of honey bee venom on microglial cells nitric oxide and tumor necrosis factor-a production stimulated by LPS. Journal of Ethnopharmacology, 111(1), 176-181. doi:10.1016/j.jep.2006.11.008 
Hartman, J. L., Garvik, B., \& Hartwell, L. (2001). Principles for the Buffering of Genetic Variation. Science, 291(5506), 1001-1004. doi:10.1126/science.1056072

Hassett, R., DIX, D. R., EIDE, D. J., \& Kosman, D. J. (2000). The Fe(II) permease Fet4p functions as a low affinity copper transporter and supports normal copper trafficking in Saccharomyces cerevisiae. Biochemical Journal, 351(Pt 2), 477-484.

Herscovic, A., \& Orlean, P. (1993). Glycoprotein biosynthesis in yeast. FASEB, 7(6), 540-550. doi:8472892

Heymann, P., Ernst, J. F., \& Winkelmann, G. (2000). Identification and substrate specficity of a ferrichrome-type siderophore transporter (Arn1p) in Saccharomyces cerevisiae. FEMS Microbiology Letters, 186(2), 221-227. doi:10802175

Huh, W.-K., Falvo, J. V., Gerle, L. C., Carroll, A. S., Howson, R. W., Weissman, J. S., \& O'Shea, E. K. (2003). Global analysis of protein localisation in budding yeast. Nature, 486, 686-691. doi:10.1038/nature02026

Jo, M., Parl, M. H., Kollipara, P. S., An, B. J., Song, H. S., Han, S. B., Kim, J.H., Song, M. J, Hong J.T. (2012). Anti-cancer effect of bee venom toxin and melittin in ovarian cancer cells through induction of death receptors and inhibition of JAK2/STAT3 pathway. Toxicology and Applied Pharmacology, 258(1), 72-81.

Kandaswami, C., \& E. Middleton, J. (1997). Flavonoids as antioxidants. In F. Shahidi, Natural Antioxidants: Chemistry, Health Effects, and Applications (pp. 174-203). Champaign, Illinois: AOCS Press.

Kennedy, M. A., Kabbani, N., Lambert, J.-P., Swayne, L. A., Ahmed, F., Figeys, D., Bennett SA., Bryan J, Baetz K. (2011). Srf1 Is a Novel Regulator of Phsopholipase D Acitvity and Is Essential to Buffer the Toxic Effects of C16:0 Plateley Activating Factor. PLoS Genetics, 7(2), 1-12. doi:10.1371/journal.pgen.1001299

Khalil, M. L. (2006). Biological activity of bee propolis in health and disease. Asian Pacific journal of cancer prevention, 7(1), 22-31. doi:16629510

Koc, M., Nad'ova, Z., Truksa, J., Ehrlicova, M., \& Kovar, J. (2005). Iron deprivation induces apoptosis via mitochondrial changes related to Bax translocation. Apoptosis, 10(2), 381-393. doi:10.1007/s10495-005-0812-8\#

Kuropatnicki, A. K., Szliszka, E., \& Krol, W. (2013). Historical Aspects of Propolis Research in Modern Times. Evidence-based Complementary and Alternative Medicine, 2013, 1-11. doi:10.1155/2013/964149

Kwon, Young Bae; Lee, Hye Jung; Han, Ho Jae; Mar, Woung Chon; Kang, Sung Keel; Yoon, Ok Byung; Beitz, Alvin J.; Lee, Jang Hern (2002). The water-soluble fraction of bee venom produces antiinociceptive and anti-inflammatory effects on rheumatoid arthritis in rats. Life Sciences, 71(2), 191-204. doi:10.1016/S0024-3205(02)01617-X

Lariviere, W. R., \& Melzack, R. (1996). The bee venom test: a new tonic-pain test. International Association for the Study of Pain, 66(2-3), 271-277. doi:8880850

Li, Hongzhen; Kapur, Aneesh; Yang, Jesse X.; Stivastava, Shiv; McLeod, David G.; Paredes-Guzman, Julio F.; Daugsch, Andreas; Park, Yong K.; Rhim, Johng S.. (2007). Antiproliferation of human 
prostate cancer cells by ethanolic extracts of Brazilian propolis and its botanical origin. International Journal of Oncology, 31(3), 601-606. doi:10.3892/ijo.31.3.601

Li, L., \& Kaplan, J. (1998). Defects in the Yeast High Affinity Iron Transport System Result in Increased Metal Snensitivity because of the Increased Expression of Transporters with a Broad Transition Metal Specificity. The Journal of Biological Chemistry, 273(35), 22181-22187. doi:10.1074/jbc.273.35.22181

Maruyama, H., Sakamoto, T., Araki, Y., \& Hara, H. (2010). Anti-inflammatory effect of be pollen ethanol etract from Cistus sp of Spanish on carrageenan-induced rat hind paw edema. BMC Complementary and Alternative Medicine, 10(30), 1-11. doi:10.1186/1472-6882-10-30

Mladenka, Premysl; Macakove, Katerina; Filipsky, Tomas; Zatloukalova, Libuse; Jahodar, Ludek; Bovicellia, Paolo; Silvestri, Ilaria Proietti; Hrdina, Radomir; Saso, Luciano. (2011). In vitro analysis of iron helating activity of flavonoids. Journal of Inorgarnic Biochemistry, 105(5), 693-701. doi:10.1016/j.jinorgbio.2011.02.003

Moon, Dong-Oh; Park, Sung-Yong; Heo, Moon-Soo; Kim, Ki-Cheon; Park, Cheol; Ko, Woo Shin; Choi, Yung Hyun; Kim, Gi-Young. Key regulators in bee venom-induced apoptosis are $\mathrm{Bcl}-2$ and caspase-3 in human leukemic U937 cells through downregulation of ERK and Akt. International Immunopharmacology, 6(12), 1796-1807. doi:10.1016/j.intimp.2006.07.027

Newman, J. R., Ghaemmaghami, S., Ihmels, J., Breslow, D. K., Noble, M., DeRisi, J. L., \& Weissman, J. S. (2006). Single-cell proteomic analysis of S. cerevisiae revelas the architecture of biological noise. Nature, 441(7095), 840-846. doi:10.1038/nature04785

Nislow, C., \& Giaever, G. (2007). Methods in Microbiology Volume 36 Yeast Gene Analysis. In I. Stansfield, \& M. J. Stark, Yeast Gene Analysis (Vol. 36, pp. 387-414). Amsterdam; Boston; Heidelberg; London; New York; Oxford; Paris; San Diego; San Francisco; Singapore; Sydney; Tokyo: Academic Press.

Orsolic, N. (2012). Bee venom in cancer therapy. Cancer Metastasis Review, 31(1-2), 173-194. doi:10.1007/s10555-011-9339-3

Ozen, T., Killic, A., Bedir, O., Koru, O., Sorkun, K., Tanyuksel, M., . . Baysallar, M. (2010). In Vitro Activity of Turkish Propolis Samples Against Anaerobic Bacteria Causing Oral Cavity Infections. Kafkas Universitesi Veteriner Fakultesi Dergisi, 16(2), 293-298. doi:10.9775/kvfd.2009.707

Parsons, Ainslie B; Brost, Renée L; Ding, Huiming; Li, Zhijian; Zhang, Chaoying; Sheikh, Bilal; Brown, Grant W; Kane, Patricia M; hugher, Timothy R; Boone, Charles. Integration of chemicalgenetic and genetic interaction data links bioactive compounds to cellular target pathways. Nature Biotechnology, 22(1), 62-69. doi:10.1038/nbt919

Pascoal, A., Rodrigues, S., Teizeira, A., \& Estevinho, X. F. (2014). Biological activities of commercial bee pollens : Antimicrobial, antimutagenic, antioxidant and anti-inflammatory. Food and Chemical Toxicology, 63, 233-239. doi:10.1016/j.fct.2013.11.010

Pavilonis, A., Baranaskas, A., Puidokaite, L., Mazeliene, Z., Savickas, A., \& Radziunas, R. (2008). Antimicrobial activity of soft and purified propolis extracts. Medicina-lithuania, 44(12), 977983. 
Philpott, C. C., \& Protechenko, O. (2008). Response to Iron Depravation in Saccharomyces cerevisiae. Eukaryotic Cell, 30(4), 20-27. doi:10.1042/bst0300698

Pratt, J., Ravnic, D., Huss, H., Jiang, X., Orozco, B., \& Mentzer, S. (2005). Melittin-induced membrane permeability: A nonosmotic mechanism of cell death. In Vitro Cellular \& Developmental Biology-Animal, 41(10), 349-355. doi:10.1007/s11626-005-0007-1

Prousek, J. (2007). Fenton chemistry in biology and medicine. Pure Applied Chemistry, 79(12), 23252338. doi:10.1351/pac200779122325

Quiroga, E., Sampietro, D., Soberon, J., Sgariglia, M., \& Vattuone, M. (2006). Propolis from the northwest of Argentina as a source of antifungal principles. Journal of Applied Microbiology, 101(1), 103-110. doi:10.1111/j.1365-2672.2006.02904.x

Samy, R. P., Gopalakrishnakone, P., Thwin, M., Chow, T., Bow, H., Yap, E., \& Thong, T. (2006). Antibacteral activity of snake, scorpion and bee venoms: A comparison with purified venom phospholipase A2 enzymes. Journal of Applied Microbiology, 102(3), 650-658. doi:10.1111/j.1365-2672.2006.03161.x

Santos, F., Bastos, E., Uzeda, M., Carvalho, M., Farias, L., Moreira, E., \& Braga, F. (2002). Antibacterial activity of Brazilian propolis and fractions against oral anaerobic bacteria. Journal of Ethnopharmacology, 80(1), 1-7. doi:10.1016/S0378-8741(02)00003-X

Schuldiner, Maya; Collins, Sean R.; Thompson, Natalie J.; Denic, Vladimir; Bhamidipati, Arunashree; Punna, Thanuja; Ihmels, Jan; Andrews, Brenda; Boone, Charles; Greenblatt, Jack F.; Weissman, Jonathan S.; Krogan, Nevan J. (2005). Exploration of the Function and Organization of the Yeast Early Secretory Pathway through and Epistatic Miniarray Profile. Cell, 123(3), 507-519. doi:10.1016/j.cell.2005.08.031

Seeley, T., \& Morse, R. (1976). The nest of the honey bee (Apis mellifera L.). Insectes Sociaux, 23(4), 495-512. doi:10.1007/BF02223477

Shiva, M., Mohammad, S., Manoochehr, H., Reza, A., Nasrin, S., \& Seyed Nasser, O. (2007). Chemical Composition, oral toxicity and antimicrobial activity of Iranian propolis. Food Chemistry, 103(4), 1097-1103. doi:10.1016/j.foodchem.2006.10.006

Son, D. J., Lee, J. W., Lee, Y. H., Song, H. S., Lee, C. K., \& Hong, J. T. (2007). Therapeutic application of anti-arthritis, pain-releasing and anti-cancer effects of bee venom and its constituent compounds. Pharmacology \& Therapeutics, 115(2), 246-270. doi:10.1016/j.pharmthera.2007.04.004

Stearman, R., Yuan, D. S., Yamaguchi-Iwai, Y., Klausner, R. D., \& Dancis, A. (1996). A PermeaseOxidase Complex Involved in High-Affinity Iron Uptake in Yeast. Science, 271(5255), 15521557. doi:10.1126/science.271.5255.1552

Tong, Amy Hin Yang; Evangelista, Marie; Parsons, Ainslie B.; Xu, Hong; Bader, Gay D.; Page, Nicholas; Robinson, Mark; Raghibizadeh, Sasan; Hogue, Christopher W.V.; Bussey, Howard; BrendaAndews; Tyers, Mike; Boone, Charles. (2001). Systemic Genetic Analysis with Ordered Arrays of Yeast Deletion Mutants. Science, 294(5550), 2364-2368. doi:10.1126/science.1065810

Tugendreich, S., Jr, D. B., McKusick, V., Boguski, M., \& Hieter, P. (1994). Genes conserved in yeast and humans. Human Molecular Genetics, 3(Suppl 1), 1509-1517. 
Uzel, A., Sorkun, K., Önçağ, Ö., Çoğulu, D., Gençay, Ö., \& Sali h, B. (2005). Chemical compositions and antimicrobial activities of four different Anatolian propolis samples. Microbiological Research, 160(2), 189-195. doi:10.1016/j.micres.2005.01.002

Valente, M. J., Baltazar, A. F., Henrique, R., Estevinho, L., \& Carvalho, M. (2011). Biological activities of Portuguese propolis: Protection against free radical-induced erythrocyte damage and inhibition of human renal cancer cell growth in vitro. Food and Chemical Toxicology, 49(1), 86-92. doi:10.1016/j.fct.2010.10.001

Wagih, O., \& Parts, L. (2014, 01 23). cran-r-project.org. Retrieved from http://cran.rproject.org/web/packages/gitter/gitter.pdf

Wagih, O., \& Parts, L. (2014). gitter: A Robust and Accurate Method for Quantification of Colony Sizes from Plate Images. G3 (Bethesda), 4(3), 547-552. doi:doi: 10.1534/g3.113.009431

Wang, J., Li, S., Wang, Q., Xin, B., \& Wang, H. (2007). Trophic Effect of Bee Pollen on Small Intestine in Broiler Chickens. Journal of Medicinal Food, 10(2), 276-280. doi:10.1089/jmf.2006.215

Williams, S., Anthony, M., \& Brindle, K. (1998). Induction of apoptosis in two mammalian cell lines results in increased levels of fructose-1,6-bisphosphate and CDP-choline as determined by 31p MRS. Society of Magnetic Resonance in Medicine, 40(3), 411-420. doi:10.1002/mrm.1910400311

Winzeler, Elizabeth A.; Shoemaker, Daniel D.; Astromoff, Anna; Liang, Hong; Anderson, Keigh; Andrew, Bruno; Bangham, Rhonda; Benito, Rocio; Boeke, Jef D.; Bussey, Howard; Chu, Angela M.; Connelly, Caria; Davis, Karen; Dietrich, Fred; Davis, Ronald W.. (1999). Functional Characterization of the S. cerevisiae Genome by Gene Deletion and Parallel Analysis. Science, 285(5429), 901-906. doi:10.1126/science.285.5429.901

Wojciki, J., Hinek, A., \& Samochowiec, L. (1985). The Protective Effect of Pollen Extracts against Allyl Alcohol Damage of the Liver. Arch Immunol Ther Exp, 33(6), 841-849.

Wojckiki, J., Samochowjec, L., Barlomowicz, B., Hinek, A., Jaworska, M., \& Gawronska, B. (1986). Effect of Pollen Extract on the Development of Experimental Atherosclerosis in Rabbits. Atherosclerosis, 62(1), 39-45. doi:10.1016/0021-9150(86)90017-1

Wright, M. M., Howe, A. G., \& Zaremberg, V. (2004). Cell membranes and apoptosis: role of cardiolipin, phosphatidylcholine, and anticancer lipid analogues. Biochemistry and Cell Biology, 82(1), 18-26. doi:10.1139/o03-092

Yamaguchi-Iwai, Y., Dancis, A., \& Klausner, R. D. (1995). AFT1: a mediator of iron regulated transcriptional control in Saccharomyces cerevisiae. The EMBO Journal, 14(6), 1231-1239.

Yu, A.-r., Kim, J.-J., Oh, G.-S. P.-M., Han, C. S., \& Lee, M.-y. (2012). The Antifungal Activity of Bee Venom against Dermatophytes. Journal of Applied Biological Chemistry, 55(1), 7-11. doi: 10.3839/jabc.2011.052

Yun, C.-W., Bauler, M., Moore, R. E., Klebba, P. E., \& Philpott, C. C. (2001). The Role of the FRE Family of Plasma Reductases in the Uptake of Siderophore-Iron in Saccharomyces cerevisiae. The Journal of Biological Chemistry, 276(13), 10218-10223. doi:10.1074/jbc.M010065200 


\section{Appendix}

\section{Appendix A}

Table A.1.1 Top ten most enriched GO term for biological processes from propolis homozygous deletion library screen

\begin{tabular}{|l|c|c|}
\hline GO Term & P-value & Gene Matches \\
\hline metal ion transport & $3.06 \mathrm{E}-05$ & CCC2, FTR1, KHA1, FET3 \\
\hline iron assimilation & $3.22 \mathrm{E}-05$ & FTR1, FET3 \\
\hline iron assimilation by reduction and transport & $3.22 \mathrm{E}-05$ & FTR1, FET3 \\
\hline arsenate ion transmembrane transport & $3.22 \mathrm{E}-05$ & FTR1, FET3 \\
\hline transition metal ion transport & $4.93 \mathrm{E}-05$ & CCC2, FTR1, FRE1, FET3 \\
\hline iron ion transport & $7.38 \mathrm{E}-05$ & FTR1, FRE1, FET3 \\
\hline iron ion homeostasis & $7.45 \mathrm{E}-05$ & CCC2, FTR1, FRE1, FET3 \\
\hline $\begin{array}{l}\text { high-affinity iron ion transmembrane } \\
\text { transport }\end{array}$ & $9.63 \mathrm{E}-05$ & FTR1, FET3 \\
\hline iron ion transmembrane transport & 0.000192 & FTR1, FET3 \\
\hline inorganic cation transmembrane transport & 0.000274 & CCC2, FTR1, KHA1, FET3 \\
\hline
\end{tabular}

Table A.1.2 Top ten most enriched GO term for biological processes of from propolis DAmP library screen

\begin{tabular}{|l|l|c|}
\hline GO Term & p-value & Gene Matches \\
\hline snoRNA processing & 0.005132 & RRP43,SEN1,CSL4,PRP4 \\
\hline snoRNA 3'-end processing & 0.006176 & RRP43,SEN1,CSL4 \\
\hline snoRNA metabolic process & 0.008706 & RRP43,SEN1,CSL4,PRP4 \\
\hline $\begin{array}{l}\text { nuclear-transcribed mRNA catabolic } \\
\text { process, exonucleolytic, 3'-5' }\end{array}$ & 0.011091 & RRP43,CSL4 \\
\hline
\end{tabular}




\begin{tabular}{|l|l|l|}
\hline $\begin{array}{l}\text { exonucleolytic nuclear-transcribed mRNA } \\
\text { catabolic process involved in } \\
\text { deadenylation-dependent decay }\end{array}$ & 0.011091 & RRP43,CSL4 \\
\hline $\begin{array}{l}\text { nuclear-transcribed mRNA catabolic } \\
\text { process, 3'-5' exonucleolytic nonsense- } \\
\text { mediated decay }\end{array}$ & 0.011091 & RRP43,CSL4 \\
\hline $\begin{array}{l}\text { nuclear-transcribed mRNA catabolic } \\
\text { process, non-stop decay }\end{array}$ & 0.011091 & RRP43,CSL4 \\
\hline $\begin{array}{l}\text { ncRNA 3'-end processing } \\
\text { nuclear-transcribed mRNA catabolic } \\
\text { process, exonucleolytic }\end{array}$ & 0.014956 & RRP43,SEN1,CSL4 \\
\hline $\begin{array}{l}\text { exonucleolytic trimming to generate } \\
\text { mature 3'-end of 5.8S rRNA from } \\
\text { tricistronic rRNA transcript }\end{array}$ & 0.015256 & RRP43,CSL4 \\
\hline
\end{tabular}

Table A.2.1 Top ten most enriched GO term for biological processes from bee venom yeast homozygous deletion library screen

\begin{tabular}{|l|l|l|}
\hline GO term & p-value & Gene matches \\
\hline histone H3-K79 methylation & 0.001549 & DOT1,RTF1 \\
\hline global genome nucleotide-excision repair & 0.001549 & DOT1,RTF1 \\
\hline nucleotide-excision repair & 0.005069 & DOT1,RAD23,RTF1 \\
\hline regulation of DNA repair & 0.006692 & RTF1,SRS2 \\
\hline methionine biosynthetic process & 0.007406 & MET8,UTR4,YLL058W \\
\hline regulation of response to DNA damage & & \\
stimulus & 0.008113 & RTF1,SRS2 \\
\hline sulfur amino acid biosynthetic process & 0.008778 & MET8,UTR4,YLL058W \\
\hline methionine metabolic process & 0.011099 & MET8,UTR4,YLL058W \\
\hline
\end{tabular}




\begin{tabular}{|l|l|l|l|}
\hline snoRNA transcription from an RNA & & \\
polymerase II promoter & & 0.012735 & RTF1 \\
\hline snoRNA transcription & 0.012735 & RTF1 \\
\hline
\end{tabular}

\section{Appendix B}

Table B.1.1: Propolis validated hits from yeast homozygous deletion library screen

\begin{tabular}{|c|c|l|}
\hline $\begin{array}{c}\text { Gene } \\
\text { Name }\end{array}$ & $\begin{array}{c}\text { Growth } \\
\text { Ratio }\end{array}$ & \multicolumn{1}{|c|}{ Description } \\
MGA2 & 2.41 & $\begin{array}{l}\text { ER membrane protein involved in regulation of OLE1 transcription; inactive ER } \\
\text { form dimerizes and one subunit is then activated by ubiquitin/proteasome- } \\
\text { dependent processing followed by nuclear targeting; MGA2 has a paralog, } \\
\text { SPT23, that arose from the whole genome duplication }\end{array}$ \\
\hline RVS161 & 2.24 & $\begin{array}{l}\text { Amphiphysin-like lipid raft protein; interacts with Rvs167p and regulates } \\
\text { polarization of the actin cytoskeleton, endocytosis, cell polarity, cell fusion and } \\
\text { viability following starvation or osmotic stress }\end{array}$ \\
\hline SNF5 & 1.96 & $\begin{array}{l}\text { Subunit of the SWI/SNF chromatin remodeling complex; involved in } \\
\text { transcriptional regulation; functions interdependently in transcriptional } \\
\text { activation with Snf2p and Snf6p; relocates to the cytosol under hypoxic } \\
\text { conditions }\end{array}$ \\
\hline SSD1 & 1.94 & $\begin{array}{l}\text { Component of the NuA4 histone acetyltransferase complex; acts as a platform } \\
\text { for assembly of NuA4 subunits into the native complex; required for initiation of } \\
\text { pre-meiotic DNA replication, likely due to its requirement for expression of IME1 }\end{array}$ \\
\hline BEM1 & 1.89 & $\begin{array}{l}\text { Translational repressor with a role in polar growth and wall integrity; regulated } \\
\text { by Cbk1p phosphorylation to effect bud-specific translational control and } \\
\text { localization of specific mRNAs; interacts with TOR pathway components; } \\
\text { contains a functional N-terminal nuclear localization sequence and } \\
\text { nucleocytoplasmic shuttling appears to be critical to Ssd1p function }\end{array}$ \\
\hline 1.88 & $\begin{array}{l}\text { Cu(+2)-transporting P-type ATPase; required for export of copper from the } \\
\text { cytosol into an extracytosolic compartment; similar to human proteins involved } \\
\text { in Menkes and Wilsons diseases; protein abundance increases in response to } \\
\text { DNA replication stress; affects TBSV model (+)RNA virus replication by } \\
\text { regulating copper metabolism; human homologs ATP7A and ATP7B both } \\
\text { complement yeast null mutant }\end{array}$ \\
\hline $\begin{array}{l}\text { Protein containing SH3-domains; involved in establishing cell polarity and } \\
\text { morphogenesis; functions as a scaffold protein for complexes that include } \\
\text { Cdc24p, Ste5p, Ste20p, and Rsr1p }\end{array}$ \\
\hline
\end{tabular}




\begin{tabular}{|c|c|c|}
\hline FTR1 & 1.59 & $\begin{array}{l}\text { High affinity iron permease; involved in the transport of iron across the plasma } \\
\text { membrane; forms complex with Fet3p; expression is regulated by iron; protein } \\
\text { abundance increases in response to DNA replication stress }\end{array}$ \\
\hline YDR541C & 1.49 & $\begin{array}{l}\text { Aldehyde reductase; substrates are both aromatic and aliphatic aldehydes; uses } \\
\text { NADPH as cofactor }\end{array}$ \\
\hline PEF1 & 1.46 & $\begin{array}{l}\text { Penta-EF-hand protein; required for polar bud growth and cell wall abscission; } \\
\text { binds calcium and zinc with different affinity; localizes to bud site in G1, bud } \\
\text { neck in G2; binds to Sec31p and modulates COPII coat assembly }\end{array}$ \\
\hline SOD2 & 1.41 & $\begin{array}{l}\text { Mitochondrial manganese superoxide dismutase; protects cells against oxygen } \\
\text { toxicity; phosphorylated }\end{array}$ \\
\hline FET3 & 1.38 & $\begin{array}{l}\text { Ferro-O2-oxidoreductase; multicopper oxidase that oxidizes ferrous }(\mathrm{Fe} 2+) \text { to } \\
\text { ferric iron (Fe3+) for subsequent cellular uptake by transmembrane permease } \\
\text { Ftr1p; required for high-affinity iron uptake and involved in mediating resistance } \\
\text { to copper ion toxicity, belongs to class of integral membrane multicopper } \\
\text { oxidases; protein abundance increases in response to DNA replication stress }\end{array}$ \\
\hline SHE4 & 1.38 & $\begin{array}{l}\text { Protein containing a UCS (UNC-45/CRO1/SHE4) domain; binds to myosin motor } \\
\text { domains to regulate myosin function; involved in endocytosis, polarization of the } \\
\text { actin cytoskeleton, and asymmetric mRNA localization }\end{array}$ \\
\hline EOS1 & 1.37 & $\begin{array}{l}\text { Protein involved in N-glycosylation; deletion mutation confers sensitivity to } \\
\text { exidative stress and shows synthetic lethality with mutations in the spindle } \\
\text { checkpoint genes BUB3 and MAD1; YNL080C is not an essential gene }\end{array}$ \\
\hline MAK10 & 1.35 & $\begin{array}{l}\text { Non-catalytic subunit of N-terminal acetyltransferase of the NatC type; required } \\
\text { for replication of dsRNA virus; expression is glucose-repressible }\end{array}$ \\
\hline YEL057C & 1.32 & $\begin{array}{l}\text { Protein of unknown function involved in telomere maintenance; target of UME6 } \\
\text { regulation }\end{array}$ \\
\hline FRE1 & 1.31 & $\begin{array}{l}\text { Ferric reductase and cupric reductase; reduces siderophore-bound iron and } \\
\text { oxidized copper prior to uptake by transporters; expression induced by low } \\
\text { copper and iron levels }\end{array}$ \\
\hline OYE3 & 1.27 & $\begin{array}{l}\text { Conserved NADPH oxidoreductase containing flavin mononucleotide (FMN); } \\
\text { homologous to Oye2p with different ligand binding and catalytic properties; has } \\
\text { potential roles in oxidative stress response and programmed cell death }\end{array}$ \\
\hline KHA1 & 1.25 & $\begin{array}{l}\text { Putative } \mathrm{K}+/ \mathrm{H}+\text { antiporter; has a probable role in intracellular cation } \\
\text { homeostasis; localized to Golgi vesicles and detected in highly purified } \\
\text { mitochondria in high-throughput studies }\end{array}$ \\
\hline GET2 & 1.24 & $\begin{array}{l}\text { Subunit of the GET complex; involved in insertion of proteins into the ER } \\
\text { membrane; required for the retrieval of HDEL proteins from the Golgi to the ER } \\
\text { in an ERD2 dependent fashion and for meiotic nuclear division }\end{array}$ \\
\hline GRR1 & 1.24 & $\begin{array}{l}\text { F-box protein component of an SCF ubiquitin-ligase complex; modular substrate } \\
\text { specificity factor which associates with core SCF (Cdc53p, Skp1p and } \\
\text { Hrt1p/Rbx1p) to form the SCF(Grr1) complex; SCF(Grr1) acts as a ubiquitin- } \\
\text { protein ligase directing ubiquitination of substrates such as: Gic2p, Mks1p, } \\
\text { Mth1p, Cln1p, Cln2p and Cln3p; involved in carbon catabolite repression, }\end{array}$ \\
\hline
\end{tabular}




\begin{tabular}{|c|c|l|}
\hline RTF1 & $\begin{array}{l}\text { glucose-dependent divalent cation transport, glucose transport, morphogenesis, } \\
\text { and sulfite detoxification }\end{array}$ \\
\hline 1.17 & $\begin{array}{l}\text { Subunit of RNAPII-associated chromatin remodeling Paf1 complex; regulates } \\
\text { gene expression by directing cotranscriptional histone modification, influences } \\
\text { transcription and chromatin structure through several independent functional } \\
\text { domains; directly or indirectly regulates DNA-binding properties of Spt15p and } \\
\text { relative activities of different TATA elements; involved in transcription } \\
\text { elongation as demonstrated by the G-less-based run-on (GLRO) assay }\end{array}$ \\
\hline
\end{tabular}

Table B.1.2: Propolis validated hits from yeast DAmP library screen

\begin{tabular}{|c|c|c|}
\hline $\begin{array}{l}\text { Gene } \\
\text { Name }\end{array}$ & $\begin{array}{l}\text { Growth } \\
\text { Ratio }\end{array}$ & Description \\
\hline YGL074C & 2.08 & $\begin{array}{l}\text { Dubious open reading frame unlikely to encode a functional protein; overlaps 5' } \\
\text { end of essential HSF1 gene encoding heat shock transcription factor }\end{array}$ \\
\hline DBP9 & 2.03 & $\begin{array}{l}\text { DEAD-box protein required for } 27 \mathrm{~S} \text { rRNA processing; exhibits DNA, RNA and } \\
\text { DNA/RNA helicase activities; ATPase activity shows preference for DNA over } \\
\text { RNA; DNA helicase activity abolished by mutation in RNA-binding domain }\end{array}$ \\
\hline ERG13 & 2.01 & $\begin{array}{l}\text { 3-hydroxy-3-methylglutaryl-CoA (HMG-CoA) synthase; catalyzes the formation of } \\
\text { HMG-CoA from acetyl-CoA and acetoacetyl-CoA; involved in the second step in } \\
\text { mevalonate biosynthesis }\end{array}$ \\
\hline GLN4 & 1.64 & $\begin{array}{l}\text { Glutamine tRNA synthetase; monomeric class I tRNA synthetase that catalyzes } \\
\text { the specific glutaminylation of tRNA(Gln); N-terminal domain proposed to be } \\
\text { involved in enzyme-tRNA interactions }\end{array}$ \\
\hline ZPR1 & 1.64 & $\begin{array}{l}\text { Essential protein with two zinc fingers; present in the nucleus of growing cells } \\
\text { but relocates to the cytoplasm in starved cells via a process mediated by Cpr1p; } \\
\text { binds to translation elongation factor eEF-1 (Tef1p); relative distribution to the } \\
\text { nucleus increases upon DNA replication stress }\end{array}$ \\
\hline ALG13 & 1.6 & $\begin{array}{l}\text { Catalytic component of UDP-GlcNAc transferase; required for the second step of } \\
\text { dolichyl-linked oligosaccharide synthesis; anchored to the ER membrane via } \\
\text { interaction with Alg14p; similar to bacterial and human glycosyltransferases; } \\
\text { protein abundance increases in response to DNA replication stress }\end{array}$ \\
\hline SEC26 & 1.56 & $\begin{array}{l}\text { Essential beta-coat protein of the COPI coatomer; involved in ER-to-Golgi } \\
\text { protein trafficking and maintenance of normal ER morphology; shares } 43 \% \\
\text { sequence identity with mammalian beta-coat protein (beta-COP) }\end{array}$ \\
\hline PRP4 & 1.55 & Splicing factor; component of the U4/U6-U5 snRNP complex \\
\hline SEC21 & 1.51 & $\begin{array}{l}\text { Gamma subunit of coatomer; coatomer is a heptameric protein complex that } \\
\text { together with Arf1p forms the COPI coat; involved in ER to Golgi transport of } \\
\text { selective cargo }\end{array}$ \\
\hline
\end{tabular}




\begin{tabular}{|c|c|c|}
\hline RIB5 & 1.5 & $\begin{array}{l}\text { Riboflavin synthase; catalyzes the last step of the riboflavin biosynthesis } \\
\text { pathway }\end{array}$ \\
\hline STH1 & 1.5 & $\begin{array}{l}\text { ATPase component of the RSC chromatin remodeling complex; required for } \\
\text { expression of early meiotic genes; promotes base excision repair in chromatin; } \\
\text { essential helicase-related protein homologous to Snf2p }\end{array}$ \\
\hline RRP43 & 1.47 & $\begin{array}{l}\text { Exosome non-catalytic core component; involved in 3'-5' RNA processing and } \\
\text { degradation in both the nucleus and the cytoplasm; has similarity to E. coli } \\
\text { RNase PH and to human hRrp43p (OIP2, EXOSC8); protein abundance increases } \\
\text { in response to DNA replication stress }\end{array}$ \\
\hline NPA3 & 1.45 & $\begin{array}{l}\text { Member of the conserved GPN-loop GTPase family; has a role in transport of } \\
\text { RNA polymerase II to the nucleus; exhibits GTP-dependent binding to PolII; has } \\
\text { ATPase activity; involved in sister chromatid cohesion; phosphorylated by the } \\
\text { Pcl1p-Pho85p kinase complex; human homolog XAB1 interacts with human RNA } \\
\text { polymerase II; protein abundance increases in response to DNA replication } \\
\text { stress }\end{array}$ \\
\hline DOP1 & 1.43 & $\begin{array}{l}\text { Golgi-localized, leucine-zipper domain containing protein; involved in endosome } \\
\text { to Golgi transport, organization of the ER, establishing cell polarity, and } \\
\text { morphogenesis; detected in highly purified mitochondria in high-throughput } \\
\text { studies }\end{array}$ \\
\hline SEN1 & 1.43 & $\begin{array}{l}\text { Presumed helicase and subunit of the Nrd1 complex (Nrd1p-Nab3p-Sen1p); } \\
\text { complex interacts with the exosome to mediate } 3 \text { ' end formation of some } \\
\text { mRNAs, snRNAs, snoRNAs, and CUTs; has a separate role in coordinating DNA } \\
\text { replication with transcription, by associating with moving replication forks and } \\
\text { preventing errors that occur when forks encounter transcribed regions; homolog } \\
\text { of Senataxin, which is implicated in Ataxia-Oculomotor Apraxia } 2 \text { and a } \\
\text { dominant form of ALS }\end{array}$ \\
\hline DUT1 & 1.42 & $\begin{array}{l}\text { deoxyuridine triphosphate diphosphatase (dUTPase); catalyzes hydrolysis of } \\
\text { dUTP to dUMP and PPi, thereby preventing incorporation of uracil into DNA } \\
\text { during replication; critical for the maintenance of genetic stability; also has } \\
\text { diphosphatase activity on deoxyinosine triphosphate }\end{array}$ \\
\hline SPC19 & 1.42 & $\begin{array}{l}\text { Essential subunit of the Dam1 complex (aka DASH complex); complex couples } \\
\text { kinetochores to the force produced by MT depolymerization thereby aiding in } \\
\text { chromosome segregation; also localized to nuclear side of spindle pole body }\end{array}$ \\
\hline UBA2 & 1.41 & $\begin{array}{l}\text { Subunit of heterodimeric nuclear SUMO activating enzyme E1 with Aos1p; } \\
\text { activates Smt3p (SUMO) before its conjugation to proteins (sumoylation), which } \\
\text { may play a role in protein targeting; essential for viability }\end{array}$ \\
\hline CSL4 & 1.4 & $\begin{array}{l}\text { Exosome non-catalytic core component; involved in 3'-5' RNA processing and } \\
\text { degradation in both the nucleus and the cytoplasm; predicted to contain an S1 } \\
\text { RNA binding domain; has similarity to human hCsI4p (EXOSC1) }\end{array}$ \\
\hline TAO3 & 1.4 & $\begin{array}{l}\text { Component of the RAM signaling network; is involved in regulation of Ace } 2 p \\
\text { activity and cellular morphogenesis, interacts with protein kinase Cbk1p and also } \\
\text { with Kic1p }\end{array}$ \\
\hline TRS31 & 1.39 & $\begin{array}{l}\text { Core component of transport protein particle (TRAPP) complexes I-III; TRAPP } \\
\text { complexes are related multimeric guanine nucleotide-exchange factor for the }\end{array}$ \\
\hline
\end{tabular}




\begin{tabular}{|c|c|l|} 
& & $\begin{array}{l}\text { GTPase Ypt1p, regulating ER-Golgi traffic (TRAPPI), intra-Golgi traffic (TRAPPII), } \\
\text { endosome-Golgi traffic (TRAPPII and III) and autophagy (TRAPPIII) }\end{array}$ \\
\hline YRB1 & 1.39 & $\begin{array}{l}\text { Ran GTPase binding protein; involved in nuclear protein import and RNA export, } \\
\text { ubiquitin-mediated protein degradation during the cell cycle; shuttles between } \\
\text { the nucleus and cytoplasm; is essential; homolog of human RanBP1 }\end{array}$ \\
\hline PSF3 & 1.36 & $\begin{array}{l}\text { Subunit of the GINS complex (Sld5p, Psf1p, Psf2p, Psf3p); complex is localized } \\
\text { to DNA replication origins and implicated in assembly of the DNA replication } \\
\text { machinery }\end{array}$ \\
\hline TIF35 & 1.36 & $\begin{array}{l}\text { eIF3g subunit of the eukaryotic translation initiation factor 3 (eIF3); subunit of } \\
\text { the core complex of eIF3; is essential for translation; stimulates resumption of } \\
\text { ribosomal scanning during translation reinitiation }\end{array}$ \\
\hline
\end{tabular}

Table B.2.1: Bee venom validated hits from yeast homozygous deletion library

\begin{tabular}{|c|c|l|}
\hline $\begin{array}{c}\text { Gene } \\
\text { Name }\end{array}$ & $\begin{array}{c}\text { Residual } \\
\text { Growth } \\
\text { (\%) }\end{array}$ & \\
\hline SRF1 & 30.3 & $\begin{array}{l}\text { Regulator of phospholipase D (Spo14p); interacts with Spo14p and regulates } \\
\text { its catalytic activity; capable of buffering the toxicity of C16:0 platelet } \\
\text { activating factor, a lipid that accumulates intraneuronally in Alzheimer's } \\
\text { patients }\end{array}$ \\
\hline CYC7 & 34.9 & $\begin{array}{l}\text { Cytochrome c isoform 2, expressed under hypoxic conditions; also known as } \\
\text { iso-2-cytochrome c; electron carrier of the mitochondrial intermembrane space } \\
\text { that transfers electrons from ubiquinone-cytochrome c oxidoreductase to } \\
\text { cytochrome c oxidase during cellular respiration; protein abundance increases } \\
\text { in response to DNA replication stress; CYC7 has a paralog, CYC1, that arose } \\
\text { from the whole genome duplication }\end{array}$ \\
\hline PAU8 & 34.9 & $\begin{array}{l}\text { Protein of unknown function; member of the seripauperin multigene family } \\
\text { encoded mainly in subtelomeric regions }\end{array}$ \\
\hline MET8 & 39.2 & $\begin{array}{l}\text { Bifunctional dehydrogenase and ferrochelatase; involved in the biosynthesis of } \\
\text { siroheme, a prosthetic group used by sulfite reductase; required for sulfate } \\
\text { assimilation and methionine biosynthesis }\end{array}$ \\
\hline MBA1 & 39.8 & $\begin{array}{l}\text { Membrane-associated mitochondrial ribosome receptor; forms a complex with } \\
\text { Mdm38p that may facilitate recruitment of mRNA-specific translational } \\
\text { activators to ribosomes; possible role in protein export from the matrix to } \\
\text { inner membrane }\end{array}$ \\
\hline
\end{tabular}




\begin{tabular}{|c|c|c|}
\hline KRE1 & 41.9 & $\begin{array}{l}\text { Cell wall glycoprotein involved in beta-glucan assembly; serves as a K1 killer } \\
\text { toxin membrane receptor }\end{array}$ \\
\hline YEL068C & 42.1 & Protein of unknown function; expressed at both mRNA and protein levels \\
\hline EDC3 & 45.03 & $\begin{array}{l}\text { Non-essential conserved protein with a role in mRNA decapping; specifically } \\
\text { affects the function of the decapping enzyme Dcp1p; mediates decay of the } \\
\text { RPS28B mRNA via binding to both Rps28Bp (or Rps28Ap) and the RPS28B } \\
\text { mRNA; mediates decay of the YRA1 mRNA by a different, translation- } \\
\text { independent mechanism; localizes to cytoplasmic mRNA processing bodies; } \\
\text { forms cytoplasmic foci upon DNA replication stress }\end{array}$ \\
\hline YGR054W & 45.1 & $\begin{array}{l}\text { Eukaryotic initiation factor (eIF) } 2 \mathrm{~A} \text {; associates specifically with both } 40 \mathrm{~S} \\
\text { subunits and } 80 \mathrm{~S} \text { ribosomes, and interacts genetically with both eIF5b and } \\
\text { eIF4E; homologous to mammalian eIF2A }\end{array}$ \\
\hline DOT1 & 45.2 & $\begin{array}{l}\text { Nucleosomal histone H3-Lys79 methylase; methylation is required for } \\
\text { telomeric silencing, meiotic checkpoint control, and DNA damage response }\end{array}$ \\
\hline AMS1 & 45.2 & $\begin{array}{l}\text { Vacuolar alpha mannosidase; involved in free oligosaccharide (fOS) } \\
\text { degradation; delivered to the vacuole in a novel pathway separate from the } \\
\text { secretory pathway }\end{array}$ \\
\hline NDE2 & 46.1 & $\begin{array}{l}\text { Mitochondrial external NADH dehydrogenase; catalyzes the oxidation of } \\
\text { cytosolic NADH; Nde1p and Nde2p are involved in providing the cytosolic } \\
\text { NADH to the mitochondrial respiratory chain; NDE2 has a paralog, NDE1, that } \\
\text { arose from the whole genome duplication }\end{array}$ \\
\hline YEL020C & 46.8 & $\begin{array}{l}\text { Protein of unknown function with low sequence identity to Pdc1p; mRNA } \\
\text { identified as translated by ribosome profiling data }\end{array}$ \\
\hline YDR018C & 46.8 & $\begin{array}{l}\text { Probable membrane protein with three predicted transmembrane domains; } \\
\text { similar to C. elegans F55A11.5 and maize 1-acyl-glycerol-3-phosphate } \\
\text { acyltransferase; YDR018C has a paralog, CST26, that arose from the whole } \\
\text { genome duplication }\end{array}$ \\
\hline ATG14 & 47 & $\begin{array}{l}\text { Autophagy-specific subunit of phosphatidylinositol 3-kinase complex I; Atg14p } \\
\text { targets complex I to the phagophore assembly site (PAS); required for } \\
\text { localizing additional ATG proteins to the PAS; required for overflow } \\
\text { degradation of misfolded proteins when ERAD is saturated; homolog of human } \\
\text { Barkor; other members are Vps34, Vps15, and Vps30p }\end{array}$ \\
\hline MAK10 & 47 & $\begin{array}{l}\text { Non-catalytic subunit of N-terminal acetyltransferase of the NatC type; } \\
\text { required for replication of dsRNA virus; expression is glucose-repressible }\end{array}$ \\
\hline ITR1 & 47.1 & $\begin{array}{l}\text { Myo-inositol transporter; member of the sugar transporter superfamily; } \\
\text { expression is repressed by inositol and choline via Opi1p and derepressed via } \\
\text { Ino2p and Ino4p; relative distribution to the vacuole increases upon DNA } \\
\text { replication stress; ITR1 has a paralog, ITR2, that arose from the whole } \\
\text { genome duplication }\end{array}$ \\
\hline YLR012C & 47.2 & Putative protein of unknown function; YLR012C is not an essential gene \\
\hline
\end{tabular}




\begin{tabular}{|c|c|c|}
\hline RTF1 & 47.88 & $\begin{array}{l}\text { Subunit of RNAPII-associated chromatin remodeling Paf1 complex; regulates } \\
\text { gene expression by directing cotranscriptional histone modification, influences } \\
\text { transcription and chromatin structure through several independent functional } \\
\text { domains; directly or indirectly regulates DNA-binding properties of Spt15p and } \\
\text { relative activities of different TATA elements; involved in transcription } \\
\text { elongation as demonstrated by the G-less-based run-on (GLRO) assay }\end{array}$ \\
\hline SRS2 & 48.8 & $\begin{array}{l}\text { DNA helicase and DNA-dependent ATPase; involved in DNA repair and } \\
\text { checkpoint recovery, needed for proper timing of commitment to meiotic } \\
\text { recombination and transition from Meiosis I to II; blocks trinucleotide repeat } \\
\text { expansion; affects genome stability; disassembles Rad51p nucleoprotein } \\
\text { filaments during meiotic recombination; functional homolog of human RTEL1 }\end{array}$ \\
\hline YOL114C & 49.3 & $\begin{array}{l}\text { Putative protein of unknown function with similarity to human ICT1; has } \\
\text { prokaryotic factors that may function in translation termination; YOL114C is } \\
\text { not an essential gene }\end{array}$ \\
\hline YNL319W & 51.2 & $\begin{array}{l}\text { Dubious open reading frame; unlikely to encode a functional protein, based on } \\
\text { available experimental and comparative sequence data; partially overlaps the } \\
\text { verified gene HXT14 }\end{array}$ \\
\hline SNC1 & 51.5 & $\begin{array}{l}\text { Vesicle membrane receptor protein (v-SNARE); involved in the fusion between } \\
\text { Golgi-derived secretory vesicles with the plasma membrane; proposed to be } \\
\text { involved in endocytosis; member of the synaptobrevin/VAMP family of R-type } \\
\text { v-SNARE proteins; SNC1 has a paralog, SNC2, that arose from the whole } \\
\text { genome duplication }\end{array}$ \\
\hline UTR4 & 51.5 & $\begin{array}{l}\text { Protein with sequence similarity to acireductone synthases; involved in } \\
\text { methionine salvage; found in both the cytoplasm and nucleus }\end{array}$ \\
\hline NGR1 & 51.8 & $\begin{array}{l}\text { RNA binding protein that negatively regulates growth rate; interacts with the } \\
\text { 3' UTR of the mitochondrial porin (POR1) mRNA and enhances its degradation; } \\
\text { overexpression impairs mitochondrial function; interacts with Dhh1p to } \\
\text { mediate POR1 mRNA decay; expressed in stationary phase }\end{array}$ \\
\hline MDS3 & 51.8 & $\begin{array}{l}\text { Putative component of the TOR regulatory pathway; negative regulator of } \\
\text { early meiotic gene expression; required, with Pmd1p, for growth under } \\
\text { alkaline conditions; has an N-terminal kelch-like domain; MDS3 has a paralog, } \\
\text { PMD1, that arose from the whole genome duplication }\end{array}$ \\
\hline AFG1 & 52.5 & $\begin{array}{l}\text { Protein that may act as a chaperone for cytochrome c oxidase subunits; } \\
\text { conserved protein; may act as a chaperone in the degradation of misfolded or } \\
\text { unassembled cytochrome c oxidase subunits; localized to matrix face of the } \\
\text { mitochondrial inner membrane; member of the AAA family but lacks a } \\
\text { protease domain }\end{array}$ \\
\hline CAJ1 & 52.5 & $\begin{array}{l}\text { Nuclear type II J heat shock protein of the E. coli dnaJ family; contains a } \\
\text { leucine zipper-like motif, binds to non-native substrates for presentation to } \\
\text { Ssa3p, may function during protein translocation, assembly and disassembly }\end{array}$ \\
\hline RAD23 & 52.6 & $\begin{array}{l}\text { Protein with ubiquitin-like } \mathrm{N} \text { terminus; subunit of Nuclear Excision Repair } \\
\text { Factor } 2 \text { (NEF2) with Rad4p that binds damaged DNA; enhances protein } \\
\text { deglycosylation activity of Png1p; also involved, with Rad4p, in ubiquitylated } \\
\text { protein turnover }\end{array}$ \\
\hline
\end{tabular}




\begin{tabular}{|c|c|c|}
\hline PHO8 & 53 & $\begin{array}{l}\text { Repressible vacuolar alkaline phosphatase; regulated by levels of Pi and by } \\
\text { Pho4p, Pho9p, Pho80p, Pho81p and Pho85p; dephosphorylates } \\
\text { phosphotyrosyl peptides; contributes to NAD+ metabolism by producing } \\
\text { nicotinamide riboside from NMN }\end{array}$ \\
\hline AGP2 & 54.8 & $\begin{array}{l}\text { Plasma membrane regulator of polyamine and carnitine transport; has } \\
\text { similarity to transporters but lacks transport activity; may act as a sensor that } \\
\text { transduces environmental signals; has a positive or negative regulatory effect } \\
\text { on transcription of many transporter genes }\end{array}$ \\
\hline SMY2 & 55.4 & $\begin{array}{l}\text { GYF domain protein; involved in COPII vesicle formation; interacts with the } \\
\text { Sec23p/Sec24p subcomplex; overexpression suppresses the temperature } \\
\text { sensitivity of a myo2 mutant; similar to S. pombe Mpd2; SMY2 has a paralog, } \\
\text { SYH1, that arose from the whole genome duplication }\end{array}$ \\
\hline MKT1 & 55.4 & $\begin{array}{l}\text { Protein similar to nucleases that forms a complex with Pbp1p; complex may } \\
\text { mediate posttranscriptional regulation of HO; involved in propagation of M2 } \\
\text { dsRNA satellite of L-A virus; allelic variation affects mitochondrial genome } \\
\text { stability, drug resistance, and more; forms cytoplasmic foci upon DNA } \\
\text { replication stress; localization to P-bodies under ethanol stress differs between } \\
\text { strains }\end{array}$ \\
\hline PRE9 & 55.8 & $\begin{array}{l}\text { Alpha } 3 \text { subunit of the } 20 \text { s proteasome; the only nonessential } 20 \text { s subunit; } \\
\text { may be replaced by the alpha } 4 \text { subunit (Pre6p) under stress conditions to } \\
\text { create a more active proteasomal isoform }\end{array}$ \\
\hline YLL059C & 56.3 & $\begin{array}{l}\text { Dubious open reading frame; unlikely to encode a functional protein, based on } \\
\text { available experimental and comparative sequence data }\end{array}$ \\
\hline YGL138C & 56.4 & $\begin{array}{l}\text { Putative protein of unknown function; has no significant sequence similarity to } \\
\text { any known protein }\end{array}$ \\
\hline ECL1 & 56.4 & $\begin{array}{l}\text { Protein of unknown function; mitochondrial-dependent role in the extension of } \\
\text { chronological lifespan; overexpression increases oxygen consumption and } \\
\text { respiratory activity while deletion results in reduced oxygen consumption } \\
\text { under conditions of caloric restriction; induced by iron homeostasis } \\
\text { transcription factor Aft2p; multicopy suppressor of temperature sensitive hsf1 } \\
\text { mutant; induced by treatment with 8-methoxypsoralen and UVA irradiation }\end{array}$ \\
\hline BUD9 & 57.5 & $\begin{array}{l}\text { Protein involved in bud-site selection; mutant has increased aneuploidy } \\
\text { tolerance; diploid mutants display a unipolar budding pattern instead of the } \\
\text { wild-type bipolar pattern, and bud at the distal pole; BUD9 has a paralog, } \\
\text { BUD8, that arose from the whole genome duplication }\end{array}$ \\
\hline VAB2 & 57.7 & $\begin{array}{l}\text { Subunit of the BLOC-1 complex involved in endosomal maturation; interacts } \\
\text { with Vps21p-GFP; has potential role in vacuolar function, as suggested by its } \\
\text { ability to bind Vac8p; likely member of; Vab2p-GFP-fusion localizes to } \\
\text { cytoplasm in punctate pattern }\end{array}$ \\
\hline YGR153W & 57.7 & Putative protein of unknown function \\
\hline NPP2 & 57.8 & $\begin{array}{l}\text { Nucleotide pyrophosphatase/phosphodiesterase; mediates extracellular } \\
\text { nucleotide phosphate hydrolysis along with Npp1p and Pho5p; activity and } \\
\text { expression enhanced during conditions of phosphate starvation; involved in } \\
\text { spore wall assembly; NPP2 has a paralog, NPP1, that arose from the whole }\end{array}$ \\
\hline
\end{tabular}




\begin{tabular}{|c|c|c|}
\hline & & $\begin{array}{l}\text { genome duplication, and an npp1 npp2 double mutant exhibits reduced } \\
\text { dityrosine fluorescence relative to the single mutants }\end{array}$ \\
\hline GPP2 & 57.8 & $\begin{array}{l}\text { DL-glycerol-3-phosphate phosphatase involved in glycerol biosynthesis; also } \\
\text { known as glycerol-1-phosphatase; induced in response to hyperosmotic or } \\
\text { oxidative stress, and during diauxic shift; GPP2 has a paralog, GPP1, that } \\
\text { arose from the whole genome duplication }\end{array}$ \\
\hline NUT1 & 58.2 & $\begin{array}{l}\text { Component of the RNA polymerase II mediator complex; mediator is required } \\
\text { for transcriptional activation and also has a role in basal transcription }\end{array}$ \\
\hline RMR1 & 58.8 & $\begin{array}{l}\text { Protein required for meiotic recombination and gene conversion; null mutant } \\
\text { displays reduced PIS1 expression and growth defects on non-fermentable } \\
\text { carbon sources and minimal media; GFP-fusion protein localizes to both } \\
\text { cytoplasm and nucleus }\end{array}$ \\
\hline HAT2 & 59 & $\begin{array}{l}\text { Subunit of the Hat1p-Hat2p histone acetyltransferase complex; required for } \\
\text { high affinity binding of the complex to free histone H4, thereby enhancing } \\
\text { Hat1p activity; similar to human RbAp46 and 48; has a role in telomeric } \\
\text { silencing }\end{array}$ \\
\hline CAD1 & 61 & $\begin{array}{l}\text { AP-1-like basic leucine zipper (bZIP) transcriptional activator; involved in stress } \\
\text { responses, iron metabolism, and pleiotropic drug resistance; controls a set of } \\
\text { genes involved in stabilizing proteins; binds consensus sequence TTACTAA; } \\
\text { CAD1 has a paralog, YAP1, that arose from the whole genome duplication }\end{array}$ \\
\hline ADE16 & 61.8 & $\begin{array}{l}\text { Enzyme of 'de novo' purine biosynthesis; contains both 5-aminoimidazole-4- } \\
\text { carboxamide ribonucleotide transformylase and inosine monophosphate } \\
\text { cyclohydrolase activities; ADE16 has a paralog, ADE17, that arose from the } \\
\text { whole genome duplication; ade16 ade17 mutants require adenine and } \\
\text { histidine }\end{array}$ \\
\hline GTT2 & 62.6 & $\begin{array}{l}\text { Glutathione S-transferase capable of homodimerization; functional overlap } \\
\text { with Gtt2p, Grx1p, and Grx2p; protein abundance increases in response to } \\
\text { DNA replication stress }\end{array}$ \\
\hline YGL117W & 62.8 & Putative protein of unknown function \\
\hline GAT3 & 64 & $\begin{array}{l}\text { Protein containing GATA family zinc finger motifs; involved in spore wall } \\
\text { assembly; sequence similarity to GAT4, and the double mutant gat3 gat } 4 \\
\text { exhibits reduced dityrosine fluorescence relative to the single mutants }\end{array}$ \\
\hline MFG1 & 66 & $\begin{array}{l}\text { Regulator of filamentous growth; interacts with FLO11 promoter and regulates } \\
\text { FLO11 expression; binds to transcription factors Flo8p and Mss11p; green } \\
\text { fluorescent protein (GFP)-fusion protein localizes to the nucleus; YDL233W is } \\
\text { not an essential gene }\end{array}$ \\
\hline LSB1 & 67.2 & $\begin{array}{l}\text { Negative regulator of actin nucleation-promoting factor activity; interacts with } \\
\text { Las17p, a homolog of human Wiskott-Aldrich Syndrome protein (WASP), via } \\
\text { an N-terminal SH3 domain, and along with PIN3 cooperatively inhibits the } \\
\text { nucleation of actin filaments; overexpression blocks receptor-mediated } \\
\text { endocytosis; protein increases in abundance and forms nuclear foci in }\end{array}$ \\
\hline
\end{tabular}




\begin{tabular}{|c|c|l|} 
& & $\begin{array}{l}\text { response to DNA replication stress; LSB1 has a paralog, PIN3, that arose from } \\
\text { the whole genome duplication }\end{array}$ \\
\hline YLL058W & 68.3 & $\begin{array}{l}\text { Putative protein of unknown function with similarity to Str2p; Str2p is a } \\
\text { cystathionine gamma-synthase important in sulfur metabolism; YLO58W is } \\
\text { not an essential gene }\end{array}$ \\
\hline PYC1 & 69 & $\begin{array}{l}\text { Pyruvate carboxylase isoform; cytoplasmic enzyme that converts pyruvate to } \\
\text { oxaloacetate; differentially regulated than isoform Pyc2p; mutations in the } \\
\text { human homolog are associated with lactic acidosis; PYC1 has a paralog, PYC2, } \\
\text { that arose from the whole genome duplication }\end{array}$ \\
\hline
\end{tabular}

Table B.2.2 : Bee venom validated hits from yeast DAmP library screen

\begin{tabular}{|c|c|l|}
\hline $\begin{array}{c}\text { Gene } \\
\text { Name }\end{array}$ & $\begin{array}{c}\text { Residual } \\
\text { Growth } \\
\text { (\%) }\end{array}$ & \multicolumn{1}{|c|}{ Description } \\
\hline SCL1 & 25 & $\begin{array}{l}\text { Alpha 1 subunit of the 20S proteasome; involved in the degradation of } \\
\text { ubiquitinated substrates; 20S proteasome is the core complex of the 26S } \\
\text { proteasome; essential for growth; detected in the mitochondria }\end{array}$ \\
\hline DOP1 & 34.8 & $\begin{array}{l}\text { Golgi-localized, leucine-zipper domain containing protein; involved in endosome } \\
\text { to Golgi transport, organization of the ER, establishing cell polarity, and } \\
\text { morphogenesis; detected in highly purified mitochondria in high-throughput } \\
\text { studies }\end{array}$ \\
\hline UBA2 & 39 & $\begin{array}{l}\text { Subunit of heterodimeric nuclear SUMO activating enzyme E1 with Aos1p; } \\
\text { activates Smt3p (SUMO) before its conjugation to proteins (sumoylation), which } \\
\text { may play a role in protein targeting; essential for viability }\end{array}$ \\
\hline RPN8 & 42.2 & $\begin{array}{l}\text { Essential non-ATPase regulatory subunit of the 26S proteasome; has similarity } \\
\text { to the human p40 proteasomal subunit and to another S. cerevisiae regulatory } \\
\text { subunit, Rpn11p }\end{array}$ \\
\hline ERG26 & 52.8 & $\begin{array}{l}\text { C-3 sterol dehydrogenase; catalyzes the second of three steps required to } \\
\text { remove two C-4 methyl groups from an intermediate in ergosterol biosynthesis }\end{array}$ \\
\hline NSL1 & 64 & $\begin{array}{l}\text { Essential component of the MIND kinetochore complex; joins kinetochore } \\
\text { subunits contacting DNA to those contacting microtubules; required for } \\
\text { accurate chromosome segregation; complex consists of Mtw1p Including } \\
\text { Nnf1p-Nsl1p-Dsn1p (MIND) }\end{array}$ \\
\hline
\end{tabular}




\begin{tabular}{|c|c|l|} 
DBP10 & 75 & $\begin{array}{l}\text { Putative ATP-dependent RNA helicase of the DEAD-box protein family; } \\
\text { constituent of 66S pre-ribosomal particles; essential protein involved in } \\
\text { ribosome biogenesis }\end{array}$ \\
\hline RPT4 & 76 & $\begin{array}{l}\text { ATPase of the 19S regulatory particle of the 26S proteasome; one of six } \\
\text { ATPases of the regulatory particle; involved in degradation of ubiquitinated } \\
\text { substrates; contributes preferentially to ERAD; required for spindle pole body } \\
\text { duplication; mainly nuclear localization }\end{array}$ \\
\hline
\end{tabular}

Table B.3.1 : Bee pollen validated hits from yeast homozygous deletion library screen

\begin{tabular}{|c|c|c|l|l|}
\hline $\begin{array}{c}\text { Systematic } \\
\text { name }\end{array}$ & $\begin{array}{c}\text { Gene } \\
\text { Name }\end{array}$ & $\begin{array}{c}\text { Growth } \\
\text { Ratio }\end{array}$ & \multicolumn{1}{|c|}{ Description } \\
YBR200W & BEM1 & 1.56 & $\begin{array}{l}\text { Protein containing SH3-domains; involved in establishing cell } \\
\text { polarity and morphogenesis; functions as a scaffold protein for } \\
\text { complexes that include Cdc24p, Ste5p, Ste20p, and Rsr1p }\end{array}$ \\
\hline YKL081W & TEF4 & 1.27 & $\begin{array}{l}\text { Gamma subunit of translational elongation factor eEF1B; } \\
\text { stimulates the binding of aminoacyl-tRNA (AA-tRNA) to ribosomes } \\
\text { by releasing eEF1A (Tef1p/Tef2p) from the ribosomal complex }\end{array}$ \\
\hline YER111C & SWI4 & 1.22 & $\begin{array}{l}\text { DNA binding component of the SBF complex (Swi4p-Swi6p); a } \\
\text { transcriptional activator that in concert with MBF (Mbp1-Swi6p) } \\
\text { regulates late G1-specific transcription of targets including cyclins } \\
\text { and genes required for DNA synthesis and repair; SIt2p- } \\
\text { independent regulator of cold growth; acetylation at two sites, } \\
\text { K1016 and K1066, regulates interaction with Swi6p }\end{array}$ \\
\hline
\end{tabular}

Table B.3.2 : Bee pollen validated hits from yeast DAmP library screen

\begin{tabular}{|c|c|c|l|l|}
\hline $\begin{array}{c}\text { Systematic } \\
\text { name }\end{array}$ & $\begin{array}{c}\text { Gene } \\
\text { Name }\end{array}$ & $\begin{array}{c}\text { Growth } \\
\text { Ratio }\end{array}$ & \multicolumn{1}{|c|}{ Description } \\
\hline YGL225W & VRG4 & 1.96 & $\begin{array}{l}\text { Golgi GDP-mannose transporter; regulates Golgi function and } \\
\text { glycosylation in Golgi; VRG4 has a paralog, HVG1, that arose from } \\
\text { the whole genome duplication }\end{array}$ \\
\hline YDR301W & CFT1 & 1.84 & $\begin{array}{l}\text { RNA-binding subunit of the mRNA cleavage and polyadenylation } \\
\text { factor; involved in poly(A) site recognition and required for both } \\
\text { pre-mRNA cleavage and polyadenylation, 51\% sequence similarity } \\
\text { with mammalian AAUAA-binding subunit of CPSF }\end{array}$ \\
\hline YIL063C & YRB2 & 1.69 & $\begin{array}{l}\text { Protein of unknown function; involved in nuclear processes of the } \\
\text { Ran-GTPase cycle; involved in nuclear protein export; contains Ran } \\
\text { Binding Domain and FxFG repeats; interacts with Srm1p, GTP- } \\
\text { Gsp1p, Rna1p and Crm1p; relocalizes to the cytosol in response to } \\
\text { hypoxia; not essential for viability }\end{array}$ \\
\hline
\end{tabular}




\begin{tabular}{|c|c|c|c|}
\hline YIR022W & SEC11 & 1.6 & $\begin{array}{l}\text { 18kDa catalytic subunit of the Signal Peptidase Complex (SPC); the } \\
\text { Signal Peptidase Complex cleaves the signal sequence of proteins } \\
\text { targeted to the endoplasmic reticulum; other members are Spc1p, } \\
\text { Spc2p, Spc3p, and Sec11p }\end{array}$ \\
\hline YFL005W & SEC4 & 1.6 & $\begin{array}{l}\text { Rab family GTPase; essential for vesicle-mediated exocytic } \\
\text { secretion and autophagy; associates with the exocyst component } \\
\text { Sec15p and may regulate polarized delivery of transport vesicles to } \\
\text { the exocyst at the plasma membrane }\end{array}$ \\
\hline YDL017W & $\mathrm{CDC7}$ & 1.43 & $\begin{array}{l}\text { DDK (Dbf4-dependent kinase) catalytic subunit; required for origin } \\
\text { firing and replication fork progression in mitotic S phase through } \\
\text { phosphorylation of Mcm2-7p complexes and Cdc45p; kinase } \\
\text { activity correlates with cyclical DBF4 expression; required for pre- } \\
\text { meiotic DNA replication, meiotic DSB formation, recruitment of the } \\
\text { monopolin complex to kinetochores during meiosis I and as a } \\
\text { gene-specific regulator of the meiosis-specific transcription factor } \\
\text { Ndt80p }\end{array}$ \\
\hline YKL012W & PRP40 & 1.35 & $\begin{array}{l}\text { U1 snRNP protein involved in splicing; interacts with the } \\
\text { branchpoint-binding protein during the formation of the second } \\
\text { commitment complex }\end{array}$ \\
\hline YMR094W & CTF13 & 1.35 & $\begin{array}{l}\text { Subunit of the CBF3 complex; CBF3 binds to the CDE III element of } \\
\text { centromeres, bending the DNA upon binding, and may be involved } \\
\text { in sister chromatid cohesion during mitosis }\end{array}$ \\
\hline YJL011C & RPC17 & 1.34 & $\begin{array}{l}\text { RNA polymerase III subunit C17; physically interacts with C } 31 \text {, } \\
\text { C11, and TFIIIB70; may be involved in the recruitment of pol III by } \\
\text { the preinitiation complex; protein abundance increases in response } \\
\text { to DNA replication stress; relocalizes to the cytosol in response to } \\
\text { hypoxia }\end{array}$ \\
\hline YMR239C & RNT1 & 1.34 & $\begin{array}{l}\text { Nuclear dsRNA-specific ribonuclease (RNase III); involved in rDNA } \\
\text { transcription, rRNA processing and U2 snRNA 3' end formation by } \\
\text { cleavage of a stem-loop structure at the 3' end of U2 snRNA; } \\
\text { involved in polyadenylation-independent transcription termination; } \\
\text { involved in the cell wall stress response, regulating the degradation } \\
\text { of cell wall integrity and morphogenesis checkpoint genes }\end{array}$ \\
\hline
\end{tabular}

